\title{
ANGIOSTATIN LIKE PEPTIDES IN MILK: POTENTIAL DEVELOPMENT FOR DAIRY PRODUCTS CAPABLE OF CANCER PREVENTION
}

\author{
A Thesis \\ Presented to \\ the Faculty of California Polytechnic State University, \\ San Luis Obispo
}

\begin{abstract}
In Partial Fulfillment
of the Requirements for the Degree

Master of Science in Agriculture, with a Specialization in:

Dairy Products Technology
\end{abstract}

by

Erin Stefanutti

March 2011 
(C) 2011

Erin Stefanutti

ALL RIGHTS RESERVED 
TITLE:

ANGIOSTATIN LIKE PEPTIDES IN MILK: POTENTIAL DEVELOPMENT FOR DAIRY PRODUCTS CAPABLE OF CANCER PREVENTION

AUTHOR: $\quad$ Erin Stefanutti

DATE SUBMITTED: $\quad$ MARCH 2011

COMMITTEE CHAIR: $\quad$ Rafael Jimenez-Flores, Ph.D.

Professor, Dairy Products Technology

California Polytechnic State University, San Luis Obispo

COMMITTEE MEMBER: Lily Laiho, Ph.D.

Professor, Biomedical and General Engineering

California Polytechnic State University, San Luis Obispo

COMMITTEE MEMBER: Michael Black, Ph.D.

Professor, Biological Sciences

California Polytechnic State University, San Luis Obispo 


\section{ABSTRACT \\ ANGIOSTATIN LIKE PEPTIDES IN MILK: POTENTIAL DEVELOPMENT FOR DAIRY PRODUCTS CAPABLE OF CANCER PREVENTION}

\section{Erin Stefanutti}

For the past 40 years, antiangiogenic approaches have been of major interest in the development of methods to cure and prevent cancer. Angiogenesis, the development of blood vessels from pre-existing vascularization, is essential for cancer growth and spread of metastasis through the delivery of nutrients and oxygen essential to sustain the metabolic activity of these malignant cells. Blocking access to blood will cause cancerous cells to assume a dormant state creating inactive micro-tumors innocuous to the host. Angiostatin, the internal fragment of the fibrinolytic zymogen plasminogen, has shown great potential in reducing cancer size and number of metastatic colonies in animal models. Owing to the success of these preliminary results angiostatin is currently on clinical trials. Plasminogen is known to be transferred from blood to milk during lactation. The objectives of this research were to: 1) investigate the ability of various proteases in cleaving plasminogen, both from human and bovine sources, and consequently release the angiostatin like fragment; 2) determine the anticancer activity of bovine angiostatin; 3) examine ability of the antiangiogenic fragment to survive digestion; 4) purify the fragment of interest through column chromatography. Production of angiostatin was tested through hydrolysis of plasminogen via Bacillus Polymyxa protease (or dispase I), elastase, lactic acid bacteria and Bacilli originated enzymes. Once proteases capable of angiostatin like peptide production were identified, and sequence analysis of the fragments obtained conducted to confirm that bovine angiostatin was indeed produced, ability of angiostatin, both human and bovine, in inhibiting malignant melanoma as well as colon cancer cells was evaluated in vitro. From the results obtained we can confirm that bovine angiostatin inhibitory activity on cancerous cells is similar to that observed for human angiostatin. Analysis of bovine angiostatin survival through in vitro human digestion model was also examined. Results show good possibility of angiostatin surviving digestion, even if confirmation of these results is required through further in vivo studies. Additionally, digestive enzymes such as trypsin and $\alpha$ - 
chymotrypsin showed ability in cleaving plasminogen directly to release a $25 \mathrm{kDa}$ fragment. Knowing that each kringle has some degree of anticancer activity it would be of interest to further study the possibility of angiostatin related fragments to be produced during milk digestion. Finally, affinity chromatography through L-lysine used to purify human angiostatin resulted to be an adequate method for bovine angiostatin purification. Preliminary results obtained from this study open a new area worth investigating to uncover the potential of using bovine angiostatin in the development of novel food products capable of cancer prevention.

Key words: angiostatin, plasminogen, proteases, angiogenesis. 


\section{ACKNOWLEDGMENTS}

Having always had a deep interest in food and health, I couldn't have asked for a better project to work on during my Master's at Cal Poly. For that, I would like to thank my advisor, and friend, Dr. Jimenez, for giving me this opportunity, and for making me become the scientist I am today. His passion, enthusiasm and encouragement always increased my motivation and my desire to succeed.

I would also like to thank Dr. Laiho and Dr. Black for accepting to be on my committee, and helping me perfect my work.

This work would have not been possible without the help of my colleagues. Thank you all for always being there for me when I needed help preparing a sample, understanding how to make the HPLC work, find a beaker I was missing in the lab, but most of all thank you for your friendship.

Finally, I would like to thank my family. My brother and sisters, and especially

my parents for their continuous support throughout my education and for always believing in me and teaching me the most important lesson of all: that no dream is impossible if you truly believe in what you want. Grazie, vi voglio bene! 


\section{Table of Contents}

LIST OF TABLES. $\mathrm{x}$

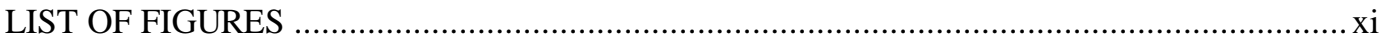

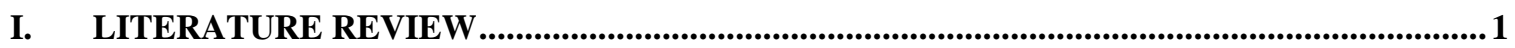

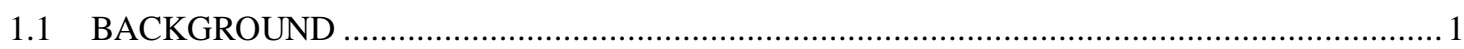

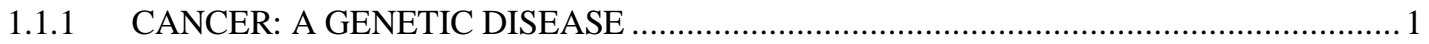

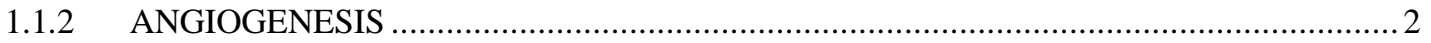

1.1.2.1 FACTORS INVOLVED IN ANGIOGENESIS INITIATION …….......................... 4

1.1.2.2 VEGF ANGIOGENESIS SIGNALING PATHWAYS ........................................

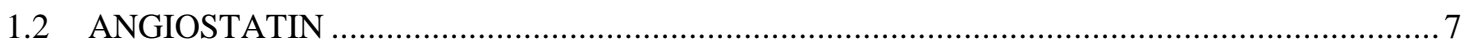

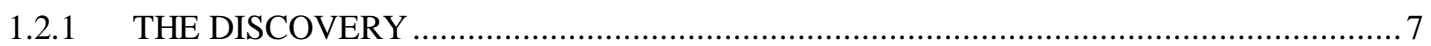

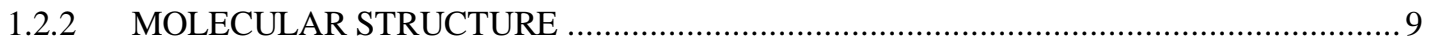

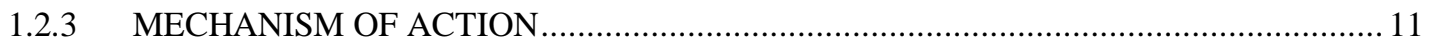

1.2.3.1 MIGRATION VS. PROLIFERATION INHIBITION …….................................. 12

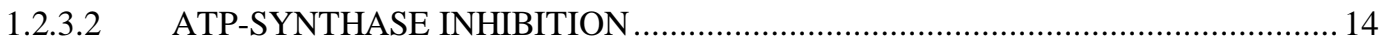

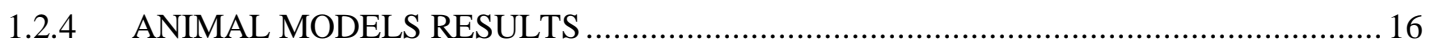

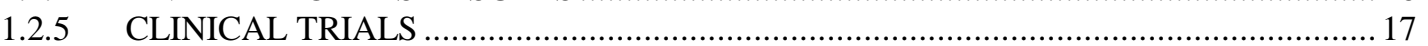

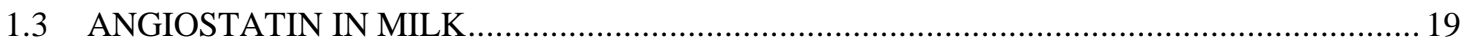

1.3.1 TRANSFER OF PLASMINOGEN FROM BLOOD TO MILK …................................... 19

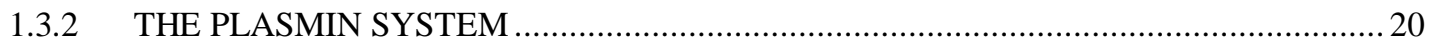

1.3.3 COMPARISON BETWEEN HUMAN AND BOVINE PLASMINOGEN ….................... 21

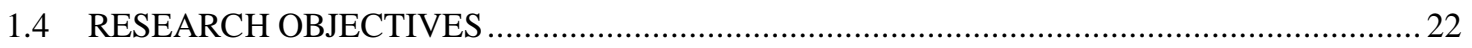

II. ANGIOSTATIN GENERATION THROUGH BOVINE PLASMINOGEN HYDROLYSIS.... 23

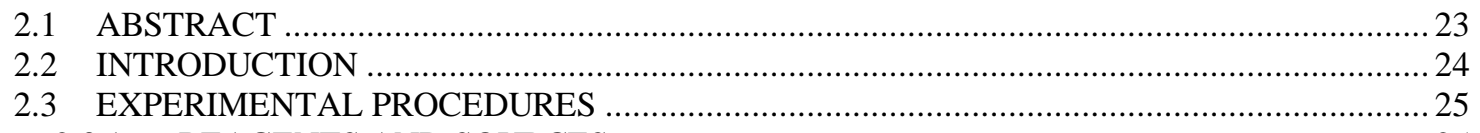

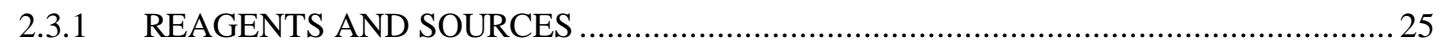

2.3.2 PART 1. Generation of angiostatin from bovine and human plasminogen hydrolysis by the

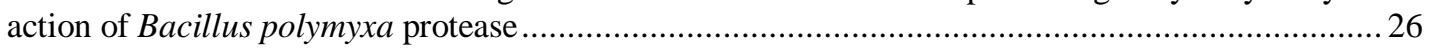

2.3.2.1 Bacillus polymyxa protease interaction with bovine plasminogen ..............................26

2.3.2.2 Temperature effect on Bacillus polymyxa protease and plasminogen interaction ....... 27

2.3.2.3 Identification of angiostatin like fragments through SDS-PAGE, western blot and

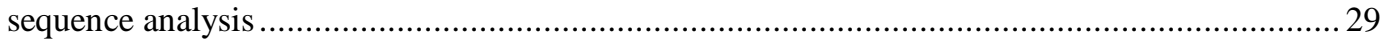

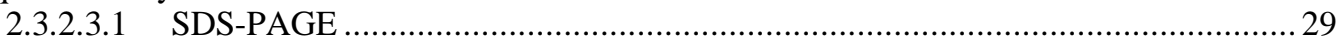

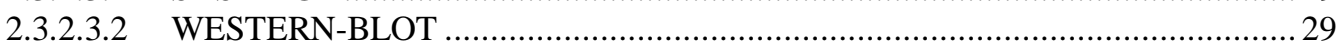

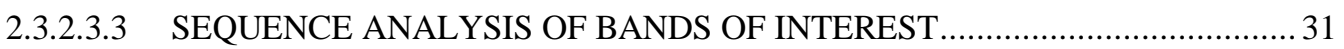

2.3.2.4 Bacillus polymyxa protease ability in generating human angiostatin ......................... 32

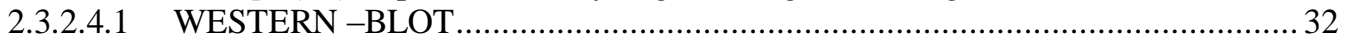

2.3.3 PART 2. Generation of angiostatin from bovine and human plasminogen hydrolysis by the

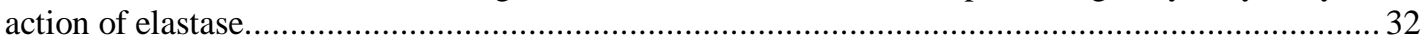

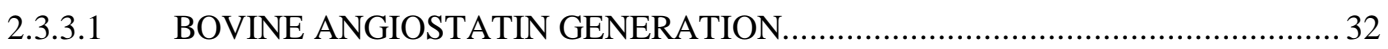

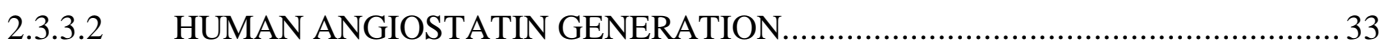

2.3.4 PART 3. Generation of angiostatin from bovine plasminogen hydrolysis by the action of

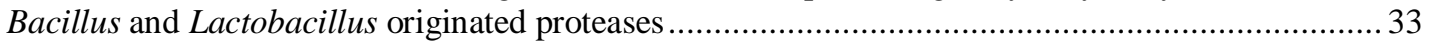

2.3.4.1 LACTOBACILLUS PROTEASES GENERATION ANALYSIS............................... 33

2.3.4.1.1 PROTEASES INTERACTION WITH BOVINE PLASMINOGEN ....................... 34

2.3.4.2 BACILLUS PROTEASES GENERATION ANALYSIS ............................................ 36

2.3.4.2.1 Interaction of proteases generated from Bacillus strains with bovine plasminogen 37

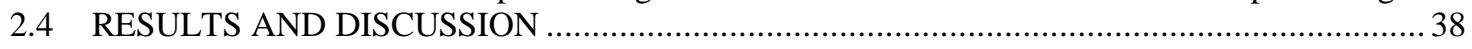

2.4.1 PART 1. Generation of angiostatin from bovine and human plasminogen hydrolysis by the

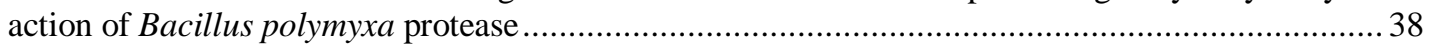

2.4.1.1 Bovine plasminogen proteolytic fragments generated by Bacillus polymyxa protease 38

2.4.1.2 Temperature effect ........................................................................................... 44 


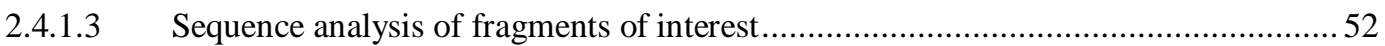

2.4.1.4 Bacillus polymyxa protease ability in generating human angiostatin ..........................5. 52

2.4.2 PART 2. Generation of angiostatin from bovine and human plasminogen hydrolysis by the

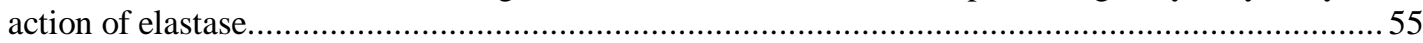

2.4.3 PART 3. Generation of angiostatin from bovine plasminogen hydrolysis by the action of

Bacillus and Lactobacillus originated proteases ...........................................................................5

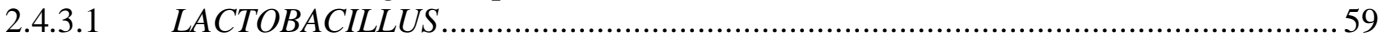

2.4.3.2 BACILLUS

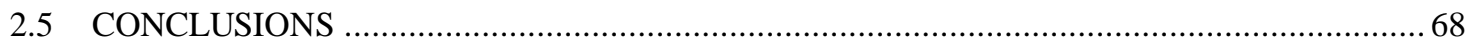

III. ANTI-CANCER ACTIVITY ANALYSIS OF BOVINE ANGIOSTATIN _..........................69

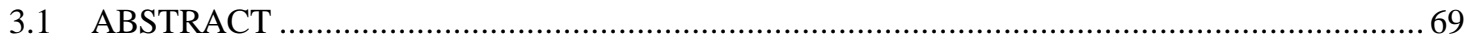

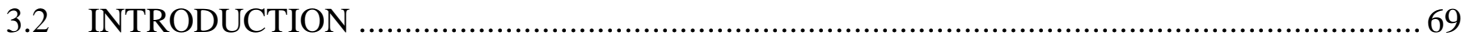

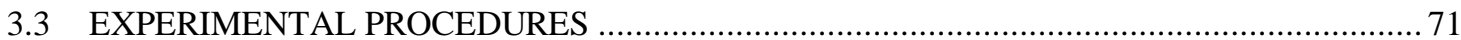

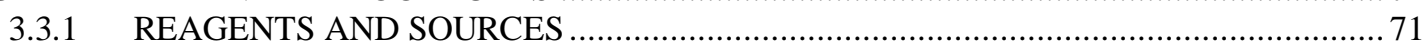

3.3.2 Inhibition of cancerous cells growth by the action of angiostatin ..................................... 71

3.3.2.1 Preparation of angiostatin for colon cancerous cells inhibition analysis .....................71

3.3.2.2 Angiostatin for melanoma inhibition activity samples preparation ............................. 71

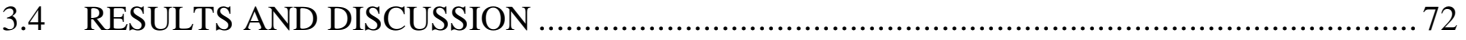

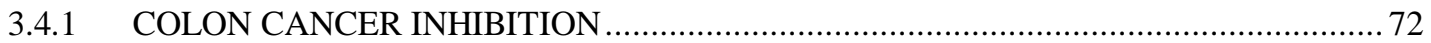

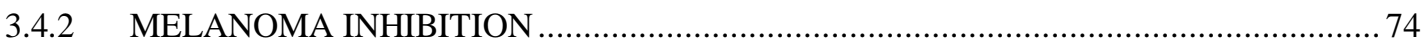

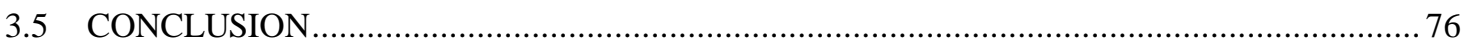

\section{ANGIOSTATIN IN VITRO DIGESTION SURVIVAL ANALYSIS AND ANGIOSTATIN}

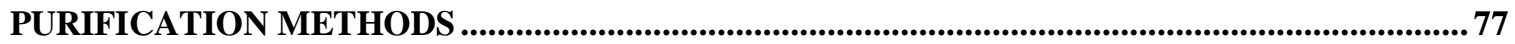

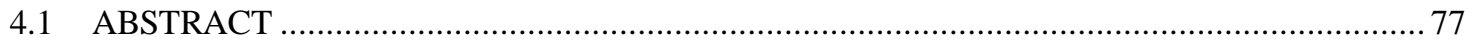

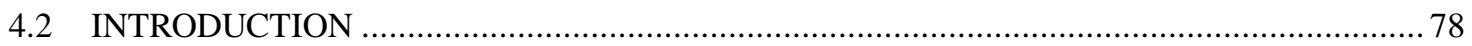

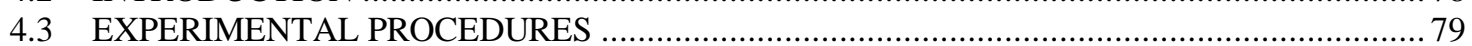

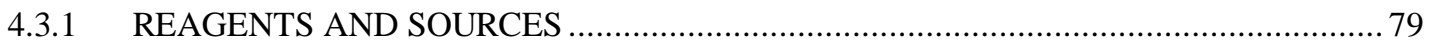

4.3.2 PART 1: ANGIOSTATIN IN VITRO DIGESTION SURVIVAL ANALYSIS .................... 80

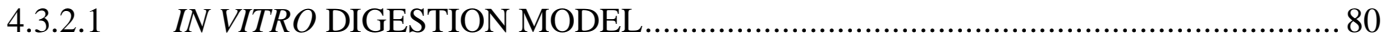

4.3.2.2 Ability of individual digestive enzymes in hydrolyzing angiostatin ........................... 81

4.3.2.2.1 VARIOUS E:S RATIOS ANALISIS FOR PEPSIN, TRYPSIN AND $\alpha-$

CHYMOTRYPSIN

4.3.3 Ability of digestive enzymes in producing angiostatin through plasminogen hydrolysis ..... 83

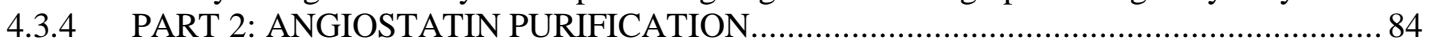

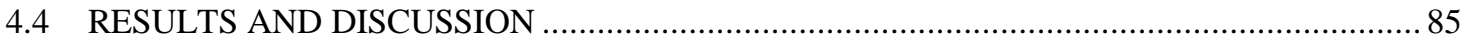

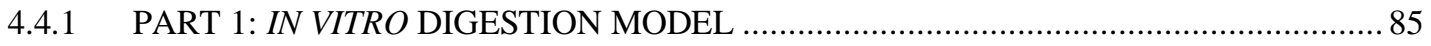

4.4.2 Analysis of the interaction between various E:S ratios for pepsin, trypsin, $\alpha$-chymotrypsin

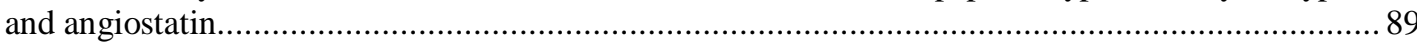

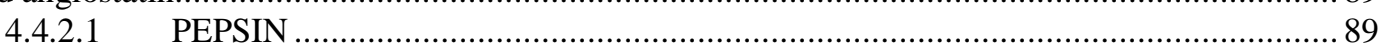

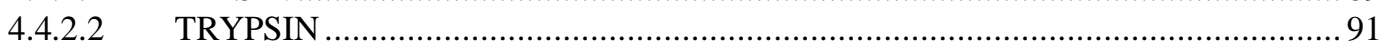

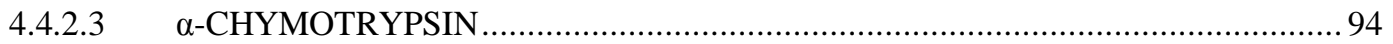

4.4.3 Ability of digestive enzymes in producing angiostatin through plasminogen hydrolysis ..... 96

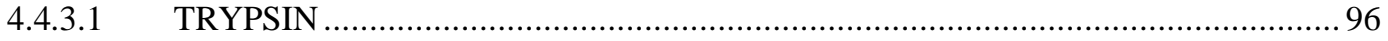

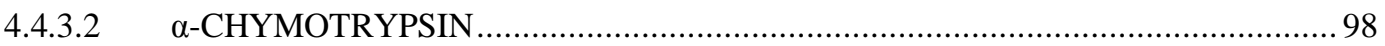

4.4.4 PART2: ANGIOSTATIN PURIFICATION

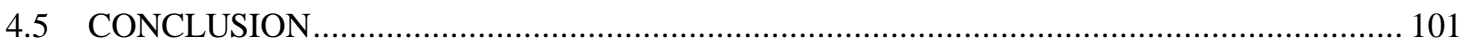

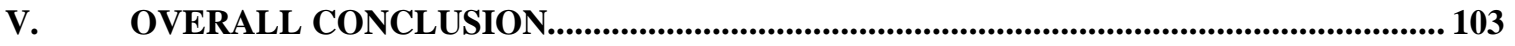

VI. FUTURE RESEARCH RECOMMENDATIONS ............................................................ 105

APPENDIX A. Supplemental data corresponding to Chapter 2: Bovine plasminogen proteolytic

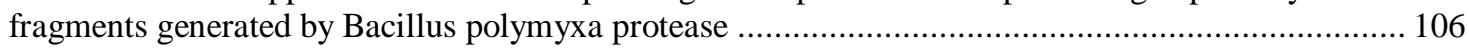
APPENDIX B. Supplemental data corresponding to Chapter 2: Bovine plasminogen proteolytic fragments generated by Bacillus polymyxa protease .......................................................................... 108 
APPENDIX C. Additional data corresponding to Chapter 2: Generation of angiostatin from bovine plasminogen hydrolysis by the action of Bacillus and Lactobacillus originated proteases .....

APPENDIX D. Additional data corresponding to Chapter 2: Generation of angiostatin from bovine plasminogen hydrolysis by the action of Bacillus and Lactobacillus originated proteases.....

APPENDIX E. Additional data corresponding to Chapter 2: Generation of angiostatin from bovine plasminogen hydrolysis by the action of Bacillus and Lactobacillus originated proteases.

APPENDIX F. Additional data corresponding to Chapter 4: In vitro digestion model .......

VII. REFERENCE 


\section{LIST OF TABLES}

Table

Table 1: Plasminogen kringle domains and their respective activity in proliferation and migration inhibition of endothelial cells, binding to EACA, and tumor inhibition capability (Geiger J. H. et al. 2004)

Table 2: Anti endothelial cell proliferation activity of angiostatin and plasminogen kringle fragments. Values represent the mean of concentration for a half-maximal inhibitory response. (Cao Renhai et al. 1999)

Table 3: Sequence analysis homology among individual kringles and connecting strands between human and bovine plasminogen (adopted from Schaller et al. 1985).

Table 4: Buffer recipes and preparation for western blotting

Table 5: analysis of slopes obtained through bPG band density variation after 30 and 60 minutes interaction with BPP

Table 6: measures of zone of clearance (in $\mathrm{mm}$ ) produced by the action of Lactobacillus originated enzymes when placed in casein agar plates for 24 hours

Table 7: measurements of zone of clearance obtained by the action of Bacillus generated enzymes when incubated in casein skim milk agar plates

Table 8: Enzyme-substrate ratios used to test ability of trypsin in digesting angiostatin

Table 9: Enzyme-substrate ratios used to test ability of $\alpha$-chymotrypsin in digesting angiostatin

Table 10: Optical density data obtained after 12 or 24 hours Bacillus growth in TSB media at $37^{\circ} \mathrm{C}$ (absorbance @ 686 nm (Colome et al. 1986))

Table 11: Buffer recipes for casein SDS-PAGE 118 


\section{LIST OF FIGURES}

Figure

Page

Figure 1: VEGF interaction with endothelial cells and activated signaling pathways (Zachary I. 2003).

Figure 2: Plasminogen Structure (Platanias Leonidas C. 2009). In red are indicated the regions of PG that need to be hydrolyzed in order to obtain angiostatin K1-4......

Figure 3: Angiostatin K1-3 molecular structure. K1, orange; K2, pink; K3, light blue (Abad Marta C. et al. 2002)

Figure 4: The plasmin system in milk (adopted from Bastian and Brown, 1996).....

Figure 5: Experimental design for determining ideal enzyme-substrate (BPP-bPG) ratio: A) ideal enzyme concentration determination; B) ideal substrate concentration determination.

Figure 6: Experimental design on the analysis of temperature effects on the interaction between BPP and bPG: A) BPP-bPG interaction was conducted at $4^{\circ} \mathrm{C}$, $37^{\circ} \mathrm{C}, 70^{\circ} \mathrm{C}$ and $90^{\circ} \mathrm{C}$; B) BPP affinity variation between native and denatured bPG. ....28

Figure 7: Experimental design to determine Lactobacillus proteolytic enzymes generation in different growth media.

Figure 8: Experimental design to determine Bacillus proteolytic enzymes generation in different growth media.

Figure 9: SDS-PAGE analysis of Bacillus polymyxa protease (BPP) and bovine plasminogen (bPG) ideal E:S ratio. Lane 1: molecular weight standard; lane 2: bPG control $(0.25 \mathrm{mg} / \mathrm{ml})$; lane 3: BPP control $(0.25 \mathrm{mg} / \mathrm{ml})$; lane $4-10: \mathrm{bPG}(1 \mathrm{mg} / \mathrm{ml})$ incubated with $0.025,0.05,0.075,0.1,0.125,0.150$ and $0.175 \mathrm{mg} / \mathrm{ml} \mathrm{BPP}$ in MTB for 1 hour at $37^{\circ} \mathrm{C}$. Bands in the $37 \mathrm{kDa}$ area correspond to potential angiostatin (AS) fragments.

Figure 10: SDS-PAGE analysis of Bacillus polymyxa protease (BPP) and bovine plasminogen (bPG) ideal E:S ratio. Lane 1: molecular weight standard; lane 2: bPG control $(0.25 \mathrm{mg} / \mathrm{ml})$; lane 3: BPP control $(0.25 \mathrm{mg} / \mathrm{ml})$; lane $4-9$ : bPG at 0.125 , $0.25,0.5,0.75,0.875$ and $1 \mathrm{mg} / \mathrm{ml}$ incubated with $0.1 \mathrm{mg} / \mathrm{ml} \mathrm{BPP}$ in MTB for 1 hour at $37^{\circ} \mathrm{C}$. Bands in the $37 \mathrm{kDa}$ area correspond to potential angiostatin (AS) fragments.

Figure 11: SDS-PAGE analysis of angiostatin like fragments produced by bPG proteolysis by the action of BPP. Lane 1: MW standard; Lane 2: bPG control; Lane 
3: BPP control; Lane 4 to 13: 0, 5, 10, 15, 20, 25, 30, 40, 50, 60 minutes bPG and BPP incubation. Fragments observed in the $37 \mathrm{kDa}$ area are potential angiostatin (AS) like fragments

Figure 12: bPG disappearance $(0.625 \mathrm{mg} / \mathrm{ml})$ over time by the action of BPP $(0.1$ $\mathrm{mg} / \mathrm{ml}$ ). Two slopes were measured, the first one was obtained by analyzing the data obtained after 30 minutes of the reaction (-422.71), while the second slope was generated by considering all the points collected after one hour (-291.09).

Figure 13: Western blot analysis of bPG fragments generated by digestion with BPP at various incubation times and E:S ratios. Reaction products were analyzed with an anti-plasminogen antibody. Lane1: MW standard; Lane 2 to 5: 0.3125 $\mathrm{mg} / \mathrm{ml}$ PG 0-40-50-60 minutes incubation respectively; Lane 6 to $9: 0.375 \mathrm{mg} / \mathrm{ml}$ PG 0-30-40-50 minutes incubation respectively; Lane 10 to $13: 0.4375 \mathrm{mg} / \mathrm{ml}$ PG 0-30-40-50 minutes incubation respectively; Lane 14 to $17: 0.5 \mathrm{mg} / \mathrm{ml}$ PG 0-30-4050 minutes incubation respectively. Immuno-reaction observed for bands in the $37 \mathrm{kDa}$ area confirm angiostatin (AS) like fragments being generated from this reaction.

Figure 15: Rate at which BPP hydrolyzes bPG at $4^{\circ} \mathrm{C}$ and $37^{\circ} \mathrm{C}$ 45

Figure 14: SDS-PAGE analysis of temperature effect on BPP-bPG interaction. Lane 1: molecular weight standard; lane 2: bPG control $(0.2 \mathrm{mg} / \mathrm{ml})$; lane 3: BPP control $(0.025 \mathrm{mg} / \mathrm{ml})$; lane $4-10$ : interaction at $4^{\circ} \mathrm{C}$ between $\mathrm{bPG}(0.75 \mathrm{mg} / \mathrm{ml})$ with BPP $(0.1 \mathrm{mg} / \mathrm{ml})$ after $1,5,10,15,20,25$ and 30 minutes incubation; lane 11: molecular weight standard; lane 12-18: interaction at $37^{\circ} \mathrm{C}$ between bPG $(0.75 \mathrm{mg} / \mathrm{ml})$ with BPP $(0.1 \mathrm{mg} / \mathrm{ml})$ after $1,5,10,15,20,25$ and 30 minutes incubation.

Figure 16: Rate at which bands in the 34 and $37 \mathrm{kDa}$ are formed from $\mathrm{bPG}$ hydrolysis by the action of BPP at $4^{\circ} \mathrm{C}(\mathrm{A})$ and $37^{\circ} \mathrm{C}(\mathrm{B})$.

Figure 17: SDS-PAGE analysis of temperature effect on BPP-bPG interaction. Lane 1: molecular weight standard; lane 2: bPG control $(0.2 \mathrm{mg} / \mathrm{ml})$; lane 3 : BPP control $(0.025 \mathrm{mg} / \mathrm{ml})$; lane $4-10$ : interaction at $70^{\circ} \mathrm{C}$ between bPG $(0.75 \mathrm{mg} / \mathrm{ml})$ with BPP $(0.1 \mathrm{mg} / \mathrm{ml})$ after 1, 2, 3, 4, 5, 6, 7 minutes incubation; lane 11: molecular weight standard; lane 12-18: interaction at $90^{\circ} \mathrm{C}$ between bPG $(0.75 \mathrm{mg} / \mathrm{ml})$ with BPP $(0.1 \mathrm{mg} / \mathrm{ml})$ after 1, 2, 3, 4, 5, 6, 7 minutes incubation

Figure 18: SDS-PAGE analysis of denaturation effect on bPG hydrolysis by the action of BPP at $37^{\circ} \mathrm{C}$. Lane 1: molecular weight standard; lane 2-6: native bPG $(0.75 \mathrm{mg} / \mathrm{ml})$ incubated with BPP $(0.1 \mathrm{mg} / \mathrm{ml})$ at $37^{\circ} \mathrm{C}$ for $1,5,10,20$ and 30 minutes incubation; lane 7-11: denatured bPG (heated at $70^{\circ} \mathrm{C}$ ) incubated with BPP at $37^{\circ} \mathrm{C}$ for $1,5,10,20$ and 30 minutes. 
Figure 19: Disappearance rate comparison between denatured and non denatured bPG by the action of BPP. Disappearance of native bPG resulted in a slope of 265.26 while denatured bPG showed -571.66 disappearance rate.

Figure 20: Production rate of 35 and 37 molecular weight peptides generated through denatured bPG hydrolysis by the action of BPP

Figure 22: denatured versus non denatured bPG proteolysis by the action of BPP when in a milk system. The rate of the reaction resulted in a slope of -208.63 when bPG is in its native form, while -316.79 for bPG in its denatured form.

Figure 21: SDS-PAGE analysis of fragments generated by the action of BPP with folded and denatured $\mathrm{bPG}$ in a milk system. Lane 1: molecular weight standard; lane 2-6: bPG in milk incubated with $\mathrm{BPP}$ at $37^{\circ} \mathrm{C}$ for $1,5,10,20$ and 30 minutes; lane 7-11: denatured bPG in milk incubated with BPP at $37^{\circ} \mathrm{C}$ for $1,5,10,20$ and 30 minutes.....

Figure 23: 35 and $37 \mathrm{kDa}$ fragments generation from denatured bPG in milk by the action of BPP.

Figure 24: SDS-PAGE visualization of the fragments generated by the action of BPP $(0.025 \mathrm{mg} / \mathrm{ml})$ hydrolysis of human PG $(1 \mathrm{mg} / \mathrm{ml})$. Lane 1: molecular weight standard; lane 2: hPG control $(0.125 \mathrm{mg} / \mathrm{ml})$; lane 3: BPP control $(0.025 \mathrm{mg} / \mathrm{ml})$; lane 4-8: hPG incubated with BPP for $0,5,10,15$, and 20 minutes incubation at $37^{\circ} \mathrm{C}$.

Figure 25: SDS-PAGE visualization of the fragments generated by the action of BPP $(0.01 \mathrm{mg} / \mathrm{ml})$ hydrolysis of human PG $(1 \mathrm{mg} / \mathrm{ml})$. Lane 1: molecular weight standard; lane 2: hPG control $(0.125 \mathrm{mg} / \mathrm{ml})$; lane 3: BPP control $(0.025 \mathrm{mg} / \mathrm{ml})$; lane 4-9: hPG incubated with BPP for $0,1,11,21,31$ and 41 minutes incubation at $37^{\circ} \mathrm{C}$.

Figure 26: Western-blot visualization of internal human PG fragments generated by the action of BPP $(0.01 \mathrm{mg} / \mathrm{ml})$, identified with polyclonal anti-human angiostatin. Lane 1: molecular weight standard; lane 2: hPG control $(0.125 \mathrm{mg} / \mathrm{ml})$; lane $3: \mathrm{BPP}$ control $(0.025 \mathrm{mg} / \mathrm{ml})$; lane 4-9: hPG incubated with BPP for $0,1,11,21,31$ and 41 minutes at $37^{\circ} \mathrm{C}$.

Figure 27: SDS-PAGE analysis of the fragments obtained through bPG hydrolysis by the action of elastase. Lane 1-5: elastase $(0.01 \mathrm{mg} / \mathrm{ml})$ incubated with $\mathrm{bPG}$ $(1 \mathrm{mg} / \mathrm{ml})$ for $1,2,4,6$ and 8 hours incubation at $37^{\circ} \mathrm{C}$; lane 6: molecular weight standard. Bands in the $37 \mathrm{kDa}$ correspond to potential angiostatin (AS) fragments.........56

Figure 28: bPG disappearance by the action of elastase overtime .57

Figure 29: generation rate of fragments obtained through bPG hydrolysis by the action of elastase 
Figure 30: SDS-PAGE analysis of proteolytic fragments generated through bovine PG hydrolysis by the action of elastase (E) and identified with a polyclonal antibovine plasminogen antibody. Lane 1: molecular weight standard; lane 2: bPG control $(0.25 \mathrm{mg} / \mathrm{ml})$; lane 3: elastase control $(0.025 \mathrm{mg} / \mathrm{ml})$; lane $4-8$ : bPG $(1 \mathrm{mg} / \mathrm{ml})$ interaction with elastase $(0.01 \mathrm{mg} / \mathrm{ml})$ after $1,2,4,6$ and 8 hours incubation at $37^{\circ} \mathrm{C}$. Bands in the $37 \mathrm{kDa}$ area correspond to potential angiostatin $\mathrm{AS}$ fragments.

Figure 31: SDS-PAGE analysis of hydrolytic products obtained from human PG hydrolysis by the action of elastase. Lane 1: molecular weight standard; lane 2: hPG control $(0.125 \mathrm{mg} / \mathrm{ml})$; lane 3-8: hPG $(1 \mathrm{mg} / \mathrm{ml})$ incubated with elastase for 30 minutes, $1,2,4,6$ and 8 hours at $37^{\circ} \mathrm{C}$.

Figure 32: western blot identification of internal human PG fragments generated by the action of elastase through anti-human angiostatin polyclonal antibody. Lane 1: molecular weight standard; lane 2 : hPG control $(0.125 \mathrm{mg} / \mathrm{ml})$; lane $3-8$ : elastase $(0.1 \mathrm{mg} / \mathrm{ml})$ interaction with $\mathrm{hPG}(1 \mathrm{mg} / \mathrm{ml})$ after 30 minutes, 1, 2, 4, 6 and 8 hours incubation.

Figure 33: Skim milk agar plates hydrolytic activity analysis of Lactobacillus grown in UHT. Zones of clearance indicate production of caseinolytic enzymes.

Figure 34: SDS-PAGE analysis of enzymes released by Lactobacilli in the supernatant to hydrolyze bPG. Lane 1: molecular weight standard; lane 2: bPG control $(0.125 \mathrm{mg} / \mathrm{ml})$; lane 3-11: bPG $(1 \mathrm{mg} / \mathrm{ml})$ interaction with the supernatant produced from Lactobacillus NCFM, T-1, MR220, 85302, 11088, L.C. 10, 23272, 661 , and 11284 after 3 hours incubation at $37^{\circ} \mathrm{C}$.

Figure 35: SDS-PAGE analysis of isolated cell wall associated enzymes ability in hydrolyzind bPG. Lane 1: molecular weight standard; lane 2: bPG control $(0.125$ $\mathrm{mg} / \mathrm{ml})$; lane 3-11: interaction between bPG $(1 \mathrm{mg} / \mathrm{ml})$ and cell wall associated enzymes isolated from Lactobacillus 661, NCFM, 23272, 11088, 11284, L.C. 10, T-1 and MR220.

Figure 36: Skim milk agar plates for Bacillus hydrolytic activity analysis after growth in TSB $+5 \%$ UHT or UHT for $12 \mathrm{~h}$.

Figure 37: SDS-PAGE analysis of bPG hydrolysis by the action of Bacillus derived proteases when grown in TSB-5\%UHT. Lane 1: molecular weight standard; lane 2: bPG control $(0.2 \mathrm{mg} / \mathrm{ml})$; lane 3: media control (TSB-5\% UHT); lane 4-17: bPG interaction with derived proteases from Bacillus ATCC14581 (lane 4), 23857 (lane5), 8186 (lane 6), 72 (lane 7), DIFCO (lane 8), 12980 (lane 9), 12759 (lane 10), 7050 (lane 11), 14579 (lane 12), 23059 (lane 13), 4513 (lane 14), 301 (lane 15), 23842 (lane 16) and 14580 (lane 17); lane 18: bPG in TSB-5\%UHT control. Fragments in the $37 \mathrm{kDa}$ represent potential angiostatin (AS) fragments.

Figure 38: Column chart indicating differences between various Bacilli tested in generating enzymes capable of hydrolyzing bPG. The highest the column the 
LOWEST the amount of enzymes produced since each column indicates the amount of bPG in solution at the end of the reaction (based on Figure 37). Vice versa, the lower the column the HIGHER the ability of the bacillus in generating bPG hydrolytic enzymes. In order from 1 to 14 the columns represent bPG hydrolyzed by Bacillus ATCC14581 (column 1), 23857 (column 2), 8186 (column 3), 72 (column 4), DIFCO (column 5), 12980 (column 6), 12759 (column 7), 7050 (column 8), 14579 (column 9), 23059 (column 10), 4513 (column 11), 301 (column 12), 23842 (column 13) and 14580 (column 14) respectively; column 15 represents bPG in TSB-5\%UHT control.

Figure 39: SDS-PAGE analysis of bPG hydrolysis by the action of Bacillus derived proteases when grown in UHT. Lane 1: molecular weight standard; lane 2: media control (UHT 1:5); lane 3: bPG in UHT 1:5 control; lane 4-17: bPG interaction with derived proteases from Bacillus ATCC14581 (lane 4), 23857 (lane 5), 8186 (lane 6), 72 (lane 7), DIFCO (lane 8), 12980 (lane 9), 12759 (lane 10), 7050 (lane 11), 14579 (lane 12), 23059 (lane 13), 4513 (lane 14), 301 (lane 15), 23842 (lane 16) and 14580 (lane 17) respectively.

Figure 40: Western blot identification of internal bPG fragments generated by the action of Bacillus produced proteases when grown in TSB-5\%UHT, by using a polyclonal anti-bovine plasminogen antibody. Lane 1: molecular weight standard; lane 2: bPG control (0.2 mg/ml); lane 3: media control (TSB-5\% UHT); lane 4-17: bPG interaction with derived proteases from Bacillus ATCC14581, 23857, 8186, 72, DIFCO, 12980, 12759, 7050, 14579, 23059, 4513, 301, 23842 and 14580 respectively; lane 18: bPG in TSB-5\%UHT control.

Figure 41: SDS-PAGE produced for sequence analysis of fragments generated through bPG hydrolysis by the action of Bacillus ATCC 7050 grown in TSB-5\% UHT. Lane 1: molecular weight standard; lane 2: bPG control $(0.125 \mathrm{mg} / \mathrm{ml})$; lane 3: media control (TSB-5\%UHT); lane 4: media control (UHT 1:5); lane 5: bPG in TSB-5\%UHT control incubated for 18 hours; lane 6: bPG in UHT control incubated for 18 hours; lane 7: bPG incubated with enzymes generated by bacillus ATCC 7050 after growth in TSB-5\%UHT; lane 8: bPG incubated with enzymes generated by bacillus ATCC 7050 after growth in UHT.

Figure 42: graph illustrating ability of various samples tested for their ability in inhibiting colon cancer cells growth. Samples tested were angiostatin (AS) generated through bPG and BPP incubation for 1 hour at $37^{\circ} \mathrm{C}$, bPG control as well as BPP control in a $2 \%$ NFDM solution.

Figure 43: Melanoma growth inhibition analysis. A) Malignant cells control treated with 5\% SDS; B) analysis of BPP control activity on melanoma cells proliferation; C-D) human and bovine plasminogen ability in inhibiting melanoma proliferation; E-F) melanoma sample treated with angiostatin (AS) generated by the reaction between BPP and human or bovine plasminogen respectively................................ 75 
Figure 44: experiment procedure scheme for analysis of individual digestive enzymes capacity in hydrolyzing angiostatin and the different solutions in which the investigation was conducted....

Figure 45: Western blot analysis of angiostatin digested through in vitro digestive model procedures. Lane 1: molecular weight standard; lane 2: bPG control (0.175 $\mathrm{mg} / \mathrm{ml})$; lane 3: 2\% NFDM control; lane 4: pepsin control $(1.82 \mathrm{mg} / \mathrm{ml})$; lane 5: pancreatin $(0.092 \mathrm{mg} / \mathrm{ml})$ control; lane 6 : bile $(1.104 \mathrm{mg} / \mathrm{ml})$ control; lane 7 : lipase $(0.046 \mathrm{mg} / \mathrm{ml})$ control; lane 8 : angiostatin (produced by interaction between $\mathrm{bPG}$ $(0.875 \mathrm{mg} / \mathrm{ml})$ and BPP $(0.1 \mathrm{mg} / \mathrm{ml}))$ control; lane 9: digestion of angiostatin in $2 \%$ NFDM after gastric phase; lane 10: digestion of angiostatin in 2\% NFDM after small intestine phase; lane 11: 2\% NFDM gastric phase digestion control; lane 12: $2 \%$ NFDM small intestine phase digestion control.

Figure 46: Western blot analysis on the of angiostatin digestion by the action of various digestive enzymes. Lane 1: molecular weight standard; lane 2: bPG (0.175 $\mathrm{mg} / \mathrm{ml})$ control; lane 3: pepsin control $(1.82 \mathrm{mg} / \mathrm{ml})$; lane $4:$ bile $(1.104 \mathrm{mg} / \mathrm{ml})$ control; lane 5: lipase $(0.046 \mathrm{mg} / \mathrm{ml})$ control; lane 6: pancreatin $(0.092 \mathrm{mg} / \mathrm{ml})$ control; lane 7: angiostatin control (produced through bPG hydrolysis from BPP); lane 9-12: angiostatin digested by the action of pepsin, bile, lipase and pancreatin respectively.

Figure 47: Western blot analysis of angiostatin digestion when in presence of NFDM. Lane 1: molecular weight standard; lane 2: bPG control $(0.175 \mathrm{mg} / \mathrm{ml}) ; 1 \%$ NFDM control; lane 4: angiostatin in buffer control (obtained through bPG hydrolysis by the action of BPP for 1 hour at $37^{\circ} \mathrm{C}$ ); lane 5: angiostatin in $2 \%$ NFDM; lane 6-9: angiostatin in NFDM digested by the action of pepsin, bile, lipase and pancreatin respectively....

Figure 48: Western blot analysis of digestion of angiostatin in skim milk by the action of various digestive enzymes. Lane 1: molecular weight standard; lane 2: bPG control $(0.175 \mathrm{mg} / \mathrm{ml})$; lane 3: skim milk (diluted 1:5 in ddwater) control; lane 4: angiostatin control (produced through bPG hydrolysis by the action of BPP at $37^{\circ} \mathrm{C}$ for 1 hour); lane 5: angiostatin in skim milk control; lane 6-9: angiostatin in skim milk digested by the action of pepsin, bile, lipase, and pancreatin respectively. .....88

Figure 49: SDS-PAGE visualization of proteolytic fragments obtained through angiostatin hydrolysis by the action of pepsin at E:S ratio 12:1. Lane 1: molecular weight standard; lane 2: angiostatin (AS) control (obtained through hydrolysis of bPG by the action of BPP for 1 hour at $\left.37^{\circ} \mathrm{C}\right)$; lane 3: pepsin $(\mathrm{P})$ control $(1 \mathrm{mg} / \mathrm{ml})$; lane 4-11: angiostatin hydrolysis by the action of pepsin after $0,1,5,10,15,20,30$ and 60 minutes incubation at $37^{\circ} \mathrm{C}$

Figure 50: SDS-PAGE analysis of angiostatin hydrolysis by the action of pepsin at pH 2 and E:S ratio of 1:100 and 1:50. Lane 1: molecular weight standard; lane 2: angiostatin (AS) control $(0.4 \mathrm{mg} / \mathrm{ml}$ ) (obtained from the reaction between $\mathrm{bPG}$ and $\mathrm{BPP}$ for 1 hour at $\left.37^{\circ} \mathrm{C}\right)$; lane 3: pepsin $(\mathrm{P})$ control $(0.004 \mathrm{mg} / \mathrm{ml})$; lane $4-9$ : 
angiostatin digestion by the action of pepsin at an $\mathrm{E}: \mathrm{S}$ ratio of $1: 100$ after $1,5,10$, 15,20 and 30 minutes incubation at $37^{\circ} \mathrm{C}$; lane 10 : pepsin control $(0.008 \mathrm{mg} / \mathrm{ml})$; lane 11-16: angiostatin digestion by the action of pepsin at an $\mathrm{E}: \mathrm{S}$ ratio of 1:50 after $1,5,10,15,20$ and 30 minutes incubation at $37^{\circ} \mathrm{C}$. Bands in the $37 \mathrm{kDa}$ area correspond to angiostatin (AS).

Figure 51: SDS-PAGE analysis of angiostatin hydrolysis by the action of pepsin at pH 2 and E:S ratio of 1:25 and 1:10. Lane 1: molecular weight standard; lane 2: angiostatin (AS) control $(0.4 \mathrm{mg} / \mathrm{ml})$ (obtained from the reaction between $\mathrm{bPG}$ and BPP for 1 hour at $\left.37^{\circ} \mathrm{C}\right)$; lane 3 : pepsin $(\mathrm{P})$ control $(0.016 \mathrm{mg} / \mathrm{ml})$; lane $4-9$ : angiostatin digestion by the action of pepsin at an $\mathrm{E}: \mathrm{S}$ ratio of 1:25 after 1, 5, 10, 15,20 and 30 minutes incubation at $37^{\circ} \mathrm{C}$; lane 10: pepsin control $(0.04 \mathrm{mg} / \mathrm{ml})$; lane 11-16: angiostatin digestion by the action of pepsin at an $\mathrm{E}: \mathrm{S}$ ratio of 1:10 after $1,5,10,15,20$ and 30 minutes incubation at $37^{\circ} \mathrm{C}$. Bands in the $37 \mathrm{kDa}$ area correspond to angiostatin (AS).

Figure 52: SDS-PAGE analysis of angiostatin digestion by the action of trypsin at various E:S after 1 hour at $37^{\circ} \mathrm{C}$. Lane 1: molecular weight standard; lane 2: angiostatin (AS) control (obtained from bPG hydrolysis by the action of BPP after 1hour at $\left.37^{\circ} \mathrm{C}\right)$; lane 3: trypsin $(\mathrm{T})$ control $(0.175 \mathrm{mg} / \mathrm{ml})$; lane $4-10$ : angiostatin interaction with trypsin at $\mathrm{E}: \mathrm{S}$ ratios of 1:50, 1:20, 1:13, 1:10, 1:8, 1:6 and 1:5 respectively.

Figure 53: SDS-PAGE analysis of the products generated by the reaction between angiostatin and trypsin at various E:S. Lane 1: molecular weight standard; lane 2: angiostatin (AS) control (obtained by bPG hydrolysis by the action of BPP at $37^{\circ} \mathrm{C}$ for 1 hour); lane 3: trypsin $(\mathrm{T})$ control $(0.75 \mathrm{mg} / \mathrm{ml})$; lane $4-10$ : angiostatin interaction with trypsin at $\mathrm{E}: \mathrm{S}$ ratios $1: 10,1: 5,1: 3,1: 1,3: 1,5: 1$ and 10:1 respectively.

Figure 54: Western blot analysis of the products generated by the reaction between angiostatin in skim milk and trypsin at various E:S. Lane 1: molecular weight standard; lane 2: angiostatin (AS) control (obtained by bPG hydrolysis by the action of BPP at $37^{\circ} \mathrm{C}$ for 1 hour); lane 3: skim milk (SM) control (diluted 1:5 v/v in ddwater) lane 4: trypsin (T) control $(0.5 \mathrm{mg} / \mathrm{ml})$; lane 5-11: angiostatin interaction with trypsin at $\mathrm{E}: \mathrm{S}$ ratios $1: 100,1: 50,1: 20,1: 10,1: 5,1: 3$ and 1:1 respectively.

Figure 55: SDS-PAGE analysis of the products generated by the reaction between angiostatin and $\alpha$-chymotrypsin at various E:S ratios. Lane 1: molecular weight standard; lane 2: angiostatin (AS) control (obtained by bPG hydrolysis by the action of $\mathrm{BPP}$ at $37^{\circ} \mathrm{C}$ for 1 hour); lane 3: $\alpha$-chymotrypsin $(\alpha-\mathrm{C})$ control $(0.5$ $\mathrm{mg} / \mathrm{ml}$ ); lane 4-10: angiostatin interaction with trypsin at $\mathrm{E}: \mathrm{S}$ ratios 1:100, 1:50, 1:20 1:10, 1:5, 1:3 and 1:1 respectively.

Figure 56: Western blot analysis of the products generated by the reaction between angiostatin in skim milk and $\alpha$-chymotrypsin at various E:S. Lane 1: molecular 
weight standard; lane 2: angiostatin (AS) control (obtained by bPG hydrolysis by the action of BPP at $37^{\circ} \mathrm{C}$ for 1 hour); lane 3: skim milk (SM) control (diluted 1:5 $\mathrm{v} / \mathrm{v}$ in ddwater) lane 4: $\alpha$-chymotrypsin $(\alpha-C)$ control $(0.5 \mathrm{mg} / \mathrm{ml})$; lane $5-11$ : angiostatin interaction with $\alpha$-chymotrypsin at $\mathrm{E}: \mathrm{S}$ ratios 1:100, 1:50, 1:20, 1:10, $1: 5,1: 3$ and $1: 1$ respectively.

Figure 57: SDS-PAGE visualization of the products generated by trypsin during bPG hydrolysis at various E:S ratios after 1 hour at $37^{\circ} \mathrm{C}$. Lane 1: molecular weight standard; lane 2: bPG control $(0.25 \mathrm{mg} / \mathrm{ml})$; lane 3: trypsin (T) control $(0.5 \mathrm{mg} / \mathrm{ml})$; lane4: reaction between $\mathrm{bPG}$ and trypsin at $\mathrm{E}: \mathrm{S}$ ratios 1:150, 1:75, 1:30, 1:15, 1:7.5, $1: 5$ and $1: 1.5$ respectively.

Figure 58: Western blot visualization of the products generated by trypsin during bPG hydrolysis at various E:S ratios after 1 hour at $37^{\circ} \mathrm{C}$. Lane 1: molecular weight standard; lane 2: bPG control $(0.25 \mathrm{mg} / \mathrm{ml})$; lane 3: trypsin $(\mathrm{T})$ control $(0.5 \mathrm{mg} / \mathrm{ml})$; lane 4: reaction between $\mathrm{bPG}$ and trypsin at $\mathrm{E}: \mathrm{S}$ ratios 1:150, 1:75, 1:30, 1:15, $1: 7.5,1: 5$ and $1: 1.5$ respectively.

Figure 59: SDS-PAGE visualization of the products generated by $\alpha$-chymotrypsin during bPG hydrolysis at various E:S ratios after 1 hour at $37^{\circ} \mathrm{C}$. Lane 1: molecular weight standard; lane 2: bPG control $(0.25 \mathrm{mg} / \mathrm{ml})$; lane $3: \alpha$-chymotrypsin $(\alpha-\mathrm{C})$ control $(0.5 \mathrm{mg} / \mathrm{ml})$; lane 4 : reaction between $\mathrm{bPG}$ and $\alpha$-chymotrypsin at $\mathrm{E}: \mathrm{S}$ ratios $1: 150,1: 75,1: 30,1: 15,1: 7.5,1: 5$ and $1: 1.5$ respectively.

Figure 60: Western blot visualization of the products generated by $\alpha$-chymotrypsin during bPG hydrolysis at various E:S ratios after 1 hour at $37^{\circ} \mathrm{C}$. Lane 1: molecular weight standard; lane 2: bPG control $(0.25 \mathrm{mg} / \mathrm{ml})$; lane 3: $\alpha$-chymotrypsin $(\alpha-\mathrm{C})$ control $(0.5 \mathrm{mg} / \mathrm{ml})$; lane 4 : reaction between bPG and $\alpha$-chymotrypsin at E:S ratios $1: 150,1: 75,1: 30,1: 15,1: 7.5,1: 5$ and $1: 1.5$ respectively.

Figure 61: Western blot of samples recovered after L-lysine affinity column chromatography. Lane 1: molecular weight standard; lane 2: interaction between $\mathrm{BPP}$ and $\mathrm{bPG}$ at $37^{\circ} \mathrm{C}$ after 1 hour incubation (control). Lanes 3 to 5 represent first purification try and samples recovered at retention times: 0 to 8.8 minutes; 8.8 to 14.3 minutes; 14.3 to 20 minutes respectively. Lanes 6 to 8 represent samples collected during second purification attempt at retention times: 0 to 5.6 minutes; 5.6 to 10.0 minutes; 10.0 to 20.8 minutes respectively

Figure 62: Chromatogram generated during purification of angiostatin from bovine plasminogen and BPP through L-lysine affinity column chromatography. The first pick obtained at 2.83 minutes retention time represent proteins recovered during binding phase, while the second pick at 13.73 minutes represent proteins recovered during elution phase.

Figure 63: Saturation curve obtained from the reaction between BPP $(0.1 \mathrm{mg} / \mathrm{ml})$ and various bPG concentrations $(0.25,0.375,0.5$ and $0.625 \mathrm{mg} / \mathrm{ml})$ after 1 hour incubation at $37^{\circ} \mathrm{C}$ 
Figure 64: Lineweaver-Burk obtained by plotting the inverse of the initial velocities from the interaction between various bPG concentrations $(0.25,0.375,0.5$ and $0.625 \mathrm{mg} / \mathrm{ml})$ and BPP $(0.1 \mathrm{mg} / \mathrm{ml})$ after 1 hour incubation at $37^{\circ} \mathrm{C}$ and the inverse of bPG concentration used .....

Figure 65: Hens-Woolf plot obtained by plotting bPG concentration vs. the value obtained by dividing the substrate concentration with the corresponding initial velocity observed between BPP and bPG interaction

Figure 66: Sequence analysis of $35 \mathrm{kDa}$ fragment generated through $\mathrm{bPG}$ hydrolysis by the action of BPP $(0.1 \mathrm{mg} / \mathrm{ml})$ after 1 hour incubation. The colored amino acids represent the sequence coverage of $\mathrm{bPG}$, and in green are observed post-translational modifications

Figure 67: Sequence analysis of $37 \mathrm{kDa}$ fragment generated through $\mathrm{bPG}$ hydrolysis by the action of BPP $(0.1 \mathrm{mg} / \mathrm{ml})$ after 1 hour incubation. The colored amino acids represent the sequence coverage of bPG, and in green are observed post-translational modifications

Figure 68: Sequence analysis of $50 \mathrm{kDa}$ fragment generated through bPG hydrolysis by the action of BPP $(0.1 \mathrm{mg} / \mathrm{ml})$ after 1 hour incubation. The colored amino acids represent the sequence coverage of bPG, and in green are observed post-translational modifications

Figure 69: Casein-agar plates for analysis of caseinolytic activity of Lactobacillus grown in MRS-5\%UHT milk.

Figure 70: Skim milk agar plates for hydrolytic analysis of Bacillus grown for 12 vs. 24 hours in TSB growth media (plates were incubated at $37^{\circ} \mathrm{C}$ for $24 \mathrm{~h}$ )

Figure 71: Sequence analysis of $22 \mathrm{kDa}$ fragment generated through bPG hydrolysis by the action of B.coagulans ATCC7050. The colored amino acids represent the sequence coverage of bPG, and in green are observed posttranslational modifications. (Sequence interpretation: K1:78\% - K2: 91\% - K3: $100 \%$ - K4: $71 \%$ - K5: $45.5 \%)$

Figure 72: Sequence analysis of $25 \mathrm{kDa}$ fragment generated through $\mathrm{bPG}$ hydrolysis by the action of B.coagulans ATCC7050. The colored amino acids represent the sequence coverage of bPG, and in green are observed posttranslational modifications. (Sequence interpretation: K1: 82\% - K2: 44\% - K3: $54.5 \%$ - K4: $0 \%$ - K5: 20\%)

Figure 73: Sequence analysis of $27 \mathrm{kDa}$ fragment generated through $\mathrm{bPG}$ hydrolysis by the action of B.coagulans ATCC7050. The colored amino acids represent the sequence coverage of bPG, and in green are observed posttranslational modifications. (Sequence interpretation: - K1: 63\% - K2: 56\% - K3: $31 \%$ - K4: $0 \%$ - K5: 0\%). 
Figure 74: Sequence analysis of $30 \mathrm{kDa}$ fragment generated through bPG hydrolysis by the action of B.coagulans ATCC7050. The colored amino acids represent the sequence coverage of bPG, and in green are observed posttranslational modifications. (Sequence interpretation: - K1: 60\% - K2: 49\% - K3: 52\% - K4: 0\% - K5: 20\%).

Figure 75: Casein SDS-PAGE for analysis of lipase contamination. Lane 1: MW standard; lane 2: cathepsin-D control; lane 3: pepsin; lane 4: bile; lane 5: lipase; lane 6: pancreatin. 


\section{LITERATURE REVIEW}

\subsection{BACKGROUND}

\subsubsection{CANCER: A GENETIC DISEASE}

Cancer is a disease that has been affecting humans throughout their history. In ancient Egypt and Greece individuals would attempt to cure this disease, defined by Hippocrates as having a crab like shape, from there the name "cancer", with magical spells or other sorcery tricks. Over the years cancer has gradually seen an increase in the number of individuals affected by this disease. This increase has been enabled by changes in our habits and in the environment in which we live today; examples are our diet, radiations and chemical exposure, etc. Moreover since cancer has a positive correlation with age, increase in longevity has resulted in a parallel increase in cancer cases. Nowadays cancer is the second leading cause of death in the United States and other economically developed countries (The history of cancer 2010; Landau Elizabeth 2010). Due to the severity with which this disease is affecting our society (one in five of us will die of cancer), scientists all over the world have been conducting extensive research to comprehend the origins of cancer in order to develop effective therapies (Alberts Bruce et al. 2008).

After more than 25 years of research, cancer has revealed to be a disease that initiates at the genomic level through a sequence of events that will irreversibly convert a normal cell into a malignant one (Hanahan Douglas et al. 2000; Alberts Bruce et al. 2008). Commonly, the first incident responsible for this alteration consists in an aberration on the hereditary information, genetic or epigenetic, of a single cell. Subsequently, through cell division, this anomalous trait gets transferred and accumulates in its progeny (Alberts Bruce et al. 2008). Succeeding cell cycles will then cause these cells to evolve assuming additional mutations that buildup in different genes overtime, promoting cancerous cells growth and tumor development (Alberts Bruce et al. 2008).

Accretion on the number of occurring mutations will enable cells to evolve and adapt to a new environment. These will gain growth and survival advantages compared to normal cells. Conditions inside a tumor are characterized by low oxygen and nutrients 
availability as well as growth barriers by presence of surrounding tissue; only evolved cells are able to survive in such harsh environment (Gatenby Robert A. et al. 2004; Alberts Bruce et al. 2008).

According to Hanahan et al., six major traits are acquired during the transition of a cell from normal to cancerous: self-sufficiency in growth signals, insensitivity to growth inhibitory signals, evasion of programmed cell death, limitless replicative potential, sustained angiogenesis, tissue invasion and metastasis (Hanahan Douglas et al. 2000).

It is also true that different cancers should be considered as different diseases, since based on their origin and nature they will present different characteristics. In fact, a treatment may be very effective in inhibiting a specific tumor but useless for treating others. Nevertheless, there is no doubt that the majority of deadly cancers are those prone to evasion and metastasis which is favored and enabled by angiogenesis (Folkman Judah 2006; Alberts Bruce et al. 2008).

\subsubsection{ANGIOGENESIS}

Angiogenesis is the process by which new blood vessels develop from preexisting vascularization. Angiogenesis is divided into physiological and pathological, which depends on whether angiogenic regulators' activity is controlled or fail to respond to specific signals (Judah Folkman et al. 1992; Losso Jack N. 2003).

Physiological angiogenesis is essential for reproduction, wound repair and tissue development, and is controlled by a balance between stimulators and inhibitors (Judah Folkman et al. 1992; Losso Jack N. 2003). In fact, when specific tissues are under hypoxia conditions they will generate particular signals that will stimulate angiogenesis and will allow the development of blood vessels necessary for the transport of oxygen and nutrients to satisfy cells' need. Once the tissue has received enough oxygen required for cells metabolism, such cells will reduce the amount of angiogenesis stimulators produced and will start expressing antiangiogenic factors that will cause the capillary vessel previously formed to stop growing or degrade (Liekens Sandra et al. 2001). 
On the other hand, during pathological angiogenesis, once angiogenic factors are stimulated and released by cells (i.e.: cancerous cells) they won't produce enough antagonists to bring back the equilibrium between anti- and pro- angiogenic factors, causing endothelial cells (EC) to be constantly stimulated. This phenomenon is known as the "angiogenic switch". Once the switch is ON, development of numerous blood vessels that will support the growth of cancerous cells by continuously provide nutrients and oxygen is inevitable (Hanahan Douglas et al. 1996; Bergers Gabriele et al. 2003). Thanks to this mechanism, tumor cells are able to grow, proliferate and escape into the circulatory system where they are transported to distant sites causing metastasis to arise (Judah Folkman et al. 1992).

Many degenerative diseases are stimulated or affected by angiogenesis both through insufficient or excessive development of blood vessels. For example, insufficient blood supply may lead to heart disease, infertility and stroke. Conversely excessive angiogenesis may function as Parkinson's and Alzheimer's disease promoter, can cause complications in diabetic patients leading to blindness and may represent an obstacle in the cure of many other disorders (Losso Jack N. 2003).

After many years of research, angiogenesis suppression is now recognized as a convincing strategy to suppress cancer growth and metastases (Hanahan Douglas et al. 1996; Nelson Nancy J. 1999; Kerbel Robert S. 2000). In fact, many studies have confirmed that tumors cannot grow beyond their critical size $(\approx 1-2 \mathrm{~mm}$ diameter $)$ at which simple diffusion of nutrients and waste products is limited; without further blood supply tumor cells may become necrotic and/or apoptotic (Hanahan Douglas et al. 1996; Zetter Bruce R. 1998; Kerbel Robert S. 2000). Owing to these results, angiogenesis suppression represents a promising approach in many areas of cancer research and possible treatment development (Kerbel Robert S. 2000).

According to Folkman and Kalluri, many individuals carry microscopic non angiogenic in situ tumors that do not progress over time. Only 1 every 600 malignancies will switch towards an active state (angiogenic switch is activated) and grow into a detectable tumor (Folkman Judah et al. 2004; Folkman Judah 2006).

From this observation it is possible to conclude that if tumors have no access to blood supply, and consequently to oxygen and nutrients, they will remain in a dormant 
state (the number of cells proliferating equals the number of cells dying) for an undefined period of time and are harmless to the host. It is believed that endogenous angiogenesis inhibitors originally present in our organism (i.e. angiostatin), control and help maintain those micrometastases in a quiescent state (Folkman Judah et al. 2004). In fact a study conducted by Soff et al. in 1999 has shown that angiostatin can occur naturally in human plasma at concentrations of 6-12nM, perhaps enough to inhibit these micro-tumors to develop, however more research is required to confirm such statement (Soff Gerald A. et al. 1999).

\subsubsection{FACTORS INVOLVED IN ANGIOGENESIS INITIATION}

Angiogenesis is a very complex process involving numerous factors that interact through different mechanisms, which makes it challenging for researchers to exactly understand the process and effectively find a way to block tumor vascularization (Hanahan Douglas et al. 1996; Cao Yihai 2004).

Additionally, in order for the capillary to form and protrude from the pre-existing vessel many steps are required: EC proliferation and migration, basement membrane disruption, EC invasion of the surrounding stroma, and lumen formation through cells adhesion (Hanahan Douglas et al. 1996; Ji Weidong-richard et al. 1998; Cao Renhai et al. 1999; Carmeliet Peter et al. 2000). Contrarily to normal blood vessels, tumor vessels are characterized by high disorganization and poor structure. Moreover, these chaotic vessels present dead ends, are leaky and arterial blood mixes with venous blood (Carmeliet Peter et al. 2000; Wahl Miriam L. et al. 2004).

Numerous angiogenic factors have been identified so far. Particularly of interest are VEGF (vascular endothelial growth factor), bFGF (basic fibroblast growth factor), angiopoietin and MMPs (metalloproteinases), which are overexpressed during tumor development. However, VEGF is known to be the most specific angiogenic factor since it only targets blood EC, and experiments conducted on mice showed that inhibition of VEGF caused complete halt of tumor growth (Cao Yihai 2004). For this reason many drugs designed to treat cancer act on this molecule by inhibiting the interaction of VEGF with its receptors found on the surface of endothelial blood cells (Cao Yihai 2004). Avastin (also known as bevacizumab) for example, was the first antiangiogenic therapy 
approved by the FDA, that consists of a recombinant humanized monoclonal IgG1 antibody that recognizes and binds to VEGF blocking its biological activity (Ferrara Napoleone et al. 2005; Folkman Judah 2006; Genentech 2008). Avastin is now used to treat lung, kidney, colorectal and brain cancer in combination with chemotherapy or other drugs.

\subsubsection{VEGF ANGIOGENESIS SIGNALING PATHWAYS}

As previously mentioned, VEGF has a central role in angiogenesis development. Many experiments show that VEGF is indispensable in both physiological and pathological processes. Particularly interesting were the results obtained from a study, where the removal of a single VEGF allele caused mice embryos death after only a few days of pregnancy, indicating that VEGF has a crucial role in proper vascular system development (Liekens Sandra et al. 2001; Dulak J. 2005). VEGF acts by interacting with its two tyrosine kinase receptors (VEGFR1 and VEGFR2) located on the surface of ECs. This contact activates numerous signaling pathways that will allow such cells to proliferate, differentiate, migrate, survive and consequently generate blood vessels (Zachary I. 2003).

The expression of this pro-angiogenesis factor is mostly stimulated by hypoxia conditions, which in case of cancer are achieved when the tumor reaches its critical size of 1-2 mm in diameter. Several of the signals activated from the interaction between ECs receptors and VEGF are outlined in Figure 1. First, the survival signaling pathway is promoted by the activation of an anti-apoptotic kinase (akt) through phosphoinositide 3'kinase pathway, which results in the phosphorylation and inhibition of a pro-apoptotic protein known as Bad. Instigation of this pathway will inhibit ability of activated ECs to undergo apoptosis that will consequently be kept active even after the signal stimulus cease.

A second important pathway activated by VEGF when in contact with its receptors is known as the mitogenic signaling (Zachary I. 2003). This cascade response is driven by the MAPKs (mitogen activated protein kinases) pathway that leads to the activation of ERK (extracellular-signal-regulated protein kinases) as a final compound. ERK travels then into the nucleus of the ECs where it will phosphorylate and activate 
specific gene regulatory proteins responsible for the expression of cell cycle initiators, such as G1 cyclins (Alberts Bruce et al. 2008).

Another pathway, known as chemotactic signaling, plays also an essential role in promoting angiogenesis. This pathway stimulates cells' migration through FAK (focal adhesion kinase) activation; this kinase is involved in cell junction and its activation will cause loss of cell adhesion allowing cells' to migrate (Alberts Bruce et al. 2008). Lastly, a less well understood pathway involves generation of nitric oxide and prostanoids (PGs) which are released outside the cell and will interact with other neighboring cells allowing vascular permeability regulation.

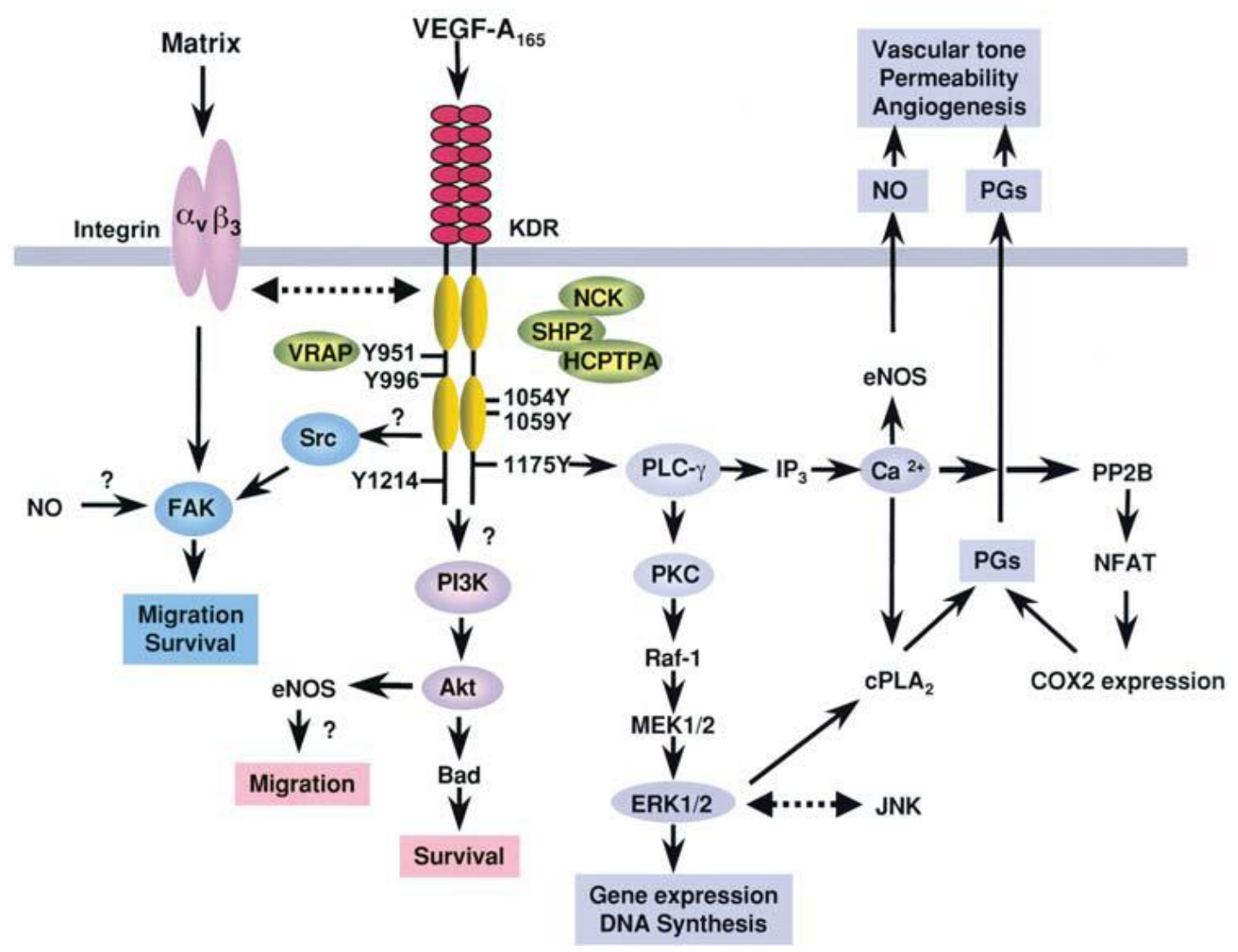

Figure 1: VEGF interaction with endothelial cells and activated signaling pathways (Zachary I. 2003) 


\subsection{ANGIOSTATIN}

\subsubsection{THE DISCOVERY}

Angiostatin is one of the most potent angiogenesis inhibitors known to date (O'Reilly Michael S. et al. 1994; Cao Renhai et al. 1999). This molecule is obtained trough hydrolysis of plasminogen (PG), the zymogen of the fibrinolytic enzyme plasmin (PL) (O'Reilly Michael S. et al. 1994; Ji Weidong-richard et al. 1998; Wahl Miriam L. et al. 2005). This antiangiogenic peptide was discovered in the Folkman's lab in 1994 by O'Reilly et al. while conducting research on the effects of primary tumors in inhibiting the development of metastasis as well as secondary tumors at distant sites (O'Reilly Michael S. et al. 1994; Zetter Bruce R. 1998; Cao Renhai et al. 1999; Soff Gerald A. 2000). At that time, cancer researchers were trying to understand why the removal of some primary tumors caused rapid development of remote metastasis (O'Reilly Michael S. et al. 1994; Zetter Bruce R. 1998; Figg William D. et al. 2008). O’Reilly et al., trough a sequence of experiments discovered that tumors were not only producing angiogenesis activators but also angiogenesis inhibitors. These experiments consisted in implanting Lewis lung carcinoma in mice, and once the tumor reached a size of 1 to $2 \mathrm{~cm}^{3}$, it was resected and growth of secondary and metastasis were examined (Figg William D. et al. 2008). From the results collected in the study, it was evident that removal of the primary tumor caused considerable increase in the rate at which distant site cancerous colonies grew compared to control mice for which the primary tumor was not removed (O'Reilly Michael S. et al. 1994; Figg William D. et al. 2008). Additionally, resected mice developed high vascularization at the malignant sites contrarily to control mice which developed only microscopic metastases or small colonies of tumor cells, but no signs of neovascularization were observed (O'Reilly Michael S. et al. 1994). It is from these observations that the idea of the primary tumor producing an angiogenesis inhibitor capable of impeding ECs proliferation at distant sites was considered. In fact, from another experiment conducted to prove the likelihood of this thought, serum and urine obtained from tumor-bearing mice, but not that of healthy mice, caused significant proliferation inhibition of ECs in vitro (O'Reilly Michael S. et al. 1994). Through further analysis, a $38 \mathrm{kDa}$ protein, later called angiostatin, was purified and confirmed to be the 
molecule responsible in inhibiting ECs activity (O'Reilly Michael S. et al. 1994; Figg William D. et al. 2008). Indeed, by way of additional experiments, angiostatin showed to be capable of inhibiting ECs proliferation and migration in vitro, tumor angiogenesis in vivo as well as tumor metastasis in animal models (Figg William D. et al. 2008).

Sequencing of this $38 \mathrm{kDa}$ band by micro molecular techniques, revealed the peptide to belong to the internal four-kringles K1-K4 domains of PG (Figure 2).

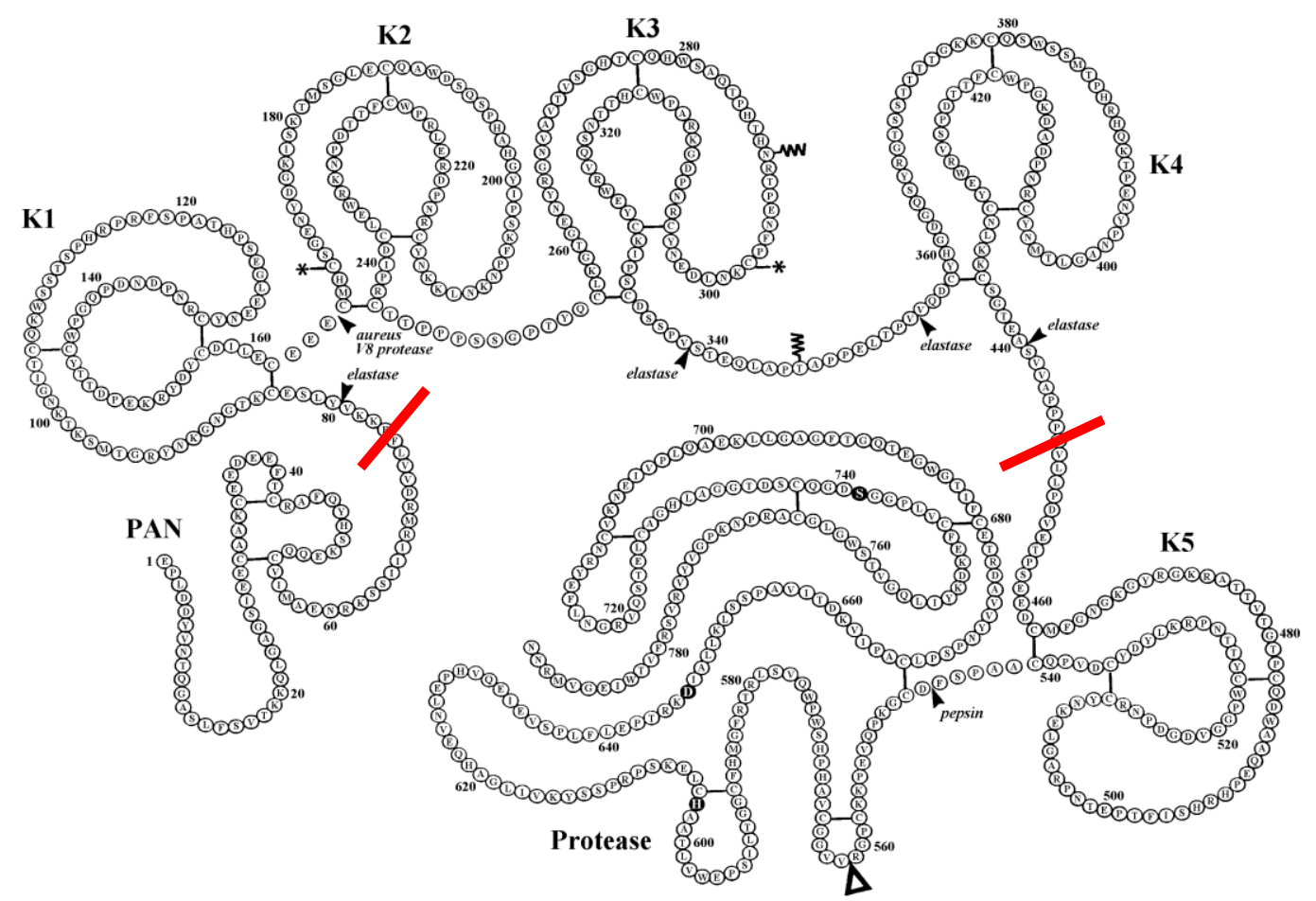

Figure 2: Plasminogen Structure (Platanias Leonidas C. 2009). In red are indicated the regions of PG that need to be hydrolyzed in order to obtain angiostatin K1-4.

The discovery that cancer could produce peptides that would inhibit its own growth and consequent survival was at first regarded with skepticism. Following investigations allowed clarification on this phenomenon, confirming that generation by cancerous cells of a molecule that interferes with their ability to grow and proliferate is 
accidental (Wahl Miriam L. et al. 2005). Tumor cells do not synthesize angiostatin, a gene coding for angiostatin does not exist. Alternatively, during expansion, cancerous cells release many proteases necessary to support their metabolism such as matrix metalloproteinases (MMPs), cathepsin and elastase that promote activation of proangiogenic factors (Ji Weidong-richard et al. 1998; O'Reilly Michael S. et al. 1999; Morikawa Wataru et al. 2000; Cao Yihai 2004). These proteases subsequently interact with PG molecules, which are present at higher concentration near the tumor due to vascularization increase. Plasminogen is then cleaved and the four kringle structure belonging to angiostatin released (Vassalli J. D. et al. 1991; O'Reilly Michael S. et al. 1994; Cao Yihai 2004). Surprisingly, many other antiangiogenic molecules are directly produced by the action of enzymes released by tumors such as endostatin, which is obtained by cleaving collagen XVIII by the action of elastase and cathepsin (Wen Wei et al. 1999; Geiger J. H. et al. 2004; Figg William D. et al. 2008).

Angiostatic molecules, such as angiostatin, have longer half-life in circulation than proangiogenic molecules, this is why they are able to reach distant micrometastasis and inhibit their growth. Contrarily, at the site of the primary tumor, the amount of angiostatin produced is not high enough to counterbalance the predominating neovascularization signals (O'Reilly Michael S. et al. 1994; Wahl Miriam L. et al. 2005).

\subsubsection{MOLECULAR STRUCTURE}

Angiostatin was initially identified as belonging to the four internal kringle domains of PG (residues 78-440). A kringle is a loop like structures stabilized by three disulfide bonds (O'Reilly Michael S. et al. 1994; Cao Yihai et al. 1996; MacDonald Nicholas J. et al. 1999; Cao Yihai 2004; Geiger J. H. et al. 2004). Although angiostatin was discovered as containing four kringles, we now know that different kringles combinations from PG, such as K1-3, K1-4, K1-5 and K5 alone, also exert antiangiogenic activity. Interestingly, each of these kringle combinations possesses different inhibitory activity on either the proliferation or migration of ECs, two major mechanisms required to initiate and sustain angiogenesis (Cao Yihai et al. 1996; Cao Yihai et al. 1997; Abad Marta C. et al. 2002). On the contrary, intact PG has shown to be ineffective in inhibiting any type of EC activity or tumor angiogenesis (O'Reilly Michael 
S. et al. 1994; O'Reilly Michael S. et al. 1996). Analysis of the structural elements of these five loops will help us recognize which characteristics may be responsible in conferring angiostatin its potent antiangiogenic activity.

The five kringles are known to have lysine binding site (LBS), however their affinity for lysine varies. In fact when in presence of epsilon-amino caproic acid (EACA), a small molecule used to mimic affinity to lysine, K1, K4 and K5 show high binding interaction, while $\mathrm{K} 2$ affinity is significantly lower and $\mathrm{K} 3$ shows almost no attraction (Lerch P. G. et al. 1980; Geiger J. H. et al. 2004). It is this difference in lysine binding that explains the affinity of PL to fibrin (Lerch P. G. et al. 1980). However it is still uncertain whether this difference in LBS affinity could also explain the different ECs inhibitory activity among kringle domains (Abad Marta C. et al. 2002; Geiger J. H. et al. 2004).

Each kringle is characterized by a string of 80 amino acids, and sequence analysis between kringles has shown 50\% homology (Ji Weidong-richard et al. 1998; Cao Yihai 2004). It is important to mention that integrity of angiostatin is essential for this molecule to maintain its activity. If the kringle folding is lost and the disulfide bonds reduced, the molecule is no longer active (Cao Yihai et al. 1996; Ji Weidong-richard et al. 1998).

Through NMR and X-ray crystallography, molecular characteristics of angiostatin K1-3, the most potent antiangiogenic form of the molecule, were determined (Abad Marta C. et al. 2002). Abad at al. defined angiostatin K1-3 as having a bowl like structure (Figure 3), with the kringle domains on the side of the bowl and the bottom represented by interkringle peptides (Abad Marta C. et al. 2002). The structure is maintained by many kringle/kringle and kringle/interkringle interactions. And interestingly a large cleft is observed between $\mathrm{K} 2$ and $\mathrm{K} 3$. Abed et al. believe this cleft to have a major role in recognizing specific ligands or sequences responsible for inhibiting ECs migration. In fact $\mathrm{K} 2-\mathrm{K} 3$ alone has shown to be a potent EC migration inhibitor (however no effect on EC proliferation was observed) (Abad Marta C. et al. 2002; Geiger J. H. et al. 2004). 


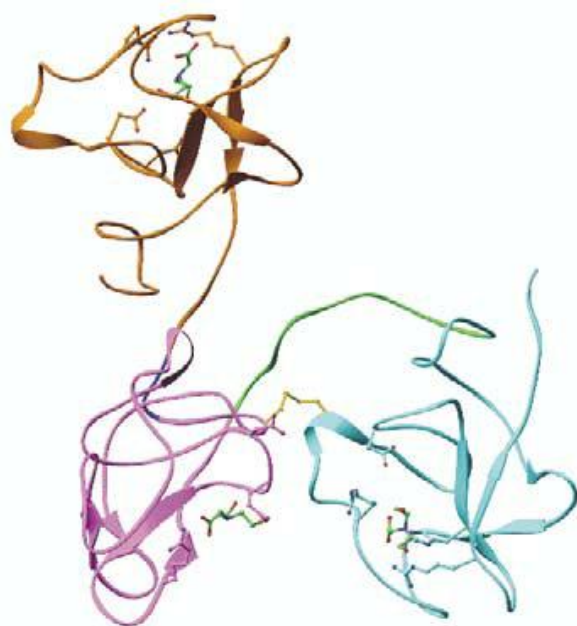

Figure 3: Angiostatin K1-3 molecular structure. K1, orange; K2, pink; K3, light blue (Abad Marta C. et al. 2002)

Another interesting fact regards the motility of the molecule. No direct linkage is observed between the three kringles allowing the molecule to orient its kringles towards their respective receptors, perhaps explaining why $\mathrm{K} 1$ alone has better proliferation inhibition activity while K2-K3 is a better migration inhibitor (Ji Weidong-richard et al. 1998; Abad Marta C. et al. 2002; Geiger J. H. et al. 2004).

Although a lot of research on the subject has been conducted much remains to be elucidated in order to understand the exact mechanism behind angiostatin-EC interaction, the receptors involved and the motifs or structure of angiostatin responsible for its anticancer activity.

\subsubsection{MECHANISM OF ACTION}

As previously mentioned, angiostatin is a strong angiogenesis inhibitor capable of inhibiting ECs proliferation and migration. Table 1 summarizes the findings obtained by various scientists which work has significantly contributed to the comprehension of angiostatin activity. 
Table 1: Plasminogen kringle domains and their respective activity in proliferation and migration inhibition of endothelial cells, binding to EACA, and tumor inhibition capability (Geiger J. H. et al. 2004).

\begin{tabular}{|c|c|c|c|c|}
\hline Kringle & Proliferation & Migration & $\begin{array}{c}\text { EACA binding } \\
(\mu \mathrm{M})\end{array}$ & $\begin{array}{c}\text { Tumor } \\
\text { Inhibitory } \\
\text { activity }\end{array}$ \\
\hline K1 & + & $+/-$ & 12 & $?$ \\
\hline K2 & + & + & 560 & $?$ \\
\hline K3 & + & + & - & $?$ \\
\hline K4 & - & + & 140 & + \\
\hline K5 & +++ & + & ++ & ++ \\
\hline K1-4 & ++ & +++ & ++ & ++ \\
\hline K1-3 & +++ & $+/-$ & ++ & $?$ \\
\hline K2-3 & - & ++ & + & + \\
\hline
\end{tabular}

No effect is shown by -, a marginal effect is shown by $+/-$, varying degrees of potency are shown by,,++++++ , an unknown effect is shown as '?'.

\subsubsection{MIGRATION VS. PROLIFERATION INHIBITION}

Angiostatin investigators have confirmed that various forms of angiostatin and individual kringles of $\mathrm{PG}$ have different inhibitory activity on the proliferation or migration of ECs. Tests on the ability of angiostatin to inhibit other non EC lines were also conducted. However, results were not relevant confirming angiostatin to be specific for ECs (Cao Yihai et al. 1996; Cao Renhai et al. 1999).

In 1996 Cao et al. conducted a study in which they characterized the ability of different kringle domains of human angiostatin in inhibiting ECs proliferation (Cao Yihai et al. 1996). Until then, angiostatin was only defined as belonging to K1-4 of PG, yet Cao et al. showed that by hydrolyzing $\mathrm{K} 4$ from this molecule a more potent inhibitor was obtained. Angiostatin as K1-3 exhibited a much higher inhibitory activity, than K1-4. In order to inhibit the proliferation of ECs by half only 70nM K1-3 were needed, while twice as much K1-4, 135nM, were necessary to obtain the same outcome (Cao Yihai et al. 1996). Interestingly, when tested alone K4 did not seem to have any effect on the proliferation of ECs, making scientists think that its presence may be futile. Though, as we will see next, K4 has shown to be one of the most potent kringles inhibiting ECs migration (Ji Weidong-richard et al. 1998).

Throughout their study Cao et al. made another significant finding. They discovered that PG kringle 5 alone and K1-5, have even stronger anti-proliferative 
activity than K1-3. For K5 alone, a half maximal concentration of 50nM was necessary to reduce by half the proliferative activity of ECs (Cao Yihai et al. 1997; Cao Renhai et al. 1999). On the other hand only 50pM were necessary to obtain the same effect by K1-5 (Cao Renhai et al. 1999). Interestingly, similar results were observed when angiostatin K1-4 plus K5 alone were tested on ECs, indicating that angiostatin and K5 have a synergistic effect and may act through different mechanism of action (Cao Renhai et al. 1999). Table 2 summarizes the kringles tested by Cao et al. during their study and the concentration needed for each of the fragments analyzed to obtain a half maximal inhibitory response.

Table 2: Anti endothelial cell proliferation activity of angiostatin and plasminogen kringle fragments. Values represent the mean of concentration for a half-maximal inhibitory response. (Cao Renhai et al. 1999)

\section{Plasminogen Fragments}

Kringle 1

Kringle 2

Kringle 3

Kringle 4

Kringle 5

Kringle 2-3

Kringle 1-3

Kringle 1-4 (angiostatin)

Kringle 1-5
$\mathrm{IC}_{50}$ Inhibition (nM)

320

$\mathrm{n} / \mathrm{a}$

460

No significant inhibition

50

$\mathrm{n} / \mathrm{a}$

70

135

0.05

Another study conducted by Ji et al. in 1998, investigated the effects of PG kringles and angiostatin in inhibiting ECs migration, another key step in angiogenesis progression. From this study interesting results were observed, and contrarily to the data collected from ECs proliferation inhibition, some kringles that were thought to have no activity resulted to be the ones with higher anti migration effect, such as K4 (Ji Weidongrichard et al. 1998). On the other hand, K1-3 had little to no effect in inhibiting EC migration. However, highest anti-migration effect was obtained by angiostatin K1-4 (Ji Weidong-richard et al. 1998). 


\subsubsection{ATP-SYNTHASE INHIBITION}

The precise mechanism through which angiostatin acts to impede the development of blood vessels has not yet been fully elucidated. Nevertheless, many researchers have shown that angiostatin may act by inhibiting the ATP-synthase pump, integrin $\alpha_{v} \beta_{3}$ or angiomotin located at the surface of ECs. Many other receptors on ECs have been examined, however ATP-synthase is the most studied and for which results have been more significant (Wahl Miriam L. et al. 2005).

$\mathrm{F}_{1} \mathrm{~F}_{0} \mathrm{ATP}$-synthase was originally thought to be only located on the mitochondrial inner membrane. It was in fact regarded as a surprise when Moser and Pizzo in 1995 discovered that ATP-synthase was indeed a receptor for angiostatin (K1-3 and K1-4). Further analysis ascertained the presence of active ATP producing ATP synthase on the surface of ECs (Moser Tammy L. et al. 1999; Moser Tammy L. et al. 2001; GonzalezGronow Mario et al. 2003). Interestingly, ATP-synthase has been identified on the surface of some cancerous cells as well (Figg William D. et al. 2008).

ATP-synthase has the function of providing energy to the cell by synthesizing ATP from ADP using a proton gradient across the membrane (Boyer Paul D. 1997; Alberts Bruce et al. 2008; Mowery Yvonne M. et al. 2009). Inhibition of this pump, impedes the escape of protons into the extracellular surroundings, resulting in a lower intracellular $\mathrm{pH}$ as well as a reduction of extracellular ATP produced, ensuing in ECs reduced proliferation due to increased cell death (Figg William D. et al. 2008; Mowery Yvonne M. et al. 2009).

Since ATP synthase has been found on the surface of many other cells lines one would question whether angiostatin would inhibit other cells, some of which may have essential roles in our body such as epithelial cells, fibroblasts, or ECs involved in physiological angiogenesis. The unique characteristic of angiostatin is that it shows higher interaction with ATP-synthase at low extracellular $\mathrm{pH}$ and almost no interaction at higher $\mathrm{pH}$ (Wahl M. L. et al. 2002; Figg William D. et al. 2008). Typically, the $\mathrm{pH}$ in normal tissues is between 7.2-7.6, while tumors have an extracellular $\mathrm{pH}$ of 5.6-7.6 (Wahl Miriam L. et al. 2004; Chi Sulene L. et al. 2006; Figg William D. et al. 2008). Tumor acidosis is a hallmark of these cells' environment. Cancerous cells need to rely more on glycolysis as an adaptation to hypoxia conditions. This form of metabolism 
results in higher release of lactic acid responsible for lowering the extracellular $\mathrm{pH}$ (Gatenby Robert A. et al. 2004).

The intracellular $\mathrm{pH}$ nevertheless remains the same in both cancerous cells and ECs situated near/inside tumors. For this reason under such conditions ATP-synthase function is essential and its activity higher in order to maintain a normal $\mathrm{pH}$ inside the cell and allow its survival (Chi Sulene L. et al. 2006). By interacting and impeding ATPsynthase activity under such critical conditions, angiostatin compromises the circumstances necessary for the survival of the cell.

The same laboratory that discovered ATP-synthase to be present on the surface of ECs and to be a target for angiostatin, later discovered the ability of angiostatin to interact with ATP-synthase located on the surface of cancerous cells. Reduced proliferation as well as cell death through necrosis (typical when ATP depletion occurs) resulted to occur in a similar manner to that observed for ECs (Chi Sulene L. et al. 2006). In fact, also in this situation angiostatin interaction with ATP-synthase was $\mathrm{pH}$ dependent (Chi Sulene L. et al. 2006).

Furthermore, angiostatin proved to be more effective in inhibiting certain type of cancers, or cell lines of the same cancer, compared to others. This is because cancerous cells will express different levels of ATP-synthase. Chi and Pizzo observed that lung adenocarcinomas cells presented on their surface a much higher amount of this ATP producing enzyme than prostate cancer cells for example. On the other hand, among two prostate cancer lines PC-3 and 1-LN, the expression of ATP-pump also differed. Interestingly the line known to be more deadly (PC-3) resulted to express fewer ATPsynthase. This phenomenon could perhaps explain PC-3 to have a higher capability of escaping into the circulatory system resulting in a highly metastatic and hostile form of cancer, since less susceptible to the action of angiostatin or other inhibitors factors (Chi Sulene L. et al. 2006).

In the same way, it was also determined that tumors characterized by a more acidic extracellular environment are statistically more inclined to evasion, mutation and drug/chemotherapy resistance (Martínez-Zaguilán Raul et al. 1996).

Summarizing the work conducted by numerous scientists through the years, it seems that ability of angiostatin in inhibiting angiogenesis or cancerous cells 
development is mostly affected by the external $\mathrm{pH}$ of the cell as well as the number of ATP-synthase expressed by the cells. Based on these finding we can predict that angiostatin will have a different inhibitory effect on different types of cancers.

\subsubsection{ANIMAL MODELS RESULTS}

As soon as angiostatin was discovered and its potent activity in vitro uncovered with a lot of excitement and positivity, various animal models were designed with a high level of expectations.

The first in vivo experiments were conducted by the Folkman's laboratory, in which various human tumors were implanted in mice and then treated with angiostatin (O'Reilly Michael S. et al. 1996). The results obtained were positively significant. Angiostatin inhibited: human breast carcinoma by $95 \%$, colon carcinoma by $97 \%$ and prostate carcinoma by $100 \%$ (O'Reilly Michael S. et al. 1996). Surprisingly, angiostatin did not cause a reduction of the rate at which the cells proliferate, which remained the same, but it triggered a significant increase in the number of cells undergoing apoptosis. Tumors reached a dormant state, in which the number of cells proliferating is balanced by the number of cells dying (O'Reilly Michael S. et al. 1996). This state was maintained as long as angiostatin was administered; as soon as angiostatin was withdraw the levels of VEGF increased and angiogenesis was once again enabled (O'Reilly Michael S. et al. 1996). In any of the cases analyzed toxicity was a concern, not even when angiostatin was administered at high doses.

MacDonald et al. analyzed whether in vivo effect of K1-3 and K1-4 differed. They compared the ability of these two molecules in inhibiting the growth of lung metastases typical of melanoma B16-BL6. Their findings showed no significant difference among the two forms of angiostatin. Kringles 1-3 and 1-4 inhibited the growth of the metastatic colonies by $80 \%$ compared to the controls (MacDonald Nicholas J. et al. 1999). Additionally, analysis of ECs also indicated a reduced number at the metastasis sites compared to controls.

Interestingly, investigation on the half-life denoted K1-4 to require significant longer time to be excreted (9.1hours) than K1-3 (4.8 hours) (MacDonald Nicholas J. et al. 
1999). However, since the antitumor activity between K1-3 and K1-4 is similar, the explanation for a different half-life may be that K1-3 is more target specific than K1-4, but more research is required for this statement to prove valid (MacDonald Nicholas J. et al. 1999).

As previously mentioned, Cao et al. discovered that K5 alone had a higher in vitro EC inhibitory activity than angiostatin. However, when tested on animal models, K5 did not produce the expected effect on tumor regression. Contrarily to in vitro results, angiostatin K1-4 had a higher antiangiogenic activity in vivo than K5. This was explained by the fact that being a small molecule, K5 is expelled by the body at a faster rate and consequently its half life is so short that K5 does not have enough time to interact with its target and exert its anticancer activity (Cao Renhai et al. 1999; Cao Yihai 2004).

Since best inhibition of proliferating ECs was observed in vitro by the five kringle fragment of PG, K1-5 in vivo antitumor activity was also tested and compared to that of angiostatin in various animal models: ability to suppress primary tumor growth, tumor neovascularization, and mouse corneal neovascularization. Kringles 1-5 (55kDa) was produced through the action of PL. K1-5 showed significant reduction of tumor vascularization, primary tumor growth and metastasis development and a much lower concentration of K1-5 was required compared to angiostatin (Cao Renhai et al. 1999). However, K1-5 over time did not cause tumors to reach a dormant state, it only reduced their growth rate (Cao Renhai et al. 1999). It would be of interest to further analyze the effects of K1-5 in humans in order to determine the half-life of this molecule, and whether its activity can be comparable to that observed in mice. Of major interest was to discover that no signs of toxicity were observed in animals, even when they were treated at high doses, giving scientists hope for positive results in clinical trials, since side effects and adverse reactions represent one of the major barriers in drug development and FDA approval.

\subsubsection{CLINICAL TRIALS}

A phase I clinical trial to evaluate primarily safety and toxicity of angiostatin was conducted at Thomas Jefferson University. Eligible patients had advanced stage of cancer 
and failed previous chemotherapy treatment. In this study, angiostatin was administered at concentrations ranging from $15-300 \mathrm{mg} / \mathrm{m}^{2} /$ day daily for a period of two weeks followed by a week break. Results proved good toxicity profile and patients did not show significant side effects (Beerepoot Laurens V. et al. 2003). However, rapid increase of VEGF and fibroblast growth factor (FGF) occurred during the time angiostatin was withdraw (Wahl Miriam L. et al. 2004; Wahl Miriam L. et al. 2005). Also, angiostatin showed a reduced serum half-life, approximately 20 minutes. Unfortunately no significant inhibition on cancer growth was seen. Perhaps patients had a too advanced phase of the disease for angiostatin to be effective and also the size of the group analyzed may have been too small to produce significant data (Beerepoot Laurens V. et al. 2003; Wahl Miriam L. et al. 2004; Wahl Miriam L. et al. 2005).

In a phase II clinical study conducted at Indiana University, angiostatin's antitumor activity was tested in combination with chemotherapy treatment. Patients with a stage IV lung cancer were treated with chemotherapy and recombinant angiostatin (rhAS) at concentrations of 15 to $60 \mathrm{mg}$ twice daily. Results obtained at the end of the study confirmed higher control rate of the disease in patients treated with both rhAS and chemotherapy compared to patients treated only with chemotherapy. Additionally, higher response was observed when rhAS was administered at the highest concentration of 60mg dose (Kurup A. et al. 2006).

From the clinical trials conducted to date on angiostatin, it was not possible to determine the maximum effective or safe dose due to its very low toxicity profile. However, its half life was proven to be very short. Based on these observations, if we were to treat patients with angiostatin, high doses and constant administration of angiostatin would be required, which would not be the best or ideal treatment for patients (Wahl Miriam L. et al. 2005). More research is require in order to determine whether angiostatin is indeed a possible candidate for development of future anticancer drug, which form and source (from other animals i.e. bovine) of this molecule is more active and if its activity is amplified if administered in combination with other treatments such chemotherapy or other anticancer drugs.

A current ongoing phase I/II clinical trial, is testing ability of angiostatin from being generated directly in the body by administration of tissue plasminogen activator 
(tPA), and the resulting effects on metastatic colonies growth inhibition when in combination with chemotherapy (www.clinicaltrials.gov).

\subsection{ANGIOSTATIN IN MILK}

Plasminogen is a molecule known to be present in the circulatory system of all animals. Bovine plasminogen (bPG), for example, gets secreted in milk. Understanding of the molecular characteristics of bPG and comparing these traits with that of hPG, would be of interest in order to determine whether bPG could also represent an effective human cancer inhibitor.

\subsubsection{TRANSFER OF PLASMINOGEN FROM BLOOD TO MILK}

Plasmin is one the most abundant enzymes in milk. This serine protease is associated with casein micelles and its proteolytic activity can be either detrimental or necessary to establish the quality of specific dairy products (Bastian Eric D. et al. 1996; Ozen Banu F. et al. 2003; Ismail B. et al. 2010).

Initially it was thought that hydrolysis in milk was produced by psychrotrophic microorganisms, however further research lead to the discovery of an enzyme, PL, originally known to be present in blood, to be also responsible for some of this proteolytic activity (Bastian Eric D. et al. 1996).

In order to determine if PL found in milk was the same as the one known to be in blood, sequence analysis of milk PG and PL was conducted. Results proved the two molecules to be identical to those in blood (Benfeldt Connie et al. 1995). Moreover, it has been proven that neither PL nor PG are directly produced by the mammalian cells (Bastian Eric D. et al. 1996). So how does PG end up in milk? A group of scientists determined PG to be transported from blood into milk through the mammary cell wall lining during milk production and involution. Plasminogen is secreted in milk at a much higher concentration than PL. In raw milk the PL and PG concentration is $0.1-0.7 \mathrm{mg} / \mathrm{mL}$ and $0.8-2.8 \mathrm{mg} / \mathrm{mL}$ respectively. The transfer of $\mathrm{PG}$ into milk is additionally affected by various factors such as stage of lactation, lactation number and mastitis. Interestingly, also other components of the plasmin system are found in milk and are responsible for 
controlling the conversion of PG into PL (Politis I. et al. 1989; Bastian Eric D. et al. 1996; Larson N. K. et al. 2006).

\subsubsection{THE PLASMIN SYSTEM}

Similarly to blood, PL belongs to a group of enzymes that together form the plasmin system (Figure 4). These enzymes comprise of: PG, PL, plasminogen activators (PA) (divided into tissue type (t-PA) and urokinase (u-PA)), plasminogen activators inhibitors (PAI) and plasmin inhibitors (PI). As their names indicate, the plasmin system interacts to promote or inhibit the proteolytic activity which is affected by milk processing and storage condition (Ismail B. et al. 2010).

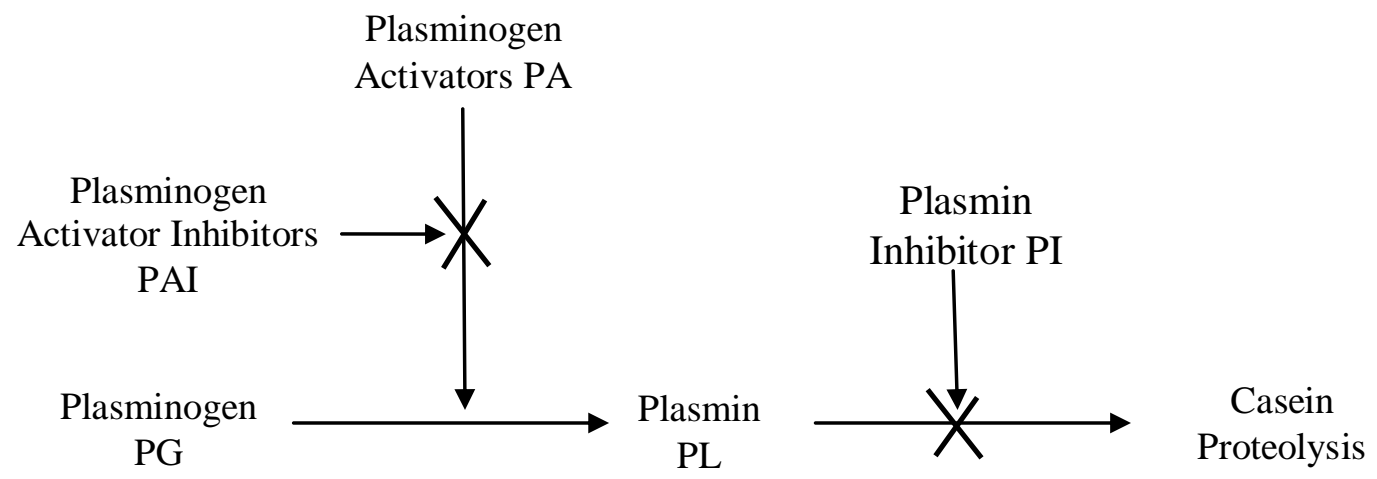

Figure 4: The plasmin system in milk (adopted from Bastian and Brown, 1996)

Interestingly, the various PL system components have different thermal stabilities to different processing conditions. For example, PG and PL are resistant to high temperature processing. They completely survive pasteurization, and may also survive certain UHT and HTST treatments as well (Bastian Eric D. et al. 1996; Ismail B. et al. 2010). Plasminogen activators also have high heat stability, even higher than PG and PL, contrarily to PAI and PI that require only pasteurization temperatures to be inhibited. Due to the inhibition of the inhibitors while the activators are still functional, PG and PL activity is maintained during storage. Additionally, by heating PG over $50-60^{\circ} \mathrm{C}$, causes the molecule to denature and consequently PA have more access to the molecule's structure and can easily activate PG (Burbrink C. N. et al. 2006; Ismail B. et al. 2010). 


\subsubsection{COMPARISON BETWEEN HUMAN AND BOVINE PLASMINOGEN}

In order to better understand some of the characteristics of bPG it would be useful to compare this molecule with human plasminogen (hPG). This will allow us to predict whether bPG could be used as a potential candidate for generation of peptides capable of anticancer activity, and how differences compared to hPG may cause this molecule to be more or less efficient.

Schaller et al. compared the molecular structure of bPG and hPG. From this study, scientists were able to conclude that bPG and hPG have many similarities (Schaller J. et al. 1985). For example, they only differ in length by four amino acids (786 for bPG and 790 for hPG). Bovine PG has a molecular weight of $88 \mathrm{kDa}$ while hPG can either be 89 or $91 \mathrm{kDa}$ depending if a glycosylation site is present or not (Schaller J. et al. 1985; Bastian Eric D. et al. 1996). Over all, the two molecules share 78\% homology; interestingly when this comparison is done only on the kringle region $83 \%$ homology is observed. This indicates that the internal triple-loop structure is maintained and is quite similar in both molecules (Schaller J. et al. 1985). Table 3 summarizes the percent homology among kringles and connecting strands between hPG and bPG.

Table 3: Sequence analysis homology among individual kringles and connecting strands between human and bovine plasminogen (adopted from Schaller et al. 1985).

\begin{tabular}{|c|c|c|c|}
\hline \multicolumn{2}{|c|}{ Kringles } & \multicolumn{2}{c|}{ Connecting Strands } \\
\hline Kringles & \% Homology & $\begin{array}{c}\text { Connecting } \\
\text { Kringles }\end{array}$ & \% Homology \\
\hline K1 & 75 & K1/K2 & 33 \\
\hline K2 & 88 & K2/K3 & 54 \\
\hline K3 & 83 & K3/K4 & 42 \\
\hline K4 & 90 & K4/K5 & 65 \\
\hline K5 & 81 & Overall Identity & \\
\hline Overall Identity & 83 & & \\
\hline
\end{tabular}




\subsection{RESEARCH OBJECTIVES}

Knowing that PG is also present in milk, but for which ability of being hydrolyzed to release potential anticancer fragments has not been extensively studied to date, the objectives of this research were to: 1) investigate the ability of various proteases in cleaving plasminogen, both from human and bovine sources, and consequently release the angiostatin like fragment; 2) determine the anticancer activity of bovine angiostatin; 3) examine ability of the antiangiogenic fragment to survive digestion; 4) purify the fragment of interest through column chromatography.

Each of the following chapters will analyze a specific aspect of this work and will represent a potential publishable paper each independent from next. 


\section{ANGIOSTATIN GENERATION THROUGH BOVINE PLASMINOGEN HYDROLYSIS}

\section{$2.1 \quad$ ABSTRACT}

Ability of various proteases in hydrolyzing bovine plasminogen (bPG) and releasing fragments in the $38 \mathrm{kDa}$ range corresponding to angiostatin's molecular weight was analyzed. Enzymes such as elastase, Bacillus polymyxa protease (BPP) as well as Bacillus and Lactobacillus derived proteolytic enzymes were tested. Fragments generated during hydrolysis were first visualized and identified using sodium-dodecyl polyacrylamide gel electrophoresis (SDS-PAGE) and western blotting methods of analysis. Subsequently, fragments of interest were analyzed for mass spectrum-based sequence analysis in order to identify the exact portion of plasminogen the fragments represented. From the results obtained we can confirm that at ideal enzyme-substrate ratio, B. polymyxa produce clear bands in the $40-34 \mathrm{kDa}$ range both from human and bovine PG, that were confirmed to belong to internal kringles 1-4 region of PG. $B$. polymyxa showed higher affinity for the human substrate since 10 fold less concentrated enzyme $(0.01 \mathrm{mg} / \mathrm{ml}$ compared to $0.1 \mathrm{mg} / \mathrm{ml})$ was needed to generate the fragments of interest. Elastase, on the other hand, revealed higher interaction with the bovine source of the molecule, and the reaction resulted in clear bands at the molecular weight of interest and almost no generation of secondary products; this was contrary to all the other enzymes analyzed for which thick bands in the $50 \mathrm{kDa}$ area were seen. Moreover, most of the Bacillus species, but not Lactobacillus, showed ability in generating proteases during growth capable of hydrolyzing PG and generating smaller molecular weight fragments. Discovery of novel enzymes capable of angiostatin generation from bovine sources and with comparable structure to that of human angiostatin, may lead to the development of novel dairy products capable of cancer prevention. 


\subsection{INTRODUCTION}

The theory initially developed by Folkman in 1971, who believed that in order for tumors to grow beyond a specific size (1-2 mm) access to blood is indispensable to allow delivery of essential nutrients and oxygen necessary to support malignant cells' metabolism, is now widely accepted (Zetter Bruce R. 1998; Folkman Judah 2006). Various experiments have proven this supposition to be correct. Investigations have demonstrated that by blocking tumors access to blood, growth is inhibited. Malignant colonies are maintained in a dormant state, in which the number of cells proliferating is balanced by the number of cells dying (Cao Renhai et al. 1999; Folkman Judah 2006). If tumors are maintained at this size and are inhibited access to elements required for further growth, they can be innocuous to the host (Folkman Judah et al. 2004; Folkman Judah 2006). The discovery that by blocking angiogenesis, the mechanism through which blood vessels develop from pre-existing vascularization in response to stimuli (i.e. hypoxia inducible factor released by cancerous cells), tumors cannot mature, opened a new area of investigation.

Many molecules with antiangiogenic activity have been discovered, and antiangiogenic drugs, such as Avastin, have been approved by the FDA as effective cancer therapies (Folkman Judah 2006). Angiostatin, a peptide obtained through hydrolysis of fibrinolytic zymogen PG, discovered in 1994 resulted to be one of the most potent antiangiogenic molecules known to date. Heterogeneous proteases capable of generating this peptide, from enzymes released directly by cancerous cells such as cathepsin D to more exotic metalloproteinases found in snake venom, have been studied for their affinity for PG and for the difference in endothelial cells inhibition obtained by the action of the angiostatins generated by each enzyme (Morikawa Wataru et al. 2000; Ho Paulo Lee et al. 2002). Angiostatin, characterized by the first four internal kringles of PG, has shown ability in endothelial cell proliferation and migration inhibition as well primary tumor shrinkage and metastasis development prevention (O'Reilly Michael S. et al. 1994; Cao Yihai et al. 1996; O'Reilly Michael S. et al. 1996; Ji Weidong-richard et al. 1998). Due to the success of these preliminary results, angiostatin is currently in clinical trials (Cao Renhai et al. 1999; Cao Yihai 2004; Wahl Miriam L. et al. 2004). 
Interestingly bovine $\mathrm{PG}$ is also present in milk, since it gets transferred from blood during milk production via the mammary cell wall lining (Ismail B. et al. 2010). Comparisons between human and bovine PG was conducted and many structural similarities were identified (Schaller J. et al. 1985; Bastian Eric D. et al. 1996). However, anticancer activity of the internal molecular structure of bPG has not been extensively studied as yet. The objective of this research was to identify various enzymes capable of hydrolyzing bPG and release the four or three internal kringle domains corresponding to angiostatin. These reactions were conducted in buffer as well as in milk systems in order to evaluate possible differences due to the presence of other proteins. Enzymes such elastase (known to be able to generate human angiostatin), BPP (proven to be capable of plasmin hydrolysis through a study conducted by Larson et al. 2006), as well as Bacillus and Lactobacillus generated proteases were tested for bovine angiostatin generation.

\subsection{EXPERIMENTAL PROCEDURES}

\subsubsection{REAGENTS AND SOURCES}

Bovine plasminogen (product \# 416), human glu-plasminogen (product \# 412) goat anti-bovine plasminogen (product \# 3416) were purchased from American Diagnostica (Greenwich, CT). Angiostatin human, rabbit polyclonal antibody (product \# RD 181056100) was purchased from BioVendor (Candler, NC). Dispase I (BPP) (product \# D4818), elastase from human leukocytes (product \# E8140) 3,3'diaminobenzidine tetrahydrochloride hydrate (DAB) (product \# D5637) and 6aminocaproic acid (product \# A2504) were purchased from Sigma-Aldrich (St. Louis, MO). Peroxidase AffiniPure Goat Anti-Rabbit IgG (H+L) (product \# 111-035-003) and Peroxidase Affinipure Rabbit Anti-Goat IgG (H+L) (product \# 305-035-003) were purchased from Jackson ImmunoResearch Laboratories (West Grove, PA). The following electrophoresis and Western blotting reagents and materials were purchased from BioRad Laboratories (Hercules, CA): 40\% Acrylamide/Bis solution (product \# 161-0148), Coomassie Brilliant Blue R-250 Staining Solution (product \# 161-0436), Precision Plus Protein All Blue Standards ( product \# 161-0373), 12 and 18 wells Criterion empty 
cassettes (product \# 345-9901 and 345-9902), Tris/Glycine/SDS 10X (product \# 1610772), Laemmli sample buffer (product 161-0737), tetramethylethylenediamine (TEMED, product 161-0800), Bio-Dot/Bio-Dot SF Filter Paper (product \# 162-0161) and Sequi-Blot PVDF $0.2 \mu \mathrm{m}$ membrane (162-0184). Ammonium Persulfate (APS, product \# BP179-100), Tween 20 (product \# BP 337-500), Granular gelatin (product \# G8-500) were purchased from Fisher Scientific (Hanover Park, IL). The strains of Bacilli and Lactobacilli used were from the Cal Poly DPTC collections.

2.3.2 PART 1. Generation of angiostatin from bovine and human plasminogen hydrolysis by the action of Bacillus polymyxa protease

2.3.2.1 Bacillus polymyxa protease interaction with bovine plasminogen In order to analyze the enzyme kinetics and determine the ideal enzyme-substrate ratio $(\mathrm{E}: \mathrm{S})$ for the generation of angiostatin like fragments, various concentrations of bPG and BPP were analyzed. Samples were prepared following Larson et al. (2006) procedure with adjustments. Both BPP and bPG were diluted in MTB (0.05 M Tris, $0.1 \mathrm{M} \mathrm{NaCl}$, $0.01 \%$ Tween $80, \mathrm{pH} 7.6)$ at a final concentration of $1 \mathrm{mg} / \mathrm{ml}(27.78 \mu \mathrm{M}$ and $11.36 \mu \mathrm{M}$ respectively) and stored at $-20^{\circ} \mathrm{C}$. In order to determine ideal enzyme concentration, BPP was first diluted in MTB to a final $\mathrm{mg} / \mathrm{ml}$ of $0.025,0.05,0.075,0.1,0.125,0.150$ and 0.175; subsequently BPP was incubated with $1 \mathrm{mg} / \mathrm{ml} \mathrm{bPG}$ at a $1: 1(\mathrm{v} / \mathrm{v})$ ratio at $37^{\circ} \mathrm{C}$ for 1 hour (Figure 5a). In a similar way, bPG was diluted in MTB to a final concentration of $0.125,0.25,0.5,0.75,0.875$ and $1 \mathrm{mg} / \mathrm{ml}$, and was then incubated at $37^{\circ} \mathrm{C}$ in $1: 1$ volume ratio with $0.1 \mathrm{mg} / \mathrm{ml}$ BPP for 1 hour (Figure $5 \mathrm{~b}$ ). Once the ideal E:S was defined, progression of the hydrolysis as well as enzyme-substrate affinity and interaction was analyzed by collecting samples after 5, 10, 15, 20, 25, 30, 40, 50 and 60 minutes incubation. Prior to SDS-PAGE or western-blotting analysis, 1:1 (v/v) Laemmli sample buffer was added to samples collected to stop the reaction and boiled for approximately 5 minutes to allow SDS binding. 


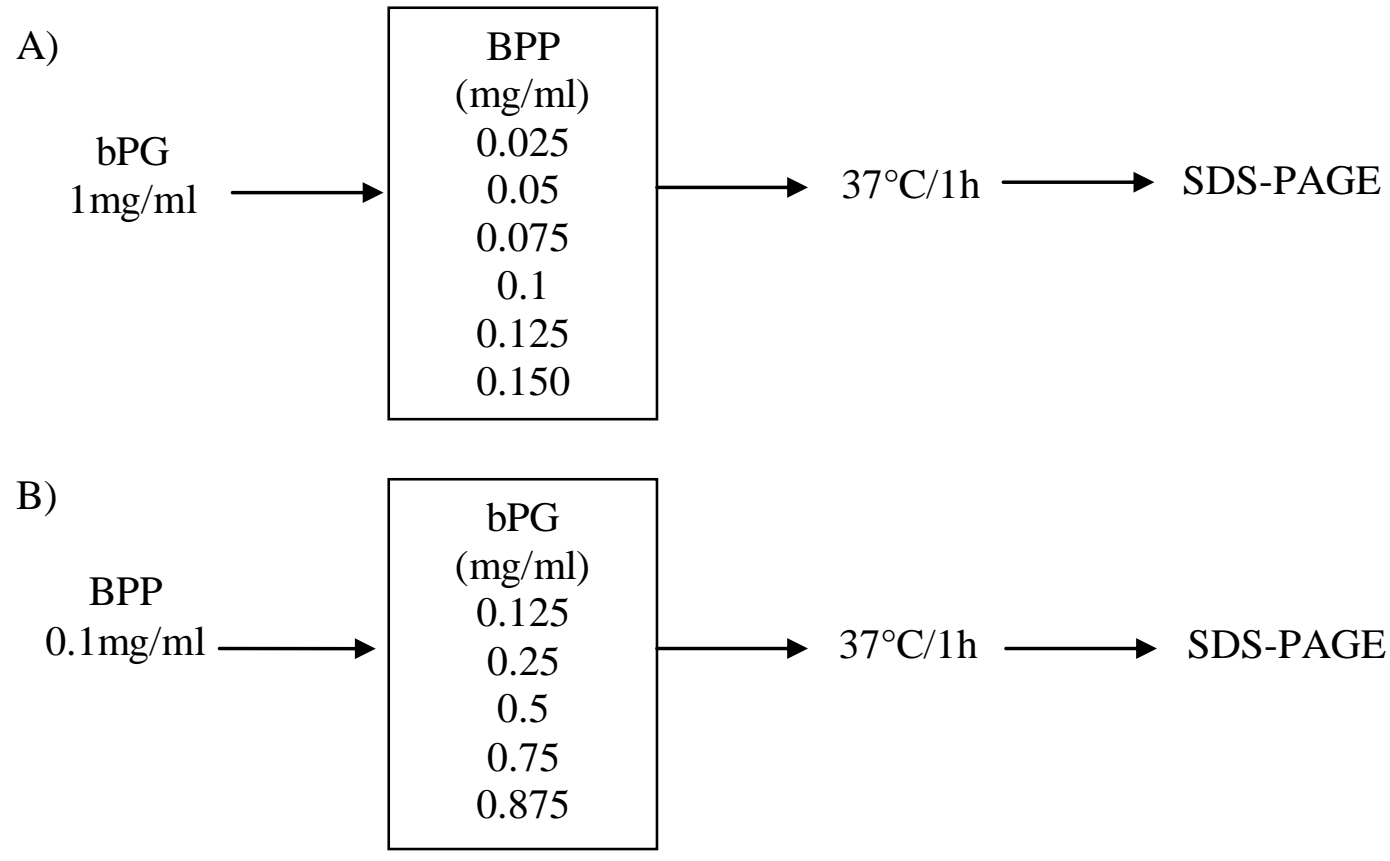

Figure 5: Experimental design for determining ideal enzyme-substrate (BPP-bPG) ratio: A) ideal enzyme concentration determination; B) ideal substrate concentration determination.

2.3.2.2 Temperature effect on Bacillus polymyxa protease and plasminogen interaction

In order to evaluate the effects of temperature on BPP-bPG interaction, and determine if bPG denaturation will enhance its hydrolysis and consequent angiostatin release by the action of BPP, two experiments were conducted. In the first one, a solution of bPG $(0.75 \mathrm{mg} / \mathrm{ml}$ or $8.52 \mu \mathrm{M})$ and BPP $(0.1 \mathrm{mg} / \mathrm{ml}$ or $2.78 \mu \mathrm{M})$ at $1: 1(\mathrm{v} / \mathrm{v})$ ratio was incubated directly at $4,37,70$ and $90^{\circ} \mathrm{C}$. In order to evaluate the progression of the reaction over time, samples were collected after 1, 5, 10, 15, 20, 25 and 30 minutes of incubation when tested at 4 and $37^{\circ} \mathrm{C}$ and after 1, 2, 3, 4, 5, 6 and 7 minutes for samples tested at 70 and $90^{\circ} \mathrm{C}$ (Figure 6a). These temperatures were chosen with the intention of simulating refrigeration, optimal, pasteurization and HTST conditions commonly used in the industry.

On a second experiment, bPG alone was heated at $70^{\circ} \mathrm{C}$ for 7 minutes. This temperature is known to cause bPG denaturation. Subsequently, after causing bPG 
tertiary structure to unfold, BPP was added to the solution at a 1:1 (v/v) ratio. Samples were immediately incubated in a water bath at $37^{\circ} \mathrm{C}$, and collected at $1,5,10,20$, and 30 minutes (Figure 6b). As a control, the enzyme was incubated with native bPG (not heated at $70^{\circ} \mathrm{C}$ prior to interaction with $\mathrm{BPP}$ ) under the same conditions and procedures previously outlined.

A)

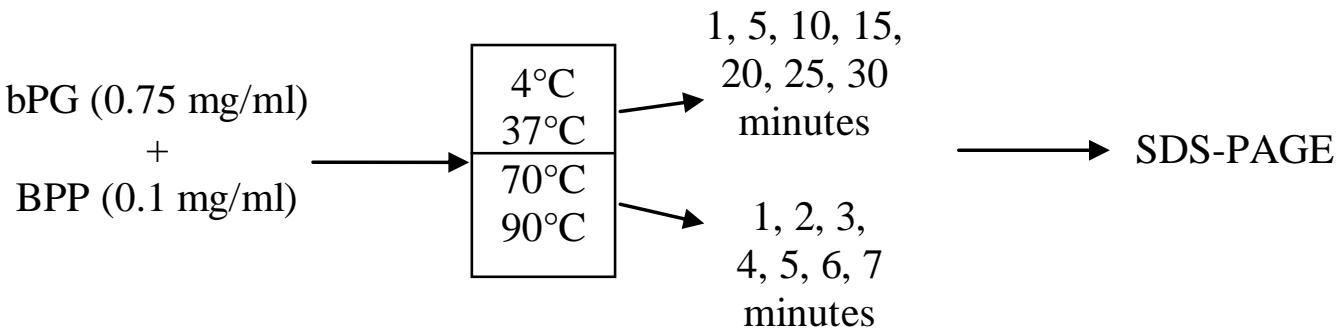

B)

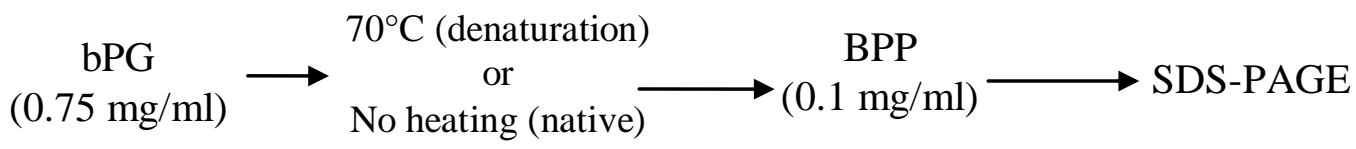

Figure 6: Experimental design on the analysis of temperature effects on the interaction between BPP and bPG: A) BPP-bPG interaction was conducted at $4^{\circ} \mathrm{C}, 37^{\circ} \mathrm{C}, 70^{\circ} \mathrm{C}$ and $90^{\circ} \mathrm{C}$; B) BPP affinity variation between native and denatured bPG.

Subsequently, the same experiment was repeated in milk in order to simulate conditions normally occurring in a milk matrix and evaluate potential differences with observations made when experiment is conducted in a buffer system. In brief, a 1:1 volume solution of $\mathrm{bPG}(0.75 \mathrm{mg} / \mathrm{ml}, 8.52 \mu \mathrm{M})$ and UHT milk (previously diluted at a 1:5 ratio in double-distilled water (ddwater)) was obtained and heated at $70^{\circ} \mathrm{C}$ for 7 minutes. Controls were prepared following the same procedures but contrarily to treatments were not subjected to heating. Samples were then incubated with BPP $(0.1$ $\mathrm{mg} / \mathrm{ml}, 2.78 \mu \mathrm{M})$ at $37^{\circ} \mathrm{C}$ and collected at $1,5,10,20$ and 30 minutes after the beginning of the reaction. Laemmli buffer was added at a 1:1 volume ratio and samples were boiled for 5 minutes and analysis through gel electrophoresis was conducted. 
2.3.2.3 Identification of angiostatin like fragments through SDS-PAGE, western blot and sequence analysis

\subsection{SDS-PAGE}

In order to analyze the molecular weight of the fragments obtained from the reaction between bPG and BPP, gel electrophoresis was conducted. The samples, prepared as previously described, and a molecular standard (range 10-250 kDa) were loaded in the wells of an 18 or 12 wells hand cast $15 \%$ tris- $\mathrm{HCl}$ gel. The gels were prepared following Laemmli (1970) adapted procedures (Laemmli U. K. 1970). Electrophoresis was conducted using a Criterion vertical midi-format electrophoresis cell (BioRad) at $200 \mathrm{~V}$ for approximately 60 minutes, in SDS-PAGE running buffer (1:10 dilution of Tris/Glycine/SDS 10X running buffer in ddwater). After electrophoresis, gels were stained in Coomassie blue (50\% methanol, 10\% glacial acetic acid and 0.25\% Coomassie brilliant blue), for one hour in a shaker plate at room temperature. Subsequently gels were destained by overnight incubation in a $10 \%$ glacial acetic acid and 5\% methanol solution. Gels were then analyzed, and the fragments of interest identified.

\subsection{WESTERN-BLOT}

To ensure that the fragments of interest observed at $40 \mathrm{kDa}$ or lower molecular weight belong to the internal molecular structure of PG, western blot was conducted following Wang et al. (2006) procedures with some modifications. Samples were prepared as outlined in section 2.3.2.1 and loaded on a 15\% Tris-HCl gel. Electrophoresis was conducted following procedures previously summarized in section 2.3.2.3.1. Once the pre-stained standard and protein samples were allowed to run through the gel, unimportant parts of the gel were cut off. In a trans-blot SD semi-dry transfer cell (BioRad) two filter papers were soaked in buffer A (Table 4) and placed on the surface of the anode plate of the cell. Subsequently, two additional filter papers were soaked on buffer B and placed on top of filter papers previously soaked in buffer A. At this point, a polyvinylidene fluoride (PVDF) membrane (pore size $0.2 \mu \mathrm{m}$ ), was cut to match the size 
of the gel and then activated in methanol for 15 seconds. Afterwards, the membrane was rinsed in ddwater and subsequently placed on top of papers previously soaked on buffer $\mathrm{B}$, ensuring that no air bubbles are trapped between the membrane and the filter paper. The gel was then placed on top of the membrane and subsequently covered with other four filter papers, previously cut to match the size of the gel and soaked in buffer C. Transfer was then effectuated at $20 \mathrm{~V}$ and $40 \mathrm{~W}$ for $15 \mathrm{~min}$. At this point, the PVDF membrane was placed in a blocking solution of $3 \%$ gelatin $(w / v)$ in PBS-Tween for one hour in a shaker plate at room temperature. Next, the membrane was washed three times for five minutes with PBS-Tween, and subsequently the primary antibody (goat antibovine PG 1:2000 dilution in PBS-Tween, Wang et al., 2006) was added and the gel was placed in a shaker for 2 hours at room temperature. The washing step was repeated prior to incubation with the secondary antibody (peroxidase-conjugated AffiniPure rabbit antigoat IgG $(\mathrm{H}+\mathrm{L})$ 1:5000 dilution in PBS-Tween, Wang et al., 2006) which was conducted for 1 hour at room temperature in a shaker plate. After incubation with the secondary antibody, the membrane was washed again three times with PBS-T for 5 minutes. The developing solution was prepared by diluting $12 \mathrm{mg}$ of 3,3'-diaminobenzidine tetrahydrochloride hydrate, in $20 \mathrm{ml}$ of tris buffered saline (TBS) and $25 \mu 1$ of $30 \%$ hydrogen peroxide, and was then added to the membrane right after the last washing step. Once the desired color on the membrane was obtained, and bands of interest visible, the reaction was stopped by addition of ddwater. The membrane was allowed to dry by placing it over night in between two filter papers. 
Table 4: Buffer recipes and preparation for western blotting

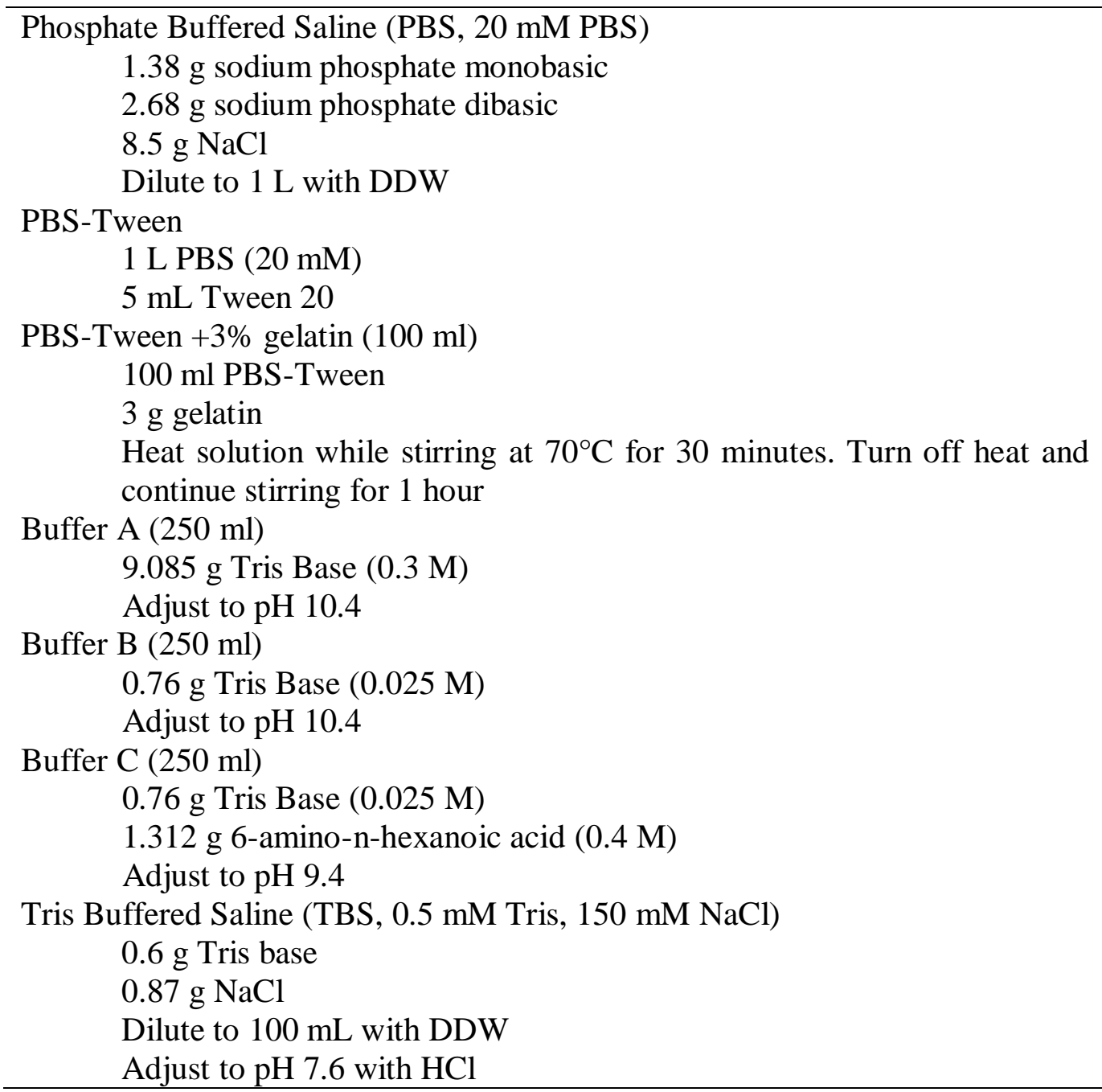

\subsection{SEQUENCE ANALYSIS OF BANDS OF INTEREST}

Once bands of interest were detected after SDS-PAGE and western blotting analysis, sequence analysis was conducted through liquid chromatography-mass spectrometry (LCMS) in order to identify the portion of PG the fragments obtained belong. By ensuring no contamination of the reagents used, samples were prepared and allowed to run normally on SDS-PAGE as outlined in section 2.3.2.1 and 2.3.2.3.1. Once the gel was obtained, the bands of interest were cut and placed in Eppendorf tubes 
containing destain solution (10\% acetic acid, 5\% methanol) and sent to UC Davis proteomics core for LCMS analysis.

\subsubsection{Bacillus polymyxa protease ability in generating human angiostatin}

Similarly as for bPG, ideal E:S concentration was investigated between hPG and BPP in order to determine conditions for highest angiostatin yield and to compare the affinity of the enzyme between human and bovine substrates. In this case, two concentrations of BPP $(0.01$ and $0.025 \mathrm{mg} / \mathrm{ml})$ were tested in a 1:1 volume ratio with hPG $(1 \mathrm{mg} / \mathrm{ml}, 11.36 \mu \mathrm{M})$. The reaction was conducted at $37^{\circ} \mathrm{C}$ and samples were collected after $0,1,11,21,31,41,51$ and 61 minutes incubation when tested with BPP at a concentration of $0.01 \mathrm{mg} / \mathrm{ml}$, or after $0,5,10,15,20,25$ and 30 minutes for samples treated with $0.025 \mathrm{mg} / \mathrm{ml}$ of BPP. All samples were diluted with Laemmli buffer $(1: 1 \mathrm{v} / \mathrm{v}$ ratio) and boiled for approximately 5 minutes. Subsequently samples were analyzed through SDS-PAGE following procedures outlined in section 2.3.2.3.1.

\subsection{WESTERN -BLOT}

Western blotting procedures were conducted as described in section 2.3.2.3.2. However, the primary antibody, Angiostatin Human Rabbit polyclonal antibody, was used at a 1:5000 dilution in PBS-T and the secondary antibody, Peroxidase-conjugated AffiniPure Goat Anti-Rabbit IgG was used at a 1:10000 dilution in PBS-T according to the manufacturer indications.

2.3.3 PART 2. Generation of angiostatin from bovine and human plasminogen hydrolysis by the action of elastase

\subsubsection{BOVINE ANGIOSTATIN GENERATION}

In order to generate angiostatin from bovine plasminogen, elastase at a concentration of $0.01 \mathrm{mg} / \mathrm{ml}(345 \mathrm{nM})$ was incubated with $\mathrm{bPG} 1 \mathrm{mg} / \mathrm{ml}(11.36 \mu \mathrm{M})$ at a 1:1 volume ratio. The reaction was conducted at $37^{\circ} \mathrm{C}$ for $1,2,4,6$ and 8 hours. Samples 
were then diluted with Laemmli buffer at 1:1 volume ratio and boiled for 5 minutes. Fragments produced from this reaction were identified through SDS-PAGE and westernblot as explained in sections 2.3.2.3.1 and 2.3.2.3.2.

\subsubsection{HUMAN ANGIOSTATIN GENERATION}

The ability of elastase in hydrolyzing hPG was tested in a similar manner as for bPG. Elastase $(0.01 \mathrm{mg} / \mathrm{ml}, 345 \mathrm{nM})$ was incubated with $\mathrm{hPG}(1 \mathrm{mg} / \mathrm{ml}, 11.36 \mu \mathrm{M})$, at $37^{\circ} \mathrm{C}$ for 30 minutes, 1, 2, 4, 6 and 8 hours. Samples were then diluted 1:1 (v/v) with Laemmli buffer, boiled for 5 minutes and then analyzed through SDS-PAGE (refer to section 2.3.2.3.1) and western-blot (refer to section 2.3.2.3.2).

2.3.4 PART 3. Generation of angiostatin from bovine plasminogen hydrolysis by the action of Bacillus and Lactobacillus originated proteases

Various lactic acid bacteria (LAB) and Bacillus strains were tested for their ability in producing proteolytic enzymes that were later examined for their ability in interacting with bPG to generate potential angiostatin fragments. Additionally, since bacteria expression of inducible genes is affected by the composition of the environment in which they are grown, the effect of different substrates and their influence on bacteria growth and proteolytic enzyme expression and release were analyzed. Summary of the experimental design is shown in Figure 7 and 8.

\subsubsection{LACTOBACILLUS PROTEASES GENERATION ANALYSIS}

Various Lactobacilli strains were tested for their capability in generating proteases with potential ability in interacting and cleaving bPG. Lactobacilli were grown in three different media and consequent proteolytic activity examined through skim milk agar plates.

First, various strains of Lactobacilli, some of which we knew from the literature to be highly hydrolytic such as L. helveticus, or commonly used in the production of cheese such as L. acidophilus (Salimen Seppo et al. 1998), were grown in $10 \mathrm{ml}$ MRS (5.5\% MRS, $0.05 \%$ cysteine solution autoclaved at $121^{\circ} \mathrm{C}$ for 15 minutes (De Man J. C. 
et al. 1960)) overnight at $37^{\circ} \mathrm{C}$ in a $\mathrm{CO}_{2}$ chamber. Subsequently, $100 \mu \mathrm{l}$ of each bacteria were transferred into falcon tubes containing $10 \mathrm{ml}$ of either $20 \%$ NFDM solution, UHT milk or MRS containing 1\% skim milk (Figure 7), and allowed to grow overnight, always at $37^{\circ} \mathrm{C}$ in a $\mathrm{CO}_{2}$ chamber. Meanwhile, skim milk agar plates were prepared $(10 \% \mathrm{v} / \mathrm{v}$ skim milk, $1.5 \% \mathrm{w} / \mathrm{v}$ agar solution autoclaved at $121^{\circ} \mathrm{C}$ for 15 minutes and poured $20 \mathrm{ml}$ into Petri dish plates (Maunsell Blaithin et al. 2006) ). After bacteria were allowed to grow and skim milk agar solidified, sterile filter paper disks (5 mm diameter) were arranged on the surface of each agar plate. Fifteen $\mu l$ of each bacteria-containing media were carefully added to one of the filter paper disk. These procedures were conducted in triplicates. Plates were incubated over night at room temperature. The proteolytic activity was quantified by measuring the visible zone of clearance surrounding the filter paper disk. If proteases were produced by the microorganisms and capable of hydrolyzing the surrounding casein, a clear halo would be observed around the filter disk, on the contrary if no proteolytic activity occurs, the area of interest would remain white.

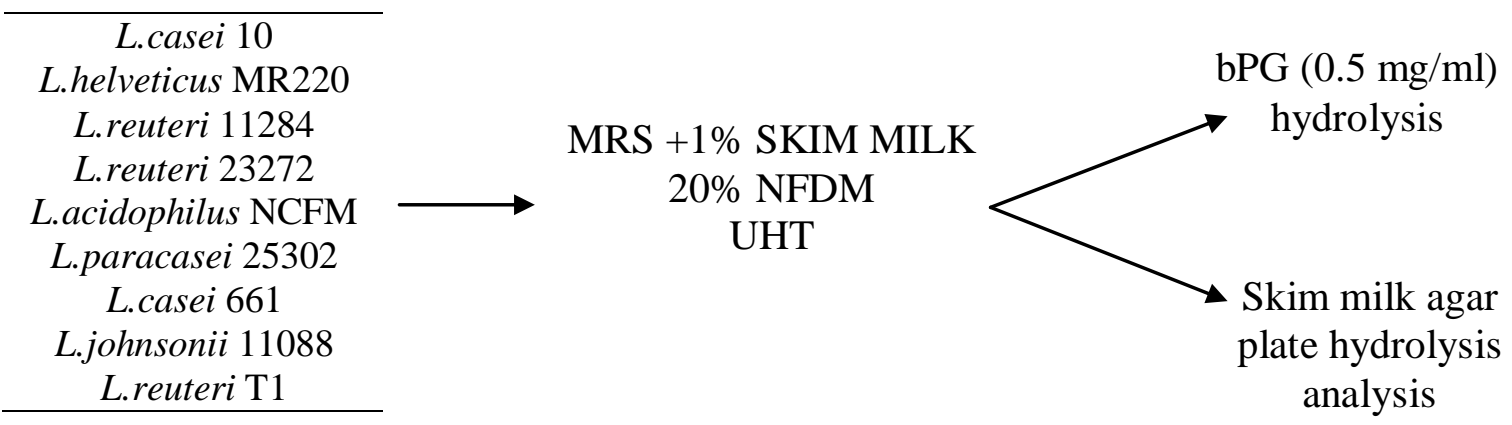

Figure 7: Experimental design to determine Lactobacillus proteolytic enzymes generation in different growth media.

\subsection{PROTEASES INTERACTION WITH BOVINE PLASMINOGEN}

It is known that LAB produce two types of proteases: extracellular or cell wall associated. These enzymes are needed by the microorganisms to hydrolyze bigger proteins that the cell will then uptake and use as a source of peptides and amino acids for metabolic purposes (Salimen Seppo et al. 1998). After analyzing which media and which strains resulted in higher generation of proteases, Lactobacilli were grown again under ideal conditions and the solution to be analyzed for enzymes activity was incubated with 
bPG. A series of experiments were conducted in order to determine whether the proteolytic enzymes released outside the cell or associated with the cell wall of the microorganism, showed ability in bPG hydrolysis. Analysis of the products obtained from this reaction was conducted through SDS-PAGE as described in section 2.3.2.3.1.

Since best hydrolytic activity observed in skim milk agar plates resulted for microorganisms grown in UHT milk and MRS-1\% skim milk, these media were used to test for bPG hydrolytic enzymes.

After inoculating UHT milk with each microorganism, and allowed Lactobacilli to grow overnight, $1 \mathrm{ml}$ of UHT milk after inoculation was transferred into a $1.5 \mathrm{ml}$ Eppendorf tube. Samples were centrifuged at $10 \mathrm{rpm}$ between 5 and 10 minutes until a clear supernatant was observed. The supernatant obtained after centrifugation, was added to $\mathrm{bPG}(1 \mathrm{mg} / \mathrm{ml}, 11.36 \mu \mathrm{M})$ at a 1:1 volume ratio and allowed to interact for 3 hours at $37^{\circ} \mathrm{C}$. After 3 hours the reaction was stopped by addition of Laemmli buffer solution $(1: 1$ volume ratio) and samples were boiled for 5 minutes and analyzed through SDS-PAGE.

Due to UHT high protein content, it was not possible to use this media to test for the cell wall associated enzymes ability in interacting with bPG since high dilutions were needed prior or after interaction with the substrate, causing poor results through electrophoresis analysis. In order to be able to have a better understanding on the ability of either extracellular or cell wall bound proteins in hydrolyzing bPG, MRS with $1 \%$ skim milk was used as growth medium instead.

In a similar way, LAB were grown in MRS overnight and then transferred into fresh MRS plus 1\% skim milk growth medium. Lactobacilli were allowed to grow and subsequently $1 \mathrm{ml}$ of $\mathrm{LAB}$ in MRS-1\% skim milk was transferred into a $1.5 \mathrm{ml}$ Eppendorf tube. Tubes were centrifuged at $10000 \mathrm{x} \mathrm{g}$ for 5 minutes to allow all the pellets to reach the bottom of the tube and obtain a clear supernatant. The supernatant was transferred into a new Eppendorf tube, and the $\mathrm{pH}$ was adjusted to 6-7 with 0.1-1 N $\mathrm{NaOH}$. Subsequently, bPG $(1 \mathrm{mg} / \mathrm{ml}, 11.36 \mu \mathrm{M})$ was added at 1:1 (v/v), and the solution was incubated at $37^{\circ} \mathrm{C}$ for 3 hours to test for extracellular enzymes presence and ability in bPG proteolysis.

On the other hand, cell wall bound enzymes were purified following McGavin et al. (1993) procedures with modifications. The pellets previously obtained were first 
resuspended in $1 \mathrm{ml}$ of phosphate buffered saline (PBS x1) using a rotor. Once the pellets were completely dissolved in PBS, samples were centrifuged at 10000 x g for 5 minutes. PBS was discarded and replaced by $1 \mathrm{ml} 5 \mathrm{M} \mathrm{LiCl}$. Pellets were resuspended again using a rotor for approximately $1 \mathrm{~h}$. When no visible pellets were observed in the tube, the solution was centrifuged again for 30 seconds at $5000 \mathrm{rpm}$. At this point the supernatant obtained should contain the proteins that were previously bound to the surface of the microbes' cell wall. Dialysis was conducted by covering and sealing the top of the Eppendorf tube with a membrane (MWCO $3500 \mathrm{Da}$ ) and placing the tubes upside down in a water bath for a period of 3 hours. During this step, diffusion of $\mathrm{LiCl}$ outside the sample occurs while water molecules will travel in the opposite direction until a balance is reached. After the dialysis, samples' $\mathrm{pH}$ was adjusted to 6-7 with $0.1 \mathrm{HCl}$. Samples were concentrated using an Eppendorf vacufuge at $30^{\circ} \mathrm{C}$ until obtaining $100 \mu 1$ solution. At this point $20 \mu \mathrm{l}$ of the concentrated solution were added to $20 \mu \mathrm{l}$ of $\mathrm{bPG}(1 \mathrm{mg} / \mathrm{ml}$, $11.36 \mu \mathrm{M}$ ) and incubated for 3 hours at $37^{\circ} \mathrm{C}$ to test for ability of cell wall bound enzymes to hydrolyze bPG which was analyzed through SDS-PAGE and western blot.

\subsubsection{BACILLUS PROTEASES GENERATION ANALYSIS}

In a similar way as for Lactobacilli, ability of various strains of Bacilli in generating proteases capable of bPG hydrolysis was tested. A scheme of the experiment procedures can be observed in Figure 8.

First, trypticase soy broth (TSB) was prepared (3\% TSB in ddwater solution was autoclaved at $121^{\circ} \mathrm{C}$ for 15 minutes) and by using a loop, the various strains of Bacillus spores were inoculated and allowed to germinate and grow overnight at $37^{\circ} \mathrm{C}$ under aerobic conditions. Bacillus obtained from this step were then inoculated in UHT or TSB

plus 5\% UHT milk solution, to examine the effect of milk nutrients in triggering the expression of proteolytic enzymes. Proteoltytic activity was examined through skim milk agar plates as previously explained in section 2.3.4.1 for Lactobacilli. 


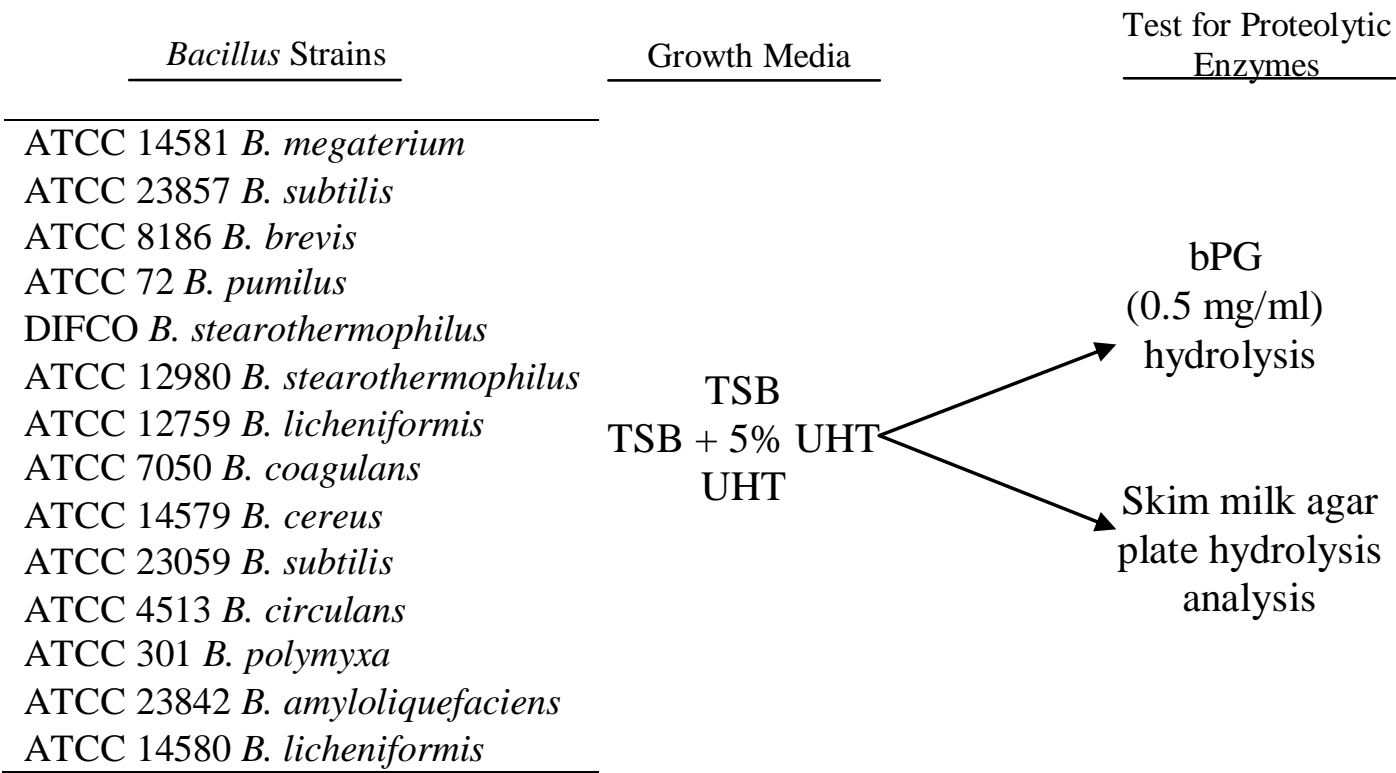

Figure 8: Experimental design to determine Bacillus proteolytic enzymes generation in different growth media.

\subsection{Interaction of proteases generated from Bacillus strains with bovine plasminogen}

After analysis of the hydrolytic activity of the enzymes generated by the Bacillus strains tested, ability of the enzymes in cleaving bPG was determined. Bacilli were grown in fresh TSB-5\% UHT milk overnight. Subsequently, $20 \mu \mathrm{l}$ bPG $(0.75 \mathrm{mg} / \mathrm{ml}, 8.52 \mu \mathrm{M})$ were added to $20 \mu \mathrm{l}$ of each Bacillus solution and incubated at $37^{\circ} \mathrm{C}$ overnight to ensure that all enzymes have sufficient time to interact with bPG. Hydrolytic products were analyzed through SDS-PAGE and western blot. In order to better understand the enzymes affinity for the substrate and hydrolytic pattern of the reaction, the experiment was repeated under same conditions previously outlined, and samples were collected after 3 , 6 , and 8 hours.

Media effect on proteolytic enzymes production was also tested. Bacilli, after being grown in TSB, were inoculated in UHT alone overnight, and later tested for PG hydrolytic enzymes as for Bacillus grown in TSB-5\%UHT. However, UHT samples had to be diluted 1:5 prior to incubation with bPG, to avoid total protein concentration in samples to be too high, and prevent poor results on SDS-PAGE. 
Bacillus trains that showed ability in generating higher amounts of fragments in the $38 \mathrm{kDa}$ region were used to generate large bands that were later analyzed for sequence analysis. After being grown in TSB-5\%UHT media, the enzymes produced by the Bacillus strain ATCC 7050 (B. coagulans) showed highest angiostatin like fragments generation. ATCC 7050 was grown again under ideal conditions, and incubated with bPG at a final volume of $60 \mu 1$ ( 3 times that previously used). This volume was added to a hand cast $15 \%$ tris $\mathrm{HCl}$ gel in which a well comb was modified to combine 3 wells to create a unique well capable of holding $60 \mu 1$ sample volume. Electrophoresis as well as sequence analysis were conducted as described in sections 2.3.2.3.1 and 2.3.2.3.3.

\subsection{RESULTS AND DISCUSSION}

2.4.1 PART 1. Generation of angiostatin from bovine and human plasminogen hydrolysis by the action of Bacillus polymyxa protease

\subsubsection{Bovine plasminogen proteolytic fragments generated by Bacillus polymyxa protease}

Ability of BPP in generating $38 \mathrm{kDa}$ fragments from bPG was evaluated. Additionally, enzyme activity as well as substrate concentration optimization was determined. SDS-PAGE analysis of samples of bPG and BPP incubated for 1 hour at $37^{\circ} \mathrm{C}$ (Figure 9) shows that possible $38 \mathrm{kDa}$ angiostatin like fragments were produced and that highest concentration of the peptides of interest is obtained when BPP is used at concentrations of $0.1,0.125,0.15$ and $0.175 \mathrm{mg} / \mathrm{ml}$ with a substrate concentration of 1 $\mathrm{mg} / \mathrm{ml}$. However, when the enzyme concentration is higher than $0.125 \mathrm{mg} / \mathrm{ml}$ substrate depletion was observed, and BPP appears to be hydrolyzing some of the products of interest. This can be confirmed by the presence of darker bands in lower molecular weight regions $(25-20 \mathrm{kDa})$. Based on these results $0.1 \mathrm{mg} / \mathrm{ml}$ seems a reasonable BPP concentration to work with for the rest of this study.

After identifying the ideal enzyme concentration, in order to evaluate the optimal substrate concentration, various amounts of bPG were reacted with a constant amount of BPP $(0.1 \mathrm{mg} / \mathrm{ml})$. As shown in Figure 10 , for bPG higher than $0.5 \mathrm{mg} / \mathrm{ml}$ no significant 
difference is observed for the products obtained or the amount of angiostatin like fragments that are generated. Based on these results, we can confirm that ideal substrate concentration is between $0.75-1 \mathrm{mg} / \mathrm{ml}$ and ideal enzyme concentration is $0.1 \mathrm{mg} / \mathrm{ml}$.

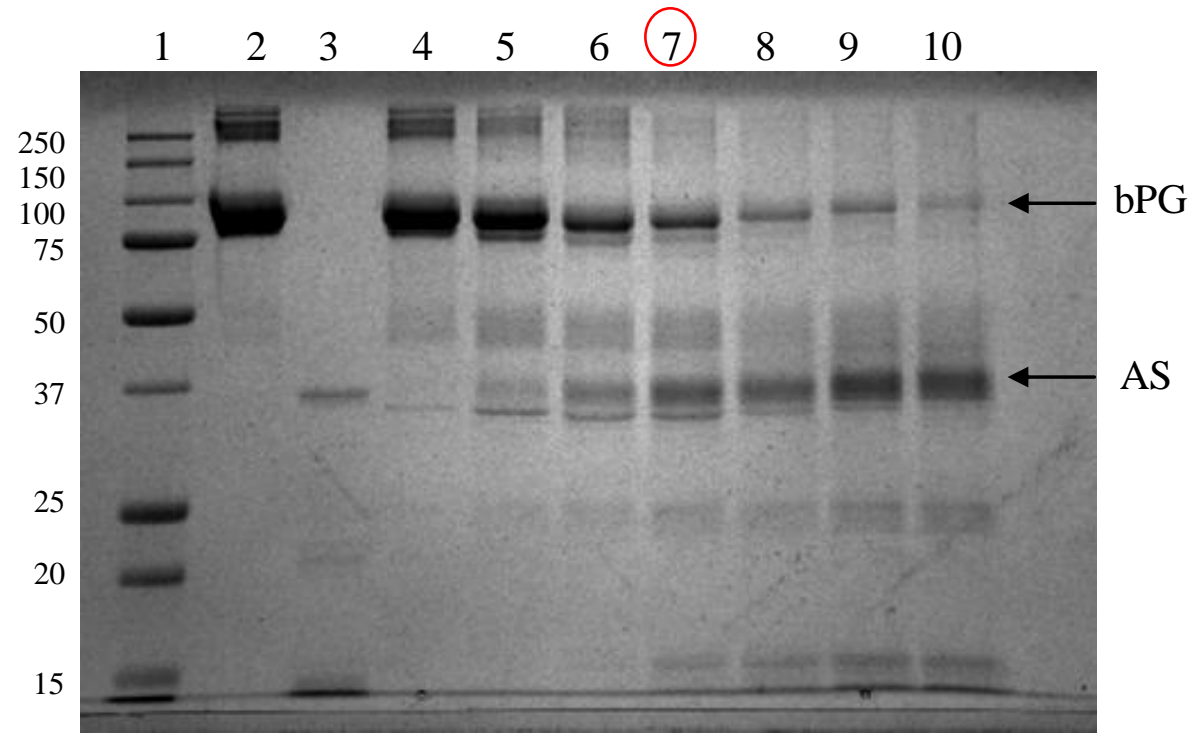

Figure 9: SDS-PAGE analysis of Bacillus polymyxa protease (BPP) and bovine plasminogen (bPG) ideal E:S ratio. Lane 1: molecular weight standard; lane 2: bPG control $(0.25 \mathrm{mg} / \mathrm{ml})$; lane 3: BPP control $(0.25 \mathrm{mg} / \mathrm{ml})$; lane $4-10$ : bPG $(1 \mathrm{mg} / \mathrm{ml})$ incubated with $0.025,0.05,0.075,0.1,0.125,0.150$ and $0.175 \mathrm{mg} / \mathrm{ml}$ BPP in MTB for 1 hour at $37^{\circ} \mathrm{C}$. Bands in the $37 \mathrm{kDa}$ area correspond to potential angiostatin (AS) fragments.

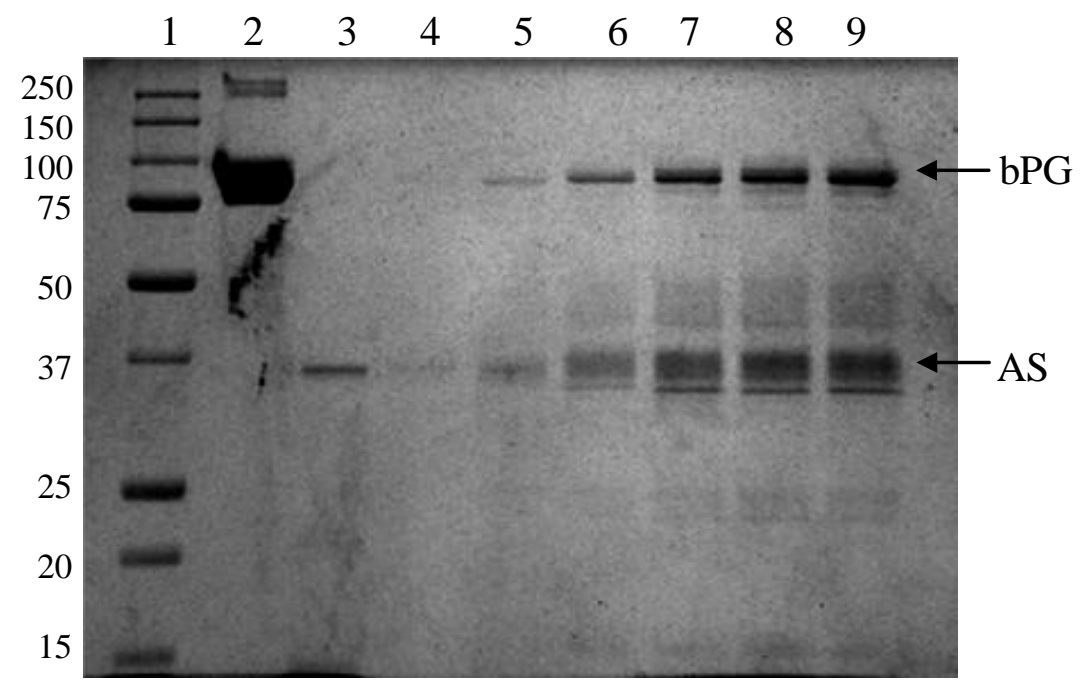

Figure 10: SDS-PAGE analysis of Bacillus polymyxa protease (BPP) and bovine plasminogen (bPG) ideal E:S ratio. Lane 1: molecular weight standard; lane 2: bPG control $(0.25 \mathrm{mg} / \mathrm{ml})$; lane 3: BPP control $(0.25 \mathrm{mg} / \mathrm{ml})$; lane $4-9$ : bPG at 0.125, 0.25, 0.5, $0.75,0.875$ and $1 \mathrm{mg} / \mathrm{ml}$ incubated with $0.1 \mathrm{mg} / \mathrm{ml}$ BPP in MTB for 1 hour at $37^{\circ} \mathrm{C}$. Bands in the $37 \mathrm{kDa}$ area correspond to potential angiostatin (AS) fragments. 
Subsequently, in order to determine the rate at which products of this reaction are formed (or substrate disappears) samples were taken at specific time intervals (Figure 11); intensity variation of the bands over time was measured using a densitometer so as to study the kinetics of the reaction. From the SDS-PAGE gels obtained, it is possible to define the hydrolytic pattern produced from the interaction between BPP and bPG. Bacillus polymyxa protease will initially cleave bPG to generate PL (50 kDa), a second peptide with $\mathrm{MW}$ around $40 \mathrm{kDa}$ and a fragment in the $35 \mathrm{kDa}$ range after 5 and 10 minutes incubation (Figure 11, lanes 4 and 5). Over time, it is possible to observe the band at $40 \mathrm{kDa}$ becoming darker until incubation reaches approximately 30 minutes and then gradually fade away. On the other hand, the band observed at angiostatin's MW, around $37 \mathrm{kDa}$, keeps getting darker and thicker. It does not seem like BPP is hydrolyzing the potential angiostatin like fragment overtime. In summary, from these observations, we can presume that BPP will initially hydrolyze bPG in three parts. Subsequently, hydrolysis of fragments in the $50-40 \mathrm{kDa}$ area occurs to generate smaller peptides potentially belonging to angiostatin. Comparison of these results with those obtained in a similar experiment by Larsen et al. (2006), show the digests in this study slightly different hydrolytic patterns. In the present study the fragments obtained appear to be characterized by a lower molecular weight than those observed in the SDS-PAGE generated by Larsen et al. (2006). Possibly this can be explained by the fact that BPP purchased was not exactly the same in both studies, the enzyme used by Larsen et al. was discontinued and due to lack of information regarding this product it is not possible to fully explain the differences observed.

Analysis on the disappearance of bPG through the band density data observed in the graph in Figure 12, indicates that substrate hydrolysis occurs mostly during the first 30 minutes, where the graph line is more sloping. After 60 minutes from the beginning of the reaction the curve seems to plateau indicating saturation (at this point the reaction rate will only depend on the speed and concentration of the enzyme). The same analysis was conducted for bPG at $0.5,0.375,0.25 \mathrm{mg} / \mathrm{ml}$ concentration, results are summarized on Table 5. From these results it is possible to conclude that higher difference in disappearing rate between 30 and 60 minutes occurs for higher substrate concentrations $(0.625$ and $0.5 \mathrm{mg} / \mathrm{ml})$. While at lower bPG concentration this difference did not appear 
to be significant since the enzyme is not saturated, and its speed will be only dependent on the substrate concentration. Analysis on appearance rate of product overtime, even though evident on the gels, could not be examined due to insufficient concentration required to overcome the background noise and for the densitometer to detect any significant difference in the amount of potential angiostatin fragments produced during the reaction. Moreover, a kinetic analysis through Lineweaver-Burk as well as HanesWoolf Plot was conducted (results can be seen in Appendix A). The $\mathrm{Km}$ and Kcat obtained from this analysis however were incoherent with observations made from the SDS-PAGE gels obtained. Km for example, resulted to be very high (0.9) insinuating poor affinity between BPP and bPG, which as we can confirm from the images of the gels, it is not the case. A plausible explanation for obtaining these results may be that, in order to calculate the initial velocity change, band intensity variation over time was used instead of the actual bPG concentration. Due to the densitometer limitations in some cases to identify significant differences above or below specific thresholds, the data obtained through this method did not accurately reflect the facts. These restraints are critical in the generation of an adequate Lineweaver-Burk due to its high sensitivity to data error, causing inaccuracy in the enzyme kinetic analysis particularly when low substrate concentrations are used (Storey Kenneth B. 2004). In this case, the inverse of very small substrate concentration is going to results in a larger number. In fact, as we can observe in Appendix A (Figure 63) for the point corresponding to the smallest concentration $(0.25 \mathrm{mg} / \mathrm{ml}$ and for which the inverse equals 4$)$, this point results to be isolated to the right of the graph. This data point will influence the resulting plotted line even more than the rest of the data points used (Bloomfield Victor 2009). For this reason, during the rest of this study the enzyme kinetics will be analyzed through the values of the slopes obtained from the density curves.

From the western blot shown in Figure 13, it is clear that the fragments obtained in the molecular weight of 50,37 and $25 \mathrm{kDa}$ belong to bPG. The strong interaction between the primary anti-plasminogen antibody and the $37 \mathrm{kDa}$ fragments indicate that the parameters used in this protocol are adequate for this study and that angiostatin like fragments are being produced. 


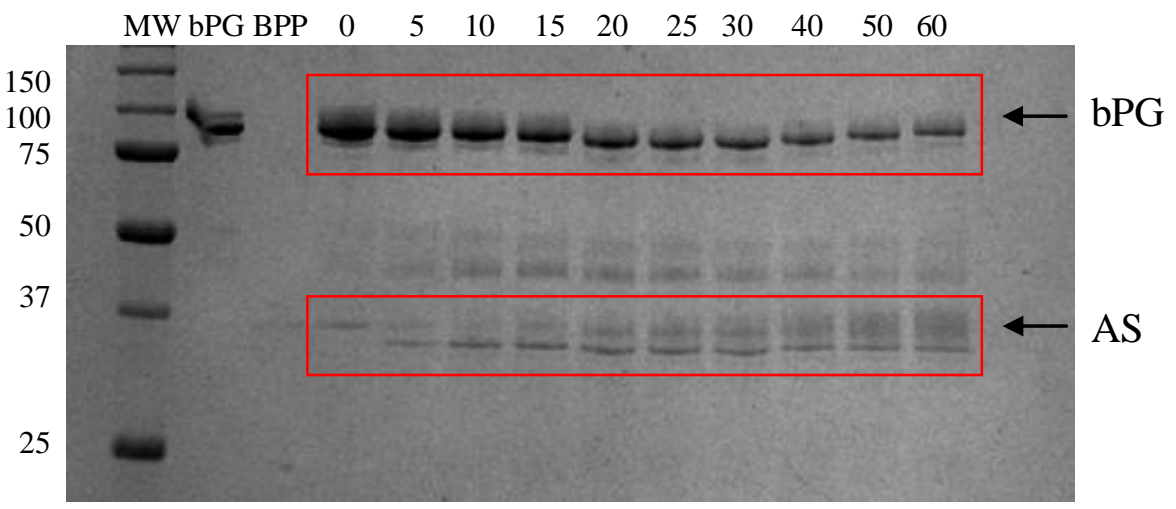

Figure 11: SDS-PAGE analysis of angiostatin like fragments produced by bPG proteolysis by the action of BPP. Lane 1: MW standard; Lane 2: bPG control; Lane 3: BPP control; Lane 4 to 13: 0, 5, 10, 15, 20, 25, 30, 40, 50, 60 minutes bPG and BPP incubation. Fragments observed in the $37 \mathrm{kDa}$ area are potential angiostatin (AS) like fragments

\section{bPG disappearance}

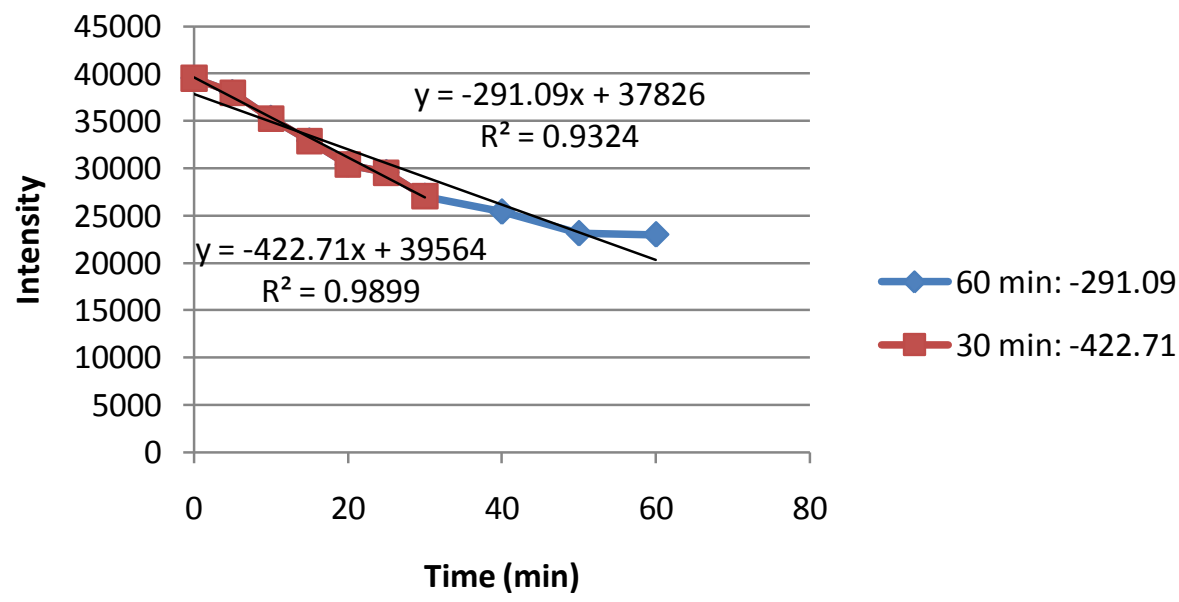

Figure 12: bPG disappearance $(0.625 \mathrm{mg} / \mathrm{ml})$ over time by the action of BPP $(0.1 \mathrm{mg} / \mathrm{ml})$. Two slopes were measured, the first one was obtained by analyzing the data obtained after 30 minutes of the reaction $(-422.71)$, while the second slope was generated by considering all the points collected after one hour (-291.09). 
Table 5: analysis of slopes obtained through bPG band density variation after 30 and 60 minutes interaction with BPP

\begin{tabular}{|c|c|c|c|}
\hline bPG Concentration & $\begin{array}{c}\text { Slope After 30 } \\
\text { Minutes }\end{array}$ & $\begin{array}{c}\text { Slope After 60 } \\
\text { Minutes }\end{array}$ & $\begin{array}{c}\text { Initial } \\
\text { Velocity } \\
\text { (int/min-Vo) }\end{array}$ \\
\hline $0.625 \mathrm{mg} / \mathrm{ml}$ & -417.935 & -291.09 & 442.13 \\
\hline $0.5 \mathrm{mg} / \mathrm{ml}$ & -345.15 & -291.39 & 426.8 \\
\hline $0.375 \mathrm{mg} / \mathrm{ml}$ & -357.07 & -341.13 & 341.73 \\
\hline $0.25 \mathrm{mg} / \mathrm{ml}$ & -144.31 & -167.93 & 242.25 \\
\hline
\end{tabular}

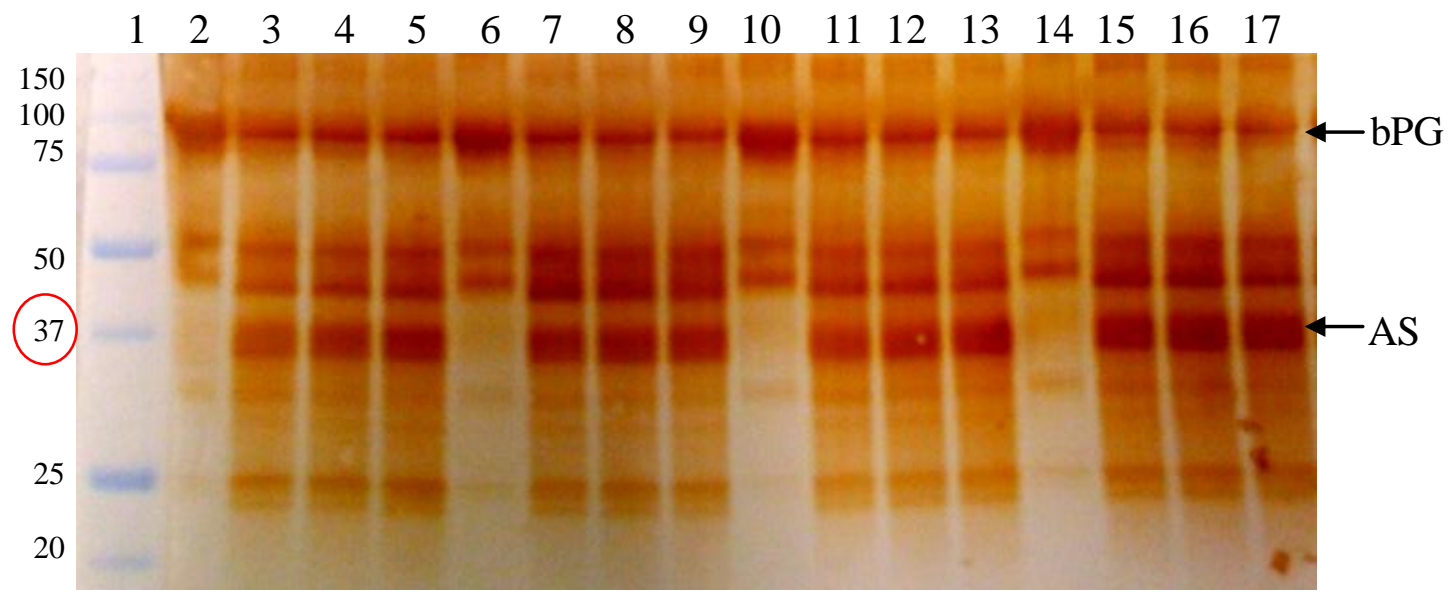

Figure 13: Western blot analysis of bPG fragments generated by digestion with BPP at various incubation times and $\mathrm{E}: \mathrm{S}$ ratios. Reaction products were analyzed with an antiplasminogen antibody. Lane1: MW standard; Lane 2 to 5: $0.3125 \mathrm{mg} / \mathrm{ml} \mathrm{PG} \mathrm{0-40-50-60}$ minutes incubation respectively; Lane 6 to 9: $0.375 \mathrm{mg} / \mathrm{ml} \mathrm{PG} \mathrm{0-30-40-50} \mathrm{minutes}$ incubation respectively; Lane 10 to $13: 0.4375 \mathrm{mg} / \mathrm{ml}$ PG 0-30-40-50 minutes incubation respectively; Lane 14 to $17: 0.5 \mathrm{mg} / \mathrm{ml}$ PG 0-30-40-50 minutes incubation respectively. Immuno-reaction observed for bands in the $37 \mathrm{kDa}$ area confirm angiostatin (AS) like fragments being generated from this reaction 


\subsubsection{Temperature effect}

A temperature effect was observed for enzyme-substrate interaction as well as substrate denaturation and consequent enzyme affinity and hydrolysis. From images 14 and 17 , it is possible to observe how temperatures $4,37,70$ and $90^{\circ} \mathrm{C}$, affected bPG-BPP interaction. Comparison between the reaction at $4{ }^{\circ} \mathrm{C}$ and $37^{\circ} \mathrm{C}$ we can see that in a fridge like environment the reaction is much slower than that at room temperature. Lines 4 to 10 show almost no difference in the amount of product generated or in bPG disappearance, contrarily to lines 12 to 18 were thicker and darker bands can be observed at 50, 37, 35 and $25 \mathrm{kDa}$. This observation is confirmed by analysis on the bands density variation over time (Figures 15 and 16), which indicate that bPG is hydrolyzed almost twice as fast at $37^{\circ} \mathrm{C}$ than at $4^{\circ} \mathrm{C}$. Additionally, when this same analysis is conducted on bands observed at 37 and $34 \mathrm{kDa}$, no significant difference is recorded by the densitometer on the amount of product produced after 30 minutes at $4{ }^{\circ} \mathrm{C}$ contrarily to when the reaction is carried out at $37^{\circ} \mathrm{C}$, allowing us to conclude that in our study $37^{\circ} \mathrm{C}$ resulted to be the most favorable temperature for angiostatin generation. Under ideal temperature, evident product formation is observed and the rate at which peptides in the 37 and $34 \mathrm{kDa}$ appear is almost the same.

At $70^{\circ} \mathrm{C}$ and $90^{\circ} \mathrm{C}$, no activity seems to occur (Figure 17). Hydrolysis of bPG is not evident. These results are no surprise since, according to Matta and Punj (1998), dispase maintains $35 \%$ of its activity at $70^{\circ} \mathrm{C}$ for 10 minutes (Matta Hittu et al. 1998). Due to the reduced activity of the enzyme at this temperature and the short period of time that is being analyzed, it is not possible to observe any significant activity on the SDSPAGE obtained. 


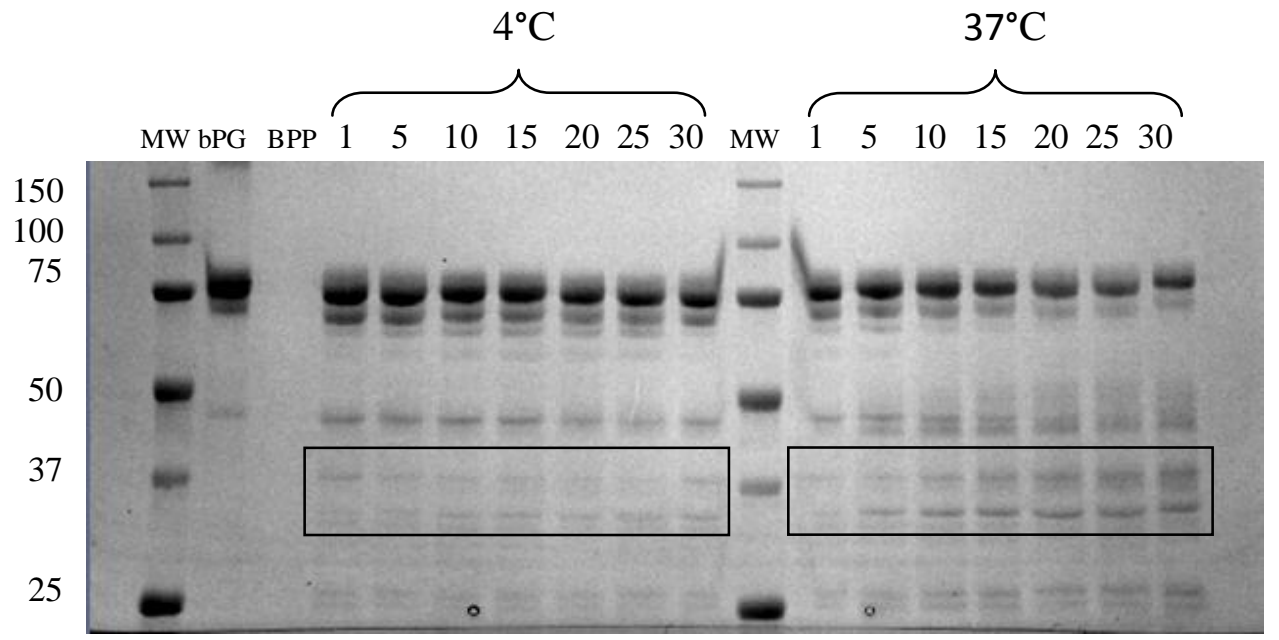

Figure 14: SDS-PAGE analysis of temperature effect on BPP-bPG interaction. Lane 1: molecular weight standard; lane 2: bPG control $(0.2 \mathrm{mg} / \mathrm{ml})$; lane 3: BPP control $(0.025 \mathrm{mg} / \mathrm{ml})$; lane $4-10$ : interaction at $4^{\circ} \mathrm{C}$ between bPG $(0.75 \mathrm{mg} / \mathrm{ml})$ with BPP $(0.1$ $\mathrm{mg} / \mathrm{ml}$ ) after 1, 5, 10, 15, 20, 25 and 30 minutes incubation; lane 11: molecular weight standard; lane 12-18: interaction at $37^{\circ} \mathrm{C}$ between bPG $(0.75 \mathrm{mg} / \mathrm{ml})$ with BPP $(0.1$ $\mathrm{mg} / \mathrm{ml}$ ) after 1, 5, 10, 15, 20, 25 and 30 minutes incubation

$4^{\circ} \mathrm{C}$ vs. $37^{\circ} \mathrm{C}$ bPG hydrolysis

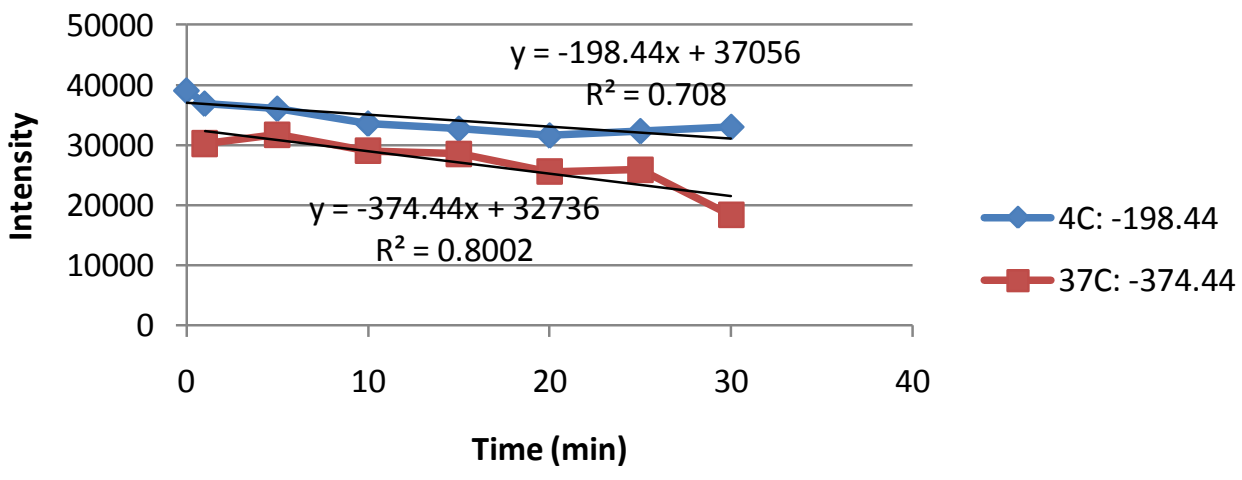

Figure 15: Rate at which BPP hydrolyzes bPG at $4^{\circ} \mathrm{C}$ and $37^{\circ} \mathrm{C}$ 

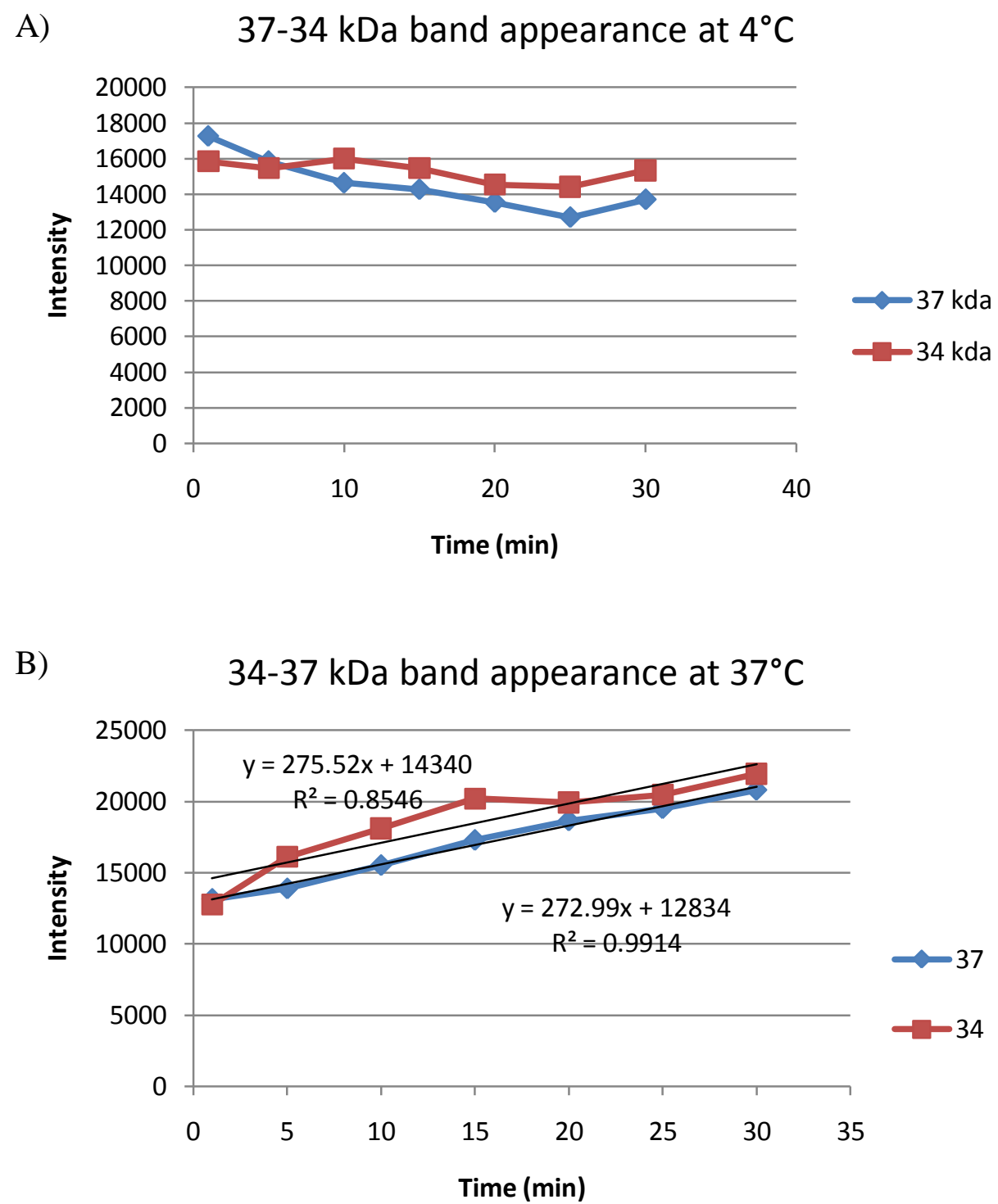

Figure 16: Rate at which bands in the 34 and $37 \mathrm{kDa}$ are formed from bPG hydrolysis by the action of $\mathrm{BPP}$ at $4^{\circ} \mathrm{C}(\mathrm{A})$ and $37^{\circ} \mathrm{C}(\mathrm{B})$. 


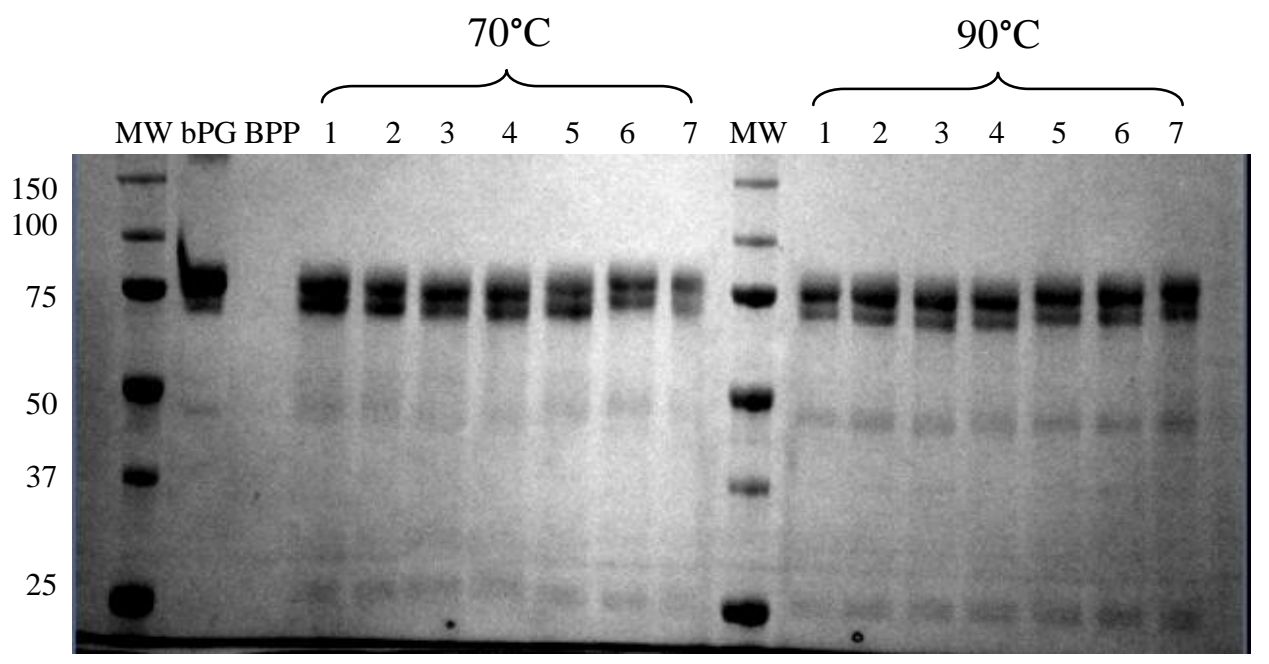

Figure 17: SDS-PAGE analysis of temperature effect on BPP-bPG interaction. Lane 1: molecular weight standard; lane 2 : bPG control $(0.2 \mathrm{mg} / \mathrm{ml})$; lane 3 : BPP control $(0.025 \mathrm{mg} / \mathrm{ml})$; lane $4-10$ : interaction at $70^{\circ} \mathrm{C}$ between bPG $(0.75 \mathrm{mg} / \mathrm{ml})$ with BPP $(0.1$ $\mathrm{mg} / \mathrm{ml}$ ) after 1, 2, 3, 4, 5, 6, 7 minutes incubation; lane 11: molecular weight standard; lane 12-18: interaction at $90^{\circ} \mathrm{C}$ between bPG $(0.75 \mathrm{mg} / \mathrm{ml})$ with BPP $(0.1 \mathrm{mg} / \mathrm{ml})$ after 1 , 2, 3, 4, 5, 6, 7 minutes incubation

From the SDS-PAGE observed in Figure 18, we can observe how bPG denaturation affects BPP affinity for the substrate as well as the hydrolytic profile. Lanes from 2 to 6 represent optimal, $37^{\circ} \mathrm{C}$, interaction between bPG and BPP. The rest of the gel, lanes 8 to 11 , show the effect of heating bPG at $70^{\circ} \mathrm{C}$ (causing denaturation of the molecule) prior to incubation with BPP. Evident increased hydrolysis can be perceived particularly between 75 and $50 \mathrm{kDa}$ molecular weight range. These results concord with the observations previously made by Burbrink and Hayes (2006), in which they determined that by denaturating PG, uPA had easier access to the internal bPG structure and consequent higher activation of the molecule was observed since higher concentration of PL in the sample. Moreover, it seems that higher concentration of the bands of interest in the $37 \mathrm{kDa}$ is also observed (comparison between lane 6 and 11). Further confirmation of these observations can be made from the band density analysis graphs observed in Figure 19 and 20. From this analysis it is possible to ratify bPG being hydrolyzed at higher rate when in a denatured state. In fact, according to the slope of the curves obtained, it seems that BPP hydrolyzes denatured bPG more than twice as fast as non denatured bPG. However, the product formation rate for bands in the 37-34 kDa area 
do not seem to significantly differ from that observed in previous analysis at $37^{\circ} \mathrm{C}$ (Figure $16 \mathrm{~B})$. Direct analysis on product formation for non denatured bPG from the gel observed in Figure 18 was not possible due to insufficient product generation for the densitometer to detect a significant difference in the concentration of the bands overtime. In conclusion, although by visually looking at the gel and comparing lanes 6 and 11 it seems that angiostatin like fragments are produced at higher concentration by the action of BPP when bPG is denatured, it is not possible to confirm such observation from the numbers obtained through density analysis since the amount of product generated is not enough to enable direct comparison in the present gel image.

Subsequently, effect of bPG hydrolysis, folded and unfolded, in a milk system and consequent BPP activity was also determined. Referring to Figure 21, we can observe differences between hydrolysis of folded bPG and denatured bPG in milk. Contrarily to the observations previously made when the reaction was conducted in a buffer system, the same hydrolytic pattern is observed between native and denatured bPG by the action of BPP. Nevertheless, the reaction for denatured bPG seems to produce higher amount of fragments in the $50 \mathrm{kDa}$ molecular weight range as well as higher bPG disappearance rate compared to the results observed when bPG did not undergo heating prior to incubation with dispase. According to the bPG disappearance rate analysis (Figure 22), denatured bPG gets hydrolyzed faster than native bPG, similarly to what previously seen in a buffer system. However, this difference is not as pronounced as the one seen in a buffer system, these rates differ by 1.52 times when analyzed in milk compared to 2.2 times in buffer. These observations can be explained by the fact that due to the presence of additional proteins in milk, BPP priority is not only bPG hydrolysis but also interaction with other high affinity peptides. These results are in accordance with findings made by Lu et al. (2009) for which analysis of various heat treatments on PG in milk resulted in higher PG activity (due to increased PL) when the zymogen was heated at $70^{\circ} \mathrm{C}$ (Platanias Leonidas C. 2009). On the other hand, through density analysis, angiostatin like fragments generation seems to be slightly higher (1.2 times) in milk for denatured bPG than in buffer. Various factors could explain such phenomenon. For example, presence of specific activators or some other molecules may function as angiostatin generation promoters; if this was true we would also observe higher 
generation of angiostatin for native bPG in milk, however detection limitations did not allow us to investigate such hypothesis further. Moreover, according to observations previously made for the hydrolytic pattern observed in Figure 11, if true that BPP can generate angiostatin from a fragment in the $50 \mathrm{kDa}$ range (believed to be $\mathrm{PL}$ ), then the higher concentration of this fragment observed under such conditions could explain consequent higher angiostatin generation.

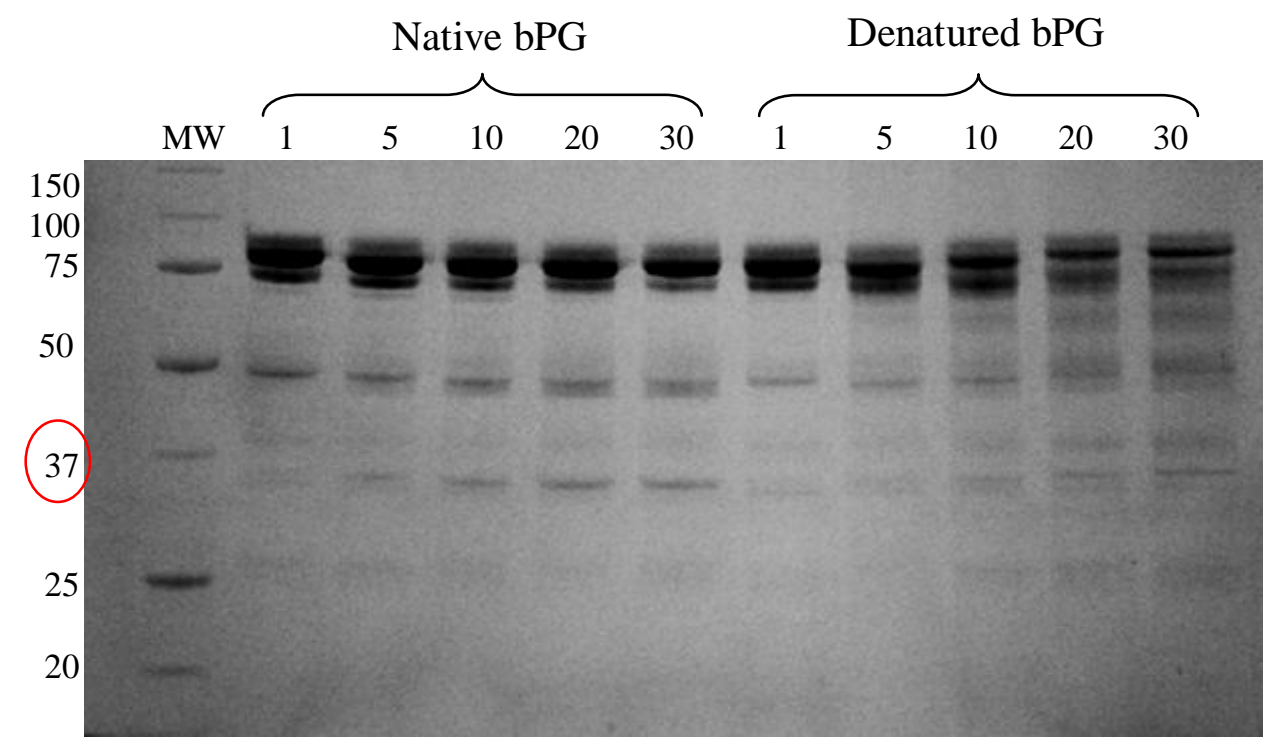

Figure 18: SDS-PAGE analysis of denaturation effect on bPG hydrolysis by the action of $\mathrm{BPP}$ at $37^{\circ} \mathrm{C}$. Lane 1: molecular weight standard; lane 2-6: native bPG $(0.75 \mathrm{mg} / \mathrm{ml})$ incubated with BPP $(0.1 \mathrm{mg} / \mathrm{ml})$ at $37^{\circ} \mathrm{C}$ for $1,5,10,20$ and 30 minutes incubation; lane 7-11: denatured bPG (heated at $70^{\circ} \mathrm{C}$ ) incubated with $\mathrm{BPP}$ at $37^{\circ} \mathrm{C}$ for $1,5,10,20$ and 30 minutes. 


\section{Denatured vs. Non Denatured}

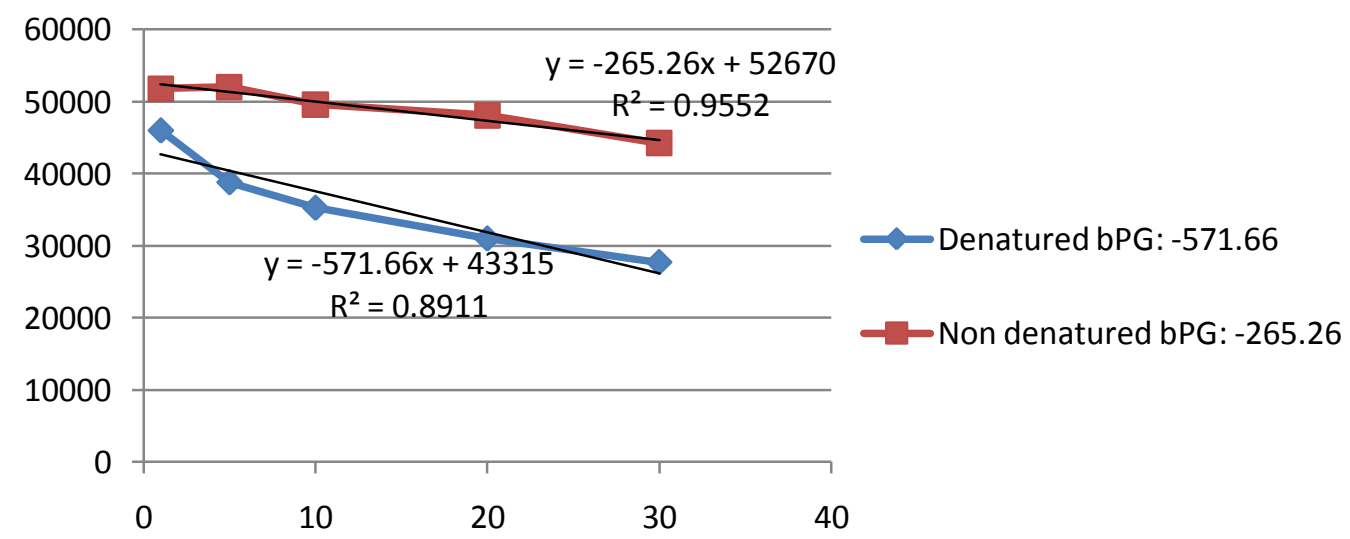

Figure 19: Disappearance rate comparison between denatured and non denatured bPG by the action of BPP. Disappearance of native bPG resulted in a slope of -265.26 while denatured bPG showed -571.66 disappearance rate.

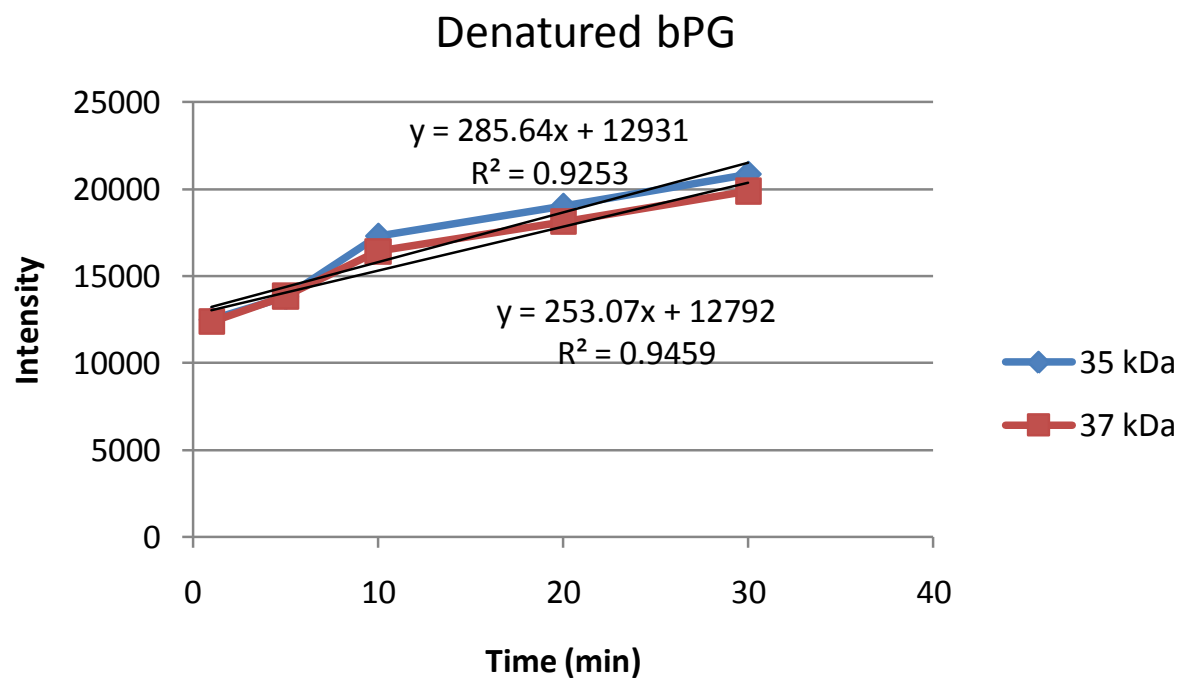

Figure 20: Production rate of 35 and 37 molecular weight peptides generated through denatured bPG hydrolysis by the action of BPP 


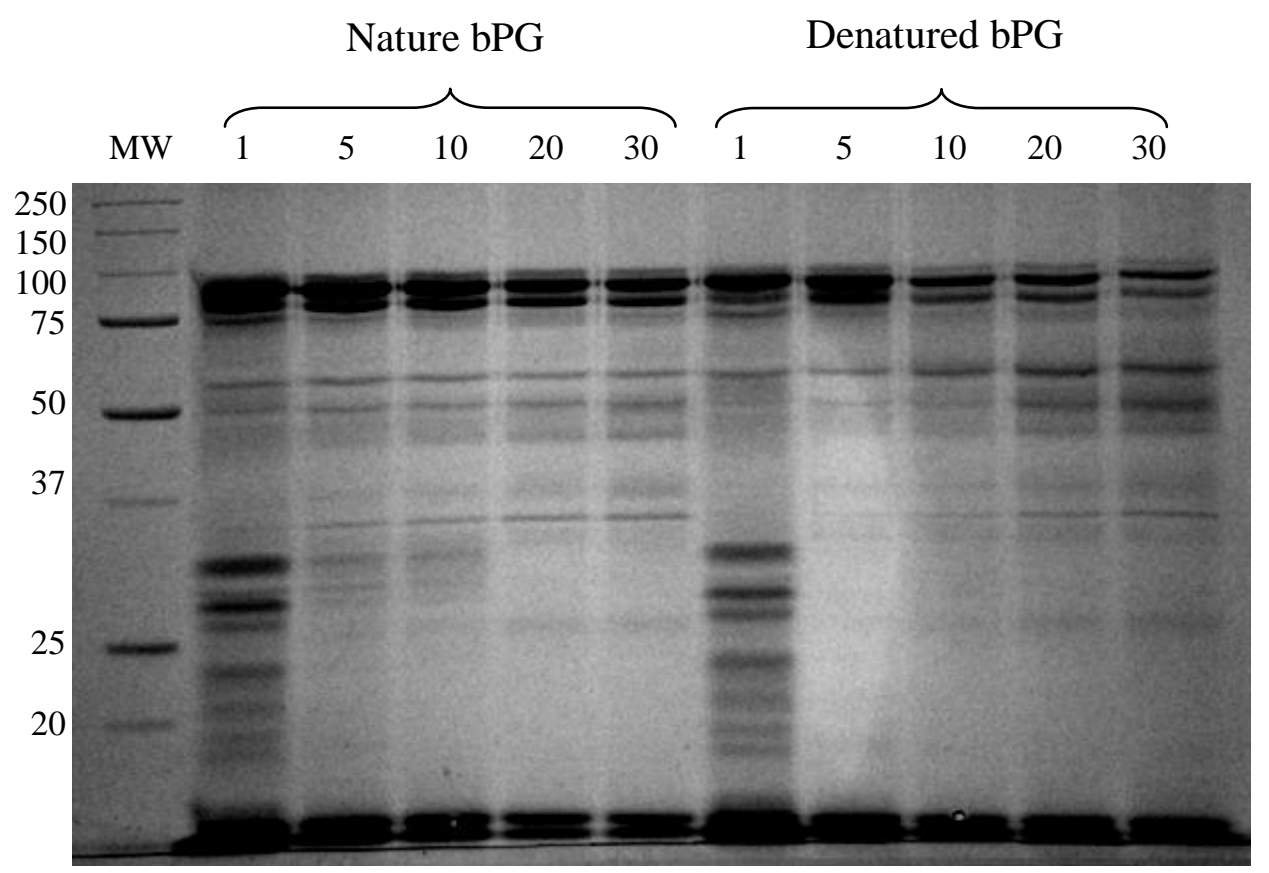

Figure 21: SDS-PAGE analysis of fragments generated by the action of BPP with folded and denatured bPG in a milk system. Lane 1: molecular weight standard; lane 2-6: bPG in milk incubated with BPP at $37^{\circ} \mathrm{C}$ for $1,5,10,20$ and 30 minutes; lane 7-11: denatured bPG in milk incubated with BPP at $37^{\circ} \mathrm{C}$ for $1,5,10,20$ and 30 minutes

\section{Denatured vs. non denatured bPG in milk}

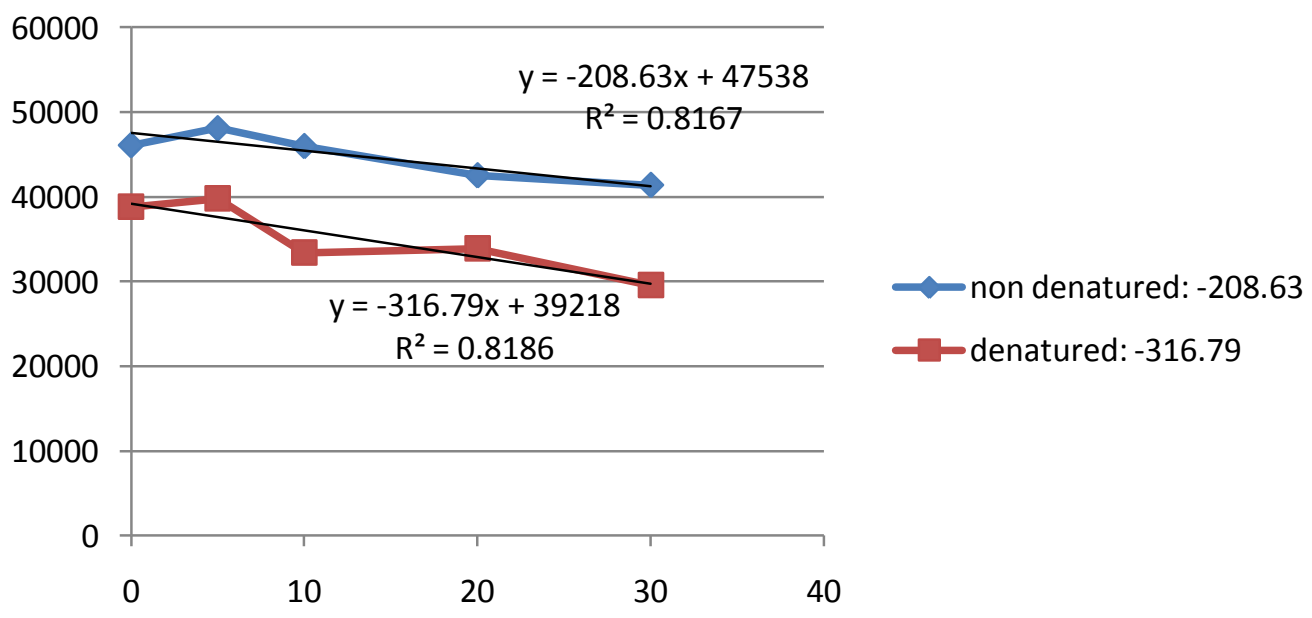

Figure 22: denatured versus non denatured bPG proteolysis by the action of BPP when in a milk system. The rate of the reaction resulted in a slope of -208.63 when bPG is in its native form, while -316.79 for bPG in its denatured form. 


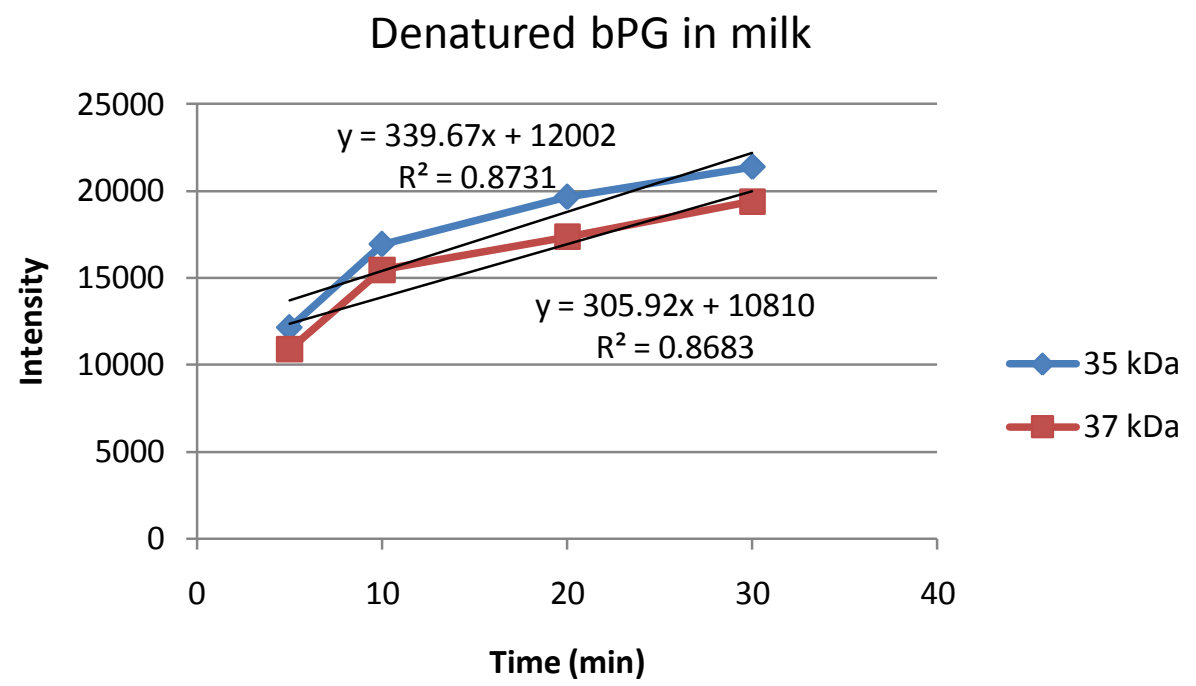

Figure 23: 35 and $37 \mathrm{kDa}$ fragments generation from denatured $\mathrm{bPG}$ in milk by the action of BPP

\subsubsection{Sequence analysis of fragments of interest}

Sequence analysis of the fragments generated by BPP with molecular weight of $50 \mathrm{kDa}, 37 \mathrm{kDa}$ and $35 \mathrm{kDa}$ (observed in Figure 11) confirmed the fragments to belong to plasmin, kringles 1 through 4 of bovine plasminogen and mini-plasminogen respectively (Appendix B). For more accurate interpretation of the results obtained, only actual minus calculated peptide mass data in the range of \pm 200 ppm were considered.

\subsubsection{Bacillus polymyxa protease ability in generating human angiostatin}

Ability of BPP in generating angiostatin from human PG was confirmed. Additionally, from the results obtained from this study it was possible to notice the evident higher affinity of BPP for human PG than for the bovine source of this molecule, since 10 fold less concentrated enzyme was necessary to generate angiostatin and other fragments. In Figures 24 and 25, products generated over time by BPP at two concentration levels can be observed. Figure 25, when BPP concentration is $0.025 \mathrm{mg} / \mathrm{ml}$, shows that after less than 5 minutes incubation the reaction is terminated. Interestingly, even 25 minutes after products being generated, hydrolysis of the fragments of interest does not occur. From the reaction observed in Figure 25, in which a lower concentration 
of BPP is used $(0.01 \mathrm{mg} / \mathrm{ml} ; 10$ fold less concentrated than that used for bPG), similar results are observed. BPP hydrolyzed hPG to generate PL $(50 \mathrm{kDa})$, a thick band between 50 and $37 \mathrm{kDa}$ (which could represent angiostatin K1-4 or K1-3 or a combination of other kringles) and a fragment which molecular weight is lower than that of angiostatin. Interestingly, when the concentration of BPP is increased, a band in the $37 \mathrm{kDa}$ appears, indicating that angiostatin in Figure 25 is being produced but at a very slow rate and almost not visible in the gel. Kinetics on BPP hydrolysis of hPG was not conducted since as it is possible to confirm from the gels obtained, at low concentration of BPP the reaction is very slow, particularly in generating the fragment of interest, while at higher concentration the angiostatin like fragment is obtained after less than 5 minutes incubation with the substrate, making it difficult to adjust concentration-time paramenters. However, the major observation and objective of this experiment was reached, and it is possible to confirm with great evidence that BPP has higher affinity for $\mathrm{hPG}$ than for $\mathrm{bPG}$, and it will produce higher amounts of angiostatin like fragments from the human version of the molecule than bPG.

Western blot analysis of the SDS-PAGE obtained for the reaction between BPP $(0.01 \mathrm{mg} / \mathrm{ml})$ and $\mathrm{hPG}(1 \mathrm{mg} / \mathrm{ml})$ in Figure 25 can be observed in Figure 26. Polyclonal anti-human angiostatin antibody used in this study, recognizes angiostatin K1-4 and part of K5 according to the manufacturer. From the results, bands located between 50 and 37 $\mathrm{kDa}$ show strong immunoreaction with the antibody. We can assume from this interaction that angiostatin K1-4 is being produced and its molecular weight may be higher than $38 \mathrm{kDa}$. Interestingly from the literature many variations on angiostatin's MW from 35 to 45 kDa (Cao Yihai et al. 1996; Morikawa Wataru et al. 2000; Migita Toshiro et al. 2001) are found, making it difficut to guess and exactly determine which kringles are being generated without sequence analysis data. Additionally, lower molecular weight fragments observed could represent combinations of some of the kringles. According to Cao et al. (1996) native angiostatin K1-3 had a MW of approximately $35 \mathrm{kDa}$, but according to a study conducted by Migita et al. (2001) this molecular weight represented native mini-plasminogen (K5 plus the light chain); in order to better understand and to confirm what products are being obtained sequence analysis is necessary. 


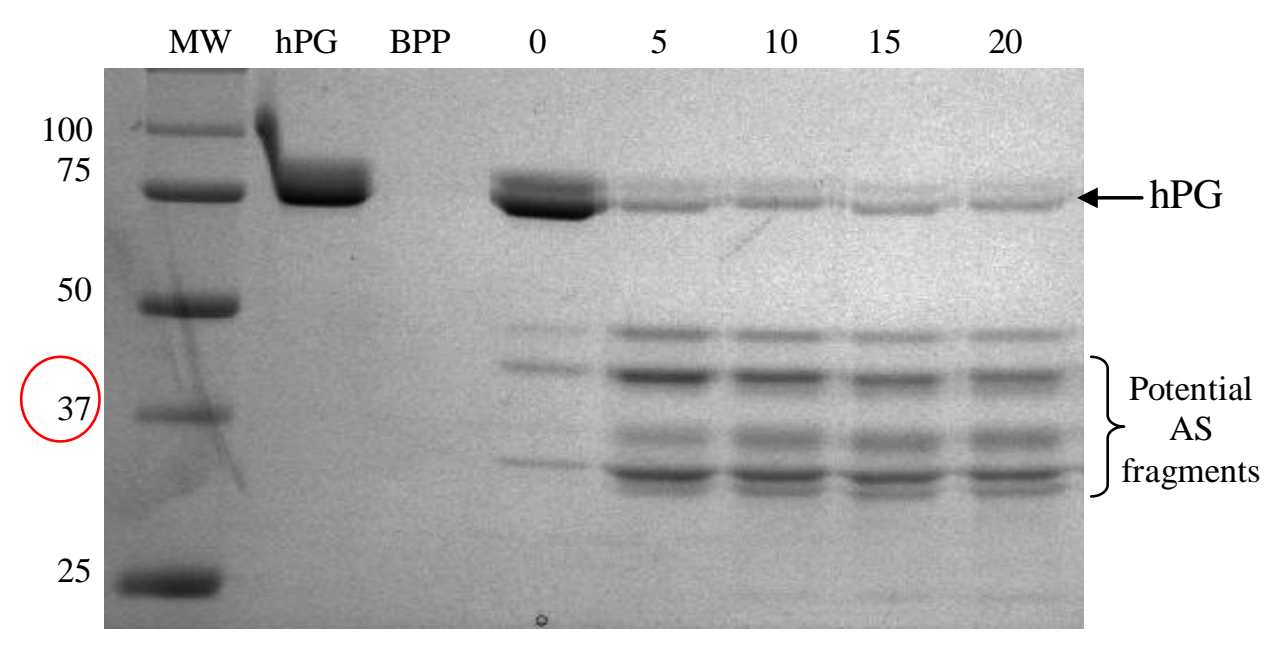

Figure 24: SDS-PAGE visualization of the fragments generated by the action of BPP $(0.025 \mathrm{mg} / \mathrm{ml})$ hydrolysis of human PG $(1 \mathrm{mg} / \mathrm{ml})$. Lane 1 : molecular weight standard; lane 2: hPG control $(0.125 \mathrm{mg} / \mathrm{ml})$; lane $3:$ BPP control $(0.025 \mathrm{mg} / \mathrm{ml})$; lane $4-8: \mathrm{hPG}$ incubated with BPP for $0,5,10,15$, and 20 minutes incubation at $37^{\circ} \mathrm{C}$.

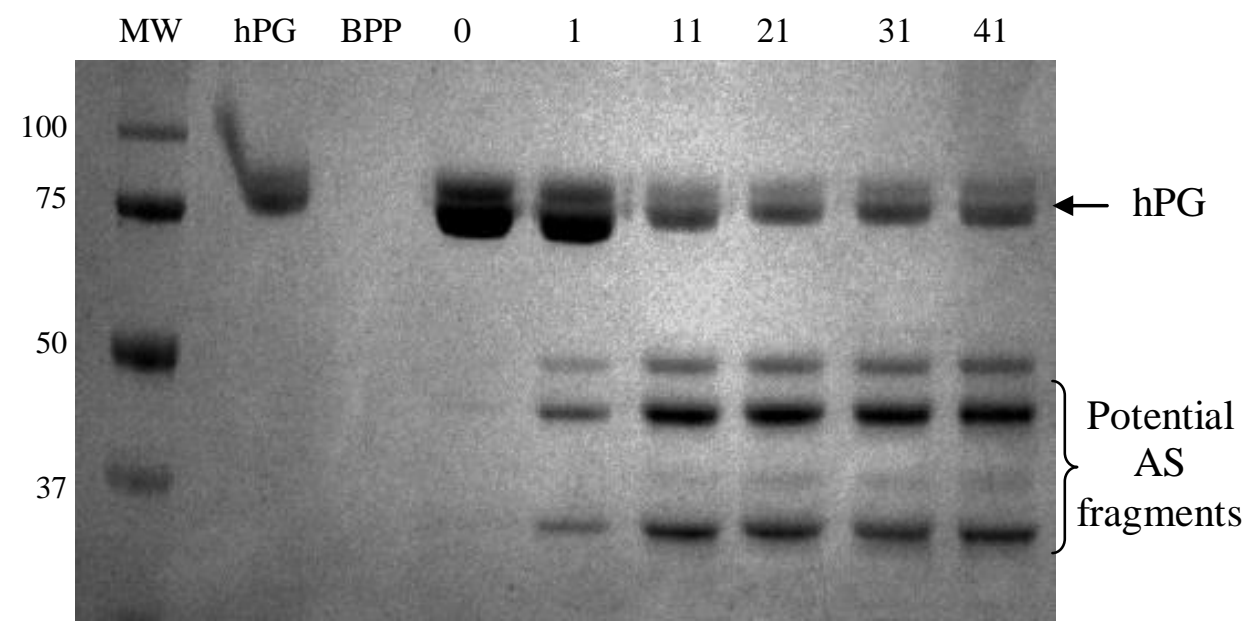

Figure 25: SDS-PAGE visualization of the fragments generated by the action of BPP $(0.01 \mathrm{mg} / \mathrm{ml})$ hydrolysis of human PG $(1 \mathrm{mg} / \mathrm{ml})$. Lane 1: molecular weight standard; lane 2: $\mathrm{hPG}$ control $(0.125 \mathrm{mg} / \mathrm{ml})$; lane $3:$ BPP control $(0.025 \mathrm{mg} / \mathrm{ml})$; lane $4-9: \mathrm{hPG}$ incubated with BPP for $0,1,11,21,31$ and 41 minutes incubation at $37^{\circ} \mathrm{C}$. 


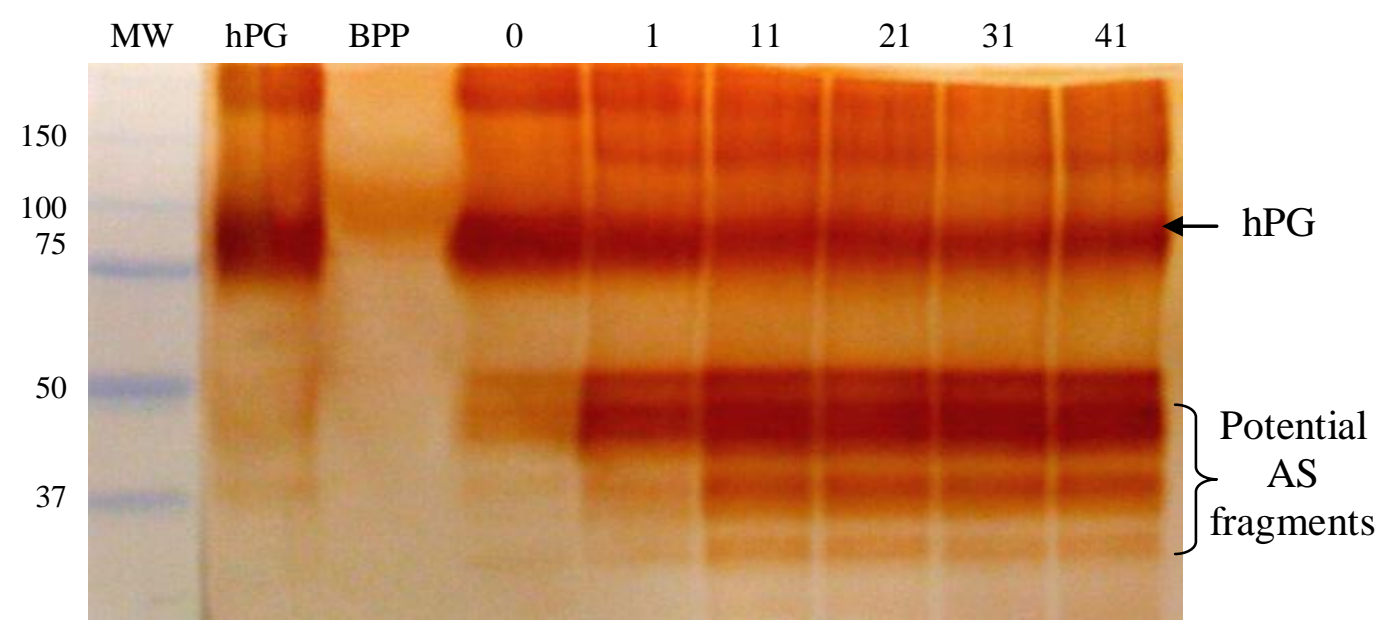

Figure 26: Western-blot visualization of internal human PG fragments generated by the action of BPP $(0.01 \mathrm{mg} / \mathrm{ml})$, identified with polyclonal anti-human angiostatin. Lane 1: molecular weight standard; lane 2: hPG control $(0.125 \mathrm{mg} / \mathrm{ml})$; lane 3: BPP control $(0.025 \mathrm{mg} / \mathrm{ml})$; lane 4-9: hPG incubated with BPP for $0,1,11,21,31$ and 41 minutes at $37^{\circ} \mathrm{C}$.

2.4.2 PART 2. Generation of angiostatin from bovine and human plasminogen hydrolysis by the action of elastase

From previous studies, it is known that elastase is capable of producing angiostatin K1-4, K1-3 and K4 alone from human PG (Cao Yihai et al. 1996). From this study we were able to determine that elastase can generate angiostatin like fragments from bPG as well. From the SDS-PAGE shown in Figure 27, a clear band in the 38kDa can be identified from the products obtained from the interaction between elastase and bPG. Interestingly, contrarily to BPP, elastase does not produce secondary products (i.e. PL), only angiostatin and a lower molecular weight band (possibly K1-3 or miniplasminogen) are observed. The western-blot (Figure 30) also confirms the bands obtained to belong to internal region of bPG. Additionally, from the band density analysis, the slope of bPG disappearance confirms the reaction to be very slow compared to BPP since in this case the reaction is analyzed over a period of 8 hours instead of 1 hour. This significant difference in incubation time does not allow direct comparison between the two enzymes in terms of kinetics. In order to enable comparison on the amount of product produced, intensity values could be used instead. Higher intensity is observed for bands in the 37 and $34 \mathrm{kDa}$ area generated through hydrolysis action from elastase. The intensity of these bands is almost twice as stronger as the same bands when 
generated by BPP (comparison between Figure 29 and 16 B), indicating ability of elastase in producing higher amounts of angiostatin from the same PG concentration.

From the hPG interaction with elastase shown in Figure 31, we notice that under the same conditions (E:S ratio, time and temperature) used for bPG, elastase shows higher affinity for bPG than for hPG, since hydrolysis of hPG is slower than that observed for bPG. Additionally, a different hydrolytic pattern between the two substrates is also observed. Higher molecular weight bands are generated from hPG hydrolysis. Moreover, from the western blot obtained two clear bands can be recognized possibly as human angiostatin K1-4 and K1-3 as seen in the experiment conducted by Cao et al. (1996). Lower MW bands able to immuno-react with the anti-human angiostatin antibody are also observed. Two main factors differ between our experiment and that conducted by Cao et al. (1996): the elastase source and the E:S ratio. The elastase used in the present study has been purified from human leukocytes while Cao et al. used porcine elastase. Additionally the E:S ratio used in our study was 1:100, while Cao et al. used a 1:133 ratio. Perhaps these differences may explain some of the dissimilarities observed between the two studies.

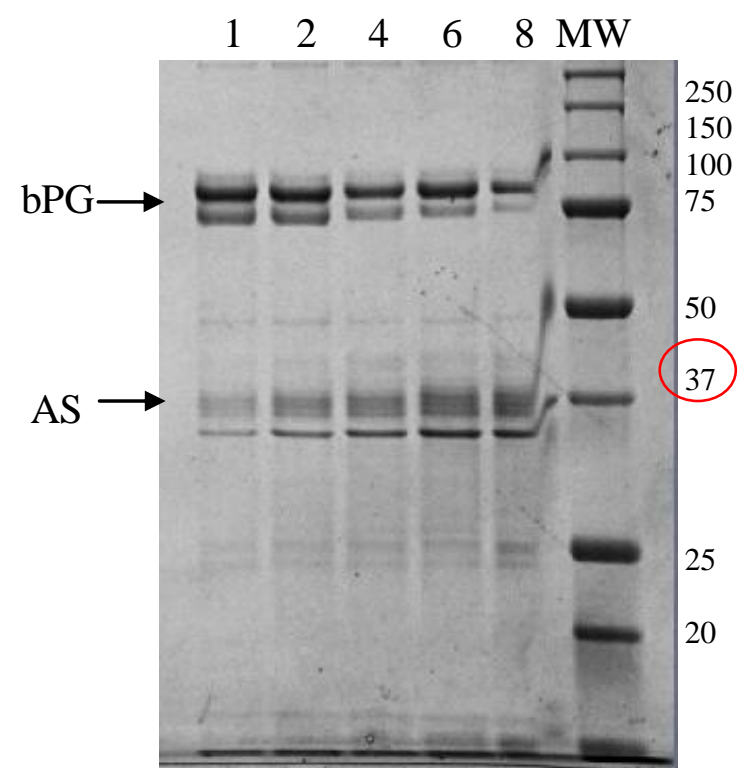

Figure 27: SDS-PAGE analysis of the fragments obtained through bPG hydrolysis by the action of elastase. Lane 1-5: elastase $(0.01 \mathrm{mg} / \mathrm{ml})$ incubated with $\mathrm{bPG}(1 \mathrm{mg} / \mathrm{ml})$ for 1, 2, 4, 6 and 8 hours incubation at $37^{\circ} \mathrm{C}$; lane 6: molecular weight standard. Bands in the $37 \mathrm{kDa}$ correspond to potential angiostatin (AS) fragments 


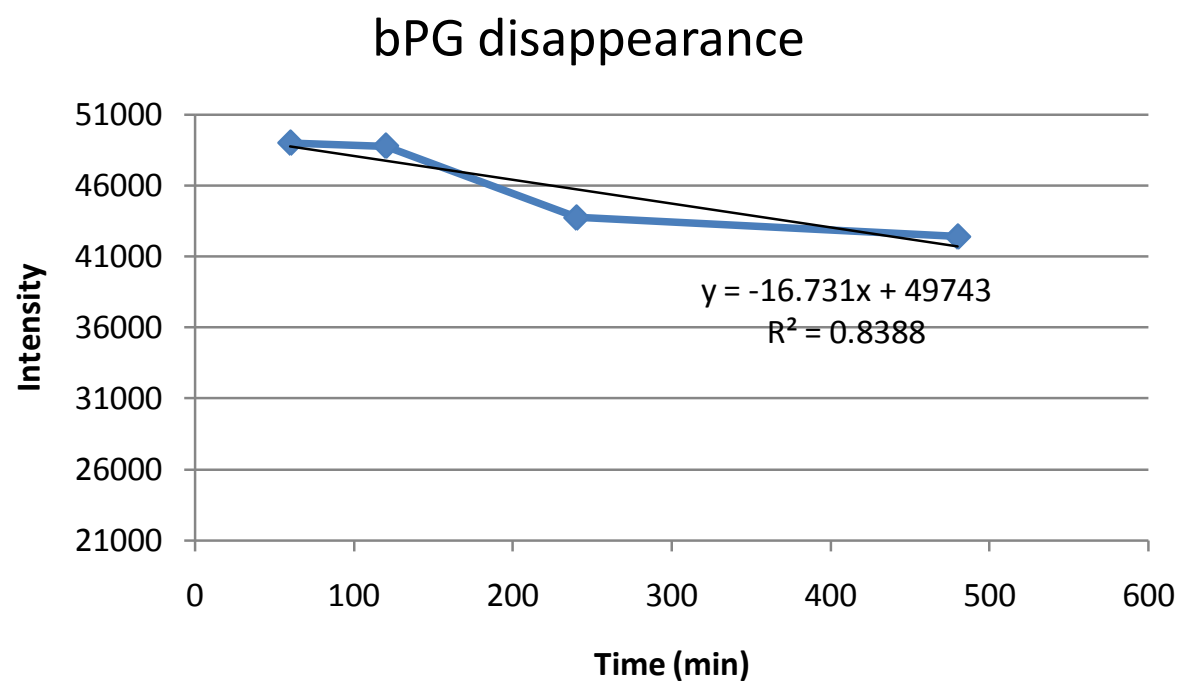

Figure 28: bPG disappearance by the action of elastase overtime

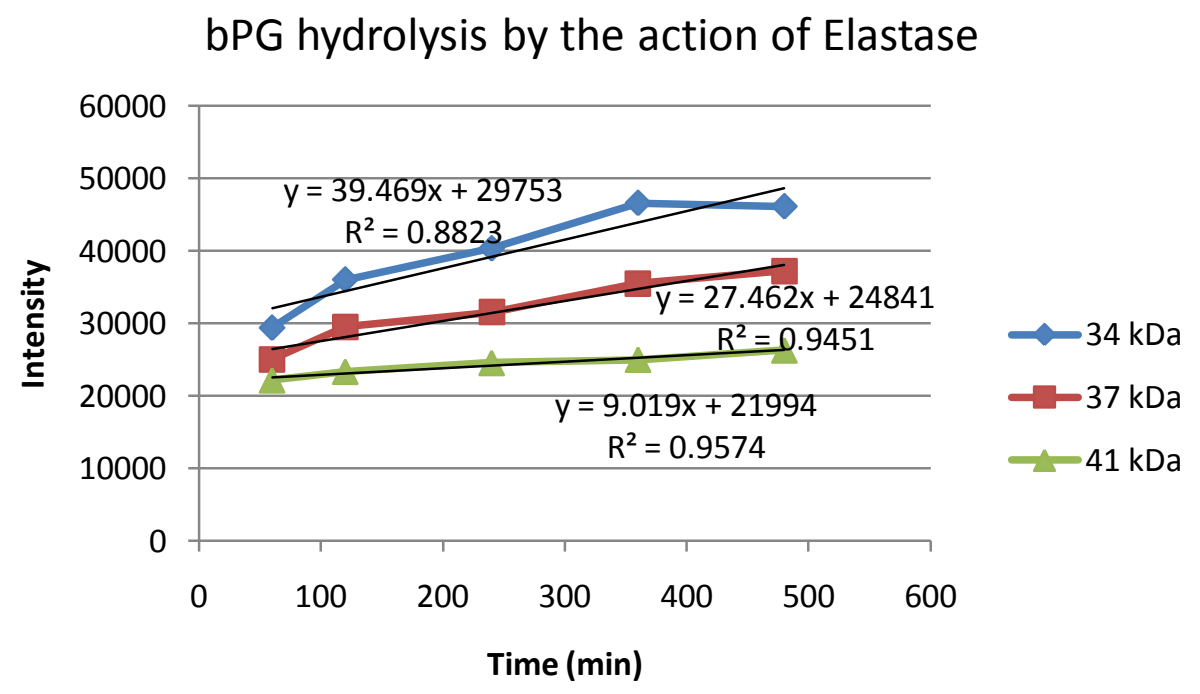

Figure 29: generation rate of fragments obtained through bPG hydrolysis by the action of elastase 


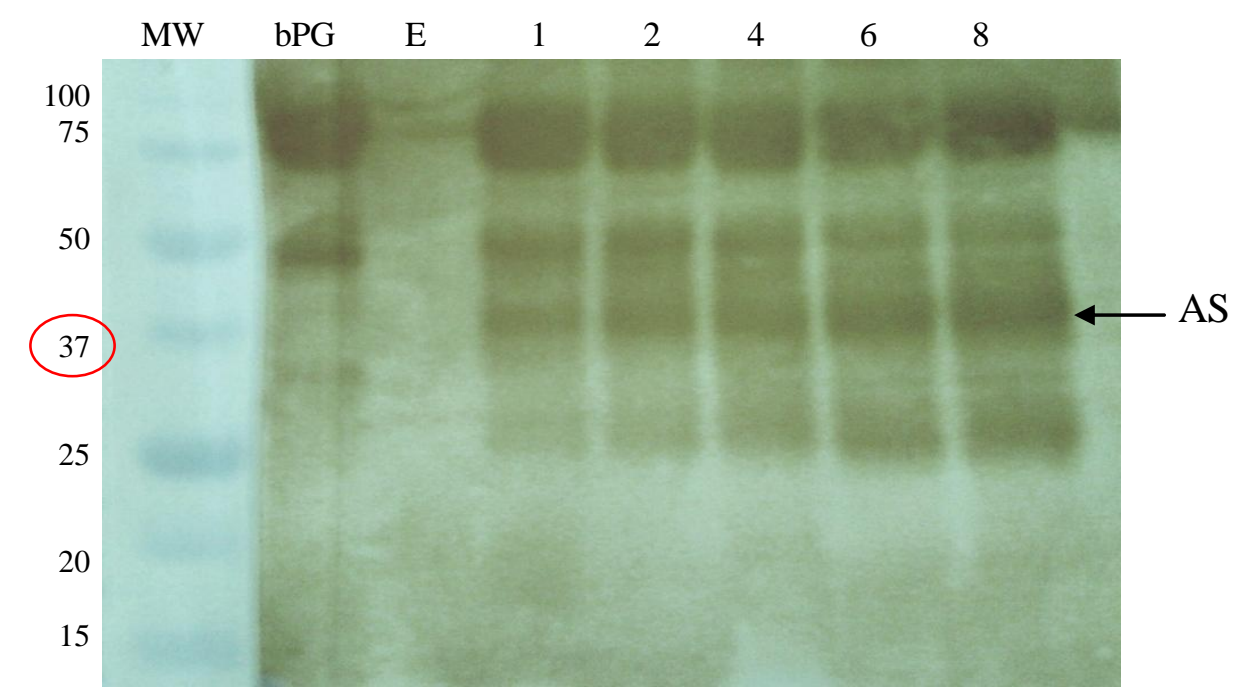

Figure 30: SDS-PAGE analysis of proteolytic fragments generated through bovine PG hydrolysis by the action of elastase (E) and identified with a polyclonal anti-bovine plasminogen antibody. Lane 1: molecular weight standard; lane 2: bPG control $(0.25$ $\mathrm{mg} / \mathrm{ml})$; lane 3: elastase control $(0.025 \mathrm{mg} / \mathrm{ml})$; lane 4-8: $\mathrm{bPG}(1 \mathrm{mg} / \mathrm{ml})$ interaction with elastase $(0.01 \mathrm{mg} / \mathrm{ml})$ after $1,2,4,6$ and 8 hours incubation at $37^{\circ} \mathrm{C}$. Bands in the $37 \mathrm{kDa}$ area correspond to potential angiostatin AS fragments.

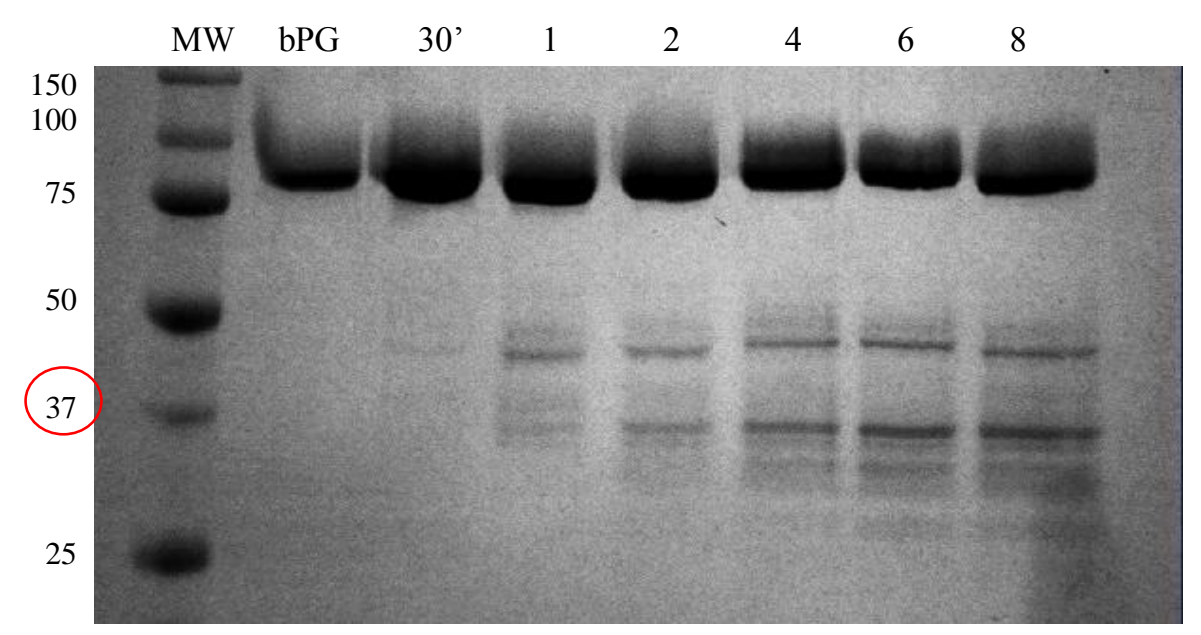

Figure 31: SDS-PAGE analysis of hydrolytic products obtained from human PG hydrolysis by the action of elastase. Lane 1: molecular weight standard; lane 2: hPG control $(0.125 \mathrm{mg} / \mathrm{ml})$; lane $3-8: \mathrm{hPG}(1 \mathrm{mg} / \mathrm{ml})$ incubated with elastase for 30 minutes, $1,2,4,6$ and 8 hours at $37^{\circ} \mathrm{C}$. 


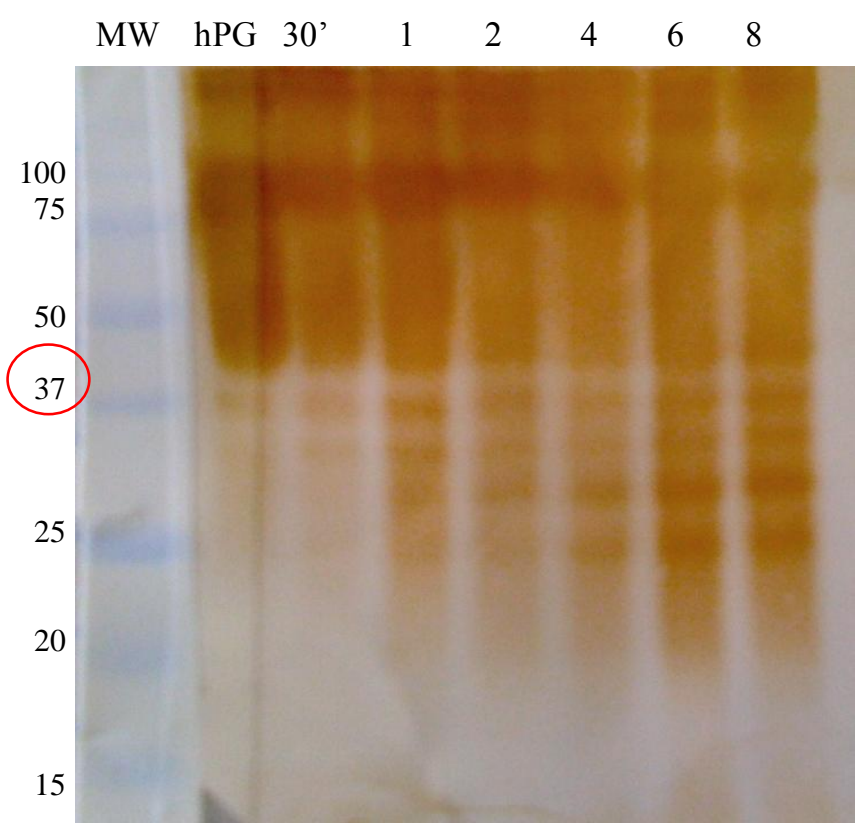

Figure 32: western blot identification of internal human PG fragments generated by the action of elastase through anti-human angiostatin polyclonal antibody. Lane 1: molecular weight standard; lane 2: hPG control $(0.125 \mathrm{mg} / \mathrm{ml})$; lane 3-8: elastase $(0.1 \mathrm{mg} / \mathrm{ml})$ interaction with $\mathrm{hPG}(1 \mathrm{mg} / \mathrm{ml})$ after 30 minutes, $1,2,4,6$ and 8 hours incubation.

2.4.3 PART 3. Generation of angiostatin from bovine plasminogen hydrolysis by the action of Bacillus and Lactobacillus originated proteases

\subsubsection{LACTOBACILLUS}

Generation of proteolytic enzymes by Lactobacillus grown in UHT was quantified (Table 6) based on observations from skim milk agar plates in Figure 33. Zones of clearance indicate casein break down by proteases generated by the action of Lactobacilli. Different results can be observed by different strains of LAB. L. reuteri 23272 and L. johnsonii 11088 showed higher caseinolytic activity compared to the other strains which showed low to no activity. Effects of other growth media, MRS-5\% UHT, on the generation of hydrolytic enzymes was also determined, however results indicated almost no caseinolytic activity (for hydrolytic activity of lactobacillus grown in MRS5\% UHT refer to Appendix C).

Determination of bPG proteolytic enzyme generation was also analyzed, but from Figures 34 and 35 we can observe that neither the enzymes released in the supernatant 
nor those bound to the cell wall surface showed capability in hydrolyzing PG. In Figure 34, for L. helveticus MR 220 a band is observed at $50 \mathrm{kDa}$. Further research through western blot analysis (results not shown), indicated this fragment not to belong to bPG since no immunoreactions with polyclonal anti-bovine plasminogen occurred.
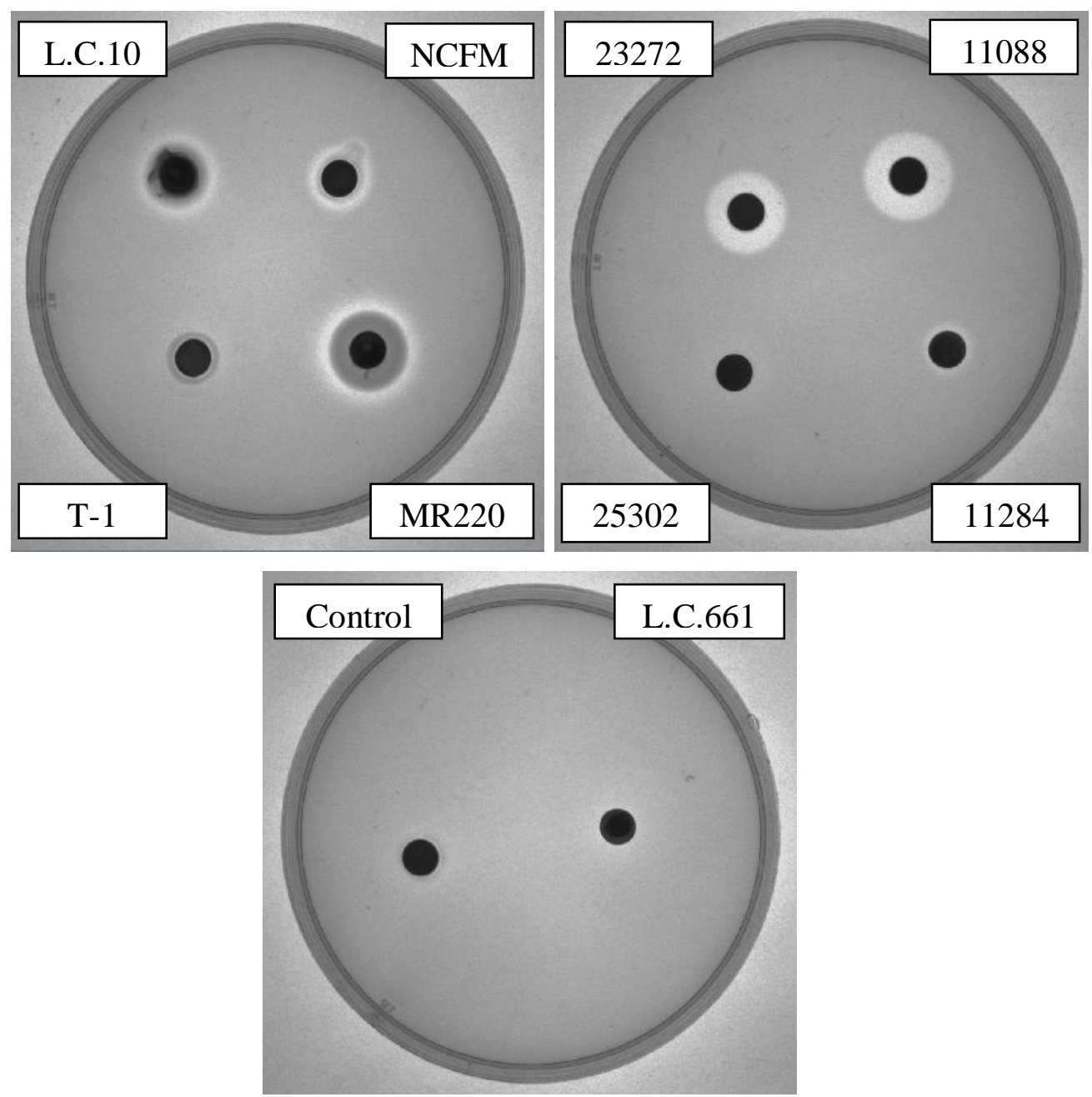

Figure 33: Skim milk agar plates hydrolytic activity analysis of Lactobacillus grown in UHT. Zones of clearance indicate production of caseinolytic enzymes. 
Table 6: measures of zone of clearance (in $\mathrm{mm}$ ) produced by the action of Lactobacillus originated enzymes when placed in casein agar plates for 24 hours

\begin{tabular}{|c|c|}
\hline Lactobacillus & Zone of clearance diameter (mm)* \\
\hline L.C. 10 & 17 \\
\hline NCFM & 13 \\
\hline T-1 & 0 \\
\hline MR 220 & 22 \\
\hline 23272 & 19 \\
\hline 11088 & 20 \\
\hline 25302 & 0 \\
\hline 11284 & 9 \\
\hline L.C.661 & 0 \\
\hline Control & 0 \\
\hline
\end{tabular}

*zone of clearance was measured by taking the average of the vertical and horizontal diameters (in $\mathrm{mm}$ ) of the halo observed in the skim milk agar plates Figure 33

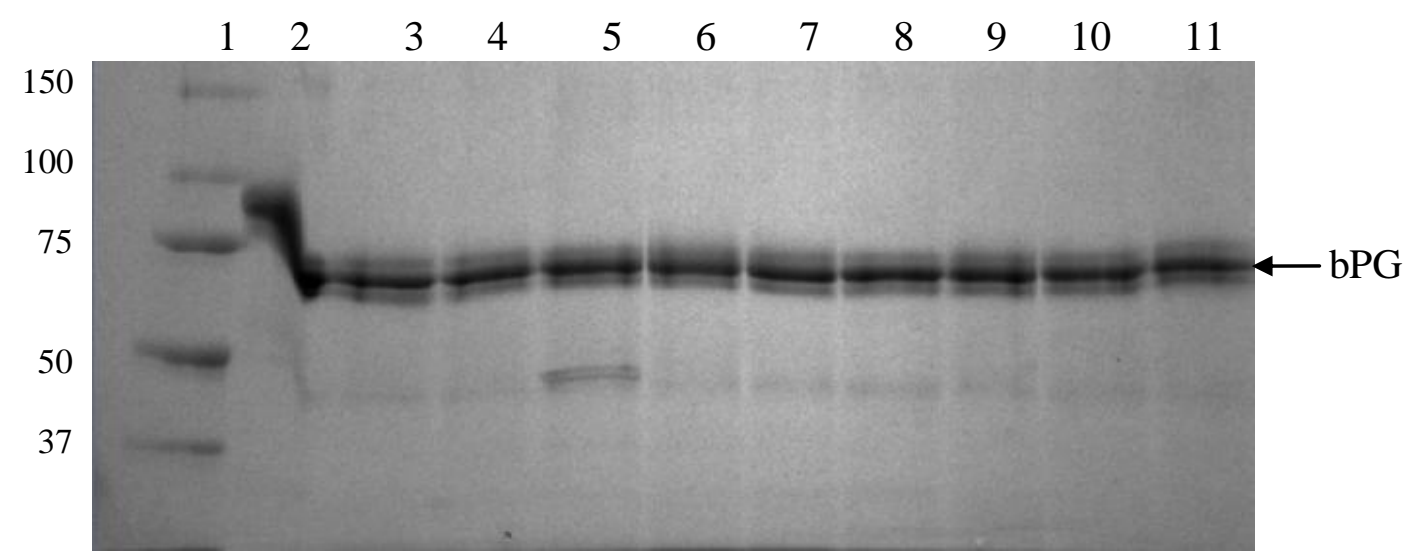

Figure 34: SDS-PAGE analysis of enzymes released by Lactobacilli in the supernatant to hydrolyze bPG. Lane 1: molecular weight standard; lane 2: bPG control $(0.125 \mathrm{mg} / \mathrm{ml})$; lane $3-11: \mathrm{bPG}(1 \mathrm{mg} / \mathrm{ml})$ interaction with the supernatant produced from Lactobacillus NCFM, T-1, MR220, 85302, 11088, L.C. 10, 23272, 661, and 11284 after 3 hours incubation at $37^{\circ} \mathrm{C}$. 


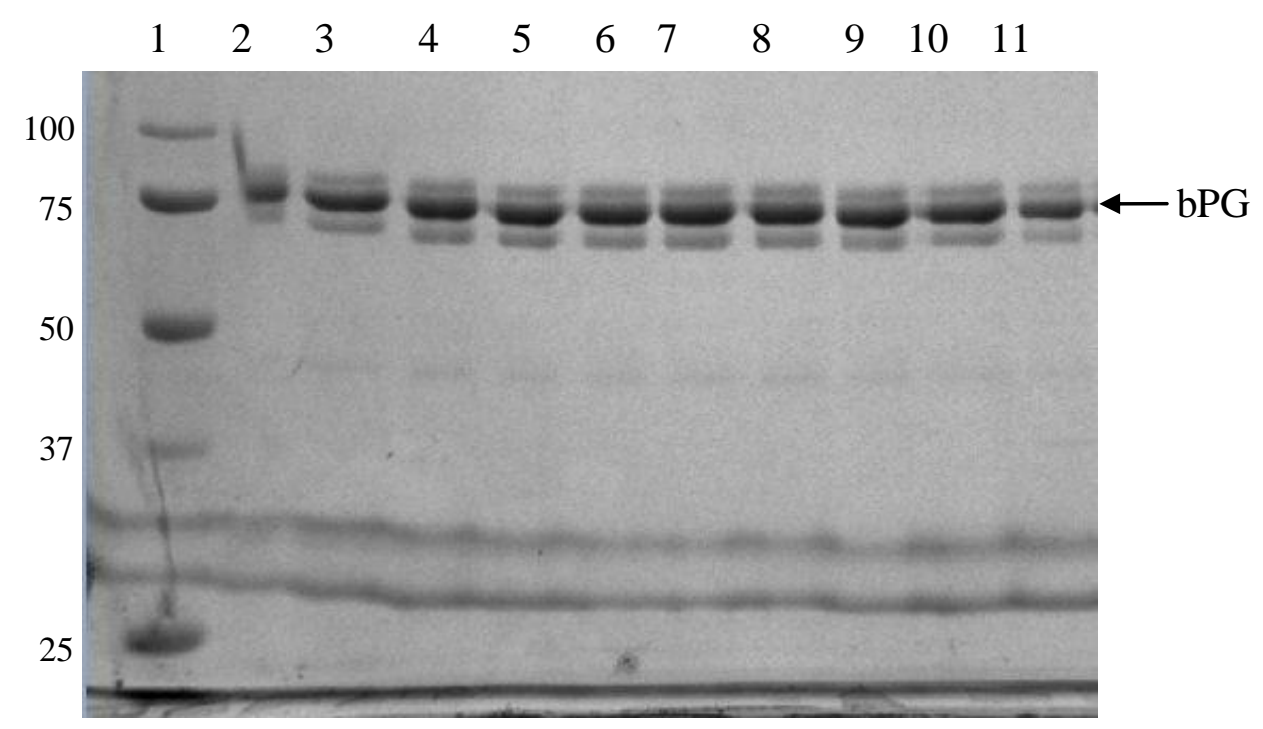

Figure 35: SDS-PAGE analysis of isolated cell wall associated enzymes ability in hydrolyzind bPG. Lane 1: molecular weight standard; lane 2: bPG control $(0.125$ $\mathrm{mg} / \mathrm{ml})$; lane 3-11: interaction between $\mathrm{bPG}(1 \mathrm{mg} / \mathrm{ml})$ and cell wall associated enzymes isolated from Lactobacillus 661, NCFM, 23272, 11088, 11284, L.C. 10, T-1 and MR220.

\subsubsection{BACILLUS}

Contrary to Lactobacillus, most of the Bacillus strains tested showed pronounced hydrolytic activity. In fact from Figure 36 we can see defined zones of clearance between various Bacillus strains and also differences between strains grown in UHT and TSB-5\% UHT. Similar hydrolytic activity is observed between the two media tested. Enzymes generation by Bacillus after 12 or 24 hours growth in TSB alone was also analyzed (Appendix D). Interestingly, enzymes were more active when generated after 12 hours growth than 1 day after inoculation. Nutrient depletion after 24 hours growth may explain the reduced enzyme generation. Ability of the strains analyzed in hydrolyzing casein are in agreement with the observations made by Gordon et al.(1973) which classified Bacillus strains characteristics, including casein hydrolysis, and observed that the majority of the strains analyzed were positive for this trait (Turnbull Peter C. B. 1996).

These proteases resulted positive also in their ability in bPG hydrolysis (Figure 37). SDS-PAGE analysis of the products obtained from the reaction between Bacilli derived enzymes and bPG shows that all the Bacilli produced proteases capable of interacting with bPG. However differences in substrate affinity and kinetics in cleaving 
PG is observed between the various strains of Bacilli analyzed. Looking at the substrate disappearance in Figure 37 and 38 we can separate the proteases in three categories: high (B. megaterium ATCC 14581, B. subtilis 23857, B. brevis 8186, B. stearothermophilus 12980, B. licheniformis 12759, B. cereus 14579, B. amyloliquefaciens 23842 and B. licheniformis 14580) medium (B. stearothermophilus DIFCO and B. coagulans ATCC 7050) and low substrate affinity (B. pumilus ATCC 72, B. subtilis 23059, B. circulans 4513 and B. polymyxa 301).

Experiment conducted by growing Bacillus in UHT milk showed generation of enzymes with similar hydrolytic pattern (Figure 39). Some variations however are observed that may be explained by higher protein content in the sample other than bPG. Enzymes may have higher affinity for proteins other than bPG, explaining why bPG is not as hydrolyzed as when Bacilli are grown in TSB with 5\% UHT. However, it is interesting to notice that most of the Bacillus that were previously categorized as high bPG affinity enzymes producers when grown in TSB with 5\% UHT, will still be recognized as such, as well as the medium and low categories. The most evident difference among these two gels (Figure 37 and 39) is in the hydrolysis of a fragment in the $50 \mathrm{kDa}$ molecular weight range (which we can assume to be PL). Bacillus grown in TSB with 5\% UHT show higher disappearance of this $50 \mathrm{kDa}$ fragment than when grown in UHT only. Additionally, bacillus for which this fragment is not produced (when compared to their activity in TSB-5\% UHT) showed little to no bPG hydrolysis. Again this observation may be explained by presence of proteins other that bPG for which bacillus enzymes show high affinity.

From Figure 37, it is possible to notice that B. coagulans ATCC 7050 resulted in higher angiostatin like fragments generation that also showed higher immunoreaction in western-blotting (Figure 40). This strain was used to produce big and large bands (Figure 41) that were later sent for sequence analysis, which results are shown on Appendix E. The results obtained from sequence analysis resulted somewhat confusing, since chances of K1-4 being produced was higher for peptides obtained in the lower molecular weight range (25-20 kDa) than for bands obtained at molecular weight known to correspond to angiostatin. Perhaps, various kringles combinations with similar molecular weight are being produced by ATCC 7050 enzymes. If this is the case, we will not be able to 
distinguish and identify through sequence analysis the various fragments being obtained. Other procedures should be used to better examine what fragments are being produced.
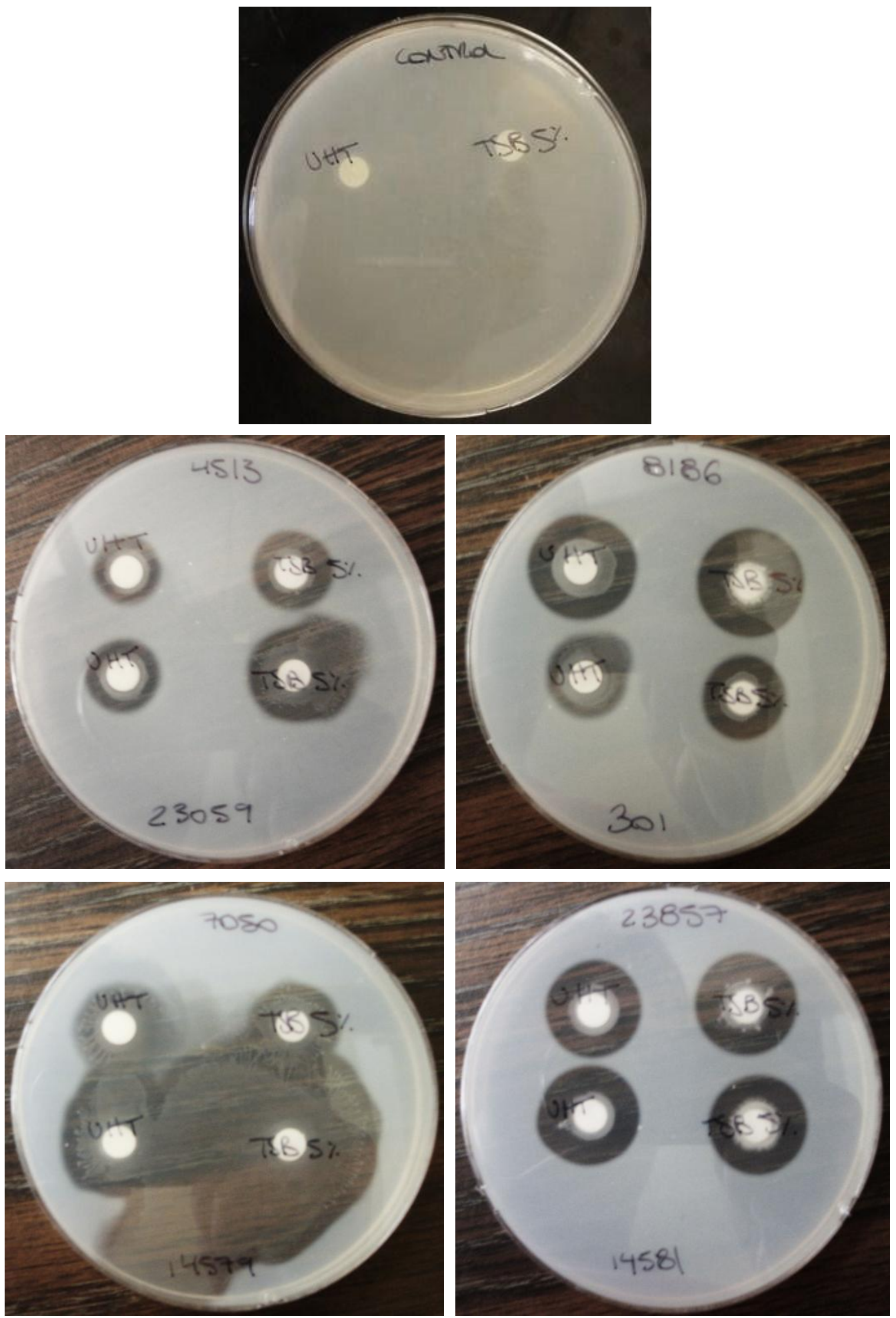

Figure 36: Skim milk agar plates for Bacillus hydrolytic activity analysis after growth in $\mathrm{TSB}+5 \% \mathrm{UHT}$ or UHT for $12 \mathrm{~h}$. 
Table 7: measurements of zone of clearance obtained by the action of Bacillus generated enzymes when incubated in casein skim milk agar plates

\begin{tabular}{|c|c|c|}
\hline Bacillus & $\begin{array}{c}\text { Zone of clearance after } \\
\text { growth in TSB -5\%UHT } \\
(\mathrm{mm})\end{array}$ & $\begin{array}{c}\text { Zone of clearance after } \\
\text { growth in UHT (mm) }\end{array}$ \\
\hline Control & 0 & 0 \\
\hline 4513 & 17 & 20 \\
\hline 23059 & 18 & 26 \\
\hline 8186 & 26 & 20 \\
\hline 301 & 20 & $\approx 20$ \\
\hline 7050 & $\approx 21$ & $>40$ \\
\hline 14579 & $\approx 30$ & 25 \\
\hline 23857 & 24 & 25 \\
\hline 14581 & 25 & \\
\hline
\end{tabular}

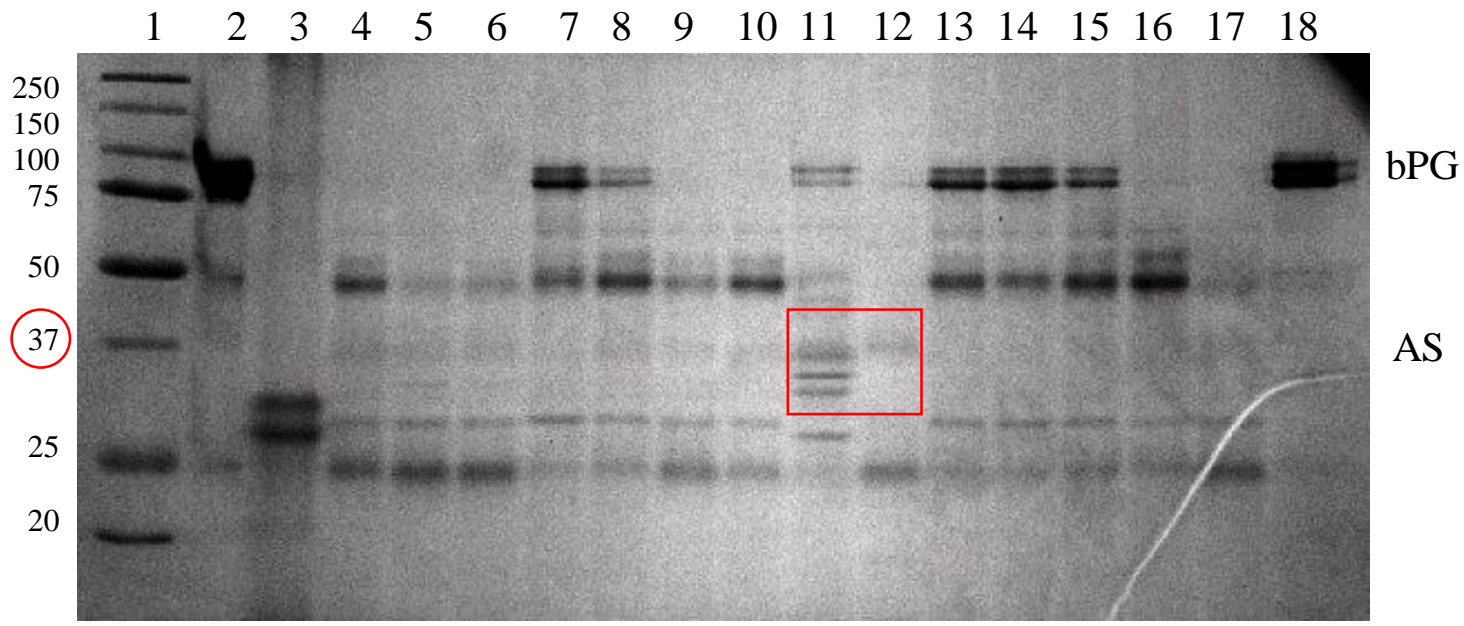

Figure 37: SDS-PAGE analysis of bPG hydrolysis by the action of Bacillus derived proteases when grown in TSB-5\%UHT. Lane 1: molecular weight standard; lane 2: bPG control $(0.2 \mathrm{mg} / \mathrm{ml})$; lane 3: media control (TSB-5\% UHT); lane 4-17: bPG interaction with derived proteases from Bacillus ATCC14581 (lane 4), 23857 (lane5), 8186 (lane 6), 72 (lane 7), DIFCO (lane 8), 12980 (lane 9), 12759 (lane 10), 7050 (lane 11), 14579 (lane 12), 23059 (lane 13), 4513 (lane 14), 301 (lane 15), 23842 (lane 16) and 14580 (lane 17); lane 18: bPG in TSB-5\%UHT control. Fragments in the $37 \mathrm{kDa}$ represent potential angiostatin (AS) fragments. 


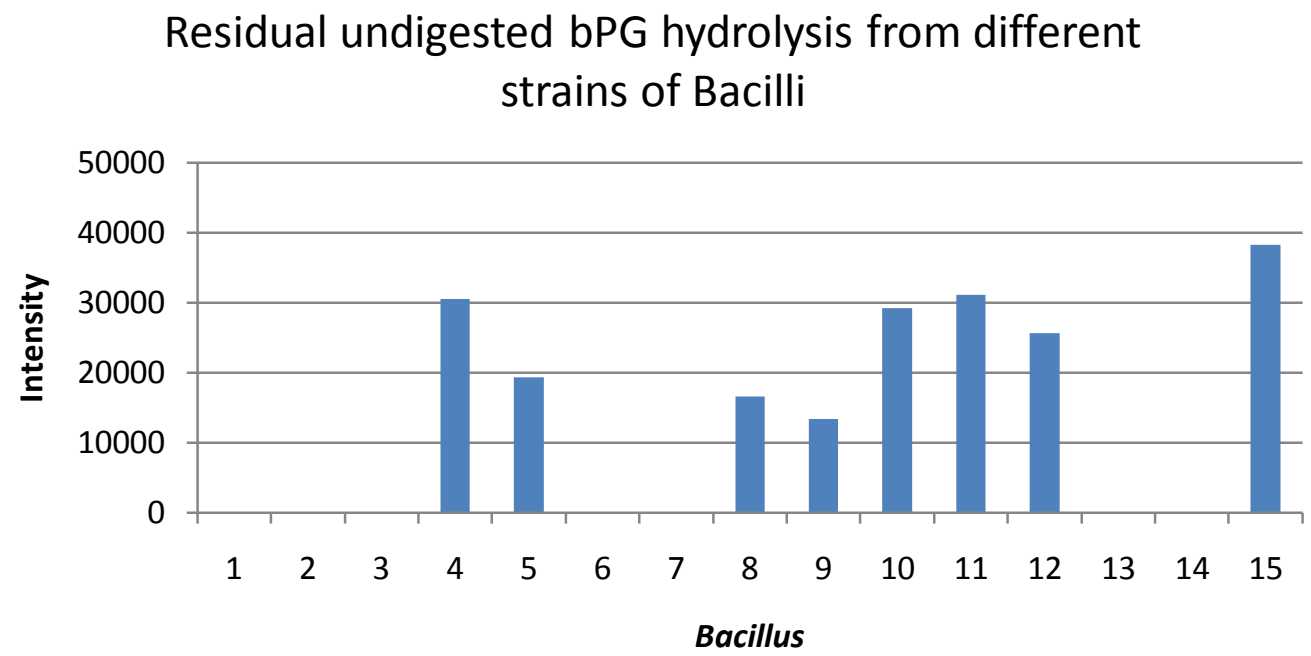

Figure 38: Column chart indicating differences between various Bacilli tested in generating enzymes capable of hydrolyzing bPG. The highest the column the LOWEST the amount of enzymes produced since each column indicates the amount of bPG in solution at the end of the reaction (based on Figure 37). Vice versa, the lower the column the HIGHER the ability of the bacillus in generating bPG hydrolytic enzymes. In order from 1 to 14 the columns represent bPG hydrolyzed by Bacillus ATCC14581 (column 1), 23857 (column 2), 8186 (column 3), 72 (column 4), DIFCO (column 5), 12980 (column 6), 12759 (column 7), 7050 (column 8), 14579 (column 9), 23059 (column 10), 4513 (column 11), 301 (column 12), 23842 (column 13) and 14580 (column 14) respectively; column 15 represents bPG in TSB-5\%UHT control.

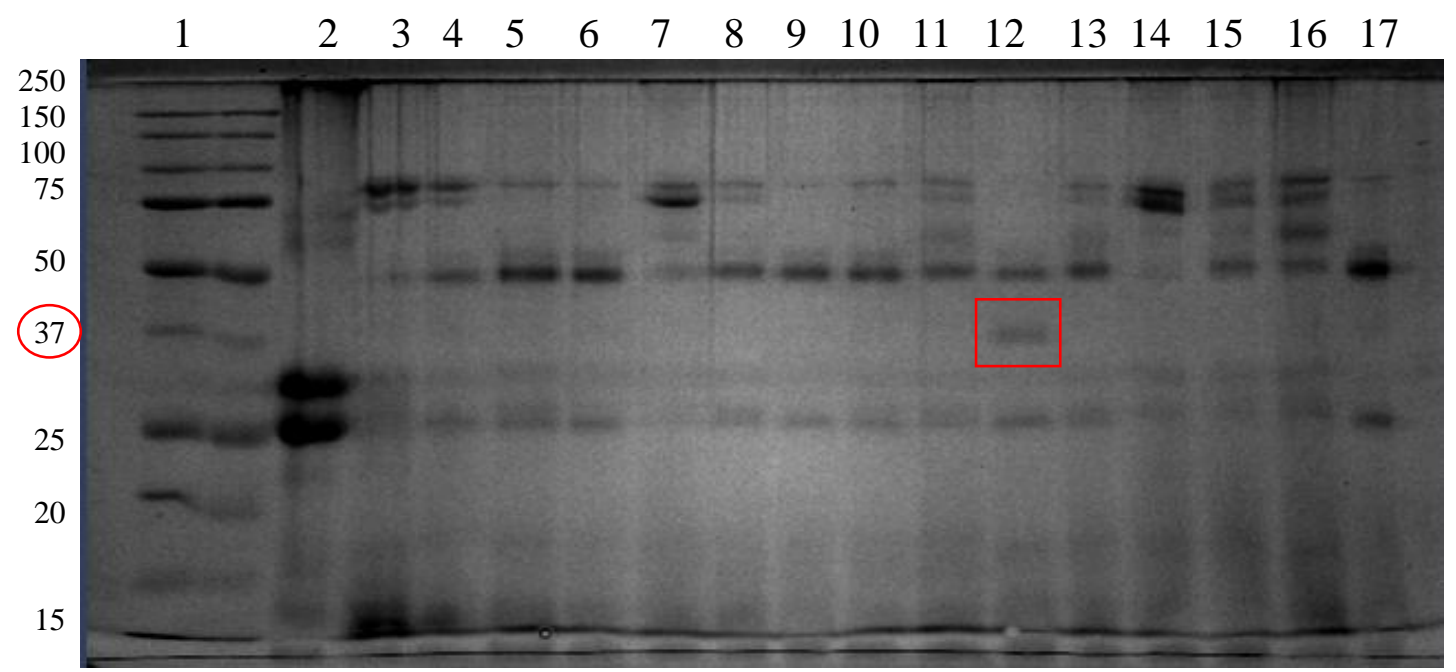

Figure 39: SDS-PAGE analysis of bPG hydrolysis by the action of Bacillus derived proteases when grown in UHT. Lane 1: molecular weight standard; lane 2: media control (UHT 1:5); lane 3: bPG in UHT 1:5 control; lane 4-17: bPG interaction with derived proteases from Bacillus ATCC14581 (lane 4), 23857 (lane 5), 8186 (lane 6), 72 (lane 7), DIFCO (lane 8), 12980 (lane 9), 12759 (lane 10), 7050 (lane 11), 14579 (lane 12), 23059 (lane 13), 4513 (lane 14), 301 (lane 15), 23842 (lane 16) and 14580 (lane 17) respectively. 


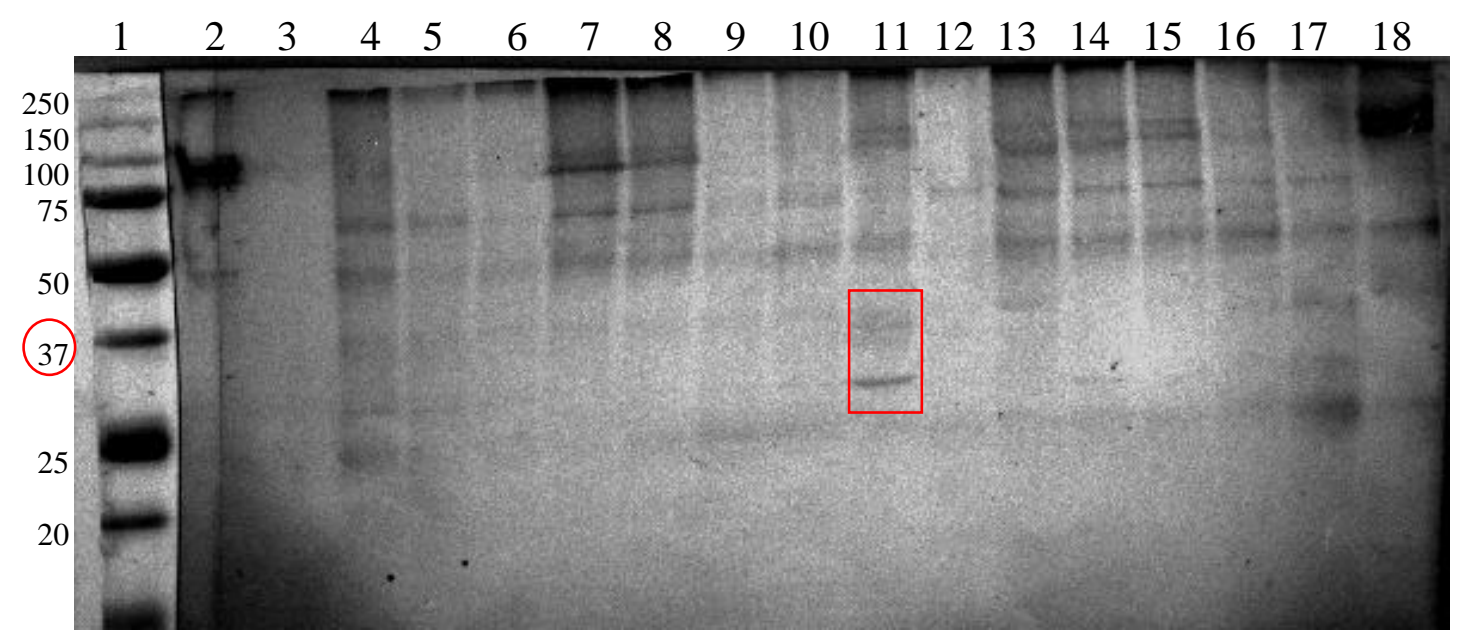

Figure 40: Western blot identification of internal bPG fragments generated by the action of Bacillus produced proteases when grown in TSB-5\%UHT, by using a polyclonal antibovine plasminogen antibody. Lane 1: molecular weight standard; lane 2: bPG control $(0.2 \mathrm{mg} / \mathrm{ml})$; lane 3: media control (TSB-5\% UHT); lane 4-17: bPG interaction with derived proteases from Bacillus ATCC14581, 23857, 8186, 72, DIFCO, 12980, 12759, $7050,14579,23059,4513,301,23842$ and 14580 respectively; lane 18: bPG in TSB$5 \%$ UHT control.

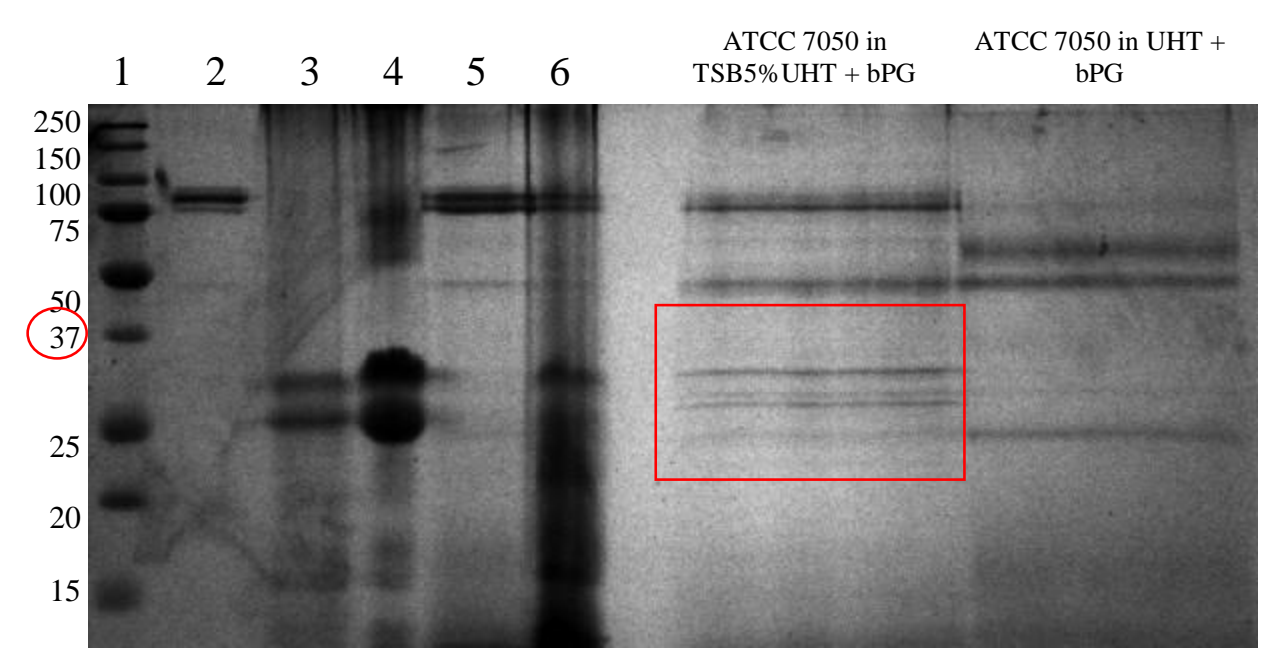

Figure 41: SDS-PAGE produced for sequence analysis of fragments generated through bPG hydrolysis by the action of Bacillus ATCC 7050 grown in TSB-5\% UHT. Lane 1: molecular weight standard; lane 2: bPG control $(0.125 \mathrm{mg} / \mathrm{ml})$; lane 3: media control (TSB-5\%UHT); lane 4: media control (UHT 1:5); lane 5: bPG in TSB-5\%UHT control incubated for 18 hours; lane 6: bPG in UHT control incubated for 18 hours; lane 7: bPG incubated with enzymes generated by bacillus ATCC 7050 after growth in TSB-5\%UHT; lane 8: bPG incubated with enzymes generated by bacillus ATCC 7050 after growth in UHT. 


\subsection{CONCLUSIONS}

Results revealed the ability of various enzymes to generate angiostatin like fragments from bPG in a similar way to angiostatin generation from hPG. Of all the enzymes analyzed BPP and elastase showed higher affinity for bPG and consequent angiostatin generation. B. polymyxa protease however, showed higher affinity for hPG since compared to bPG 10 fold less concentrated enzyme as well as less incubation time were necessary to obtain angiostatin like fragments. On the other hand, elastase was preferred to generate angiostatin from bovine than human PG since angiostatin was the main product of this hydrolysis, and little secondary products were generated compared to hPG. Subsequently, from the examination of Bacillus and Lactobacillus ability in generating proteases during growth, we discovered ability of all Bacillus to produce

proteases capable of hydrolyzing bPG and some even generating angiostatin like fragments, while none of the Lactobacilli analyzed generated enzymes (released or cell wall associated) displaying such characteristic. At this point, it remains to investigate if these bovine angiostatin like fragments generated have anti-cancer activity and how similar it is to that known for human angiostatin. The next chapters will investigate the anticancer activity of bovine angiostatin, and also the ability of this peptide to survive digestive enzymes proteolysis. 


\section{ANTI-CANCER ACTIVITY ANALYSIS OF BOVINE ANGIOSTATIN}

\subsection{ABSTRACT}

Ability of bovine angiostatin in inhibiting malignant melanoma and colon cancerous cells growth was analyzed. This analysis was conducted on in vitro models using SW480 human colon cancer cells lines and reconstructed human malignant melanoma (A375) skin model. For the colon cancer analysis, bovine angiostatin as well as bovine plasminogen (bPG) and the enzyme used to generate angiostatin from bPG (Bacillus polymyxa protease, BPP), were used and anticancer activities analyzed and compared. Results from this investigation showed ability of bovine angiostatin in inhibiting colon cancer cells growth by $100 \%$ when administered at $3 \mu \mathrm{g} / \mathrm{ml}$. Moreover, bPG as well as BPP controls showed some anticancer effect but never reached complete inhibition as the angiostatin treatment. From the second study conducted on melanoma, additionally to bovine angiostatin, bPG and BPP, human angiostatin and human plasminogen (hPG) were also used as controls to allow direct comparison with anticancer activity of that already known for human angiostatin. Findings from this investigation indicate ability of both human and bovine angiostatin as well as human and bovine plasminogen in notably inhibiting the spread of malignant cells when compared to BPP and a negative control. These preliminary results confirm potential similarity between human and bovine angiostatin and their ability in inhibiting cancerous cells.

\subsection{INTRODUCTION}

Angiostatin is recognized as one of the most potent antiangiogenic molecules known to date (Cao Renhai et al. 1999; Wahl Miriam L. et al. 2004). Interestingly angiostatin is not only known to inhibit the development of blood vessels involved in "feeding" a tumor through supply of nutrients and oxygen, but also in causing direct malignant cells necrosis by interacting and inhibiting ATP-synthase, a surface enzyme which function is to maintain a normal internal $\mathrm{pH}$; failure of this enzyme by the action of angiostatin will impede protons inside the cell to escape into the extracellular 
environment causing the internal $\mathrm{pH}$ to decrease compromising the cells survival (Wahl Miriam L. et al. 2005; Figg William D. et al. 2008; Mowery Yvonne M. et al. 2009).

Angiostatin is produced through hydrolysis of fibrinolytic zymogen PG (Wahl Miriam L. et al. 2004). Many are the enzymes that have shown ability in angiostatin generation. Additionally, depending on where plasminogen is hydrolyzed many angiostatin variants are created each showing a specific anti-cancer activity (either ECs proliferation or migration inhibition or direct cancerous cells growth restriction) (Cao Yihai et al. 1996; Ji Weidong-richard et al. 1998; Cao Renhai et al. 1999; MacDonald Nicholas J. et al. 1999; Geiger J. H. et al. 2004).

Interestingly many animals show fibrinolytic systems similar to that of humans, and many of the plasmin system components (from activators to inhibitors) get transferred into milk during milk production (Korycha-Dahl M. et al. 1983; Bastian Eric D. et al. 1996; Ismail B. et al. 2010). It is known that PG from bovine origin shares $78 \%$ homology with hPG. Moreover, average similarity among kringles, the region corresponding to angiostatin, is of $83 \%$ (Schaller J. et al. 1985). Despite the resemblance between human and bovine plasminogen, and the fact that bovine milk is highly consumed in the U.S. and other countries, no in depth research on the potential of bPG in generating angiostatin like fragments with anticancer activity has been studied to date.

From previous studies conducted in our laboratory we confirmed ability of angiostatin to be produced from bPG by the action of a variety of enzymes. The obtained fragments seem to be structurally comparable to that known for human angiostatin. From this study anticancer activity of bovine angiostatin was analyzed through malignant colon and melanoma cells in vitro models. Results demonstrated evident delay in the proliferation of cancerous cells compared to controls when treated both with human and bovine angiostatin and plasminogen. In conclusion, the preliminary results obtained from this study open a new area of research for future development of novel dairy products capable of cancer prevention. 


\subsection{EXPERIMENTAL PROCEDURES}

\subsubsection{REAGENTS AND SOURCES}

Bovine plasminogen (product \# 416), human glu-plasminogen (product \# 412) were purchased from American Diagnostica (Greenwich, CT). Dispase I (BPP) (product \# D4818) was purchased from Sigma-Aldrich (St. Louis, MO).

\subsubsection{Inhibition of cancerous cells growth by the action of angiostatin}

In order to determine possible anti-cancer activity of angiostatin produced from bPG hydrolysis by the action of B. polymyxa protease, inhibition of malignant colon cancer cells as well as melanoma growth was analyzed. Controls such as human angiostatin and plasminogen alone (both from human and bovine sources) were used.

\subsubsection{Preparation of angiostatin for colon cancerous cells inhibition analysis}

Three samples, one treatment and two controls, were prepared and tested on SW480 human colon cancer cells which was conducted at Teagasc, the Agriculture and Food Development Authority, in Oak Park, Carlow, Ireland.

Solution of bPG alone at a final concentration of $0.375 \mathrm{mg} / \mathrm{ml}(4.26 \mu \mathrm{M})$ and BPP containing a total of $0.075 \mathrm{mg} / \mathrm{ml}(2.08 \mu \mathrm{M})$ protein were used as controls in $2 \%$ NFDM. The treatment was prepared by reacting $1: 1(\mathrm{v} / \mathrm{v})$ ratio $\mathrm{bPG}(1 \mathrm{mg} / \mathrm{ml}, 11.36 \mu \mathrm{M})$ and BPP $(0.1 \mathrm{mg} / \mathrm{ml}, 2.78 \mu \mathrm{M})$ at $37^{\circ} \mathrm{C}$ for 1 hour. Subsequently, $2 \%$ NFDM was added to the total bPG-BPP volume to have a final concentration of the substrate and the enzyme similar to that of the controls. Samples were boiled for 5minutes to stop the reaction and stored at $15^{\circ} \mathrm{C}$ until analysis.

\subsubsection{Angiostatin for melanoma inhibition activity samples preparation}

Samples tested for melanoma growth inhibition, included hPG as a control and human angiostatin generated from BPP. Human PG and bPG controls were both prepared 
to a final concentration of $0.164 \mathrm{mg} / \mathrm{ml}(1.86 \mu \mathrm{M})$ in ddwater. Human angiostatin was prepared by incubating $\mathrm{hPG}(1 \mathrm{mg} / \mathrm{ml}, 11.36 \mu \mathrm{M})$ with BPP $(0.025 \mathrm{mg} / \mathrm{ml}, 0.69 \mu \mathrm{M})$ at $1: 1$ $(\mathrm{v} / \mathrm{v})$ ratio for 30 minutes at $37^{\circ} \mathrm{C}$; ddwater was then added to dilute samples to a final concentration of $0.164 \mathrm{mg} / \mathrm{ml}(1.86 \mu \mathrm{M})$ for $\mathrm{hPG}$ and $0.0041 \mathrm{mg} / \mathrm{ml}(113.89 \mathrm{nM})$ for BPP (these dilutions were chosen since not possible to directly quantify the amount of plasminogen present at the end of the reaction, we assumed all fragments belonging to

plasminogen after being hydrolyzed would equal the amount of plasminogen in the control and allow comparison of the results obtained). Bovine angiostatin was prepared by incubating bPG $(1 \mathrm{mg} / \mathrm{ml}, 11.36 \mu \mathrm{M})$ with BPP $(0.1 \mathrm{mg} / \mathrm{ml}, 2.78 \mu \mathrm{M})$ for 1 hour at $37^{\circ} \mathrm{C}$ at 1:1 ratio. Similarly to human angiostatin, samples were diluted with ddwater in order to obtain a total final concentration of $0.164 \mathrm{mg} / \mathrm{ml}(1.86 \mu \mathrm{M})$ for $\mathrm{bPG}$ and $0.0164 \mathrm{mg} / \mathrm{ml}$ $(455.56 \mathrm{nM})$ of BPP. Samples were diluted in order to obtain similar protein content in each sample and allow comparison in anticancer activity. BPP control was prepared by using the highest concentration of the enzyme used to prepare bovine angiostatin $(0.0164$ $\mathrm{mg} / \mathrm{ml}, 455.56 \mathrm{nM})$.

The experiment on melanoma cells was conducted at the department of Biomedical Engineering at California Polytechnic State University, were melanoma skin model tissues (MatTek, Ashland, MA) were incubated with their respective sample (which were further diluted in $5 \mathrm{ml}$ buffer prior to melanoma specimen treatment) every other day for a two-week period of time. If we take into account also this final dilution, the real final concentration at which bPG and hPG were analyzed is $0.0164 \mathrm{mg} / \mathrm{ml}$ (186.4nM) (approximately 9 times more concentrated than the average amount of bPG in milk (1.8 $\mu \mathrm{g} / \mathrm{ml}, 20.45 \mathrm{nM})$ (Ismail B. et al. 2010)).

\subsection{RESULTS AND DISCUSSION}

\subsubsection{COLON CANCER INHIBITION}

According to the graph in Figure 42, we can observe that angiostatin treatment caused $100 \%$ growth inhibition of cancerous cells when administered at a concentration of approximately $3 \mu \mathrm{g} / \mathrm{ml}$ (concentration of PG in milk is between $0.8-2.8 \mu \mathrm{g} / \mathrm{ml}$ ). On the 
other hand, controls, which are also present in the treatment since not pure but at a much lower concentration, showed also some cytotoxicity however not as high as inhibition caused by angiostatin.

\section{Cytotoxicity of liquid samples on SW480 colon cancer}

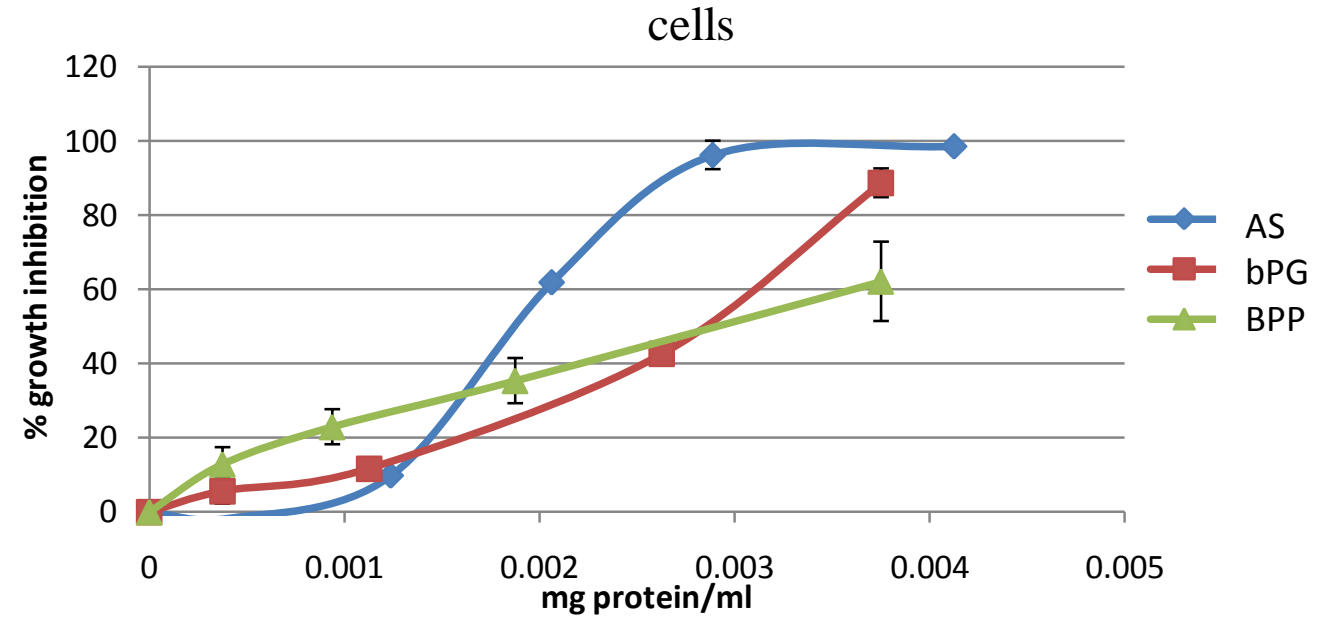

Figure 42: graph illustrating ability of various samples tested for their ability in inhibiting colon cancer cells growth. Samples tested were angiostatin (AS) generated through bPG and BPP incubation for 1 hour at $37^{\circ} \mathrm{C}$, bPG control as well as BPP control in a $2 \%$ NFDM solution.

The exact mechanism of action through which angiostatin from bPG inhibits colon cancer cells development is not yet known, however based on previous experiments conducted on human angiostatin we can hypothesize that bovine angiostatin may interact with the ATP-synthase located on the surface of colon cancer cells causing internal $\mathrm{pH}$ to decrease and consequent acidification compromising the cells survival.

As seen in other studies, inhibition caused by bPG may be explained by potential proteases released by cancerous cells during growth that may interact and cut the protein into angiostatin like fragments responsible for the activity observed (Cao Renhai et al. 1999; Soff Gerald A. 2000; Migita Toshiro et al. 2001). However, since to date no anticancer activity on either bovine plasminogen or angiostatin has been studied, it is also possible that other mechanism of actions may be involved; perhaps some dissimilarity between human and bovine sources cause these molecules to act on different targets. 
Dispase is commonly used to separate epidermis from the dermis and it is known to hydrolyze collagen and fibrin (Stenn Kurt S. et al. 1989). Additionally, this metalloproteinase is known to be produced by the action of Bacillus polymyxa during milk storage (Matta Hittu et al. 1998; Larson N. K. et al. 2006). However, no recognized anticancer activity has ever been associated with BPP to date. Possibly, BPP modest anticancer activity shown in this study may be due by some inhibitory activity not yet studied, or since it is known that dispase inhibits cells clumping (Roche, Worthington) perhaps this enzyme reduces contact between cancerous cells diminishing their ability to communicate or exchange information required for their growth.

Despite the exciting results obtained from this study, more investigation is required to better understand the mechanism of action behind the anticancer activity observed, particularly in the case of bPG and bovine angiostatin.

\subsubsection{MELANOMA INHIBITION}

Results from the melanoma skin model are summarized in Figure 43. Interestingly, many similarities can be perceived to the results obtained for the colon cancerous cells inhibition analysis. In fact, comparison of images A, B, D and F in Figure 43 confirms BPP (B), bovine angiostatin (F) and bPG (D) to display different inhibition degrees when compared to the negative control (A), with bovine angiostatin and bovine plasminogen showing higher anticancer activity. The same explanations as previously provided for the results obtained in the colon cancer analysis, can be applied in this case for elucidating the observations obtained in this study.

Interesting is to observe that human and bovine angiostatin as well as plasminogen act in a very similar way. As we can observe from the images below it is not possible to identify or confirm which of these molecule showed higher inhibitory activity.

Lee et al. (1998) showed ability of human angiostatin in increasing human melanoma apoptosis in mice (Lee Tong-Young et al. 2009; Mowery Yvonne M. et al. 2009). According to Lee et al., angiostatin causes a reduced expression of Bcl-2 (a mitochondrial antiapoptotic protein) consequently increasing the apoptosis rate. The 
observations made by Lee et al. may explain the observation made in our study. However, further research is necessary before confirming any conclusion.

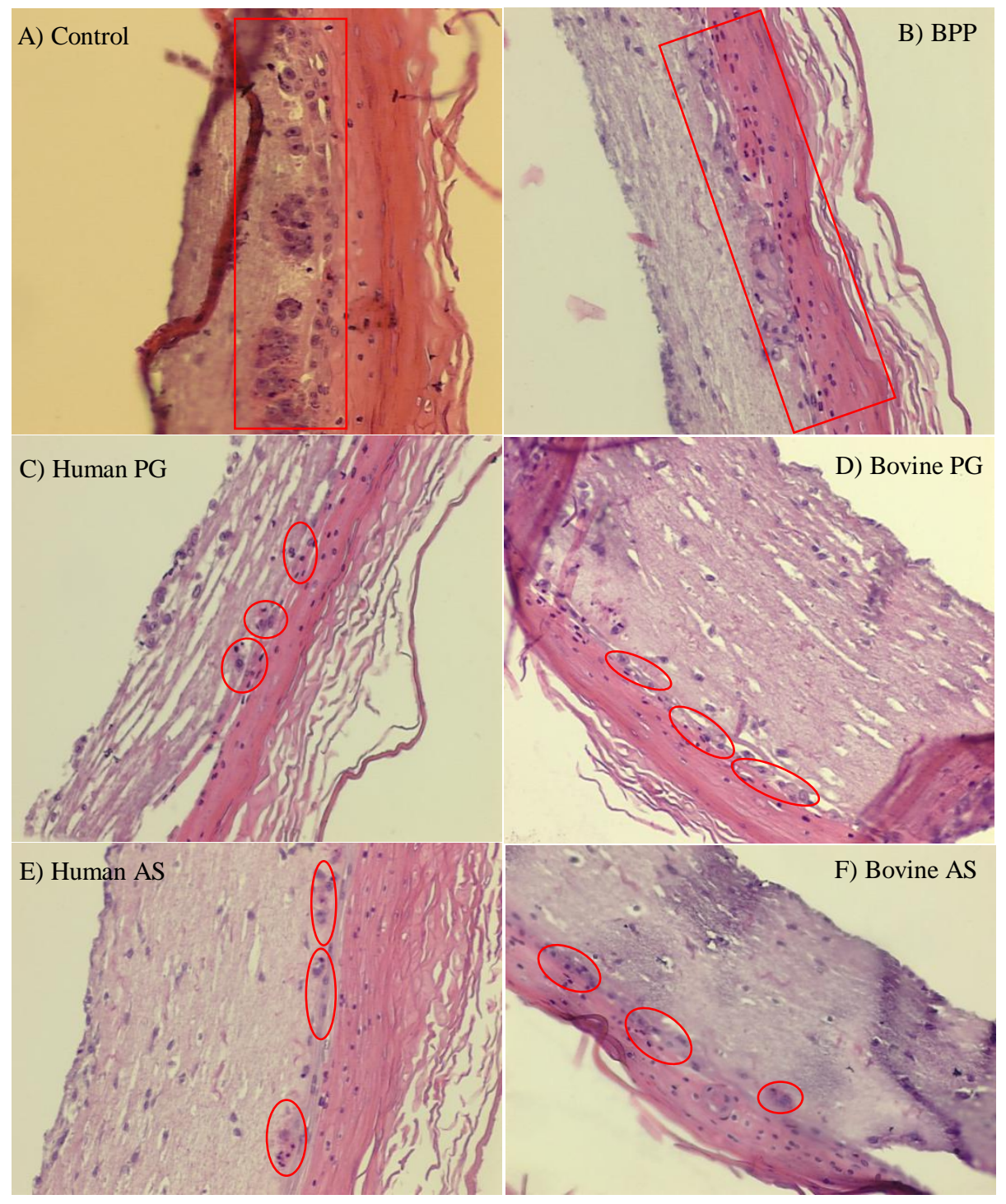

Figure 43: Melanoma growth inhibition analysis. A) Malignant cells control treated with $5 \%$ SDS; B) analysis of BPP control activity on melanoma cells proliferation; C-D) human and bovine plasminogen ability in inhibiting melanoma proliferation; E-F) melanoma sample treated with angiostatin (AS) generated by the reaction between BPP and human or bovine plasminogen respectively. 


\subsection{CONCLUSION}

The results obtained from the anticancer activity analysis confirm ability of angiostatin from bovine source to notably inhibit cancerous melanoma and colon cells proliferation when administered at a concentration of $3-16 \mu \mathrm{g} / \mathrm{ml}(34-182 \mathrm{nM})$. The exact mechanism of action has not been investigated as yet, however due to the similarity in the anticancer activity results between human and bovine angiostatin, we can assume bovine angiostatin to act through a mechanism similar to that known for human (ATP-synthase inhibition, Bcl-2 increase, etc.). Moreover, it would be of interest to understand the mechanism behind the anticancer activity seen in plasminogen (both human and bovine). If true that enzymes are being produced from cancerous cells responsible for cleaving PG and releasing angiostatin, understanding the nature if these enzymes could be of interest to determine if bPG could be generated directly from i.e. bacteria in our intestine or other enzymes, during milk digestion for example. Other important questions need to be examined, such as the ideal PG or angiostatin concentration, as well as treatment duration, in order to determine optimal conditions for eventual analysis on animal models. Also, would angiostatin be able to survive digestion? And if it does, would the body absorb this molecule, or other methods (such as encapsulation) would be necessary to ensure angiostatin delivery to its target cells if we were to develop a dairy product enriched in this peptide? Some of the answers to these questions were analyzed and uncovered in the following chapter. 


\section{ANGIOSTATIN IN VITRO DIGESTION SURVIVAL ANALYSIS AND ANGIOSTATIN PURIFICATION METHODS}

\subsection{ABSTRACT}

In order to analyze angiostatin's ability in surviving digestive enzymes activity, angiostatin in buffer or milk system was incubated at stomach as well as small intestine simulated conditions. In vitro digestive model was used, as well as investigation on ability of each individual digestive enzyme (pepsin, lipase and pancreatin) in hydrolyzing the internal bovine plasminogen (bPG) structure at different enzyme:substrate ratios (E:S). Results were analyzed through western blotting and sodium dodecyl sulfate polyacrylamide gel electrophoresis (SDS-PAGE) techniques. Pepsin showed high affinity for angiostatin at E:S ratios of 12:1 used in the in vitro digestion model; however hydrolysis was not significant up to a ratio of 1:10 when the enzyme was individually analyzed for its affinity for the anticancer peptide, which may represent a more realistic proportion. Pancreatin also showed some affinity for angiostatin when independently tested; particularly a fragment in the $25 \mathrm{kDa}$ with high immuno-reactivity to anti-bovine plasminogen antibody was identified. Knowing that pancreatin consists in a mixture of enzymes, mostly trypsin and $\alpha$-chymotrypsin, activity of these latter were separately tested and results indicated trypsin to have very low affinity for angiostatin, while $\alpha$ chymotrypsin showed ability in hydrolyzing the fragment of interest even at ratios of 1:50. Interestingly, the two enzymes generated fragments in the $25 \mathrm{kDa}$ range from bPG hydrolysis. These results indicated that not only angiostatin could survive digestion but also digestive enzymes (trypsin and $\alpha$-chymotrypsin) could be generating angiostatin related fragments during digestion. Moreover, bovine angiostatin purification was conducted through L-lysine affinity chromatography. Results from this experiment confirm efficacy of this method to obtain a pure angiostatin solution. 


\subsection{INTRODUCTION}

Angiostatin is a peptide generated through bPG hydrolysis from a variety of enzymes. Interestingly this protein can assume a variety of forms based on the enzyme used to cut and release the internal portion of interest from bPG. This molecule has gained increased attention since its discovery in 1994, for its potent ability in inhibiting the development of new blood vessels from pre-existing vascularization (this mechanism is known as angiogenesis) that would otherwise reach a tumor and support its growth and spread through delivery of nutrients and oxygen (O'Reilly Michael S. et al. 1994; Cao Yihai et al. 1996; O'Reilly Michael S. et al. 1996; Cao Renhai et al. 1999; Wahl Miriam L. et al. 2004; Wahl Miriam L. et al. 2005). Various forms of angiostatin or portions of bPG have shown different anticancer mechanism. Due to the success seen in preliminary studies in animal models, angiostatin is now in clinical trials (Cao Renhai et al. 1999; Wahl Miriam L. et al. 2004). Interestingly, PG is found in the blood of most animals since its function, when activated into plasmin, is to hydrolyze blood clots created by fibrin. In fact, for a long time methods to inhibit PL activity, that gets transferred from the blood of the cow into milk during milk production, have been investigated since this enzyme can be responsible for spoilage and reduced quality of many dairy products (Bastian Eric D. et al. 1996; Ismail B. et al. 2010). However, no in depth research on the ability of bovine plasminogen in being hydrolyzed into anticancer peptides has been conducted to date. In our laboratory, we have shown ability of various proteases in generating angiostatin like fragments from $\mathrm{bPG}$, and for which in vitro anticancer activity resulted to be comparable to that known for human angiostatin. From this study we are now further analyzing ability of bovine angiostatin, both in buffer and milk systems, to survive digestion. In vitro digestion model from Ferruzzi et al. (2001) was used. However, due to incongruity in the information available describing the enzymes involved in human digestion and the concentration at which they are released in the stomach and small intestine, pepsin, tryspin and $\alpha$-chymotrypsin were individually tested at various E:S ratios. Additionally, ability of these enzymes to generate angiostatin or related kringles directly from bPG has been investigated. 


\subsection{EXPERIMENTAL PROCEDURES}

\subsubsection{REAGENTS AND SOURCES}

Bovine plasminogen (product \# 416), human glu-plasminogen (product \# 412) goat antibovine plasminogen (product \# 3416) were purchased from American Diagnostica (Greenwich, CT). Dispase I (BPP) (product \# D4818), elastase from human leukocytes (product \# E8140) 3,3'-diaminobenzidine tetrahydrochloride hydrate (DAB) (product \# D5637), lipase from porcine pancreas (product \# L3126), pepsin from porcine gastric mucosa (product \# P7000), bile extract porcine (product \# B8631), trypsin from porcine pancreas (product \# T7409), pancreatin from porcine pancreas (product \# P1750), $\alpha$ chymotrypsin from bovine pancreas (product \# C3142), Cyanogen bromide (product \# C91492), L-lysine (product \# L5501), sepharose (product \# 6B100), ethanolamine (product \# E9508) and 6-aminocaproic acid (product \# A2504) were purchased from Sigma-Aldrich (St. Louis, MO). Peroxidase AffiniPure Goat Anti-Rabbit IgG (H+L) (product \# 111-035-003) and Peroxidase Affinipure Rabbit Anti-Goat IgG (H+L) (product \# 305-035-003) were purchased from Jackson ImmunoResearch Laboratories (West Grove, PA). The following electrophoresis and Western blotting reagents and materials were purchased from Bio-Rad Laboratories (Hercules, CA): Bio-scale MT columns (product \# 751-0083), 40\% Acrylamide/Bis solution (product \# 161-0148), Coomassie Brilliant Blue R-250 Staining Solution (product \# 161-0436), Precision Plus Protein All Blue Standards ( product \# 161-0373), 12 and 18 wells Criterion empty cassettes (product \# 345-9901 and 345-9902), Tris/Glycine/SDS 10X (product \# 1610772), Laemmli sample buffer (product 161-0737), tetramethylethylenediamine (TEMED, product \# 161-0800), Bio-Dot/Bio-Dot SF Filter Paper (product \# 162-0161) and Sequi-Blot PVDF $0.2 \mu \mathrm{m}$ membrane (162-0184) as well as the Bio-scale column for protein purification (product \# 751-0083). Ammonium Persulfate (APS, product \# BP179-100), Tween 20 (product \# BP 337-500), Granular gelatin (product \# G8-500) were purchased from Fisher Scientific (Hanover Park, IL). 


\subsubsection{PART 1: ANGIOSTATIN IN VITRO DIGESTION SURVIVAL ANALYSIS}

\subsubsection{IN VITRO DIGESTION MODEL}

In order to determine ability of angiostatin to survive digestion, stomach and small intestine conditions were simulated in vitro. Various protocols were used and adapted to the protein concentration of the sample in order to have the most accurate E:S ratio that would normally occur in the digestive system. First, in vitro digestion was conducted following the model outlined by Ferruzzi et al.(2001) (Green Rodney J. et al. 2007). One $\mathrm{ml}$ of angiostatin solution was first prepared by incubating $0.875 \mathrm{mg} / \mathrm{ml}(9.94$ $\mu \mathrm{M}) \mathrm{bPG}$ with $0.1 \mathrm{mg} / \mathrm{ml}(2.78 \mu \mathrm{M}) \mathrm{BPP}$ for 1 hour at $37^{\circ} \mathrm{C}$. At the end of the reaction $50 \mu 1$ of EDTA were added to the sample which was then boiled for 5 minutes, in order to ensure BPP inhibition to avoid further hydrolysis over time that may affect the following steps of the experiment. The solution was transferred into a $15 \mathrm{ml}$ falcon tube and $0.9 \%$ $\mathrm{NaCl}$ were added to obtain a $1.5 \mathrm{ml}$ solution volume. The gastric phase was then initiated by addition of $0.15 \mathrm{ml}$ of $40 \mathrm{mg} / \mathrm{ml}(1.16 \mathrm{mM})$ pepsin solution previously prepared in 0.1 $\mathrm{M} \mathrm{HCl}$. The $\mathrm{pH}$ was adjusted to $2.0( \pm 0.1)$ by addition of $0.1-1 \mathrm{M} \mathrm{HCl}$. Nitrogen gas was flushed on top of the tube, which was subsequently sealed and covered in aluminum foil to avoid light penetrating the tube. The sample was incubated for 1 hour at $37^{\circ} \mathrm{C}$ and vortexed at low speed every 20 minutes.

Subsequently, the small intestinal phase was initiated by neutralization of the gastric digesta to a $\mathrm{pH}$ of 5.3 through addition of $1 \mathrm{~N} \mathrm{NaOH}$. Small intestinal enzymes were then added: $0.23 \mathrm{ml}(24 \mathrm{mg} / \mathrm{ml})$ bile extract, $0.115 \mathrm{ml}(4 \mathrm{mg} / \mathrm{ml})$ pancreatin and $0.115 \mathrm{ml}(2 \mathrm{mg} / \mathrm{ml}, 44.44 \mu \mathrm{M})$ of lipase in $100 \mathrm{mM} \mathrm{NaHCO}$. The final $\mathrm{pH}$ was further adjusted to $7.2( \pm 0.1)$ by addition of $0.1 \mathrm{M} \mathrm{NaOH}$, additionally the final volume was regulated to $2.5 \mathrm{ml}$ by addition of $0.9 \% \mathrm{NaCl}$. The sample was then incubated in the dark at $37^{\circ} \mathrm{C}$ for 2 hours and vortexed every 30 minutes. Prior to analysis, 1:1 Laemmli buffer was added and the sample was boiled for approximately 5 minutes and angiostatin survival was analyzed through western blotting. Angiostatin digestion was also tested when in presence of milk in order to determine whether presence of other peptides in the solution would protect angiostatin from being hydrolyzed. 


\subsubsection{Ability of individual digestive enzymes in hydrolyzing angiostatin}

After stomach and small intestine in vitro digestion analysis, enzymes responsible for angiostatin hydrolysis were identified by testing every enzyme individually always following the procedures outlined and described by Ferruzzi et al. (2001) and ensuring the same E:S ratio for each enzyme tested is maintained in all samples analyzed. Briefly, for gastric phase, and thus analysis of pepsin hydrolytic activity on angiostatin, $100 \mu 1$ angiostatin containing sample was incubated with $15 \mu$ l of pepsin $(40 \mathrm{mg} / \mathrm{ml}, 1.16 \mathrm{mM})$ and $50 \mu 10.9 \% \mathrm{NaCl}$ were added to the solution that was adjusted to a final $\mathrm{pH}$ of 2.0 and incubated at $37^{\circ} \mathrm{C}$ for 1 hour. In a similar way $100 \mu$ of angiostatin were added to: 11.5 $\mu 1$ of pancreatin $(4 \mathrm{mg} / \mathrm{ml})$, to $11.5 \mu \mathrm{l}$ of lipase $(2 \mathrm{mg} / \mathrm{ml}, 44.44 \mu \mathrm{M})$ and to $25 \mathrm{ul}$ of bile (24 $\mathrm{mg} / \mathrm{ml}$ ) respectively. These solutions were adjusted to $\mathrm{pH} 7.2$ and the reaction was conducted at $37^{\circ} \mathrm{C}$ for 2 hours. Samples were diluted with 1:1 (v/v) Laemmli buffer and analyzed through western-blot.

Addition of skim milk or NFDM to angiostatin samples in order to analyze the effect of presence of additional proteins in protecting angiostatin from being hydrolyzed were also studied (experiment procedures are summarized in Figure 44).

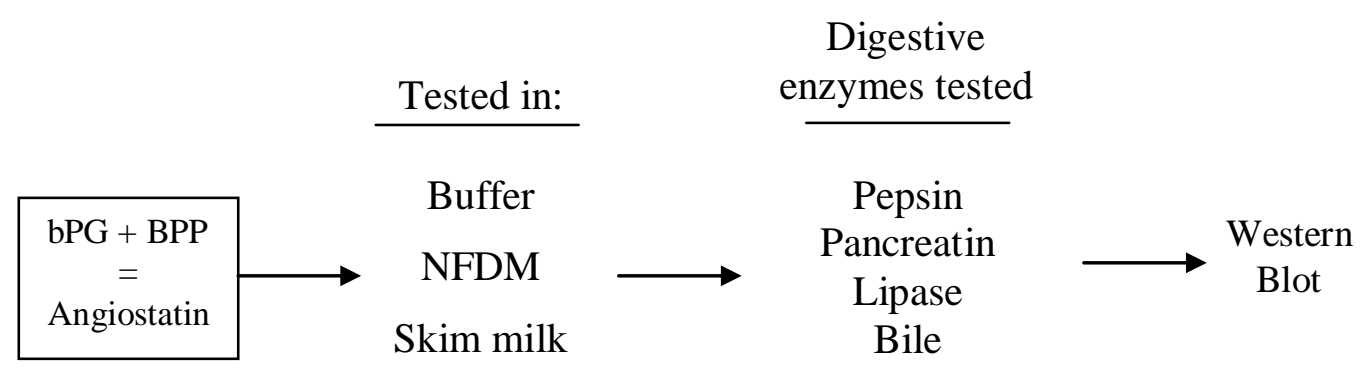

Figure 44: experiment procedure scheme for analysis of individual digestive enzymes capacity in hydrolyzing angiostatin and the different solutions in which the investigation was conducted 


\subsection{VARIOUS E:S RATIOS ANALISIS FOR PEPSIN, TRYPSIN AND $\alpha$ - CHYMOTRYPSIN}

Various concentrations of pepsin, trypsin and $\alpha$-chymotrypsin were reacted with angiostatin in order to analyze the kinetics and the hydrolytic pattern of each enzyme.

For pepsin digestion, procedures from Astwood et al. (1996) and Fu et al. (2002) with some modifications were followed. Simulated gastric fluid (SGF) was prepared (3.2 $\mathrm{mg} / \mathrm{ml}(92.5 \mu \mathrm{M})$ pepsin in $0.03 \mathrm{M} \mathrm{NaCl} \mathrm{pH} 1.2)$. In a $1.5 \mathrm{ml}$ Eppendorf tube $130 \mu \mathrm{l}$ of SGF were heated to $37^{\circ} \mathrm{C}$. Subsequently angiostatin was added to obtain a final E:S ratio of 12:1 (w/w) (similar to that previously analyzed by Ferruzzi et al.) (Astwood James D. et al. 1996; Fu Tong-Jen et al. 2002). Samples were incubated at $37^{\circ} \mathrm{C}$ and collected after $0,1,5,10,15,20,30,60$ minutes and diluted in 1:1 Laemmli buffer. Pepsin ability in digesting angiostatin was also tested at E:S ratios of 1:100, 1:50, 1:25 and 1:10 (w/w) and samples were taken after 1, 5, 10, 15, 20 and 30 minutes incubation and analyzed through gel electrophoresis (Sathe Shridhar K. et al. 1997; Roufik Samira et al. 2006).

Results obtained from the in vitro digestion by individual digestive enzymes previously described in section 4.3.2.2, showed pancreatin to exert some hydrolytic activity on angiostatin. Since pancreatin is known to be a mixture of trypsin, amylase, lipase and other enzymes, in order to better identify which of these proteases is responsible for the hydrolysis seen from previous analysis, trypsin and chymotrypsin, since two of the major proteolytic digestive enzymes, were individually tested on angiostatin and PG breakdown. Various E:S ratios were tested based on Bodwell et al. (1980), Sathe et al. (1997) and Roufik et al. (2006) procedures. Briefly, various Trypsin or $\alpha$-Chymotrypsin concentrations were prepared in digestion buffer $(0.05 \mathrm{M}$ Tris- $\mathrm{HCl}$ and 0.01M CaCl2 $\mathrm{pH} 8.1$ (Sathe Shridhar K. et al. 1997)) and incubated with angiostatin at $37^{\circ} \mathrm{C}$ for 1 hour. SDS-PAGE as well as western blot were conducted to analyze the products obtained from the reaction. Tables 8 and 9 summarize the concentrations used for samples preparation. 
Table 8: Enzyme-substrate ratios used to test ability of trypsin in digesting angiostatin

\begin{tabular}{|c|c|c|}
\hline E:S (w/w) analyzed & $\begin{array}{c}\text { Trypsin (final) } \\
\mathrm{mg} / \mathrm{ml}\end{array}$ & $\mathrm{mg} / \mathrm{ml}$ AS (final) \\
\hline $1: 50$ & 0.0067 & 0.333 \\
\hline $1: 20$ & 0.0167 & 0.333 \\
\hline $1: 13$ & 0.025 & 0.333 \\
\hline $1: 10$ & 0.033 & 0.333 \\
\hline $1: 8$ & 0.04167 & 0.333 \\
\hline $1: 6$ & 0.05 & 0.333 \\
\hline $1: 5$ & 0.0583 & 0.333 \\
\hline $1: 3$ & 0.1 & 0.333 \\
\hline $1: 1$ & 0.25 & 0.25 \\
\hline $3: 1$ & 0.5 & 0.1667 \\
\hline $5: 1$ & 0.333 & 0.0667 \\
\hline $10: 1$ & 0.333 & 0.033 \\
\hline
\end{tabular}

Table 9: Enzyme-substrate ratios used to test ability of $\alpha$-chymotrypsin in digesting angiostatin

\begin{tabular}{|c|c|c|}
\hline $\begin{array}{c}\text { E:S (w/w) } \\
\text { analyzed }\end{array}$ & $\begin{array}{c}\mathrm{mg} / \mathrm{ml} \text { Chymotrypsin } \\
\text { (final) }\end{array}$ & $\mathrm{mg} / \mathrm{ml}$ AS (final) \\
\hline $1: 100$ & 0.004 & 0.4 \\
\hline $1: 50$ & 0.0067 & 0.333 \\
\hline $1: 20$ & 0.0167 & 0.333 \\
\hline $1: 10$ & 0.033 & 0.333 \\
\hline $1: 5$ & 0.0667 & 0.333 \\
\hline $1: 3$ & 0.1 & 0.333 \\
\hline $1: 1$ & 0.25 & 0.25 \\
\hline
\end{tabular}

4.3.3 Ability of digestive enzymes in producing angiostatin through plasminogen hydrolysis

Analysis of trypsin and $\alpha$-chymotrypsin hydrolytic products generated from bPG breakdown was examined. Similarly to the experiment conducted for angiostatin, various $E: S$ ratios were used to determine the affinity of these enzymes for the substrate and also to investigate the kinetics of the reaction. Enzyme-substrate ratios of 1:150, 1:75, 1:30, $1: 15,1: 7.5,1: 5$ and 1:1.5 were prepared for both trypsin an $\alpha$-chymotrypsin and incubated 1 hour at $37^{\circ} \mathrm{C}$. Products obtained from this reaction were analyzed through SDS-PAGE and western blotting. 


\subsubsection{PART 2: ANGIOSTATIN PURIFICATION}

Purification of angiostatin was conducted through L-lysine sepharose column chromatography following procedures outlined by Cao et al. with some modifications (Cao Yihai et al. 1996).

First, the column was prepared by activating sepharose hydroxyl groups with $\mathrm{CNBr}$ to allow binding to the L-lysine ligands' amino groups. Briefly, $10 \mathrm{ml}$ of sepharose were washed with $1 \mathrm{~L}$ of ddwater by vacuum filtration and resuspended in $18 \mathrm{ml}$ ddwater. Two $\mathrm{ml}$ of $0.5 \mathrm{M}$ sodium carbonate buffer $\mathrm{pH} 10.5$, were then added and the solution was slowly stirred. Under the hood, $1.5 \mathrm{~g}$ of $\mathrm{CNBr}$ were weighted and added to the stirred sepharose ensuring that the $\mathrm{pH}$ was being maintained between 10.5 and 11 at all times using $4 \mathrm{M} \mathrm{NaOH}$. Once the $\mathrm{pH}$ has stabilized and all the $\mathrm{CNBr}$ dissolved (approximately 8 min reaction) the solution was filtered using a Buchner funnel, and washed with $2 \mathrm{~L}$ of cold 0.1M sodium bicarbonate buffer pH 9.0 (Mallia A. Krishna et al. 1992; Walker John M. 1996). At this point the washed sepharose solution was suspended in $0.1 \mathrm{M} \mathrm{NaHCO}_{3}$ $\mathrm{pH} 9.0$ in a volume equal to that of the original sepharose $(10 \mathrm{ml})$. At this time, the hydroxyl groups are activated and have high affinity for amino groups. L-lysine was subsequently added to the solution at a concentration representing $12 \%$ of the final volume (1.2g L-lysine which equal $0.008 \mathrm{~mol} / 10 \mathrm{ml})$ under constant stirring at $4^{\circ} \mathrm{C}$ for 24 hours. The coupled gel obtained was extensively washed with $0.1 \mathrm{M}$ sodium carbonate buffer $\mathrm{pH} 8.5,1 \mathrm{M} \mathrm{NaCl}$ and water to remove unbound ligands (samples of sepharose before and after coupling were saved in order to measure the absorbance variation and determine success of coupling and measure the amount of coupled ligand that will be present in the column). Excess active groups (which are still active but failed to bind to L-lysine) were blocked by suspending in $10 \mathrm{ml} 1 \mathrm{M}$ ethanolamine $\mathrm{pH} 9.0$ and stirred for 1h at RT (Cuatrecasas P. et al. 1968; Deutsch Dale G. et al. 1970; Mallia A. Krishna et al. 1992; Walker John M. 1996). Finally, the gel was washed again with $1 \mathrm{M} \mathrm{NaCl}$ and a 5 $\mathrm{ml}$ borosilicate glass tube column from Bio-Rad was packed according to the instructions provided by the manufacturer.

According to Cao et al. (1996), 50mM Tris- $\mathrm{HCl} \mathrm{pH} 8.0$ was used as the binding buffer while absorbed kringles were eluted using 50mM Tris- $\mathrm{HCl}$ containing $200 \mathrm{mM} 6-$ 
aminohexanoicacid $\mathrm{pH}$ 5.0. After obtaining the chromatogram and collecting the samples after purification, in order to identify the peptides purified western blot was conducted.

\subsection{RESULTS AND DISCUSSION}

\subsubsection{PART 1: IN VITRO DIGESTION MODEL}

Results obtained from the in vitro model described by Ferruzzi et al. (2001) outlined in section 4.3.2.1, can be observed in Figure 45. From this western blot it is possible to observe how from this digestion method angiostatin does not survive. Immediately after gastric phase (lane 9) no angiostatin remains are observed. It seems that pepsin has hydrolyzed all the proteins in the sample. Moreover, it is possible to notice, particularly from lane 4, that some of the pepsinogen ( $\mathrm{MW} 43 \mathrm{kDa}$ ) present in the pepsin (MW $34.5 \mathrm{kDa}$ ) solution is slightly cross reacting with the primary anti-bovine plasminogen antibody used in this western blot. In fact, if we look at pepsinogen's molecular structure we will discover a single peptide loop-like structure hold together by disulfide bonds (Herriott Roger M. 1962), somewhat comparable to the kringle structures seen in plasminogen. Even if pepsinogen's molecular weight is very close to that of angiostatin, we do not believe its cross reaction will affect the results of our study significantly, since as seen in lane 4 in Figure 45, the band observed is slightly noticeable, and as we will indeed confirm during the rest of this study, angiostatin immunoreactions with anti-bovine plasminogen antibody is much greater and consequently can be easily distinguished from pepsinogen.

In order to better understand exactly which enzymes are responsible for the disappearance of angiostatin (as well as the PG present in the sample being digested) each enzyme used in this in vitro analysis was individually tested for its hydrolytic activity on angiostatin. From the western blot presented in Figure 46, it is interesting to notice that, as expected from the results seen in Figure 45, pepsin shows high hydrolytic activity on angiostatin, but also pancreatin shows some affinity for the anti-cancer protein. Pancreatin appears to be hydrolyzing all the peptides in the sample with molecular weight higher than $30 \mathrm{kDa}$ to generate smaller fragments in the $25 \mathrm{kDa}$ range, 
perhaps a combination of kringles, showing high immunoreaction. A less credible finding was to discover that lipase also show ability in hydrolyzing angiostatin (lane 11).

Strangely, lipase exhibits the same hydrolytic pattern as pancreatin. In order to confirm these results and ensure that no errors took place during the experiment, this same experiment was conducted in triplicates, each time with new reagents (enzymes solutions were freshly prepared) but the same observation made for western blot in Figure 46 were obtained. At this point, a plausible explanation to this phenomenon may be that the lipase used in this study is not pure enough. Casein SDS-PAGE was conducted (Appendix F) and results confirmed indeed some contamination. Zone of clearances near 25 and $50 \mathrm{kDa}$, indicating enzyme caseinolytic activity, were observed both for pancreatain and lipase. These finding indicate that most probably some of the enzymes present in pancreatin and responsible for angiostatin hydrolysis are also present in lipase. Moreover, according to the manufacturer, protease presence may not be surprising in purchased lipase product, since it may be difficult to obtain a lipase protease free when purified from the pancreas. For the rest of the study, since it is known lipase to be specific for lipids and not proteins, we will not discuss or examine its activity any further.

When angiostatin digestion is conducted in NFDM (Figure 47), the additional proteins present in the sample help protect somewhat the hydrolysis of angiostatin by the hydrolytic action of pancreatin, since generation of $25 \mathrm{kDa}$ fragments is not as evident and peptides in the $37 \mathrm{kDa}$ area are still visible, contrarily to observations made when digestion was conducted in buffer. On the other hand, milk proteins do not help protect angiostatin's hydrolysis by the action of pepsin; as shown in lane 6 of the gel in Figure 47, all the proteins bands seem to have disappeared. Similar results can also be observed when the experiment is conducted in a skim milk system. In none of the experiments bile has shown proteolytic activity since bile is known to be a mixture of salts secreted by the liver into the small intestine to help lipids digestion. 


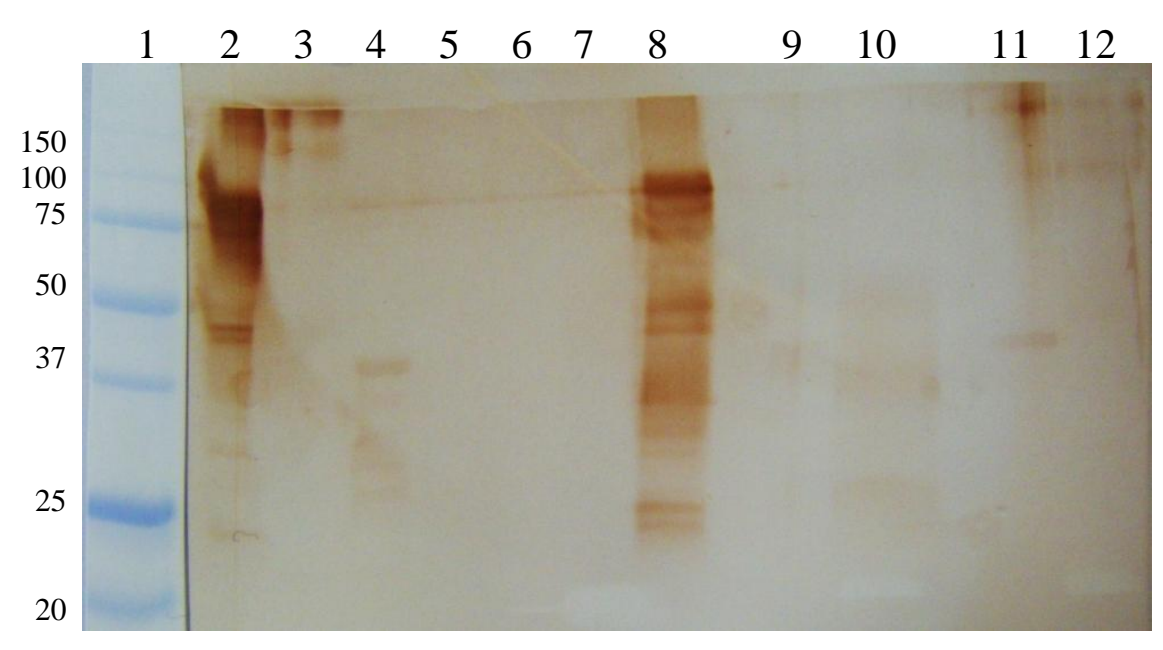

Figure 45: Western blot analysis of angiostatin digested through in vitro digestive model procedures. Lane 1: molecular weight standard; lane 2: bPG control $(0.175 \mathrm{mg} / \mathrm{ml})$; lane 3: $2 \%$ NFDM control; lane 4: pepsin control $(1.82 \mathrm{mg} / \mathrm{ml})$; lane 5: pancreatin $(0.092$ $\mathrm{mg} / \mathrm{ml})$ control; lane 6: bile $(1.104 \mathrm{mg} / \mathrm{ml})$ control; lane 7: lipase $(0.046 \mathrm{mg} / \mathrm{ml})$ control; lane 8: angiostatin (produced by interaction between bPG $(0.875 \mathrm{mg} / \mathrm{ml})$ and BPP $(0.1 \mathrm{mg} / \mathrm{ml})$ ) control; lane 9: digestion of angiostatin in 2\% NFDM after gastric phase; lane 10: digestion of angiostatin in 2\% NFDM after small intestine phase; lane 11: $2 \%$ NFDM gastric phase digestion control; lane 12: 2\% NFDM small intestine phase digestion control.

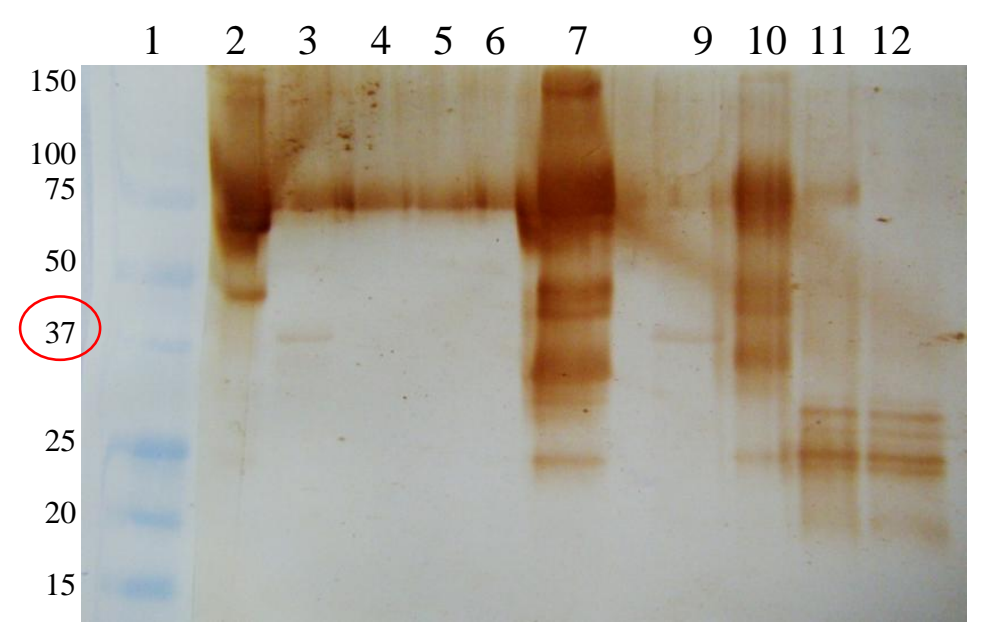

Figure 46: Western blot analysis on the of angiostatin digestion by the action of various digestive enzymes. Lane 1: molecular weight standard; lane $2:$ bPG $(0.175 \mathrm{mg} / \mathrm{ml})$ control; lane 3: pepsin control $(1.82 \mathrm{mg} / \mathrm{ml})$; lane 4: bile $(1.104 \mathrm{mg} / \mathrm{ml})$ control; lane 5: lipase $(0.046 \mathrm{mg} / \mathrm{ml})$ control; lane 6 : pancreatin $(0.092 \mathrm{mg} / \mathrm{ml})$ control; lane 7 : angiostatin control (produced through bPG hydrolysis from BPP); lane 9-12: angiostatin digested by the action of pepsin, bile, lipase and pancreatin respectively. 


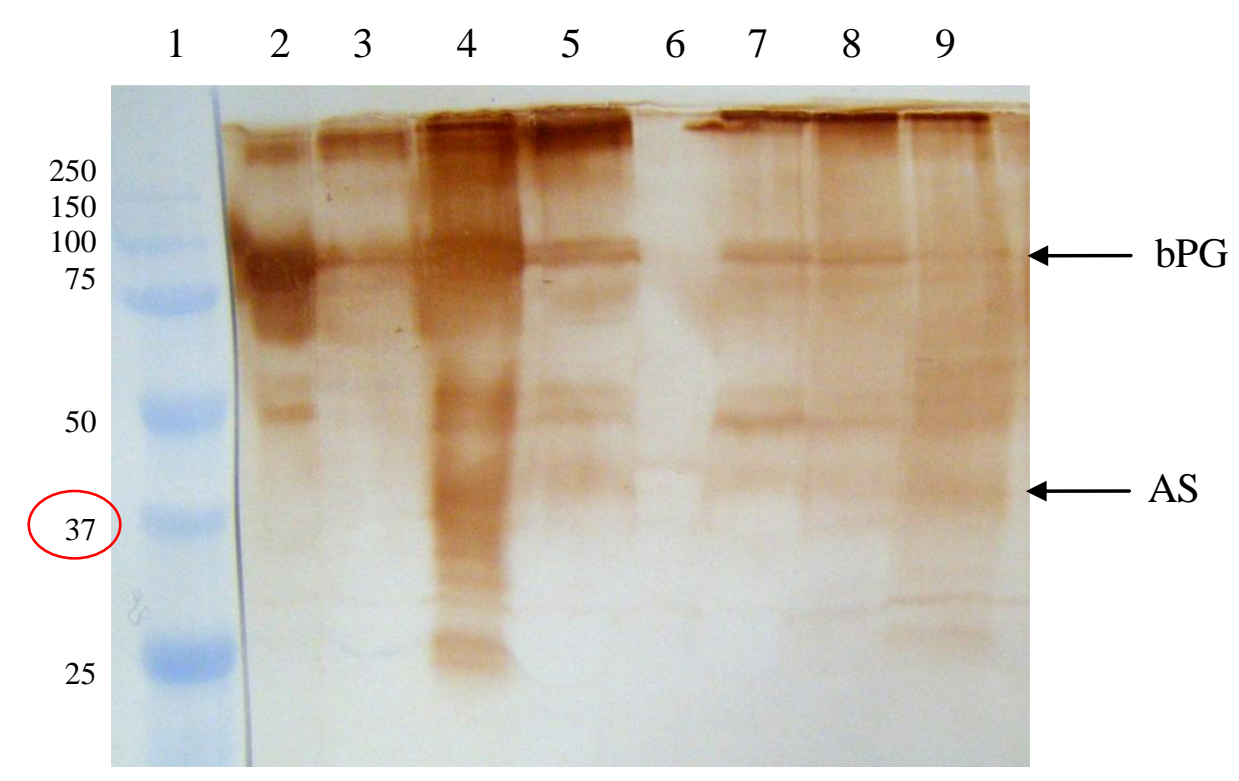

Figure 47: Western blot analysis of angiostatin digestion when in presence of NFDM. Lane 1: molecular weight standard; lane $2:$ bPG control $(0.175 \mathrm{mg} / \mathrm{ml}) ; 1 \% \mathrm{NFDM}$ control; lane 4: angiostatin in buffer control (obtained through bPG hydrolysis by the action of BPP for 1 hour at $37^{\circ} \mathrm{C}$ ); lane 5: angiostatin in $2 \%$ NFDM; lane 6-9: angiostatin in NFDM digested by the action of pepsin, bile, lipase and pancreatin respectively.

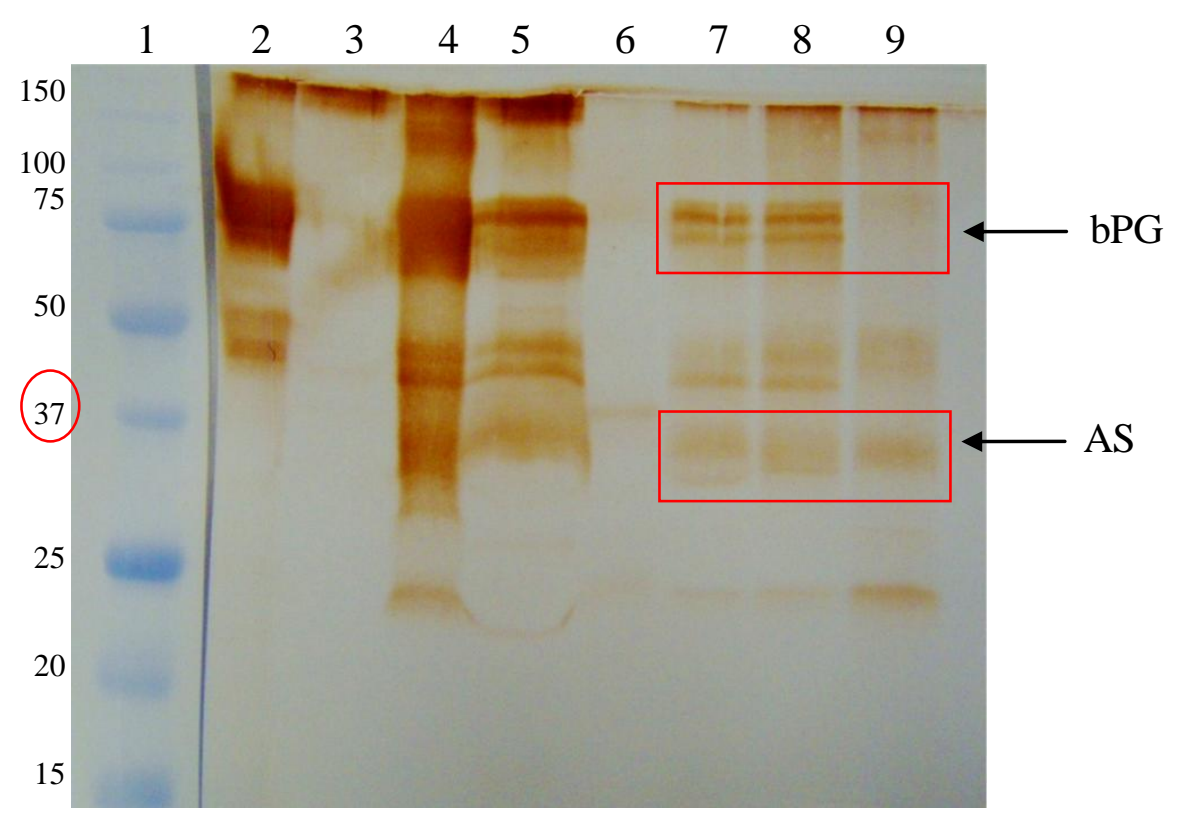

Figure 48: Western blot analysis of digestion of angiostatin in skim milk by the action of various digestive enzymes. Lane 1: molecular weight standard; lane 2: bPG control $(0.175 \mathrm{mg} / \mathrm{ml})$; lane 3: skim milk (diluted 1:5 in ddwater) control; lane 4: angiostatin control (produced through bPG hydrolysis by the action of BPP at $37^{\circ} \mathrm{C}$ for 1 hour); lane 5: angiostatin in skim milk control; lane 6-9: angiostatin in skim milk digested by the action of pepsin, bile, lipase, and pancreatin respectively. 
4.4.2 Analysis of the interaction between various E:S ratios for pepsin, trypsin, $\alpha$ chymotrypsin and angiostatin

\subsubsection{PEPSIN}

Observations made from the in vitro analysis previously analyzed, infer that angiostatin cannot survive gastric phase due to pepsin's high hydrolytic activity. Before confirming such observation it would be of interest to investigate more in depth the hydrolytic pattern and the affinity of pepsin to angiostatin, at what E:S ratio does angiostatin start being hydrolyzed? Does a E:S ratio of 12:1 really mimic the digestion conditions, particularly when such a small amount of protein is being analyzed in a pure form and not in a real food system?

First, using a ratio of 12:1, as suggested by Ferruzzi et al. (2001), we examined angiostatin's proteolytic pattern over time. As Figure 49 indicate, after only 10 minutes, pepsin breaks down angiostatin into a $25 \mathrm{kDa}$ fragment that will then disappear in the following 10 minutes of the reaction.

From the literature a lot of disagreement is found in the determination of an ideal E:S ratio to study digestion of proteins by the action of pepsin. Ranges from 12:1 to 1:7500 are observed (Hur Sun Jin et al. 2011). Due to this great incongruity, we decided to analyze a broad range of $\mathrm{E}: \mathrm{S}$ ratios from 1:100 to 1:10 based on in vitro digestibility experiment conducted by Astwood et al. (1996), Sathe et al (1997) and Roufik et al. (2006). As results in Figure 50 and 51 reveal, even when pepsin is reacted at an E:S ratio of 1:10 no significant hydrolysis of angiostatin seems to occur. In this images it s possible to notice angiostatin having a higher molecular weight, this is because the reaction is conducted at $\mathrm{pH} 2$ causing the molecule to denature and appear to have a higher molecular weight. Interesting is to notice that bPG is hydrolyzed at a much higher rate than angiostatin. In fact, a darker band is observed over time in the $25 \mathrm{kDa}$ range even though angiostatin concentration does not significantly decrease over time. Therefore according to these findings, it is evident that more data is necessary before making any assertion about the fate of angiostatin in the stomach if an in vitro procedure is to be accurate. This work demonstrates that further in vitro methods of analysis need to be conducted in order to determine the more accurate $\mathrm{E}: \mathrm{S}$ ratios mimicking real digestion 
conditions and at what concentration should angiostatin be added to a dairy product if we were to develop a cancer preventive food.

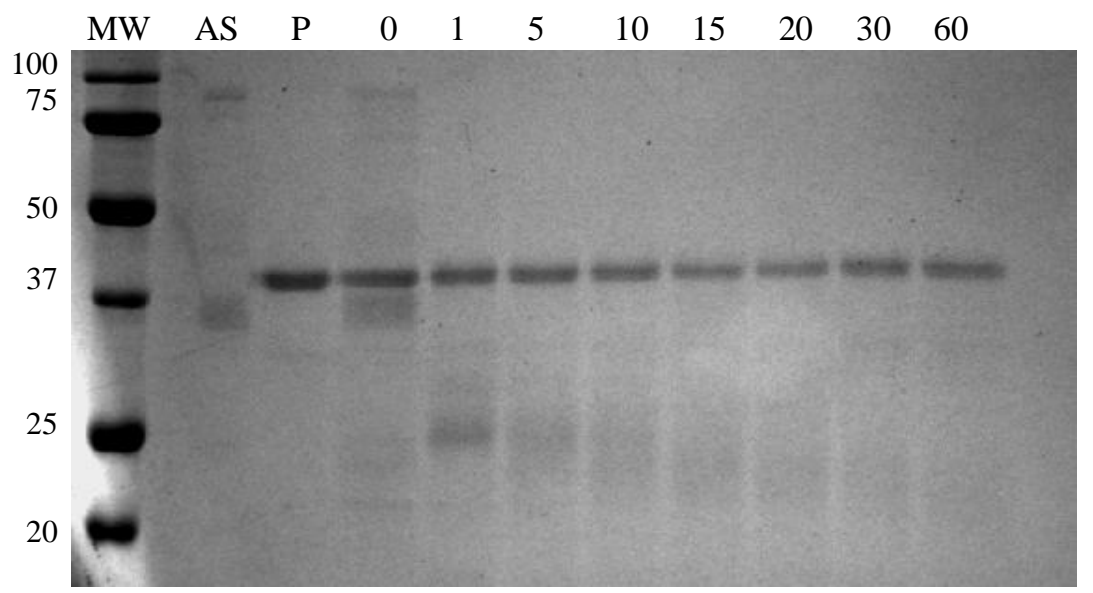

Figure 49: SDS-PAGE visualization of proteolytic fragments obtained through angiostatin hydrolysis by the action of pepsin at E:S ratio 12:1. Lane 1: molecular weight standard; lane 2: angiostatin (AS) control (obtained through hydrolysis of bPG by the action of BPP for 1 hour at $\left.37^{\circ} \mathrm{C}\right)$; lane 3: pepsin $(\mathrm{P})$ control $(1 \mathrm{mg} / \mathrm{ml})$; lane $4-11$ : angiostatin hydrolysis by the action of pepsin after $0,1,5,10,15,20,30$ and 60 minutes incubation at $37^{\circ} \mathrm{C}$.

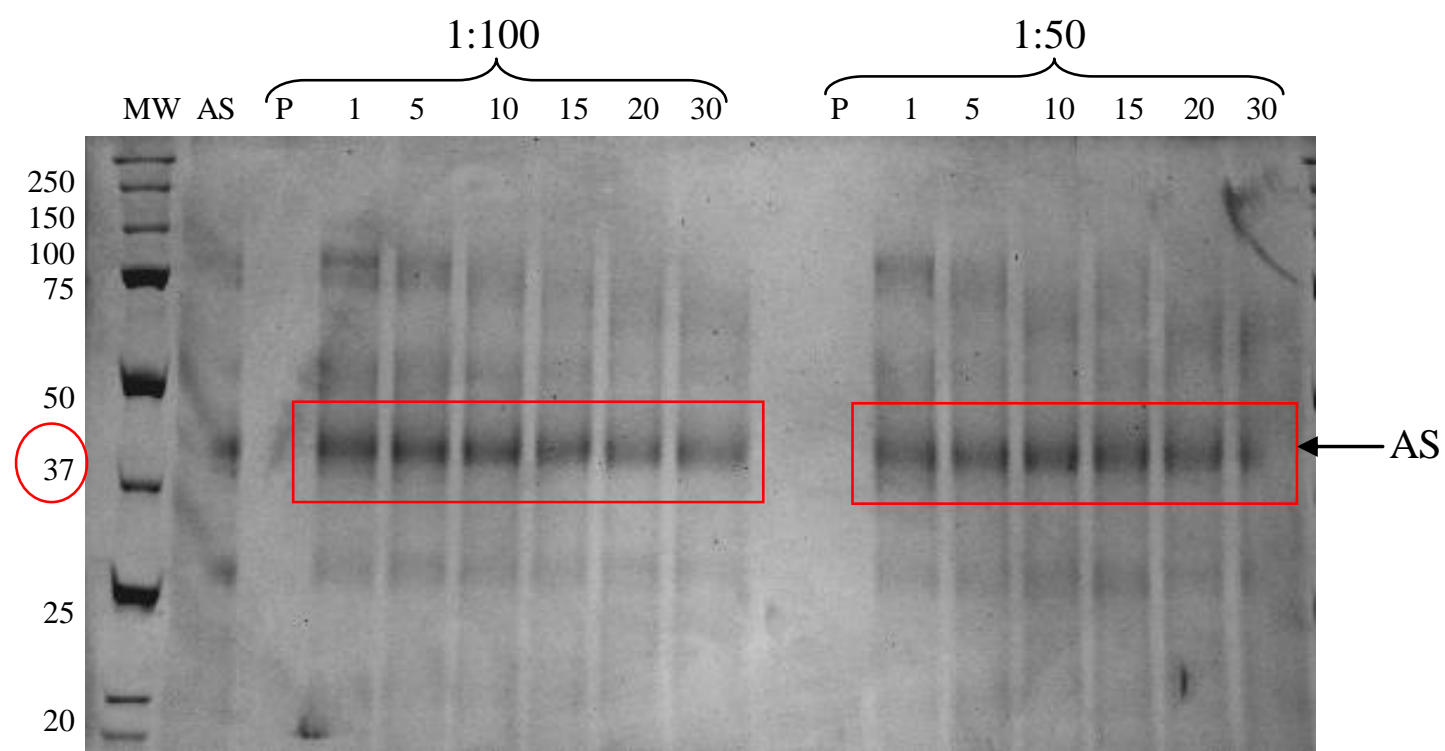

Figure 50: SDS-PAGE analysis of angiostatin hydrolysis by the action of pepsin at $\mathrm{pH} 2$ and E:S ratio of 1:100 and 1:50. Lane 1: molecular weight standard; lane 2: angiostatin (AS) control $(0.4 \mathrm{mg} / \mathrm{ml}$ ) (obtained from the reaction between $\mathrm{bPG}$ and BPP for 1 hour at $\left.37^{\circ} \mathrm{C}\right)$; lane 3: pepsin $(\mathrm{P})$ control $(0.004 \mathrm{mg} / \mathrm{ml})$; lane $4-9$ : angiostatin digestion by the action of pepsin at an E:S ratio of 1:100 after 1, 5, 10, 15, 20 and 30 minutes incubation at $37^{\circ} \mathrm{C}$; lane 10 : pepsin control $(0.008 \mathrm{mg} / \mathrm{ml})$; lane $11-16$ : angiostatin digestion by the action of pepsin at an E:S ratio of 1:50 after 1, 5, 10, 15, 20 and 30 minutes incubation at $37^{\circ} \mathrm{C}$. Bands in the $37 \mathrm{kDa}$ area correspond to angiostatin (AS). 


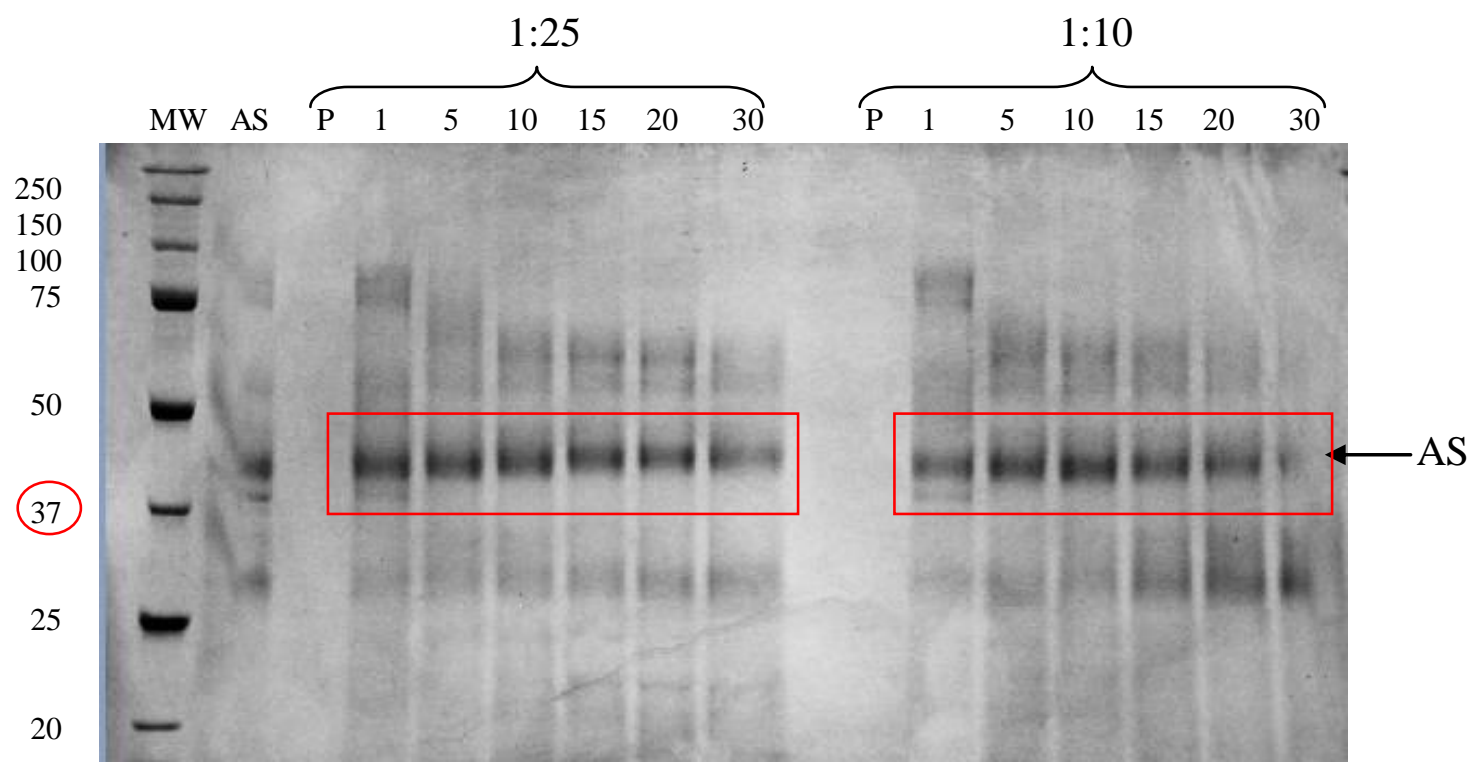

Figure 51: SDS-PAGE analysis of angiostatin hydrolysis by the action of pepsin at $\mathrm{pH} 2$ and E:S ratio of 1:25 and 1:10. Lane 1: molecular weight standard; lane 2: angiostatin (AS) control $(0.4 \mathrm{mg} / \mathrm{ml}$ ) (obtained from the reaction between bPG and BPP for 1 hour at $\left.37^{\circ} \mathrm{C}\right)$; lane 3: pepsin $(\mathrm{P})$ control $(0.016 \mathrm{mg} / \mathrm{ml})$; lane $4-9$ : angiostatin digestion by the action of pepsin at an E:S ratio of 1:25 after 1, 5, 10, 15, 20 and 30 minutes incubation at $37^{\circ} \mathrm{C}$; lane 10: pepsin control $(0.04 \mathrm{mg} / \mathrm{ml})$; lane $11-16$ : angiostatin digestion by the action of pepsin at an E:S ratio of 1:10 after 1, 5, 10, 15, 20 and 30 minutes incubation at $37^{\circ} \mathrm{C}$. Bands in the $37 \mathrm{kDa}$ area correspond to angiostatin (AS).

\subsubsection{TRYPSIN}

The possibility of trypsin being responsible, at some degree, in the angiostatin hydrolysis previously seen in the pancreatin samples was analyzed. Some activity was indeed discovered. The pancreatin to angiostatin ratio used in section 4.3.2.2 was approximately 1:1 (w/w). Since pancreatin contains a variety of enzymes other than trypsin, we would assume the ratio between trypsin and angiostatin to be less than 1 . Based on these assumptions, trypsin activity in pancreatin would be the one observed in either lane 4, 5 or 6 of Figure 53 or some other ratio analyzed in Figure 52. From these images it is clear that at ratios of 1:50 (w/w) to approximately 1:5 (w/w) no significant angiostatin hydrolysis occurs, however a thick band in the $25 \mathrm{kDa}$ band with strong immunoreactivity for anti-bovine plasminogen antibody (Figure 54) is observed and it seems to be produced primarily through hydrolysis of bPG present in the samples. 
A dilution effect may be misled into hydrolytic activity. In fact the disappearance of angiostatin observed in Figure 53 from lane 7 to 10 is due to a reduction in angiostatin concentration. As outlined in Table 8 , angiostatin concentration is constant $(0.333 \mathrm{mg} / \mathrm{ml})$ until E:S ratio 1:3 is reached, at higher ratios lower angiostatin is used. Nevertheless, analysis of the western blot (which technique is characterized by a higher detection limit than SDS-PAGE) shows that even at 1:1 ratio angiostatin is well characterized by a thick band at its corresponding molecular weight range.

From these observations it is possible to conclude that at E:S ratios lower than 1, trypsin does not significantly hydrolyze angiostatin. As in the case for pepsin, incongruity in the best E:S ratio representative of real digestive conditions are observed. This difficulty is mostly caused by variations among individuals. In fact according to Dr. McClements "The human body... is very complex and varies from person to person, depending on age, sex, health status, and type of meal, so it is difficult to accurately simulate the digestion process" (Mermelstein Neil H. 2010). Ratios from 1:100 to 12:1 are found in the literature making conclusions from our observations very dissimilar based on which procedure is being considered. For example, if we make conclusions based on Sathe et al. (1997) study, we would be thrilled to find out that at a ratio of $1: 100$, trypsin affinity for the peptide of interest is extremely low; angiostatin will with no doubt survive trypsin activity during digestion. On the other hand, if conclusions are made based on another study conducted by Bodwell et al. (1980), we would probably need to consider encapsulation methods to protect angiostatin from being digested by trypsin (as well as pepsin and chymotrypsin). In order to be able to make accurate conclusions, ideal E:S ratio needs to be determined or usage of a TNO-intestinal model or in vivo digestion may be considered for more conclusive observations. 


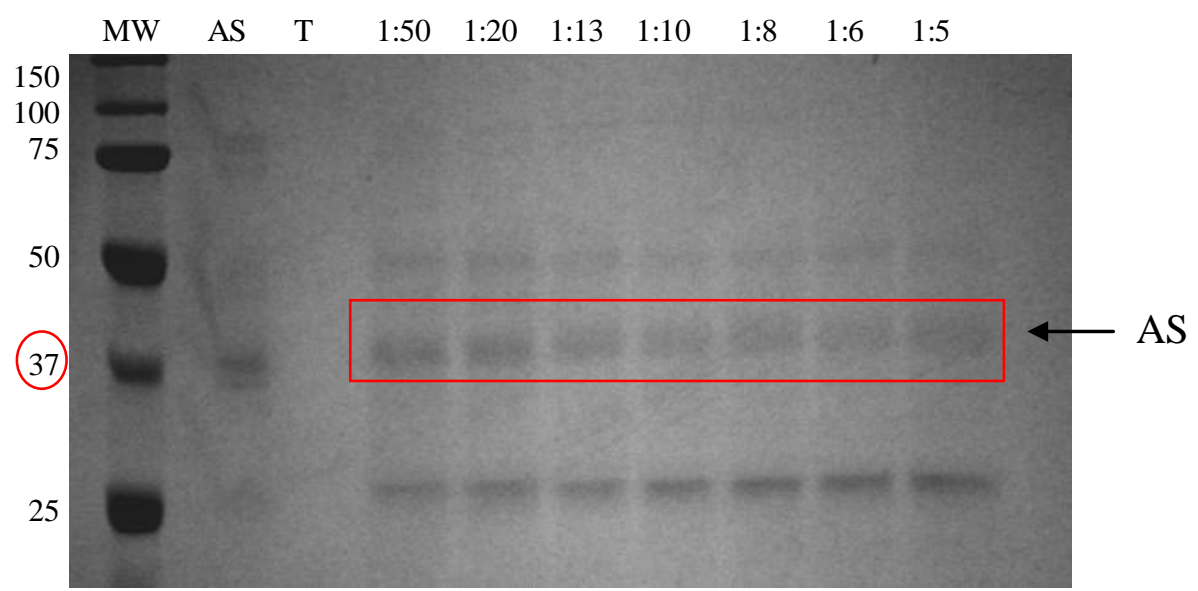

Figure 52: SDS-PAGE analysis of angiostatin digestion by the action of trypsin at various E:S after 1 hour at $37^{\circ} \mathrm{C}$. Lane 1: molecular weight standard; lane 2: angiostatin (AS) control (obtained from bPG hydrolysis by the action of BPP after 1 hour at $37^{\circ} \mathrm{C}$ ); lane 3 : trypsin (T) control $(0.175 \mathrm{mg} / \mathrm{ml})$; lane $4-10$ : angiostatin interaction with trypsin at $\mathrm{E}: \mathrm{S}$ ratios of 1:50, 1:20, 1:13,1:10, 1:8, 1:6 and 1:5 respectively.

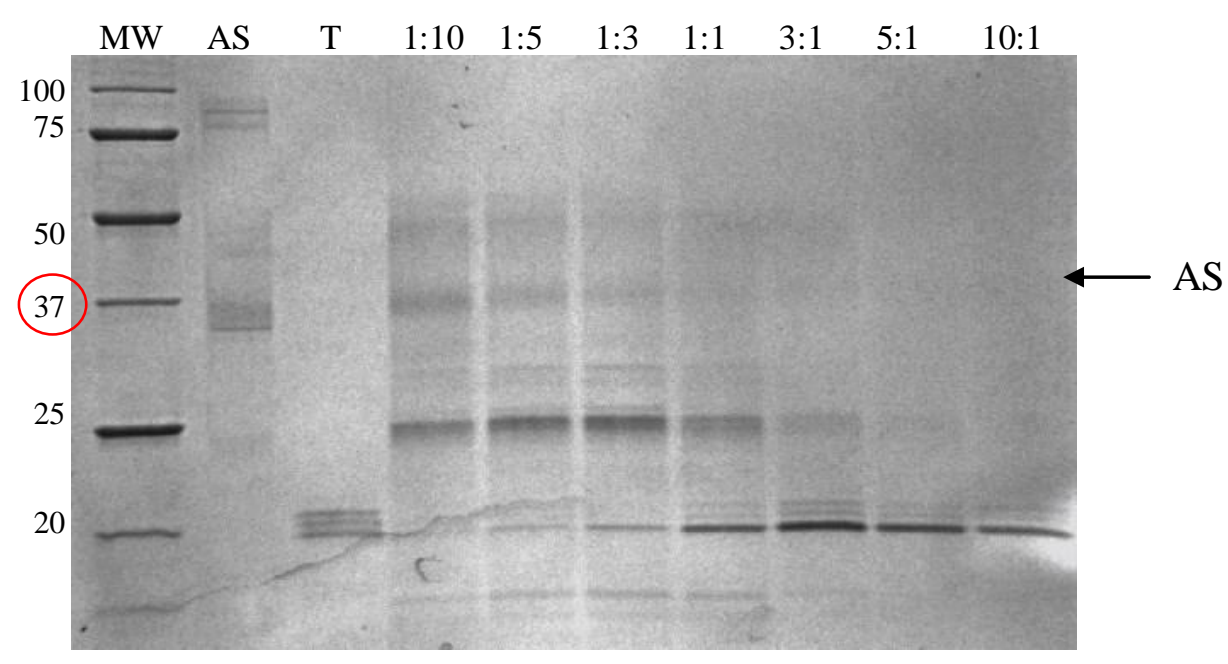

Figure 53: SDS-PAGE analysis of the products generated by the reaction between angiostatin and trypsin at various E:S. Lane 1: molecular weight standard; lane 2: angiostatin (AS) control (obtained by bPG hydrolysis by the action of BPP at $37^{\circ} \mathrm{C}$ for 1 hour); lane 3: trypsin $(\mathrm{T})$ control $(0.75 \mathrm{mg} / \mathrm{ml})$; lane 4-10: angiostatin interaction with trypsin at E:S ratios 1:10, 1:5, 1:3, 1:1, 3:1, 5:1 and 10:1 respectively. 


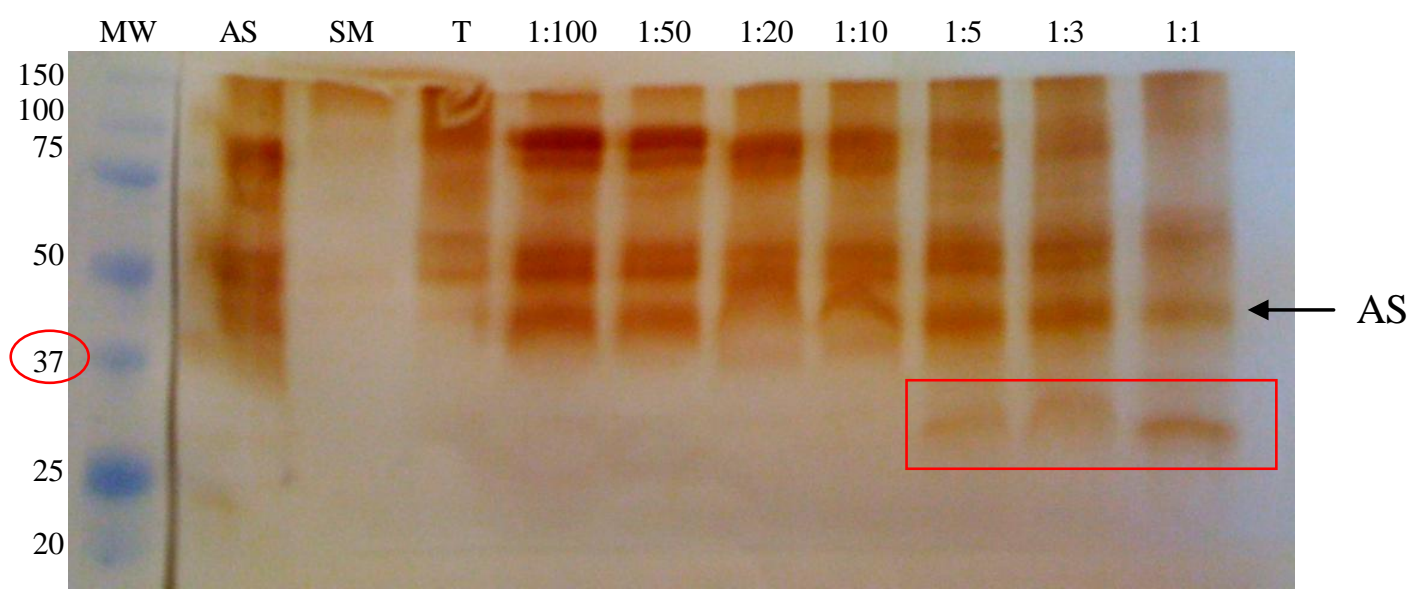

Figure 54: Western blot analysis of the products generated by the reaction between angiostatin in skim milk and trypsin at various E:S. Lane 1: molecular weight standard; lane 2: angiostatin (AS) control (obtained by bPG hydrolysis by the action of BPP at $37^{\circ} \mathrm{C}$ for 1 hour); lane 3: skim milk (SM) control (diluted 1:5 v/v in ddwater) lane 4: trypsin (T) control $(0.5 \mathrm{mg} / \mathrm{ml})$; lane 5-11: angiostatin interaction with trypsin at E:S ratios 1:100, 1:50, 1:20, 1:10, 1:5, 1:3 and 1:1 respectively.

\subsubsection{3 $\alpha$-CHYMOTRYPSIN}

As previously mentioned, $\alpha$-chymotrypsin was also another enzyme possibly involved in the hydrolysis of angiostatin seen in pancreatin. Similar to trypsin, various E:S ratios were analyzed and results can be observed in Figures 55 and 56. Compared to trypsin, $\alpha$-chymotrypsin showed much higher affinity for angiostatin since at a ratio of only 1:50, hydrolysis of this molecule is observed; and at a 1:10 ratio all the proteins in the sample seem to be completely hydrolyzed (between 1:50 and 1:3 no dilution effect is seen since the same angiostatin concentration is used; refer to Table 9 for more information). Interestingly, also in this case a fragment in the $22 \mathrm{kDa}$ area is observed. However, when analyzing the results obtained from the SDS-PAGE a very thick and dark band corresponding to this MW is seen, but when examining the results from the western blot, this band is barely noticeable. Perhaps the $\alpha$-chymotrypsin hydrolyzes angiostatin or bPG to release fragments for which the anti-bovine plasminogen antibody is hardly capable of recognizing. This same phenomenon will be observed later from the interaction between $\alpha$-chymotrypsin and bPG. 


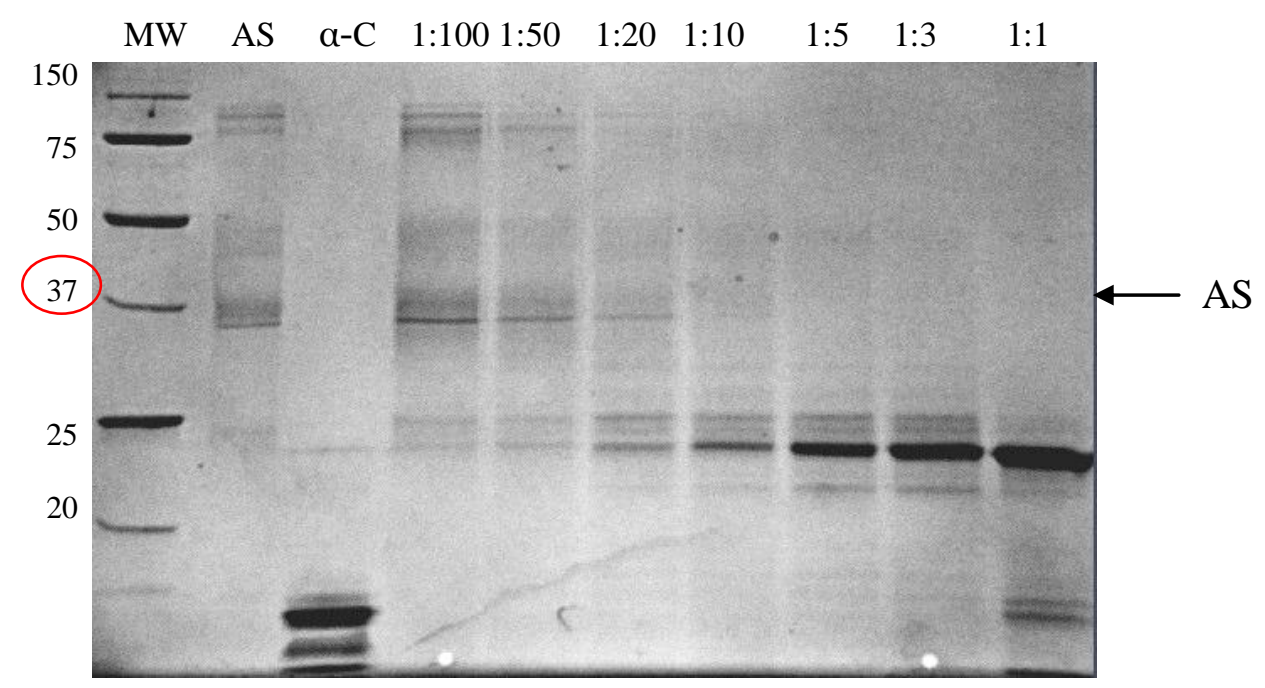

Figure 55: SDS-PAGE analysis of the products generated by the reaction between angiostatin and $\alpha$-chymotrypsin at various E:S ratios. Lane 1: molecular weight standard; lane 2: angiostatin (AS) control (obtained by bPG hydrolysis by the action of BPP at $37^{\circ} \mathrm{C}$ for 1 hour $)$; lane 3: $\alpha$-chymotrypsin $(\alpha-\mathrm{C})$ control $(0.5 \mathrm{mg} / \mathrm{ml})$; lane $4-10$ : angiostatin interaction with trypsin at E:S ratios 1:100, 1:50, 1:20 1:10, 1:5, 1:3 and 1:1 respectively.

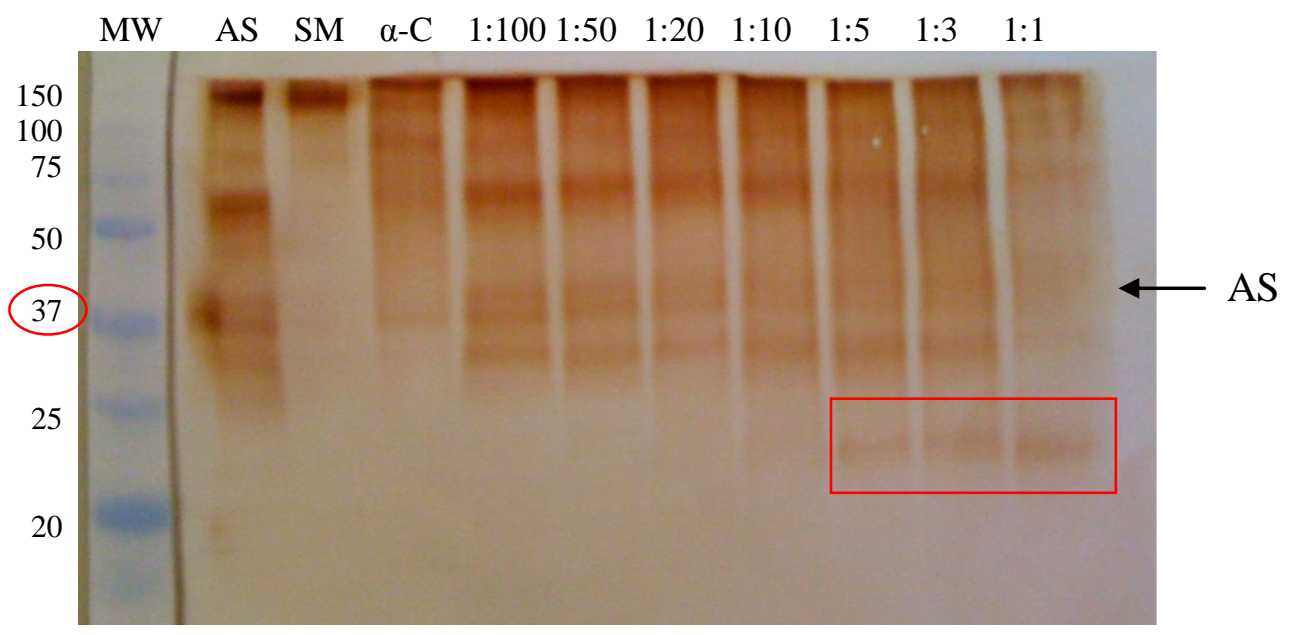

Figure 56: Western blot analysis of the products generated by the reaction between angiostatin in skim milk and $\alpha$-chymotrypsin at various E:S. Lane 1: molecular weight standard; lane 2: angiostatin (AS) control (obtained by bPG hydrolysis by the action of $\mathrm{BPP}$ at $37^{\circ} \mathrm{C}$ for 1 hour); lane 3: skim milk (SM) control (diluted 1:5 v/v in ddwater) lane 4: $\alpha$-chymotrypsin $(\alpha-\mathrm{C})$ control $(0.5 \mathrm{mg} / \mathrm{ml})$; lane 5-11: angiostatin interaction with $\alpha$ chymotrypsin at E:S ratios 1:100, 1:50, 1:20, 1:10, 1:5, 1:3 and 1:1 respectively. 
4.4.3 Ability of digestive enzymes in producing angiostatin through plasminogen hydrolysis

An interesting question can be asked with regards to the creation of a dairy product enriched in angiostatin: is our body capable of producing angiostatin directly from bPG in milk during digestion? If true, this would perhaps explain some observations made from epidemiological studies in which it has been confirmed that people who regularly consume milk tend to have lower risk of developing colon cancer, but for which the specific compound (lactose, calcium, fat or other) responsible in imparting this health benefit has yet to be discovered (Järvinen R. et al. 2001; Cho Eunyoung et al. 2004).

\subsubsection{TRYPSIN}

As previously mentioned, the exact amount of trypsin released in the small intestine during digestion has not been determined. In order to analyze the affinity and hydrolytic patter between trypsin and bovine plasminogen, various E:S ratios from 1:150 to $1: 1.5$ were examined. From Figure 57, it is possible to notice that a simple and clear reaction occurs from this interaction. Trypsin starts showing high affinity for bPG at ratios of 1:15; at higher ratios bPG is completely hydrolyzed. From both the SDS-PAGE and the western blot seen below, trypsin appears to generate a fragment in the 50kDa area (probably PL) and a $25 \mathrm{kDa}$ peptide contemporaneously and with high immunoreactivity for anti-bovine plasminogen antibody. Knowing that $25 \mathrm{kDa}$ could correspond to kringles 2-3, known to be able to inhibit endothelial cells proliferation ( $\mathrm{Ji}$ Weidong-richard et al. 1998), or to some other kringle combination, it would be of interest to investigate in the future the sequence of this fragment generated by trypsin and its ability in inhibiting cancerous cells growth. 


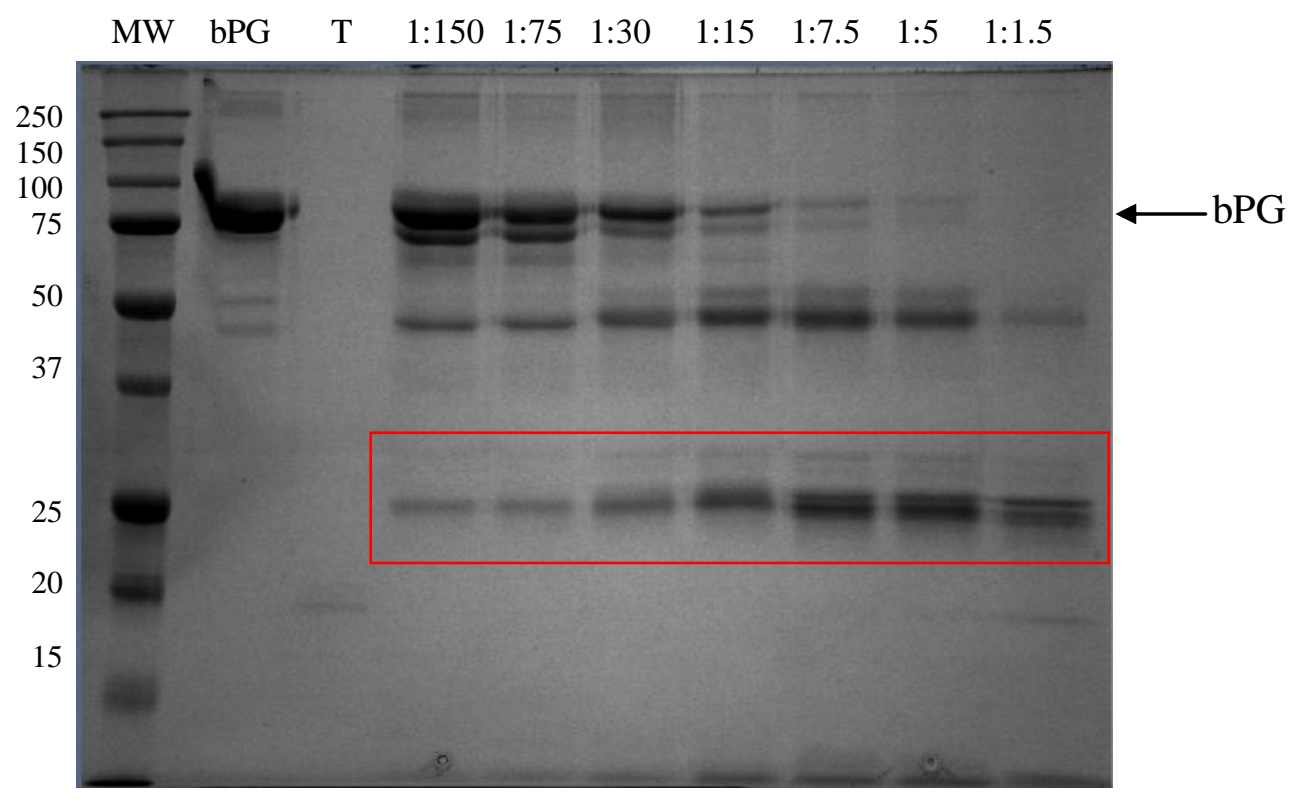

Figure 57: SDS-PAGE visualization of the products generated by trypsin during bPG hydrolysis at various E:S ratios after 1 hour at $37^{\circ} \mathrm{C}$. Lane 1: molecular weight standard; lane 2: bPG control $(0.25 \mathrm{mg} / \mathrm{ml})$; lane 3: trypsin $(\mathrm{T})$ control $(0.5 \mathrm{mg} / \mathrm{ml})$; lane4: reaction between bPG and trypsin at E:S ratios 1:150, 1:75, 1:30, 1:15, 1:7.5, 1:5 and 1:1.5 respectively.

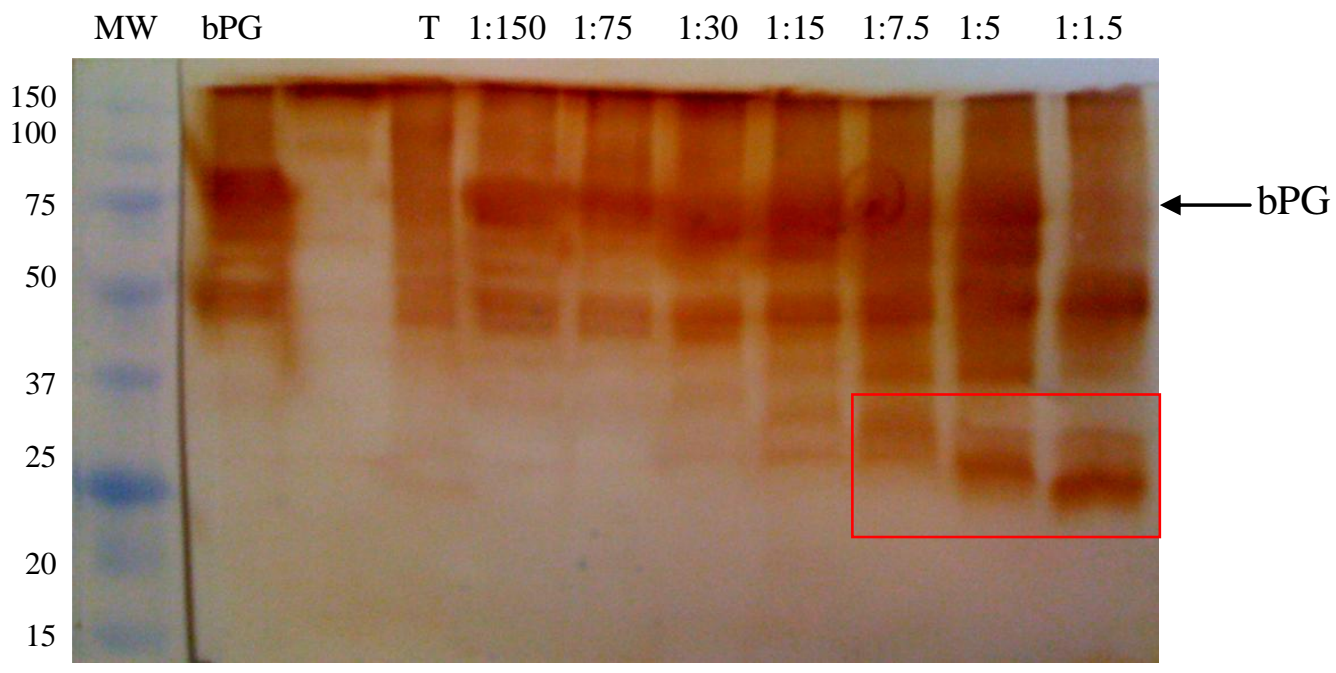

Figure 58: Western blot visualization of the products generated by trypsin during bPG hydrolysis at various E:S ratios after 1 hour at $37^{\circ} \mathrm{C}$. Lane 1: molecular weight standard; lane 2: bPG control $(0.25 \mathrm{mg} / \mathrm{ml})$; lane 3: trypsin $(\mathrm{T})$ control $(0.5 \mathrm{mg} / \mathrm{ml})$; lane 4: reaction between bPG and trypsin at E:S ratios 1:150, 1:75, 1:30, 1:15, 1:7.5, 1:5 and 1:1.5 respectively. 


\subsubsection{2 $\alpha$-CHYMOTRYPSIN}

Similarly to trypsin, $\alpha$-chymotrypsin was tested on its ability in bPG hydrolysis. From the results obtained, and presented in Figure 59, chymotrypsin shows very similar affinity to bPG, to that previously seen in trypsin under same experimental conditions. However, contrarily to trypsin, chymotrypsin main products are fragments with molecular weight around $25-22 \mathrm{kDa}$. Plasmin $(50 \mathrm{kDa})$ is also produced, but as the E:S ratio increases, PL gets hydrolyzed into smaller fragments. Despite the bands in the 25 $\mathrm{kDa}$ area being very dark and thick, the western blot does not translate into a dark brown band as expected. The immunoreaction between the primary antibody and these lower MW peptides is not as strong as one would imagine. Most probably this phenomenon is caused by the fact that MW of the enzyme is in the same range as that of the fragments observed (Figure 59 lane 3), explaining why a thicker band in the gel but not in the western blot is observed.

As in the case of trypsin, it would be of interest to further analyze what portion of bPG the fragments obtained belong, and test for their anticancer activity to investigate whether or not angiostatin related fragments are produced in the human body during digestion.

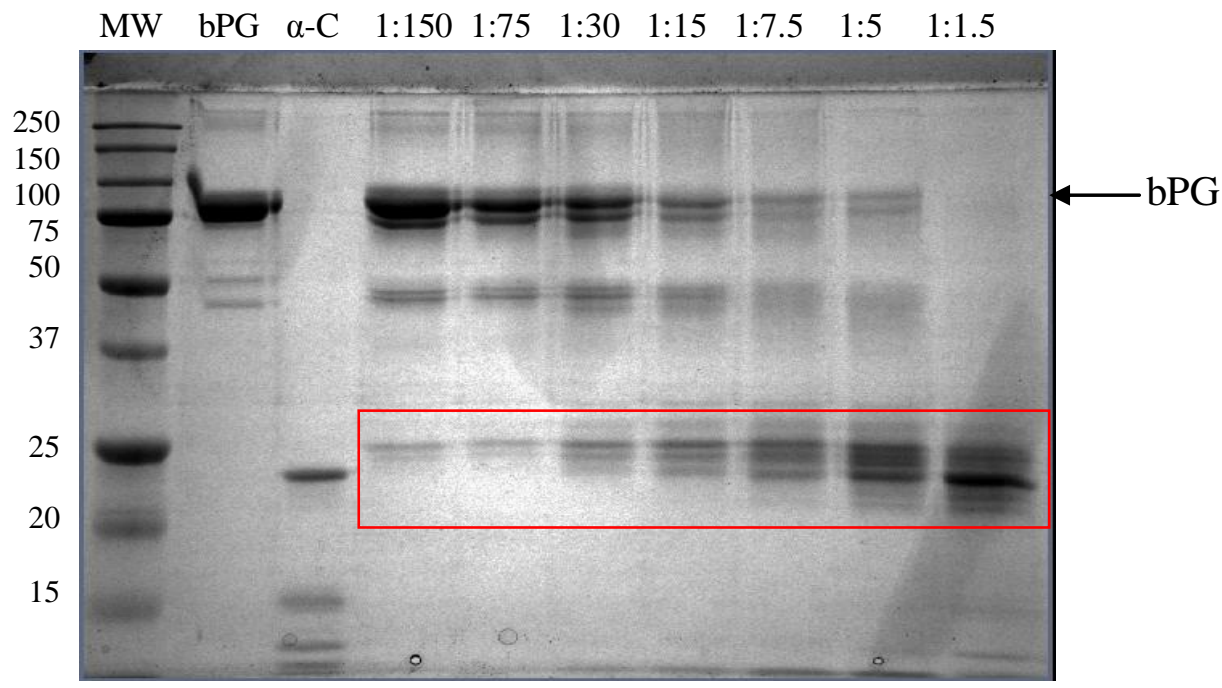

Figure 59: SDS-PAGE visualization of the products generated by $\alpha$-chymotrypsin during bPG hydrolysis at various E:S ratios after 1 hour at $37^{\circ} \mathrm{C}$. Lane 1: molecular weight standard; lane 2: bPG control $(0.25 \mathrm{mg} / \mathrm{ml})$; lane 3: $\alpha$-chymotrypsin $(\alpha-\mathrm{C})$ control $(0.5 \mathrm{mg} / \mathrm{ml})$; lane4: reaction between $\mathrm{bPG}$ and $\alpha$-chymotrypsin at E:S ratios 1:150, 1:75, $1: 30,1: 15,1: 7.5,1: 5$ and 1:1.5 respectively. 


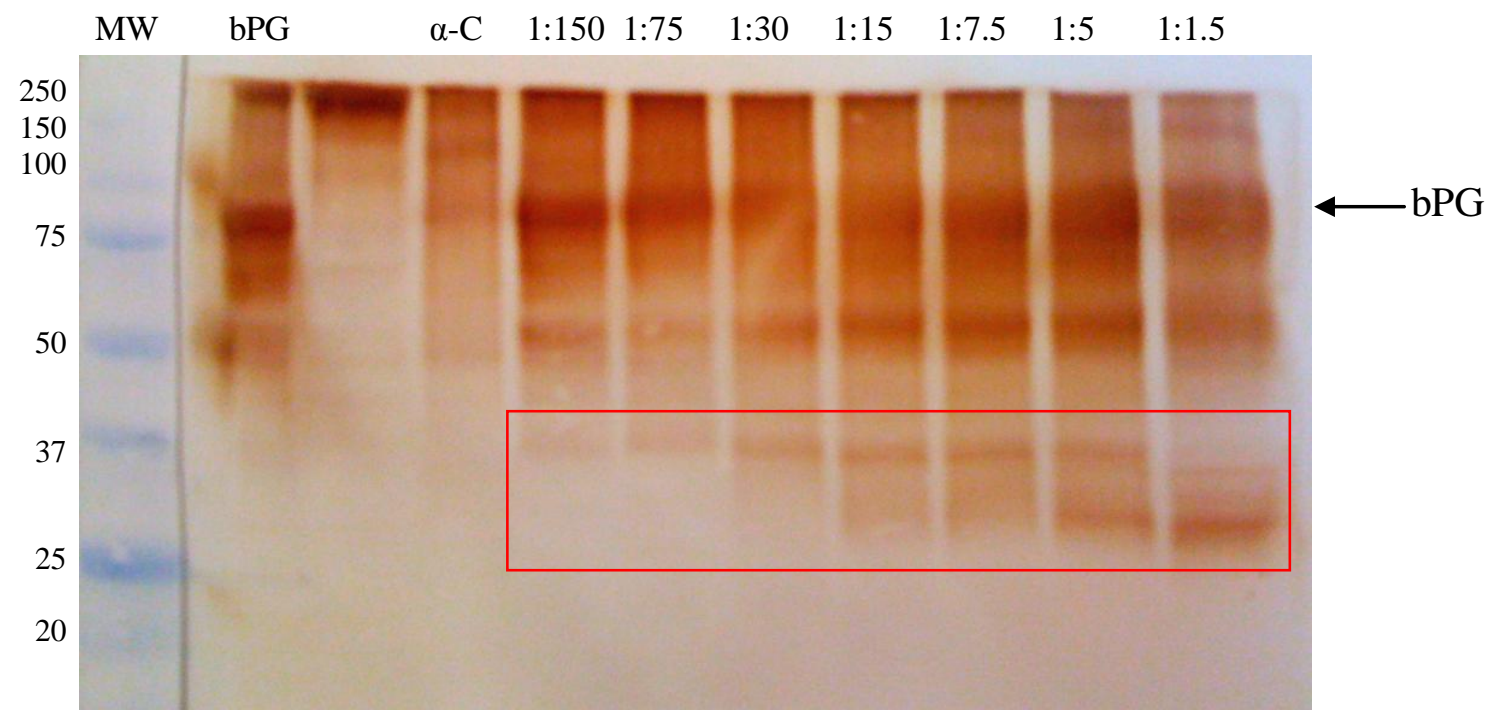

Figure 60: Western blot visualization of the products generated by $\alpha$-chymotrypsin during bPG hydrolysis at various E:S ratios after 1 hour at $37^{\circ} \mathrm{C}$. Lane 1: molecular weight standard; lane 2: bPG control $(0.25 \mathrm{mg} / \mathrm{ml})$; lane 3: $\alpha$-chymotrypsin $(\alpha-\mathrm{C})$ control $(0.5 \mathrm{mg} / \mathrm{ml})$; lane 4 : reaction between bPG and $\alpha$-chymotrypsin at E:S ratios 1:150, 1:75, $1: 30,1: 15,1: 7.5,1: 5$ and $1: 1.5$ respectively.

\subsubsection{PART2: ANGIOSTATIN PURIFICATION}

Purification of bovine angiostatin was for the first time successfully conducted in our laboratory. Figure 61 and 62 shows the western blot obtained from the samples recovered after being purified through affinity column chromatography and the corresponding chromatogram. Purification was conducted in duplicates and the results for both tries are shown in the western blot below. From the first try in angiostatin purification (lanes 3 to 5), it is possible to observe how a single band in the $37 \mathrm{kDa}$ area is seen in lane 5 of the western blot corresponding to the sample recovered from the elution phase. A less evident PL residue can be also seen in the 50kDa MW for the same sample. Similar results are seen for the second attempt in angiostatin purification, in which the same procedures as the ones conducted in the first try were followed. However, from the second try a lot more protein is recovered, particularly in the $75-50 \mathrm{kDa} \mathrm{MW}$, from the sample retrieved right after injection into the column (lane 6). Contrarily to the second purification attempt, during the first try, due to difficulties in setting the equipment and adjusting the background noise seen in the readings, more binding buffer was used 
causing the sample to being further diluted as well as lower flow rate into the column. These differences among these two tries, may indicate that under the conditions (sample protein concentration and flow rate) initially planned on using, saturation of the column may occur, inhibiting the desired protein to have enough time or space to interact with the ligands. This may explain why in lane 8 less angiostatin was recovered from the eluted sample, and why the pick in the chromatogram resulted to be very small.

In conclusion, from our first attempt in bovine angiostatin purification it can be confirmed that L-lysine column chromatography is an adequate method to employ and the binding and elution buffers used are suitable for this experiment. However, adjustment on the flow rate or different size column, according to the protein concentration in the sample will be require in the future in order to maximize protein of interest and ligand interaction to avoid saturation and obtain pure angiostatin.

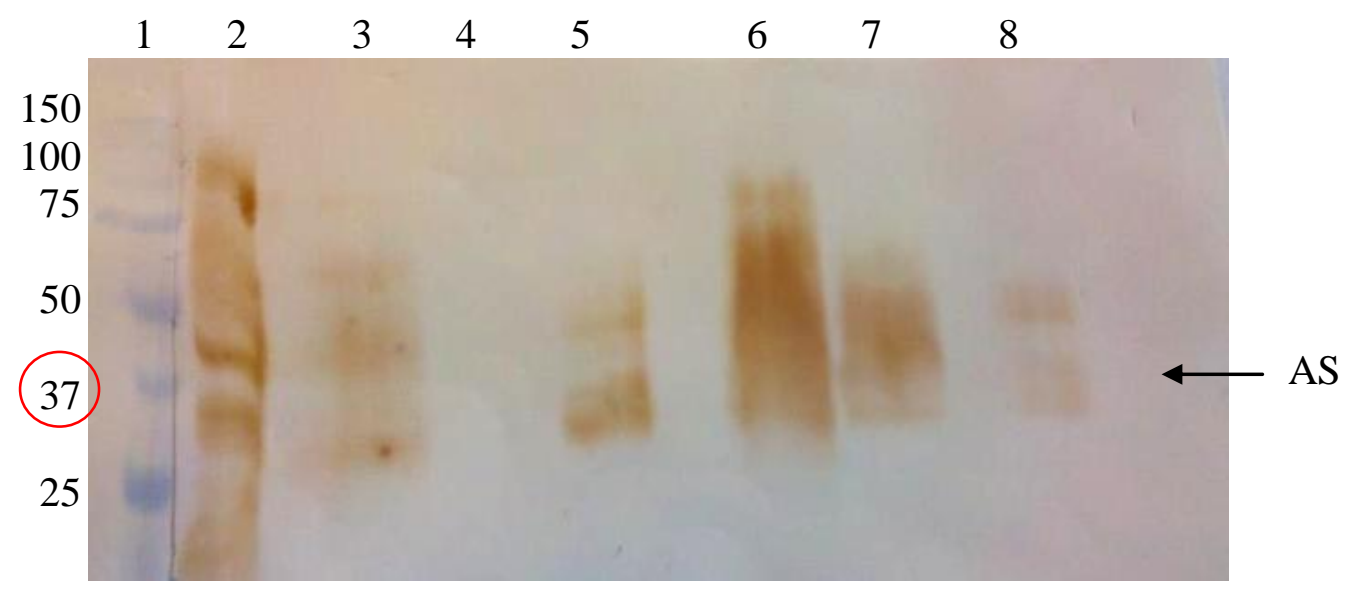

Figure 61: Western blot of samples recovered after L-lysine affinity column chromatography. Lane 1: molecular weight standard; lane 2: interaction between BPP and $\mathrm{bPG}$ at $37^{\circ} \mathrm{C}$ after 1 hour incubation (control). Lanes 3 to 5 represent first purification try and samples recovered at retention times: 0 to 8.8 minutes; 8.8 to 14.3 minutes; 14.3 to 20 minutes respectively. Lanes 6 to 8 represent samples collected during second purification attempt at retention times: 0 to 5.6 minutes; 5.6 to 10.0 minutes; 10.0 to 20.8 minutes respectively 


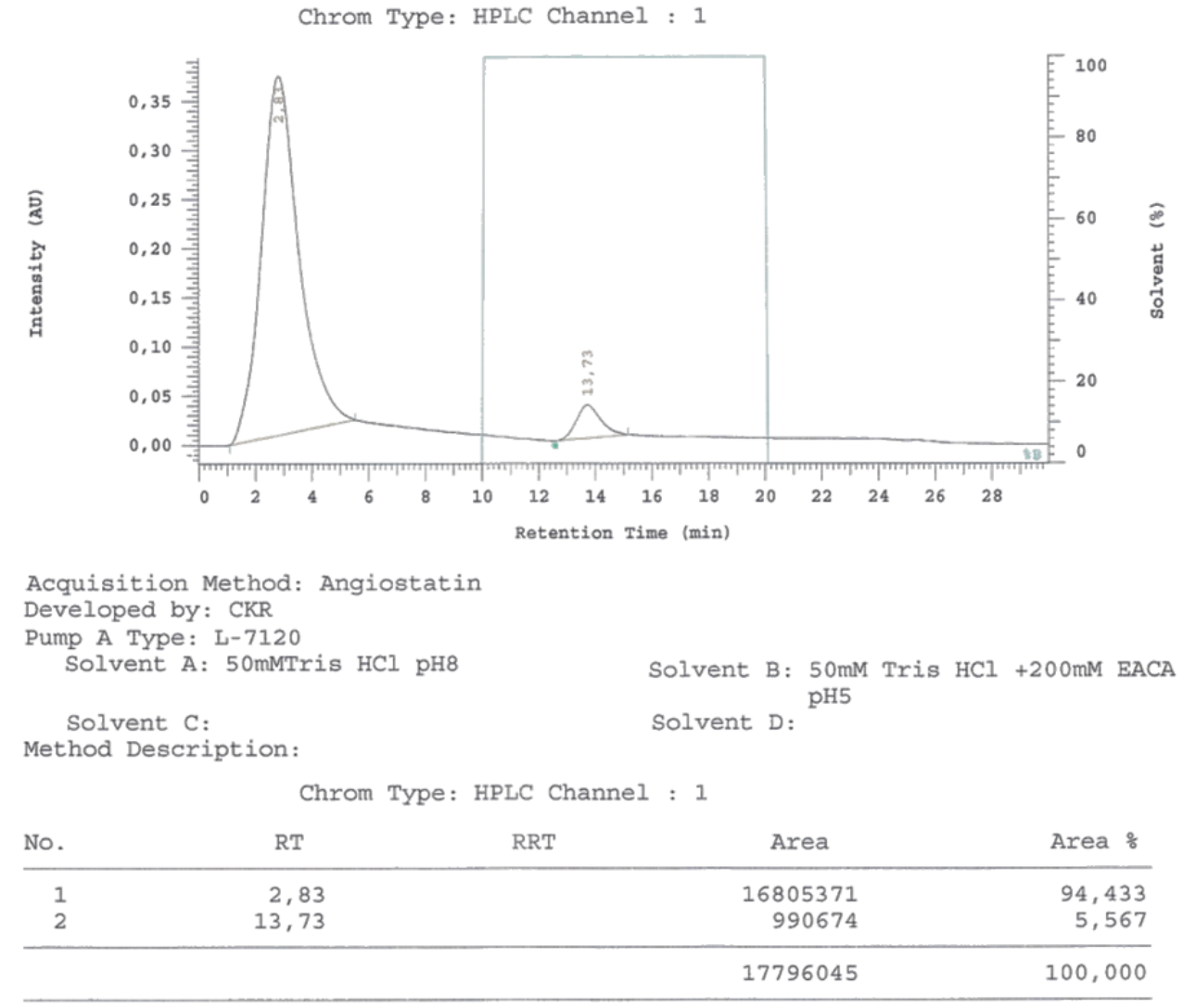

Figure 62: Chromatogram generated during purification of angiostatin from bovine plasminogen and BPP through L-lysine affinity column chromatography. The first pick obtained at 2.83 minutes retention time represent proteins recovered during binding phase, while the second pick at 13.73 minutes represent proteins recovered during elution phase.

\subsection{CONCLUSION}

Results from in vitro digestion initially implied inability of angiostatin to survive digestion. Further examination on affinity of individual enzymes to the anticancer peptide showed pepsin to be the enzyme responsible for completely hydrolyzing angiostatin under stomach conditions and at 12:1 enzyme substrate ratio. Nevertheless, at various E:S ratios, pepsin did not show significant hydrolysis even at a proportion of 1:10, which may represent a more credible relationship between pepsin and the substrate that may occur in the stomach during digestion. 
When individually analyzed, pancreatin also showed some hydrolytic activity on angiostatin. Knowing that pancreatin consist in a mixture of enzymes, with proteases being mostly trypsin and $\alpha$-chymotrypsin, individual analysis of these two proteases was conducted to better identify the enzyme responsible for the hydrolytic activity observed. Results indicated $\alpha$-chymotrypsin to have higher affinity for the substrate than trypsin, since even at very low E:S ratios (1:50) $\alpha$-chymotrypsin showed angiostatin hydrolysis, contrarily to trypsin for which ratios of 1:3 were needed to see a similar effect.

In a similar way, these two digestive proteases were tested for their ability in hydrolyzing and generating anti-cancer fragments directly from bPG. As seen for angiostatin, $\alpha$-chymotrypsin showed higher hydrolytic activity than trypsin. However, ability in generating fragments in the $25 \mathrm{kDa}$ area, confirmed to belong to bPG internal structure, was seen for both trypsin and $\alpha$-chymotrypsin. It would be of interest in the future to further analyze the structure of these fragments obtained, and to examine their ability in inhibiting growth of cancerous cells. However, due to incongruity in the literature regarding the concentration of each digestive enzyme released in the stomach and small intestine, in order to better understand what really occurs during digestion, further in vivo analysis are suggested.

Subsequently, ability of bovine angiostatin to be purified through column chromatography using L-lysine affinity, as it is used to purify human angiostatin, was proven to be an efficient method to obtain a much purified molecule. 


\section{OVERALL CONCLUSION}

From this study it was possible to confirm ability of generating angiostatin like fragments from bPG through a variety of enzymes. The enzyme that showed higher ability in generating this $37 \mathrm{kDa}$ fragment, from the bovine source of the fibrinolytic zymogen, was elastase. In contrast, BPP showed higher affinity for hPG, since less incubation time as well as 10 fold less concentrated enzyme were required to obtain the fragment of interest compared to bPG. On the other hand, when comparing BPP with elastase and their ability in generating the bovine form of angiostatin, BPP reaction was much shorter, only one hour compared to the 8 hours required by elastase. However, the amount of the fragment produced was considerably higher from the action of elastase than BPP.

Moreover, from sequence analysis techniques, it was possible to confirm ability of BPP in generating angiostatin K1-4 and mini-PG having molecular weight of $37 \mathrm{kDa}$ and $34 \mathrm{kDa}$ respectively.

Discovery of Bacillus strains capable of generating proteases showing bPG affinity was also possible from this study. Particularly interesting was to uncover ability of some Bacillus, such as B.coagulans ATCC 7050, of releasing a fragment in the $37 \mathrm{kDa}$ area showing immunoreaction with the anti-bovine plasminogen antibody utilized to conduct western blotting analysis.

From the anticancer activity conducted on human melanoma and colon cancerous cells, results showed significant activity in growth inhibition of these malignant cells by the action of bovine angiostatin when administered at concentrations of 3-16 $\mu \mathrm{g} / \mathrm{ml}$. Comparison of this activity between human and bovine sources of angiostatin, showed resemblance among the results obtained, inferring that the two molecules may act through the same mechanism and have similar affinity for specific targets located on cancerous cells. Additionally, human and bovine PG also showed ability in inhibiting cancerous cells growth. Knowing that malignant cells secrete enzymes necessary for the support of their metabolism, it would be of interest to further examine if the anticancer activity seen in PG samples is not actually due to angiostatin produced by the action of the proteases released during cancerous cells growth. 
From the in vitro digestion analysis, results at first suggested inability of angiostatin to survive digestion. Individual analysis of digestive enzymes in hydrolyzing angiostatin showed pepsin to be responsible for this observation. However, in order to further analyze the interaction between pepsin and angiostatin various E:S ratios were analyzed. High hydrolysis was observed for ratios of 12:1 pepsin:angiostatin (ratio used for the in vitro analysis). This ratio however may not mimic real stomach conditions, particularly since small amounts of protein and in a pure form are being used in this study. When this ratio is reduced to 1:10 no significant hydrolysis, even after 1 hour incubation, is observed. Since determination of real digestive conditions (i.e. amount of digestive enzymes involved) are still under investigation due to difficulties related to variability among individuals and the numbers of factors that need to be considered, in order to verify validity of these results in vivo analysis is suggested.

Regardless of the uncertain amount of specific digestive enzymes released in the stomach and small intestine during digestion, analysis on the ability of trypsin and $\alpha$ chymotrypsin in hydrolyzing angiostatin or bPG was conducted. Various E:S ratios were examined, and results showed $\alpha$-chymotrypsin to have higher affinity, both for bPG and angiostatin, that trypsin. Nevertheless, both proteases were able to generate a fragment in the $25 \mathrm{kDa}$ area belonging to the internal portion of PG. Knowing that each kringle or various kringle combinations have shown to exert some anticancer activity, it would be of interest to further investigate the structure and possible anticancer activity of these fragments, to analyze if peptides capable of cancer prevention can be generated directly in our body during milk digestion.

Finally, methods to purify bovine angiostatin were confirmed. Affinity 1-lysine column chromatography, used in the purification of human angiostatin, resulted to be an effective method to obtain pure bovine angiostatin. 


\section{FUTURE RESEARCH RECOMMENDATIONS}

Results obtained from this study open a new area of investigation, particularly in the food science field. Before being able to generate a food product enriched in angiostatin, it is necessary to further investigate what form of the molecule exert the higher anticancer activity (i.e. K1-4, K1-3 or other).

Also, it remains to be elucidated what concentration of angiostatin would be ideal to have a significant anticancer activity, as well as what type of cancer is more susceptible to bovine angiostatin. The mechanism through which this molecule acts to stop cancerous cells growth and spread also requires deeper investigation.

Additionally, it would be of interest to better understand what conditions and nutrients cause Bacillus to generate proteases capable of releasing angiostatin like fragments from plasminogen. Identification of the genes activated under ideal conditions could be then be used to genetically modify LAB that can be subsequently used to produce dairy products, i.e. yogurt, enriched in angiostatin.

Moreover, knowing that in vitro analysis not always reflect in vivo conditions, tests on animals and humans are necessary to prove validity of the results obtained in the laboratory.

Subsequently, further analysis on angiostatin digestion survival is highly recommended. Particularly of interest is to further study the ability and amount of this peptide to be absorbed by the body during digestion and if digestive enzymes can indeed interact directly with bPG in milk during digestion to generate potential anticancer peptides. 


\section{APPENDIX A. Supplemental data corresponding to Chapter 2: Bovine plasminogen proteolytic fragments generated by Bacillus polymyxa protease}

\section{A.1 Objective}

To analyze the kinetics of the reaction between BPP and bPG through Lineweaver-Burk and Hanes-Woolf Plot.

\section{A.2 Materials and Methods}

All materials and methods have been described in Chapter 2, section 2.3.1 (reagents and sources), 2.3.2 (sample preparation), and 2.3.2.3.1 (SDS-PAGE).

\section{A.3 Results and Conclusions}

Looking at the saturation curve in Figure 63, it is possible to determine Vmax as $442.13 \mathrm{int} / \mathrm{min}$ that is reached when BPP is reacted at $0.1 \mathrm{mg} / \mathrm{ml}$ with $0.625 \mathrm{mg} / \mathrm{ml}$ of bPG. Subsequently from the Lineweaver-Burk observed in Figure 64, Vmax and Km are identified as 1203.369 and 0.977 respectively, while from the Hanes-Woolf Plot (Figure 65), Vmax result to be equal to 1000 and $\mathrm{Km}$ to 0.8 . The results obtained from these two kinetic analyses are not in agreement with the observation made from the SDS-PAGE obtained in Figure 11. Knowing that a large $\mathrm{Km}$ (which can assume values between 0 and 1) indicate little affinity of the enzyme for the substrate, values of Km of 0.977 or 0.8 as those obtained in this kinetic analysis, imply that BPP has little to no affinity for bPG. However, from the gel images obtained throughout this study it is possible to confirm that it is not the case, and that BPP actually shows high affinity for bPG. An explanation to the incongruity between these results may be the values used to construct the graphs in Figure 64 and 65. In general, enzyme and substrate concentration is used to examine the kinetics of a reaction. In our case however this was not possible, quantification of the substrate was analyzed through band intensity measure from the SDS-PAGE through densitometry. Perhaps the intensity readings made from the densitometer are not accurate enough to translate what observed in the gel into a graph. 


\section{Saturation Curve}

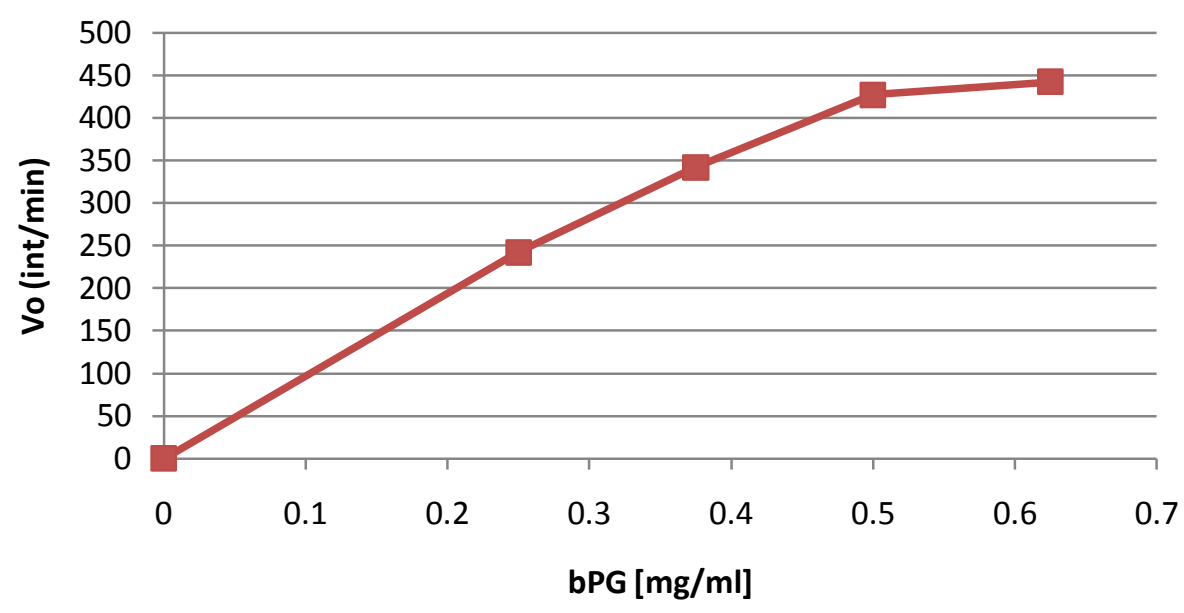

Figure 63: Saturation curve obtained from the reaction between BPP $(0.1 \mathrm{mg} / \mathrm{ml})$ and various bPG concentrations $(0.25,0.375,0.5$ and $0.625 \mathrm{mg} / \mathrm{ml})$ after 1 hour incubation at $37^{\circ} \mathrm{C}$

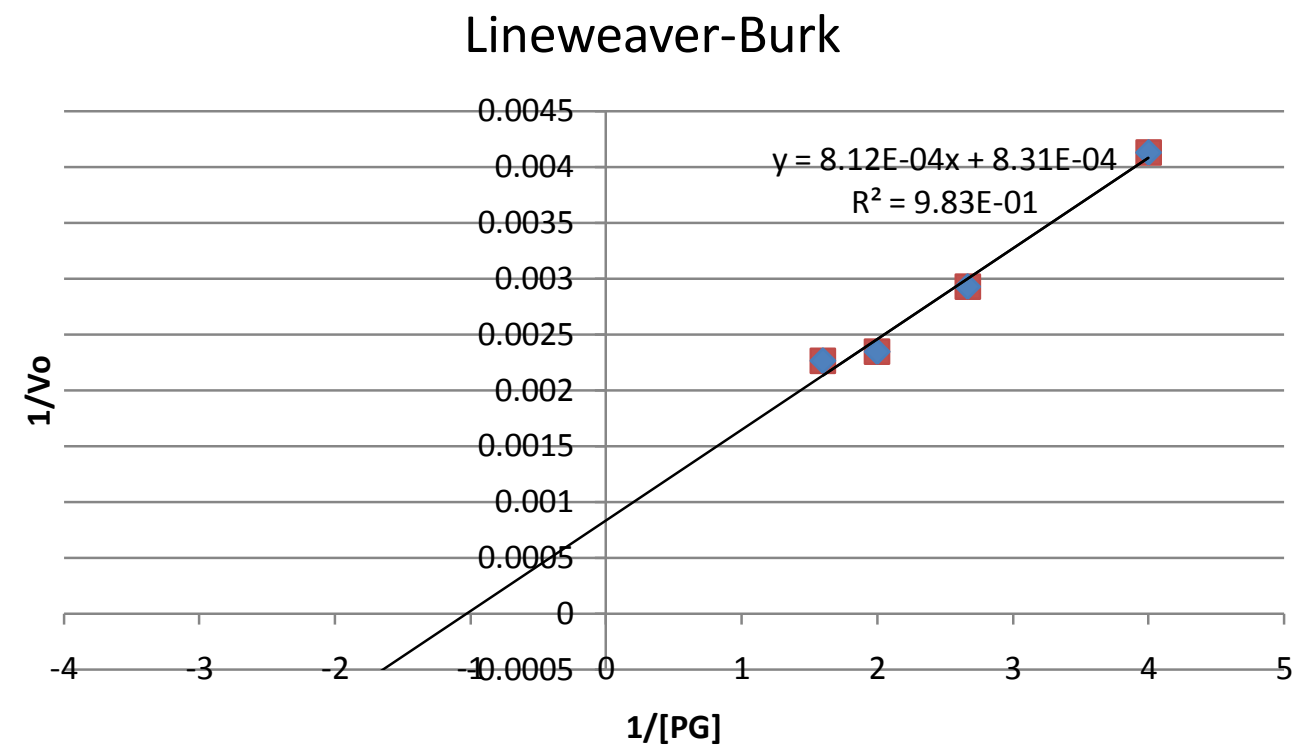

Figure 64: Lineweaver-Burk obtained by plotting the inverse of the initial velocities from the interaction between various bPG concentrations $(0.25,0.375,0.5$ and $0.625 \mathrm{mg} / \mathrm{ml})$ and $\operatorname{BPP}(0.1 \mathrm{mg} / \mathrm{ml})$ after 1 hour incubation at $37^{\circ} \mathrm{C}$ and the inverse of $\mathrm{bPG}$ concentration used 


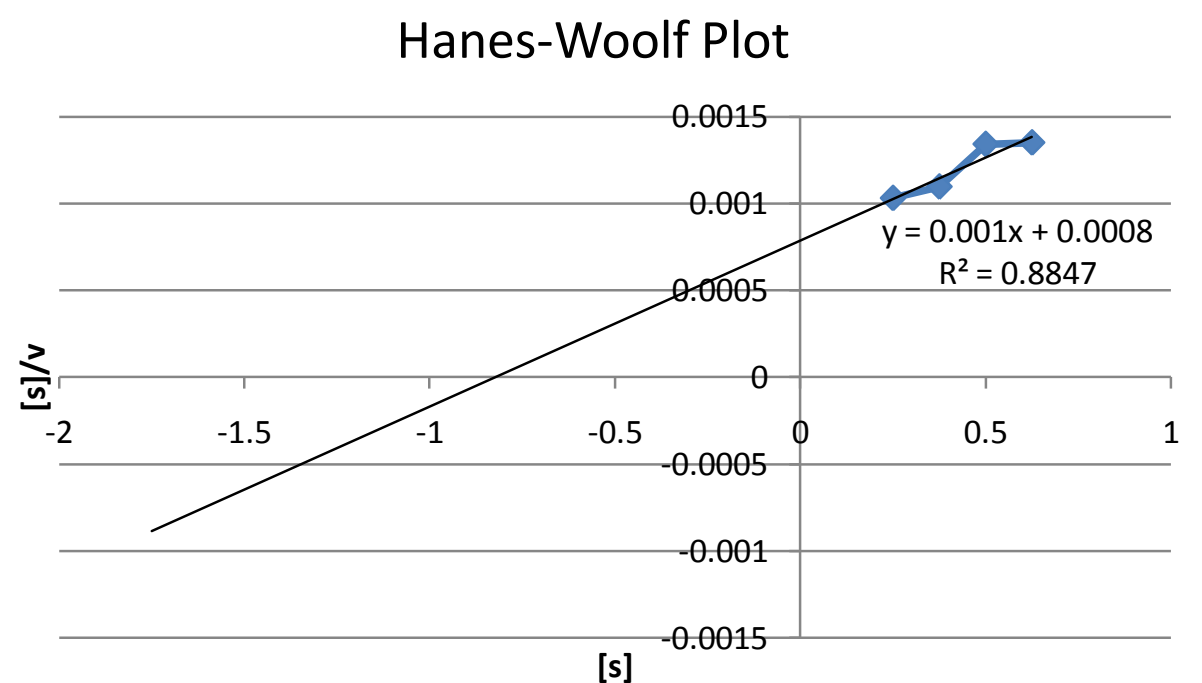

Figure 65: Hens-Woolf plot obtained by plotting bPG concentration vs. the value obtained by dividing the substrate concentration with the corresponding initial velocity observed between BPP and bPG interaction

\title{
APPENDIX B. Supplemental data corresponding to Chapter 2: Bovine plasminogen proteolytic fragments generated by Bacillus polymyxa protease
}

\author{
B. 1. Objective
}

Determine sequence analysis of bands of interest obtained from BPP and bPG hydrolysis

\section{B. 2. Results and Conclusions}

From the data obtained from sequence analysis obtained through LCMS conducted at UC Davis proteomics core, it was possible to identify peptides generated at 35,37 and $50 \mathrm{kDa}$, after reaction between BPP and bPG, as mini-PG, angiostatin K1-4 and PL respectively. Even if results can be observed in Figures 66, 67 and 68, for more accurate interpretation only fragments that resulted to have an actual minus calculated 
peptide mass (PPM) between \pm 200 were considered in order to examine only peptides showing higher probability.

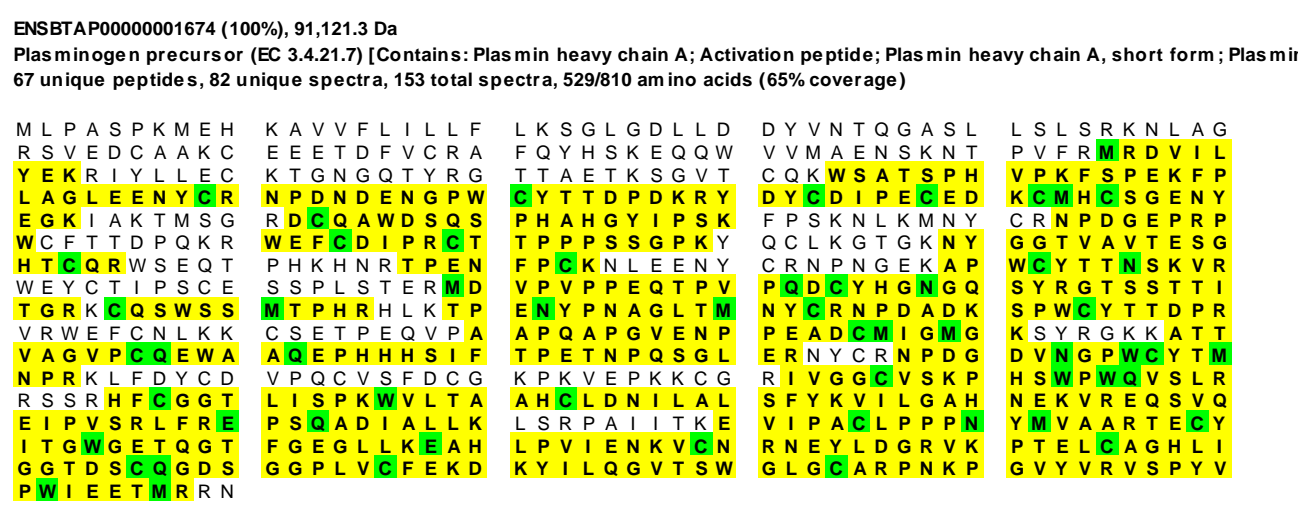

Figure 66: Sequence analysis of $35 \mathrm{kDa}$ fragment generated through bPG hydrolysis by the action of BPP $(0.1 \mathrm{mg} / \mathrm{ml})$ after 1 hour incubation. The colored amino acids represent the sequence coverage of bPG, and in green are observed post-translational modifications

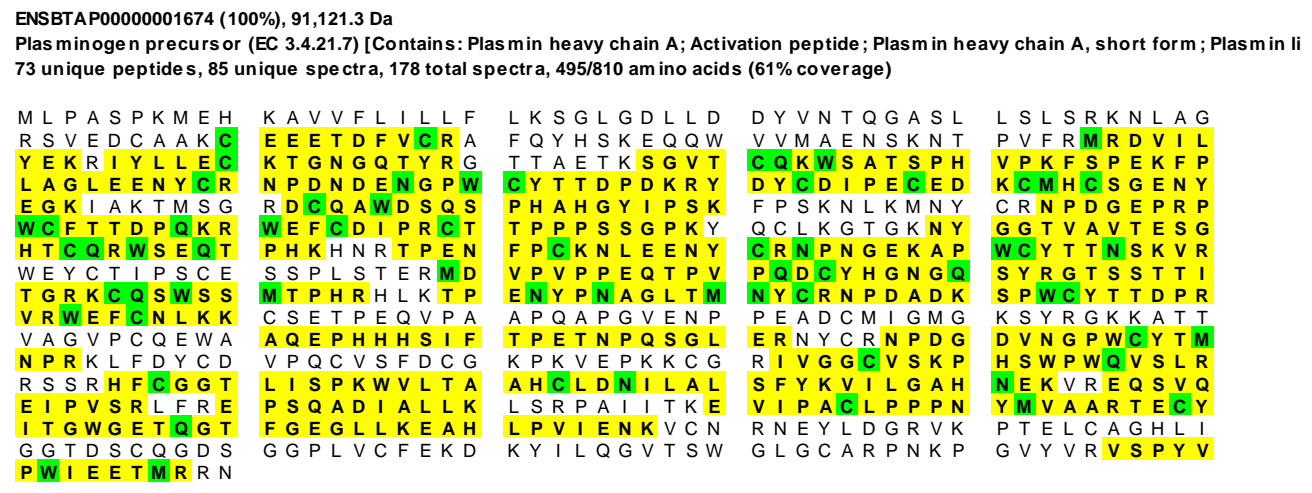

Figure 67: Sequence analysis of $37 \mathrm{kDa}$ fragment generated through bPG hydrolysis by the action of BPP $(0.1 \mathrm{mg} / \mathrm{ml})$ after 1 hour incubation. The colored amino acids represent the sequence coverage of bPG, and in green are observed post-translational modifications 


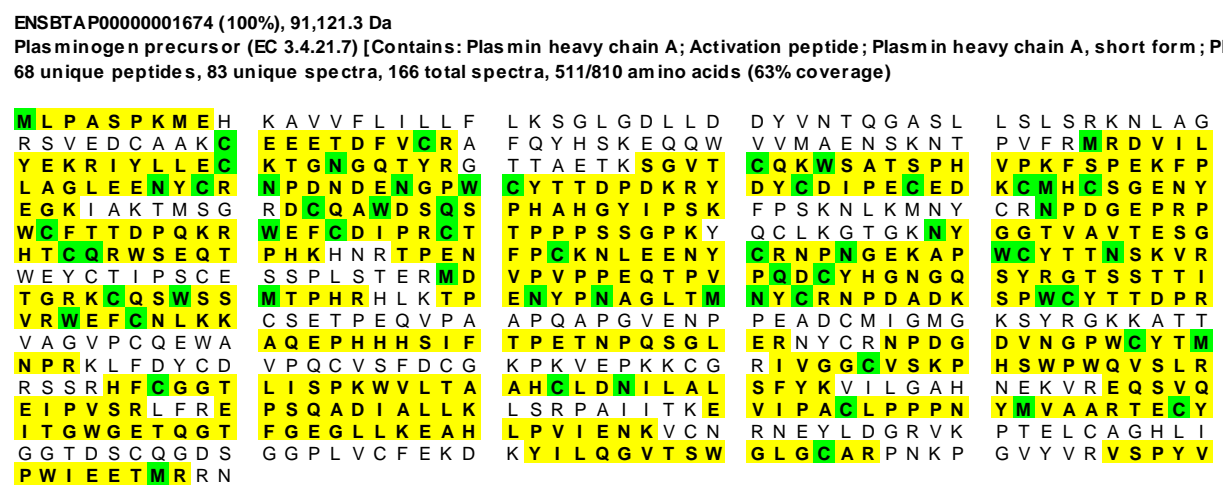

Figure 68: Sequence analysis of $50 \mathrm{kDa}$ fragment generated through bPG hydrolysis by the action of BPP $(0.1 \mathrm{mg} / \mathrm{ml})$ after 1 hour incubation. The colored amino acids represent the sequence coverage of $\mathrm{bPG}$, and in green are observed post-translational modifications

\section{APPENDIX C. Additional data corresponding to Chapter 2: Generation of angiostatin from bovine plasminogen hydrolysis by the action of Bacillus and Lactobacillus originated proteases}

\section{C.1. Objective}

To analyze ability of Lactobacillus in generating proteases when grown in MRS$5 \%$ UHT

\section{C.2. Reagents and Sources}

All materials and methods have been described in Chapter 2, sections 2.3.1 (reagents and sources), 2.3.4.1 (sample preparation), and 2.3.4.1 (Casein-agar plates).

\section{C.3. Results and Conclusions}

From the casein agar plates seen in Figure 68, it is possible to observe how Lactobacillus grown in MRS with 5\% UHT milk did not develop proteases capable of casein hydrolysis since zones of clearance are not observed for most of the lactobacilli tested except for Bifidobacterium longum 15708 and slightly for Lactobacillus reuteri 23272. 

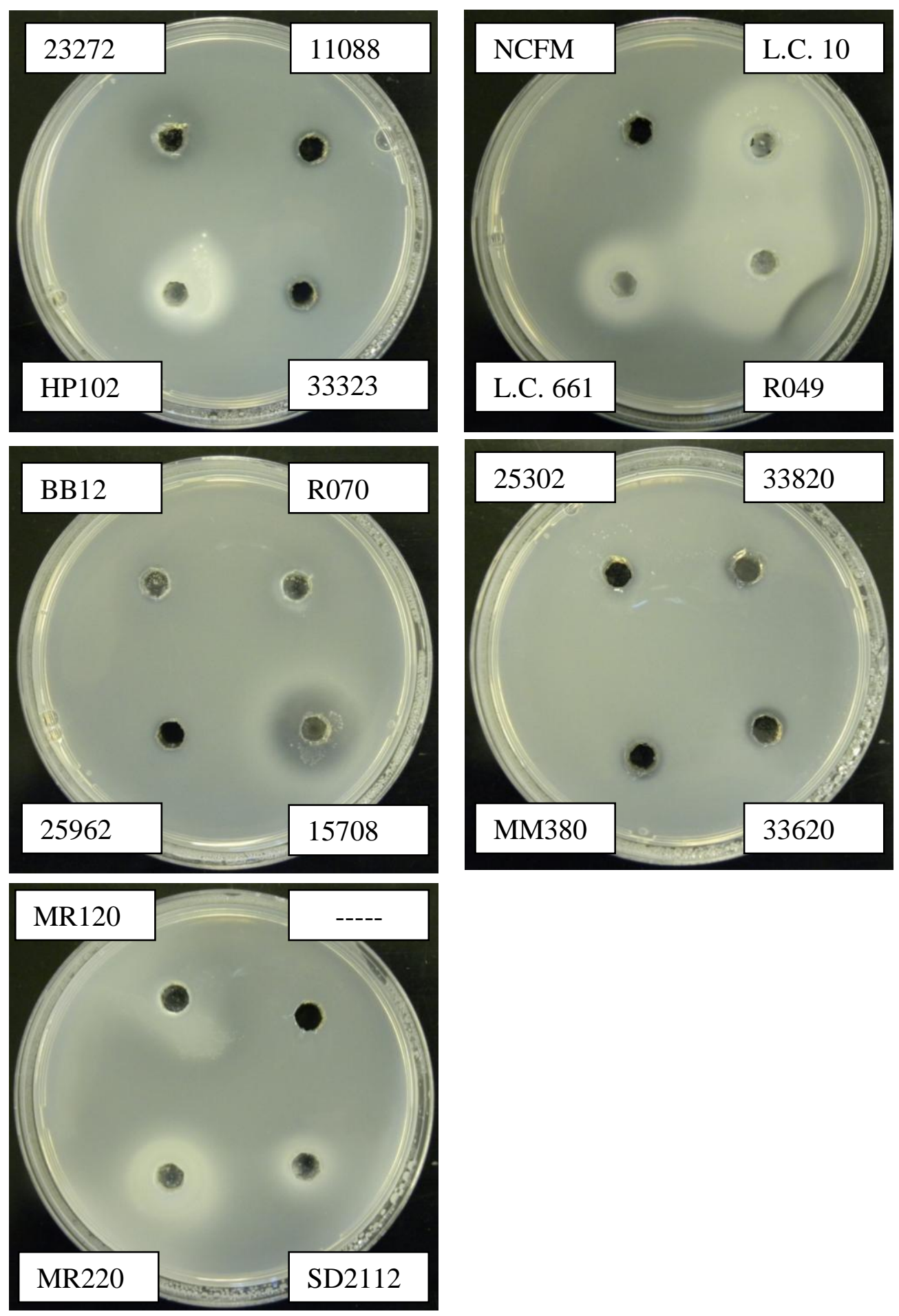

Figure 69: Casein-agar plates for analysis of caseinolytic activity of Lactobacillus grown in MRS-5\%UHT milk. 


\section{APPENDIX D. Additional data corresponding to Chapter 2: Generation of angiostatin from bovine plasminogen hydrolysis by the action of Bacillus and Lactobacillus originated proteases}

\section{D.1. Objective}

To determine different Bacillus growth and proteolytic enzymes generation between 12 and 24 hour incubation in TSB media at $37^{\circ} \mathrm{C}$.

\section{D.2. Material and sources}

Bacillus spores were grown in TSB media at $37^{\circ} \mathrm{C}$ for 12 and 24 hours. Subsequently optical density as well as hydrolytic activity was analyzed to compare growth between different strains and incubation length effect.

Strains analyzed: (classified based on observations made in previous experiments)

High affinity: ATCC 23857, ATCC 14581, ATCC 8186

Low affinity: ATCC 301, ATCC 4513, ATCC 23059

High Angiostatin generation: ATCC 7050, ATCC 14579

\section{D.3. Results and Conclusions}

According to the optical density obtained in Table 10, it is possible to observe how the absorbance is significantly reduced after 24 hours growth compared to that seen after only 12 hours incubation in TSB media. This indicates that fewer bacteria are present after 24 hours. This phenomenon is most probably due to nutrients depletion that occurs after bacteria have reached a specific concentration. Moreover from the plates seen in Figure 69, the majority of the Bacilli analyzed show higher caseinolytic activity after being grown for 12 hours than after 24 hours. It is based on these observations that in our study bacillus were prepared by growing them in media for 12 hours. 
Table 10: Optical density data obtained after 12 or 24 hours Bacillus growth in TSB media at $37^{\circ} \mathrm{C}$ (absorbance @ 686 nm (Colome et al. 1986))

\begin{tabular}{ccc}
\hline Strain & Optical density after 12h & Optical density after 24h \\
\hline $\mathbf{2 3 8 5 7}$ & 0.500 & 0.150 \\
$\mathbf{1 4 5 8 1}$ & 0.528 & 0.360 \\
$\mathbf{8 1 8 6}$ & 0.351 & 0.163 \\
$\mathbf{3 0 1}$ & 0.370 & 0.410 \\
$\mathbf{4 5 1 3}$ & 0.406 & 0.436 \\
$\mathbf{2 3 0 5 9}$ & 0.759 & 0.454 \\
$\mathbf{7 0 5 0}$ & 0.470 & 0.294 \\
$\mathbf{1 4 5 7 9}$ & 0.197 & 0.157 \\
Control (only media) & -0.021 & -0.022 \\
\hline
\end{tabular}
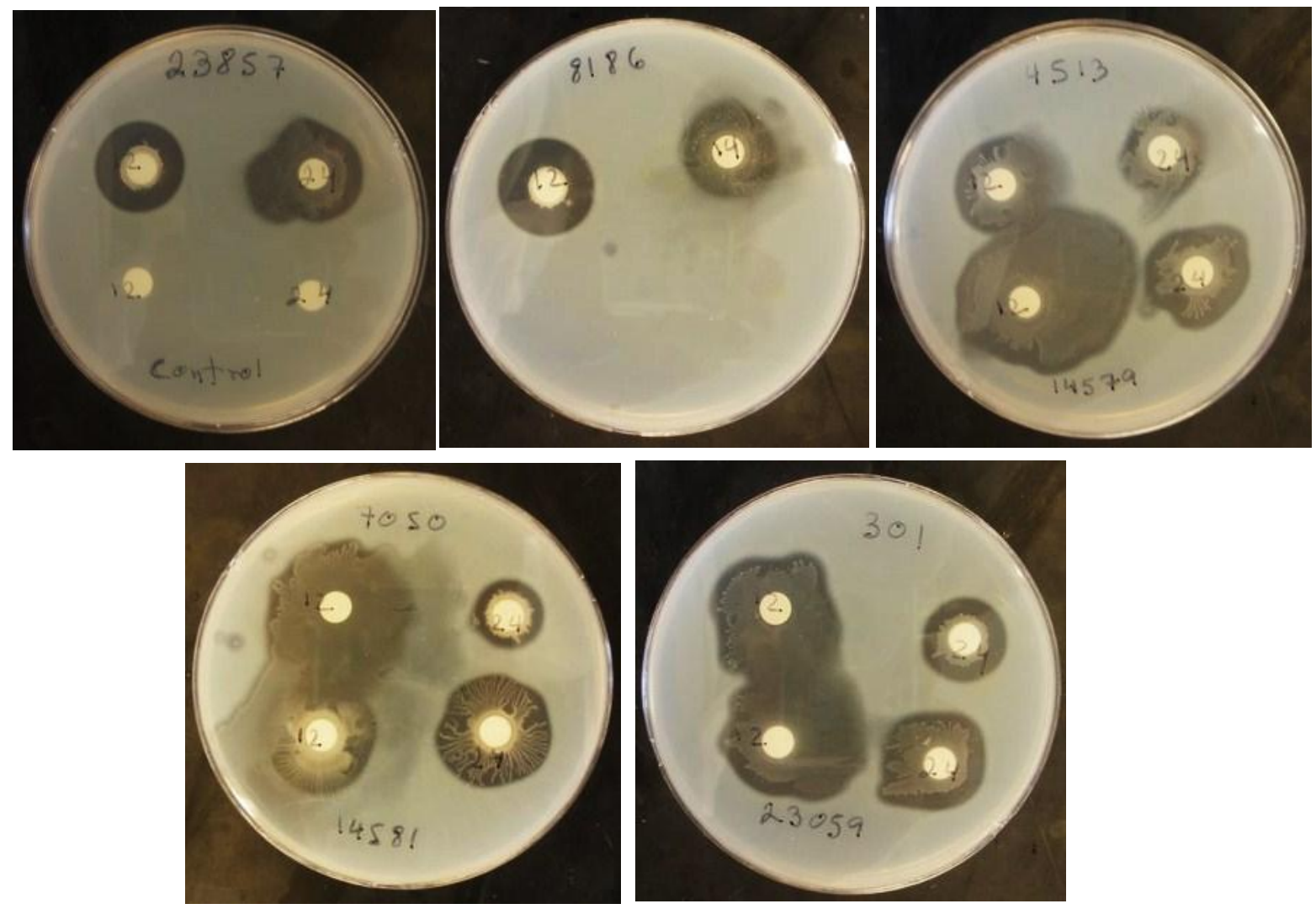

Figure 70: Skim milk agar plates for hydrolytic analysis of Bacillus grown for 12 vs. 24 hours in TSB growth media (plates were incubated at $37^{\circ} \mathrm{C}$ for $24 \mathrm{~h}$ ) 


\section{APPENDIX E. Additional data corresponding to Chapter 2: Generation of angiostatin from bovine plasminogen hydrolysis by the action of Bacillus and Lactobacillus originated proteases}

\section{E.1. Objective}

Identify fragments generated through bPG hydrolysis by the action of enzymes released from B.coagulans ATCC 7050 observed in Figure 41.

\section{E.2. Results and Conclusions}

From the sequence analysis data seen in Figures 70, 71, 72 and 73 no clear identification of the fragments generated was possible. Perhaps various fragments with same molecular weight were generated, causing difficulty in identification of individual peptides present in the same band. In fact if we consider Figure 70, analysis of the data shows that for example $78 \%$ of kringle 1 of bPG is present, while $92 \%$ of K2, $100 \%$ of K3 and $45.5 \%$ of K5. On the other hand Figure 73 shows that only $60 \%$ of K1 is present, $49 \%$ of $\mathrm{K} 2,52 \%$ of $\mathrm{K} 3,0 \%$ of $\mathrm{K} 4$ and only $20 \%$ of $\mathrm{K} 5$. Based on this information it seems that Figure 70 covers more bPG than Figure 73, however the sequence of the peptide analyzed in Figure 73 has a much higher molecular weight than that in Figure 70. Based on these observations it is not possible to identify which fragments are generated from bPG by the action of B.coagulans ATCC 7050 generated enzymes through LCMS. Other methods of analysis are required in order to clarify what products are being generated from this reaction. 


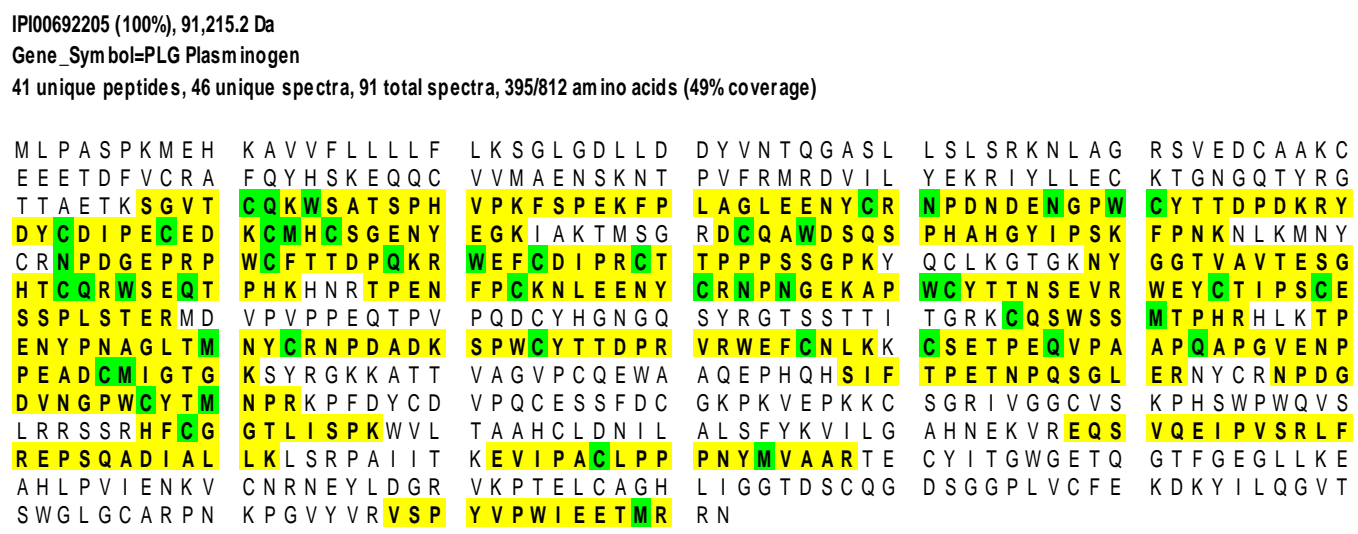

Figure 71: Sequence analysis of $22 \mathrm{kDa}$ fragment generated through bPG hydrolysis by the action of B.coagulans ATCC7050. The colored amino acids represent the sequence coverage of bPG, and in green are observed post-translational modifications. (Sequence interpretation: K1: 78\% - K2: 91\% - K3: 100\% - K4: 71\% - K5: 45.5\%)

\begin{tabular}{|c|c|c|c|c|c|}
\hline IPI00692205 (100\%), 91,215.2 Da & \multicolumn{5}{|c|}{ Gene_Sym bol=PLG Plasm inogen } \\
\hline \multicolumn{6}{|c|}{17 unique peptides, 19 unique spectra, 27 total spectra, $205 / 812$ am ino acids ( $25 \%$ coverage) } \\
\hline MLPASPKMEH & K A V V F L L L L F & L K S G L GD L L D & DY V N T Q GASL & LS LSRKNLAG & RSVEDCAAKC \\
\hline EEETDFVCRA & FQYHSKEQQC & V VMAENSKN T & P V FRMRDVIL & Y EKR I Y L LEC & K T GN GQT Y R G \\
\hline T T A E TKSGVT & CQKWS A T S PH & V PKF S P EK F P & L A G L E E N Y C R & N P D N D E G P W & CYTTDPDKRY \\
\hline DYCDIPECED & KCMHCSGENY & E GK I A K TMSG & $R D C Q A W D S Q S$ & PHAHGY I PSK & F P N K N LKMNY \\
\hline C R N P D G E P P & WCF T T D Q K R & WEFCDIPRCT & T P P P S S G PKY & QC L K G T GKN Y & G G T V A V TESG \\
\hline H T C QR W S E Q T & PHKHNRT PEN & F PCKN LEENY & CRNPNGEKAP & WCYTTNSEVR & WEYCTIPSCE \\
\hline SSPLSTERMD & V P V P P EQTPV & $P Q D C Y H G N G Q$ & S Y R G T S S T T I & T GRKCQSWS S & M T PHRHLKT P \\
\hline E N Y P N A G L T M & NYCR N PDADK & S PWCYTTDPR & VRWEFCNLKK & C S E T PEQVPA & A P Q A P GVEN P \\
\hline$P E A D C M \mid G T G$ & K S Y R GKKAT T & VAGVPCQEWA & $A Q E P H Q H S I F$ & TPETNPQSGL & ERNYCRNPDG \\
\hline D V N G P WCY T M & N PRKPFDYCD & VPQCESSFDC & GK PKVEPKKC & $S G R \mid V G G C \vee S$ & K P H SWPWQVS \\
\hline L R R S SRHFC G & G T L I S P K WV L & TAAHCLDNIL & $A L S F Y K V I L G$ & A H N EKVREQS & VQE I P VSRLF \\
\hline$R E P S Q A D \mid A L$ & LKLSRPAII T & KEV I PACLPP & PN Y M V A ARTE & $C Y \mid T G W G E T Q$ & G TFGEGLLKE \\
\hline A H L P V I ENK V & CNRNEYLDGR & VKPTELCAGH & $L \mid G G T D S C Q G$ & $D S G G P L V C F E$ & KDKY I LQGVT \\
\hline$S W G L G C A R P N$ & $K P G \vee Y \vee R \vee S P$ & Y V PW I E E T MR & R N & & \\
\hline
\end{tabular}

Figure 72: Sequence analysis of $25 \mathrm{kDa}$ fragment generated through bPG hydrolysis by the action of B.coagulans ATCC7050. The colored amino acids represent the sequence coverage of bPG, and in green are observed post-translational modifications. (Sequence interpretation: K1: $82 \%$ - K2: 44\% - K3: 54.5\% - K4: 0\% - K5: 20\%) 


\begin{tabular}{|c|c|c|c|c|c|}
\hline \multicolumn{6}{|c|}{ IPI00692205 (100\%), 91,215.2 Da } \\
\hline \multicolumn{6}{|c|}{ Gene_Sym bol=PLG Plasm inogen } \\
\hline \multicolumn{6}{|c|}{13 unique peptides, 14 unique spectra, 21 total spectra, $176 / 812$ am ino acids ( $22 \%$ coverage) } \\
\hline MLPASPKMEH & $K A \vee V F L L L L F$ & LKSGLGDLLD & $D Y \vee N T Q G A S L$ & LS L SRKNLAG & RS VEDCAAKC \\
\hline EEETDF V C R A & $F Q Y H S K E Q Q C$ & V VMAENSKN T & P V FRMRDVIL & YEKR I YLLEC & $K T G N G Q T Y R G$ \\
\hline T T A E TKSGVT & CQKW S A T S P H & VPKF SPEKF P & L A G LEEN Y C R & NPDNDENGPW & CYTTDPDKRY \\
\hline DYCDIPECED & KCMHCSGENY & $E G K \mid A K T M S G$ & $R D C Q A W D S Q S$ & PHAHGY I PSK & F PNKNLKMNY \\
\hline CRN PDGEPRP & WCFT T D PQK R & WEFCD I PRCT & T P P P S S G PKY & QCLKGTGKN Y & G G T VA V TESG \\
\hline H T CQRWSEQT & PHKHNRT PEN & F PCKN LEENY & CRNPNGEKAP & WCYTT N SE VR & WEYCT I PSCE \\
\hline S SPLSTERMD & V P VPPEQTP V & $P Q D C Y H G N G Q$ & SYRGTSSTTI & $T G R K C Q S W S S$ & M T PHRH LKT P \\
\hline EN Y P N A GL T M & NYCRNPDADK & SPWCYTTDPR & VRWEFCNLKK & CSETPEQVPA & A P Q A P GVEN P \\
\hline$P E A D C M I G T G$ & K S Y R GKKAT T & VAG VPCQEWA & $A Q E P H Q H S \mid F$ & TPETNPQSGL & ERN Y CRN PDG \\
\hline D VNGPWCY T M & NPRKPFDYCD & VPQCESSFDC & GKPKVEPKKC & $S G R \mid V G G C \vee S$ & K PH SWPWQ V S \\
\hline LRRSSRHFCG & G T L I SPKWVL & TAAHCLDN I L & $A L S F Y K V I L G$ & A HNEKVREQS & VQE I P V SRLF \\
\hline REPSQADIAL & LKLSRPA I I T & KEV I PACLPP & PN Y M V A ARTE & $C Y \mid T G W G E T Q$ & GTFGEGLLKE \\
\hline A H L P V I ENKV & CNRNEYLDGR & VKPTELCAGH & $L I G G T D S C Q G$ & $D S G G P L V C F E$ & $K D K Y$ I LQGVT \\
\hline$S W G L G C A R P N$ & $K P G \vee Y \vee R \vee S P$ & Y V P W I E ETMR & $\mathrm{R} \mathrm{N}$ & & \\
\hline
\end{tabular}

Figure 73: Sequence analysis of $27 \mathrm{kDa}$ fragment generated through bPG hydrolysis by the action of B.coagulans ATCC7050. The colored amino acids represent the sequence coverage of bPG, and in green are observed post-translational modifications. (Sequence interpretation: - K1: $63 \%$ - K2: 56\% - K3: $31 \%$ - K4: 0\% - K5: 0\%)

IPI00692205 (100\%), $91,215.2$ Da
Gene_Symbol=PLG Plasminogen
20 unique peptides, 22 unique spectra, 32 total spectra, 244/812 amino acids (30\% coverage)
MLPASPKMEH
K A V V L LLLF

Figure 74: Sequence analysis of $30 \mathrm{kDa}$ fragment generated through bPG hydrolysis by the action of B.coagulans ATCC7050. The colored amino acids represent the sequence coverage of bPG, and in green are observed post-translational modifications. (Sequence interpretation: - K1: $60 \%$ - K2: 49\% - K3: 52\% - K4: 0\% - K5: 20\%) 


\section{APPENDIX F. Additional data corresponding to Chapter 4: In vitro digestion model}

F.1. Objective

To determine lipase contamination through casein-SDS-PAGE

\section{F.2. Materials and Sources}

Casein-SDS-PAGE was prepared following procedures outlined by Fajardo-Lira and Nielsen (1998) with some modifications, and using the buffers which recipes are outlines in Table 11. Briefly, 20ul of each samples were prepared and 1:1 v/v Laemmli buffer was added without boiling. In order to allow SDS binding, samples were incubated at room temperature 30 minutes prior to electrophoresis.

Prior to loading samples, casein-SDS-PAGE gel was pre-run at $200 \mathrm{~V}$ for $60 \mathrm{~min}$ to disperse the casein. Samples were then loaded and electrophoresis conducted following regular procedures. Once the proteins reach the bottom of the gel, the gel is removed and washed in casein-SDS-PAGE washing buffer to remove SDS, and subsequently incubated with casein-SDS-PAGE incubating buffer for $24 \mathrm{~h}$. At this point the molecular weight marker is removed and stored it in ddwater. The rest of the gel is stained and distained following regular procedures. 
Table 11: Buffer recipes for casein SDS-PAGE

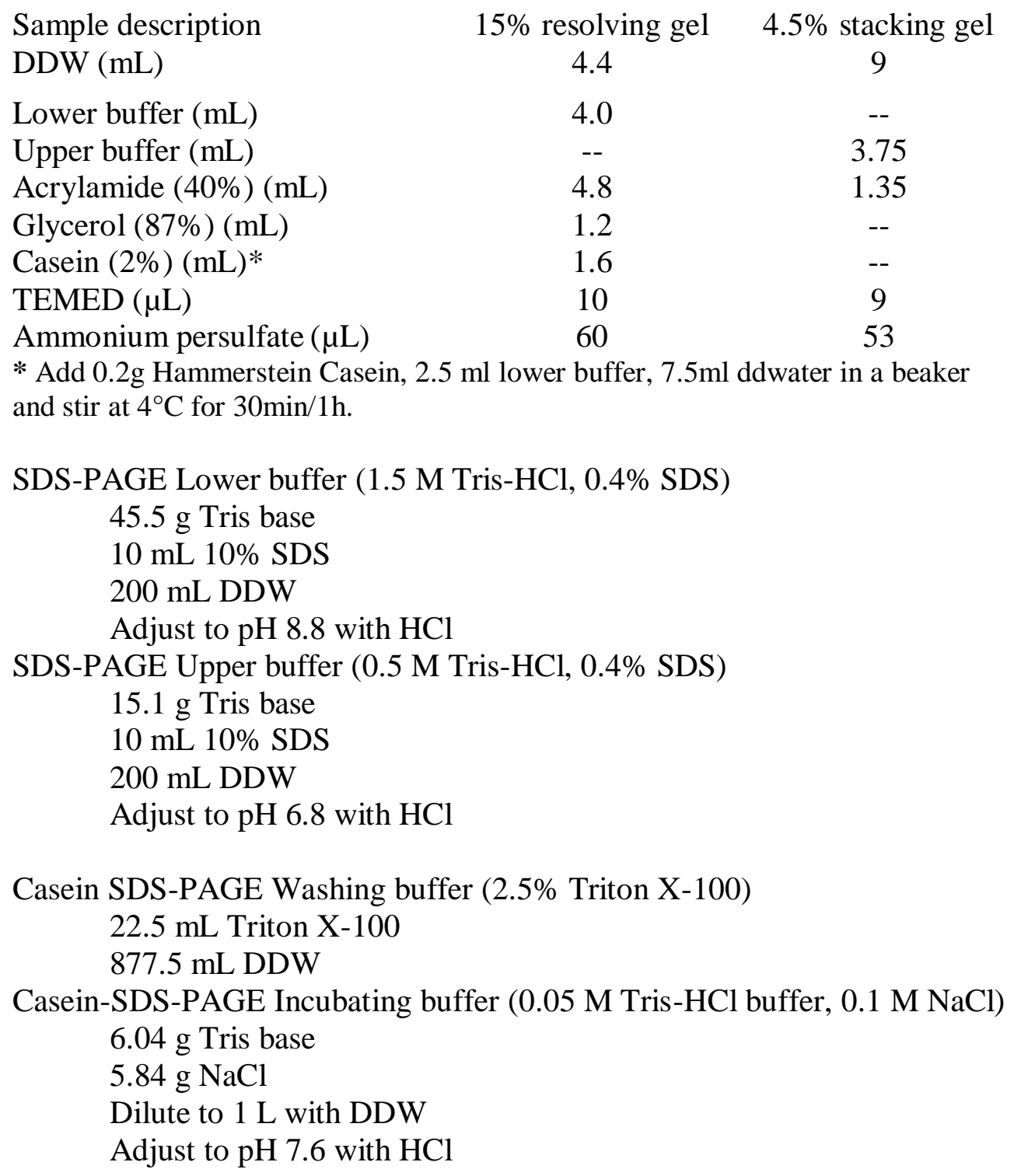

\section{F.3. Results and Conclusions}

Based on the CN-SDS-PAGE obtained in Figure 74, it is possible to observe contamination in lipase sample (lane 5), since lipase is not supposed to be able to hydrolyze casein, since it activity its lipid specific. Additionally, the enzymes seen in lipase sample seem to be the same observed in pancreatin samples known to contain proteases such as trypsin and chymotrypsin. Based on these observations, lipase was not used in our study. 


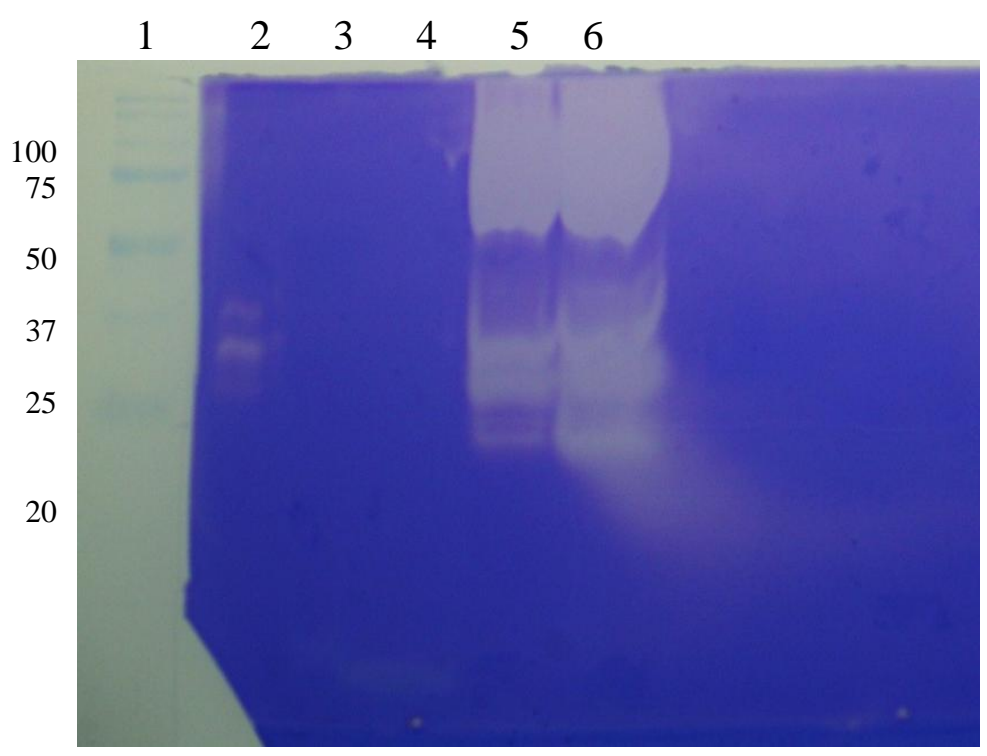

Figure 75: Casein SDS-PAGE for analysis of lipase contamination. Lane 1: MW standard; lane 2: cathepsin-D control; lane 3: pepsin; lane 4: bile; lane 5: lipase; lane 6: pancreatin 


\section{REFERENCE}

Abad Marta C.,Arni R. K., et al. (2002). "The X-ray Crystallographic Structure of the Angiogenesis Inhibitor Angiostatin." Journal of Molecular Biology 318(4): 10091017.

Alberts Bruce,Alexander Johnson, et al. (2008). Molecular biology of the cell New York Garland Science

Astwood James D.,Leach John N., et al. (1996). "Stability of food allergens to digestion in vitro." Nat Biotech 14(10): 1269-1273.

Bastian Eric D. and Brown Rodney J. (1996). "Plasmin in milk and dairy products: an update." International Dairy Journal 6(5): 435-457.

Beerepoot Laurens V.,Witteveen Els O., et al. (2003). "Recombinant Human Angiostatin by Twice-Daily Subcutaneous Injection in Advanced Cancer." Clinical Cancer Research 9(11): 4025-4033.

Benfeldt Connie,Larsen Lotte B., et al. (1995). "Isolation and characterization of plasminogen and plasmin from bovine milk." International Dairy Journal 5(6): 577-592.

Bergers Gabriele and Laura E. Benjamin (2003). "Tumorigenesis and the angiogenic switch " Nature reviews 3: 401-410.

Bloomfield Victor (2009). Computer Simulation and Data Analysis in Molecular Biology and Biophysics: An Introduction Using R (Biological and Medical Physics, Biomedical Engineering) New York, NY, Springer

Bodwell C. E. ,Satterlee L. D. , et al. (1980). "Protein digestibility of the same protein preparations by human and rat assays and by in vitro enzymic digestion methods." The American Journal of Clinical Nutrition 33: 677-686.

Boyer Paul D. (1997). The ATP synthase-a splendid molecular machine. Annual Review of Biochemistry, Annual Reviews Inc. 66: 717.

Burbrink C. N. and Hayes K. D. (2006). "Effect of thermal treatment on the activation of bovine plasminogen." International Dairy Journal 16(6): 580-585.

Cao Renhai, Wu Hua-Lin, et al. (1999). "Suppression of angiogenesis and tumor growth by the inhibitor K1-5 generated by plasmin-mediated proteolysis." Proceedings of the National Academy of Sciences of the United States of America 96(10): 57285733.

Cao Yihai (2004). "Angiogenesis cancer therapy " Seminars in Cancer Biology 14: 139145. 
Cao Yihai,Chen Andrew, et al. (1997). "Kringle 5 of Plasminogen is a Novel Inhibitor of Endothelial Cell Growth." Journal of Biological Chemistry 272(36): 2292422928.

Cao Yihai,Ji Richard W., et al. (1996). "Kringle Domains of Human Angiostatin." Journal of Biological Chemistry 271(46): 29461-29467.

Carmeliet Peter and Jain Rakesh K. (2000). "Angiogenesis in cancer and other diseases." Nature 407(6801): 249-257.

Chi Sulene L. and Pizzo Salvatore V. (2006). "Angiostatin Is Directly Cytotoxic to Tumor Cells at Low Extracellular pH: A Mechanism Dependent on Cell SurfaceAssociated ATP Synthase." Cancer Research 66(2): 875-882.

Cho Eunyoung,Smith-Warner Stephanie A., et al. (2004). "Dairy Foods, Calcium, and Colorectal Cancer: A Pooled Analysis of 10 Cohort Studies." Journal of the National Cancer Institute 96(13): 1015-1022.

Colome,Kubinski, et al. (1986). Laboratory exercises in microbiology St. Paul, MN.

Cuatrecasas P.,Wilchek M., et al. (1968). "Selective enzyme purification by affinity chromatography." Proceedings of the National Academy of Sciences 61(2): 636643.

De Man J. C.,Rogosa M., et al. (1960). "A MEDIUM FOR THE CULTIVATION OF LACTOBACILLI." Journal of Applied Microbiology 23(1): 130-135.

Deutsch Dale G. and Mertz Edwin T. (1970). "Plasminogen: Purification from Human Plasma by Affinity Chromatography." Science 170(3962): 1095-1096.

Dulak J. (2005). "Nutraceuticals and Anti-angiogenic Agents: Hopes and Reality." Journal of Physiology and Pharmacology 56: 51-69.

Ferrara Napoleone and Kerbel Robert S. (2005). "Angiogenesis as a therapeutic target." Nature 438(7070): 967-974.

Ferruzzi Mario G.,Failla Mark L., et al. (2001). "Assessment of Degradation and Intestinal Cell Uptake of Carotenoids and Chlorophyll Derivatives from Spinach Puree Using an In Vitro Digestion and Caco-2 Human Cell Model." Journal of Agricultural and Food Chemistry 49(4): 2082-2089.

Figg William D. and Folkman Judah (2008). Angiostatin and Endostatin: Angiogenesis Inhibitors in Blood and Stroma. Angiogenesis, Springer US: 129-146.

Folkman Judah (2006). "Angiogenesis." Annual Review of Medicine 57(1): 1-18.

Folkman Judah and Kalluri Raghu (2004). "Cancer without disease." Nature 427(6977): 787-787. 
Fu Tong-Jen,Abbott Upasana R., et al. (2002). "Digestibility of Food Allergens and Nonallergenic Proteins in Simulated Gastric Fluid and Simulated Intestinal FluidA Comparative Study." Journal of Agricultural and Food Chemistry 50(24): 7154-7160.

Gatenby Robert A. and Gillies Robert J. (2004). "Why do cancers have high aerobic glycolysis?" Nat Rev Cancer 4(11): 891-899.

Geiger J. H. and Cnudde S. E. (2004). "What the structure of angiostatin may tell us about its mechanism of action." Journal of Thrombosis and Haemostasis 2(1): 2334.

Genentech (2008). Avastin (Bevacizumab) For Intravenous Use. Inc. BL125085/145 Amendment: Bevacizumab-Genentech. South San Francisco.

Gonzalez-Gronow Mario,Kalfa Theodosia, et al. (2003). "The Voltage-dependent Anion Channel Is a Receptor for Plasminogen Kringle 5 on Human Endothelial Cells." Journal of Biological Chemistry 278(29): 27312-27318.

Gordon R. E.,Haynes W. C., et al. (1973). "The genus Bacillus." U.S. Department of Agriculture Handbook 427.

Green Rodney J.,Murphy Angus S., et al. (2007). "Common tea formulations modulate in vitro digestive recovery of green tea catechins." Molecular Nutrition \& Food Research 51(9): 1152-1162.

Hanahan Douglas and A. Weinberg R. (2000). "The Hallmarks of Cancer " Cell 100: 5770.

Hanahan Douglas and Folkman Judah (1996). "Patterns and emerging mechanisms of the angiogenic switch during tumorigenesis " Cell 86 (3): 353-364.

Herriott Roger M. (1962). "Pepsinogen and pepsin " The Journal of General Physiology 45(4): 57-76.

The history of cancer (2010). American Cancer Society.

Ho Paulo Lee,Serrano Solange Maria de Toledo, et al. (2002). "Angiostatin-like molecules are generated by snake venom metalloproteinases." Biochemical and Biophysical Research Communications 294(4): 879-885.

Hur Sun Jin,Lim Beong Ou, et al. (2011). "In vitro human digestion models for food applications." Food Chemistry 125(1): 1-12.

Ismail B. and Nielsen S. S. (2010). "Invited review: Plasmin protease in milk: Current knowledge and relevance to dairy industry." Journal of dairy science 93(11): 4999-5009. 
Järvinen R.,Knekt P., et al. (2001). "Prospective study on milk products, calcium and cancers of the colon and rectum." European Journal of Clinical Nutrition 55: 1000-1007.

Ji Weidong-richard,Castellino Francis J., et al. (1998). "Characterization of kringle domains of angiostatin as antagonists of endothelial cell migration, an important process in angiogenesis." FASEB J. 12(15): 1731-1738.

Judah Folkman and Yuen Shing (1992). "Angiogenesis " The Journal of Biological Chemistry 267(16): 10931-10934.

Kerbel Robert S. (2000). "Tumor angiogenesis: past, present and the near future." Carcinogenesis 21(3): 505-515.

Korycha-Dahl M.,Dumas B. Ribadeau, et al. (1983). "Plasmin Activity in Milk." Journal of dairy science 66(4): 704-711.

Kurup A.,Lin C.-W., et al. (2006). "Recombinant human angiostatin (rhAngiostatin) in combination with paclitaxel and carboplatin in patients with advanced non-smallcell lung cancer: a phase II study from Indiana University." Annals of Oncology 17(1): 97-103.

Laemmli U. K. (1970). "Cleavage of Structural Proteins during the Assembly of the Head of Bacteriophage T4." Nature 227(5259): 680-685.

Landau Elizabeth (2010) "How the ancient world dealt with cancer." $\underline{\text { CNNHealth. }}$

Larson N. K.,Ismail B., et al. (2006). "Activity of Bacillus polymyxa protease on components of the plasmin system in milk." International Dairy Journal 16(6): 586-592.

Lee Tong-Young,Muschal Stefan, et al. (2009). "Angiostatin regulates the expression of antiangiogenic and proapoptotic pathways via targeted inhibition of mitochondrial proteins." Blood 114(9): 1987-1998.

Lerch P. G.,Rickli E. E., et al. (1980). "Localization of Individual Lysine-Binding Regions in Human Plasminogen and Investigations on Their Complex-Forming Properties." European Journal of Biochemistry 107(1): 7-13.

Liekens Sandra,De Clercq Erik, et al. (2001). "Angiogenesis: regulators and clinical applications " Biochemical Pharmacology 61: 253-270.

Losso Jack N. (2003). "Targeting excessive angiogenesis with functional foods and nutraceuticals " Food Science and Technology 14: 455-468.

MacDonald Nicholas J.,Murad Amy Chang, et al. (1999). "The Tumor-Suppressing Activity of Angiostatin Protein Resides within Kringles 1 to 3." Biochemical and Biophysical Research Communications 264(2): 469-477. 
Mallia A. Krishna,Smith Paul K., et al. (1992). Immobilized Affinity Ligand Techniques. San Diego, CA Academic Press.

Martínez-Zaguilán Raul,Seftor Elisabeth A., et al. (1996). "Acidic pH enhances the invasive behavior of human melanoma cells." Clinical and Experimental Metastasis 14(2): 176-186.

Matta Hittu and Punj Vasu (1998). "Isolation and partial characterization of a thermostable extracellular protease of Bacillus polymyxa B-17." International Journal of Food Microbiology 42(3): 139-145.

Maunsell Blaithin,Adams Claire, et al. (2006). "Complex regulation of AprA metalloprotease in Pseudomonas fluorescens M114: evidence for the involvement of iron, the ECF sigma factor, PbrA and pseudobactin M114 siderophore." Microbiology 152(1): 29-42.

McGavin M J,Gurusiddappa S, et al. (1993). "Fibronectin receptors from Streptococcus dysgalactiae and Staphylococcus aureus. Involvement of conserved residues in ligand binding." Journal of Biological Chemistry 268(32): 23946-23953.

Mermelstein Neil H. (2010). Simulating digestion Food Technology, IFT: 71-76.

Migita Toshiro,Oda Yoshinao, et al. (2001). "The Accumulation of Angiostatin-like Fragments in Human Prostate Carcinoma." Clinical Cancer Research 7(9): 27502756.

Morikawa Wataru,Yamamoto Kenji, et al. (2000). "Angiostatin Generation by Cathepsin D Secreted by Human Prostate Carcinoma Cells." Journal of Biological Chemistry 275(49): 38912-38920.

Moser Tammy L.,Kenan Daniel J., et al. (2001). "Endothelial cell surface F1-FO ATP synthase is active in ATP synthesis and is inhibited by angiostatin." Proceedings of the National Academy of Sciences of the United States of America 98(12): 6656-6661.

Moser Tammy L.,Stack M. Sharon, et al. (1999). "Angiostatin binds ATP synthase on the surface of human endothelial cells." Proceedings of the National Academy of Sciences of the United States of America 96(6): 2811-2816.

Mowery Yvonne M. and Pizzo Salvatore V. (2009). "The antitumorigenic trifecta." Blood 114(9): 1727-1728.

Nelson Nancy J. (1999). "Angiogenesis Research Is on Fast Forward." J. Natl. Cancer Inst. 91(10): 820-822.

O'Reilly Michael S.,Holmgren Lars, et al. (1996). "Angiostatin induces and sustains dormancy of human primary tumors in mice." Nat Med 2(6): 689-692. 
O'Reilly Michael S.,Holmgren Lars, et al. (1994). "Angiostatin: A novel angiogenesis inhibitor that mediates the suppression of metastases by a lewis lung carcinoma." Cell 79(2): 315-328.

O'Reilly Michael S.,Wiederschain Dmitri, et al. (1999). "Regulation of Angiostatin Production by Matrix Metalloproteinase-2 in a Model of Concomitant Resistance." Journal of Biological Chemistry 274(41): 29568-29571.

Ozen Banu F.,Hayes Kirby D., et al. (2003). "Measurement of plasminogen concentration and differentiation of plasmin and plasminogen using Fourier-transform infrared spectroscopy." International Dairy Journal 13(6): 441-446.

Platanias Leonidas C. (2009). Cytokines and cancer, Springer-Verlag New York, LLC.

Politis I.,Lachance E., et al. (1989). "Plasmin and Plasminogen in Bovine Milk: A Relationship with Involution?" Journal of dairy science 72(4): 900-906.

Roufik Samira,Gauthier Sylvie F., et al. (2006). "In vitro digestibility of bioactive peptides derived from bovine [beta]-lactoglobulin." International Dairy Journal 16(4): 294-302.

Salimen Seppo and Atte Von Wright (1998). Lactic acid bacteria: microbiology and functional aspects, Marcel Dekker.

Sathe Shridhar K.,Sze-Tao K. W. Clara, et al. (1997). "Biochemical Characterization and in Vitro Digestibility of the Major Globulin in Cashew Nut (Anacardium occidentale)." Journal of Agricultural and Food Chemistry 45(8): 2854-2860.

Schaller J.,Moser P. W., et al. (1985). "Complete amino acid sequence of bovine plasminogen." European Journal of Biochemistry 149(2): 267-278.

Soff Gerald A. (2000). "Angiostatin and Angiostatin-related Proteins." Cancer and Metastasis Reviews 19(1): 97-107.

Soff Gerald A.,Hong J., et al. (1999). "Angiostatin 4.5: a naturally occurring human angiogenesis inhibitor." Proc Am Assoc Canc Res 40.

Stenn Kurt S.,Link Richard, et al. (1989). "Dispase, a Neutral Protease From Bacillus Polymyxa, Is a Powerful Fibronectinase and Type IV Collagenase." J Investig Dermatol 93(2): 287-290.

Storey Kenneth B. (2004). Functional metabolism: regulation and adaptation Hobocken, New Jersey, Wiley-IEEE.

Turnbull Peter C. B. (1996). Chapter 15 - Bacillus Medical Microbiology, 4th edition. Samuel Baron. Galveston, TX, University of Texas Medical Branch at Galveston. 
Vassalli J. D.,Sappino A. P., et al. (1991). "The plasminogen activator/plasmin system." J Clin Invest 88(4): 1067-1072.

Wahl M. L.,Owen C. S., et al. (2002). "Angiostatin induces intracellular acidosis and anoikis in endothelial cells at a tumor-like low pH." Endothelium-New York 9(3): 205-216.

Wahl Miriam L. ,Kenan Daniel J. , et al. (2005). Angiostatin's molecular mechanism: Aspects of specificity and regulation elucidated. 96: 242-261.

Wahl Miriam L.,Kenan Daniel J., et al. (2005). "Angiostatin's molecular mechanism: Aspects of specificity and regulation elucidated." Journal of Cellular Biochemistry 96(2): 242-261.

Wahl Miriam L.,Moser Tammy L., et al. (2004). "Angiostatin and Anti-angiogenic Therapy in Human Disease." Recent Prog Horm Res 59(1): 73-104.

Walker John M. (1996). The Protein Protocols Handbook. Totowa, NJ, Humana Press.

Wen Wei,Moses Marsha A., et al. (1999). "The Generation of Endostatin Is Mediated by Elastase." Cancer Research 59(24): 6052-6056.

Zachary I. (2003). "VEGF signalling: integration and multi-tasking in endothelial cell biology " Biochemical Society 31(6): 1171-1177.

Zetter Bruce R. (1998). "Angiogenesis and tumor metastasis " Annual Review of Medicine 49: 407-24. 